JOÃO VITOR FONTENELE ROMERO

\title{
ESTUDO EXPERIMENTAL DE SONDA DIRECIONAL PARA DETERMINAÇÃO DA VELOCIDADE DO ESCOAMENTO DE AR
}

São Paulo

2011 


\section{JOÃO VITOR FONTENELE ROMERO}

\section{ESTUDO EXPERIMENTAL DE SONDA DIRECIONAL PARA DETERMINAÇÃO DA VELOCIDADE DO ESCOAMENTO DE AR}

Dissertação apresentada à Escola Politécnica da Universidade de São Paulo para obtenção do título de Mestre em Engenharia

Área de Concentração: Engenharia Mecânica de Energia e Fluidos

Orientador: Prof. Dr. Antonio Luís de Campos Mariani

São Paulo 
Este exemplar foi revisado e alterado em relação à versão original, sob responsabilidade única do autor e com a anuência de seu orientador.

São Paulo, 05 de maio de 2011.

Assinatura do autor

Assinatura do orientador

\section{FICHA CATALOGRÁFICA}

Romero, João Vitor Fontenele

Estudo experimental de sonda direcional para determinação da velocidade do escoamento de ar / J.V.F. Romero. - ed.rev. -São Paulo, 2011.

$167 \mathrm{p}$.

Dissertação (Mestrado) - Escola Politécnica da Universidade de São Paulo. Departamento de Engenharia Mecânica.

1. Velocidade do fluxo dos fluídos (Medição) 2.Instrumenta ção (Física) I. Universidade de São Paulo. Escola Politécnica. Departamento de Engenharia Mecânica II. t. 


\section{DEDICATÓRIA}

Dedico este trabalho à minha esposa Ana, ao meu filho Vítor, aos meus pais Paulo Romero e Silvia Romero e a meu irmão Gabriel Romero. 


\section{AGRADECIMENTOS}

À minha esposa Ana, pelo apoio e companheirismo durante o trabalho.

Ao Professor Dr. Antonio Luis de Campos Mariani pela orientação e parceria no decorrer de todo o projeto, aos técnicos do Laboratório de Instrumentação em Mecânica dos Fluidos Laércio Damacena e Douglas Silva por toda a ajuda e participação no projeto.

Aos profissionais Dr. Gilder Nader, Prof. Dr. Antônio Luiz Pacífico, MSc. Paulo Jabardo, Josiel e André pelo suporte nos ensaios realizados na Divisão de Metrologia de Fluidos do Intituto de Pesquisas Tecnológicas de São Paulo (IPT). Ao Professor Dr. Gustavo Assi do NDF pela fabricação de sondas em prototipagem rápida, a Daniel Strauss, da TECSIS, pelo incentivo nas etapas iniciais do trabalho. 


\section{RESUMO}

O presente trabalho trata do desenvolvimento de uma sonda de pressão para medição de magnitude e direção da velocidade em um escoamento de ar.

Primeiramente, é feita uma pesquisa sobre métodos e instrumentos de medição de velocidade de escoamentos de ar, utilizando a literatura existente sobre os tipos de medidores e suas restrições e capacidades na medição de direção do escoamento.

Em seguida, são escolhidos dois tipos de medidores capazes de atender aos requisitos de fabricação simples e robusta, sendo um deles aplicado a escoamentos bidimensionais (sensor de três orifícios, tipo prisma) e o outro, a escoamentos tridimensionais (sensor de cinco orifícios, tipo pirâmide).

É feito o projeto detalhado destes medidores e define-se o método de fabricação dos mesmos, comparando o método da prototipagem rápida com a usinagem.

Uma vez fabricados os sensores, são realizados ensaios de caráter investigativo para mensurar a faixa de ângulos de medição de cada sensor. De posse dos resultados, é feito um estudo sobre os coeficientes adimensionais utilizados para a definição do ângulo de escoamento a partir das medições de pressão realizadas pelo sensor. É proposto um novo conjunto de coeficientes adimensionais com os quais se determina uma faixa de medição de ângulos entre $-25^{\circ}$ e $+25^{\circ}$ para a sonda tipo prisma e uma faixa entre $-35^{\circ} \mathrm{e}+35^{\circ}$ para a sonda tipo pirâmide.

Finalmente, são feitas as curvas de calibração para os sensores e se discute sobre suas aplicações na medição de velocidade de escoamentos de ar.

Palavras-chave: Tubo de Pitot. Medidor de velocidade direcional. Ventilação Industrial. Escoamento de ar. 


\section{ABSTRACT}

The present work deals with the development of a pressure probe for measuring magnitude and direction of velocity from an air flow.

Initially, it is made a review of methods and instruments to measure air flow velocity, using the existing literature on kinds of instruments with their restrictions and capabilities on flow direction measurement.

Secondly, two kinds of sensors are chosen based on the requirements of easy and robust manufacturing, being one of them applied to bi-dimensional flows (three-hole probe, prism type) and the other one for tri-dimensional flows (five-hole probe, pyramid type).

The detailed design of these probes is made and the fabrication method is chosen comparing the fast prototyping method with machining.

Once these sensors are manufactured, investigative tests are carried out in order to measure the flow angle range for each sensor. With these results, a study is made on the non-dimensional coefficients used for definition of flow angle from the pressure measurements from the sensor. A new set of non-dimensional coefficients is proposed and a flow angle range between $-25^{\circ}$ and $+25^{\circ}$ is determined for the prism probe and a range between $-35^{\circ}$ and $+35^{\circ}$ for the pyramid probe,

Finally, the calibration curves are made for the two sensors, followed by a discussion on the applications on air flow velocity measurements.

Keywords: Pitot probes. Multihole velocity probes. Industrial ventilation. Air flow. 


\section{LISTA DE ILUSTRAÇÕES}

Figura 1 Algumas configurações de sondas: Tubo de Pitot (a). Tubo estático (b). Tubo Pitotestático (c)

$\begin{array}{llr}\text { Figura } 2 & \text { Representação de um anemômetro de fio quente } & 17\end{array}$

$\begin{array}{llll}\text { Figura } 3 & \text { Anemômetro de pás modelo Pacer DA400 } & 18\end{array}$

$\begin{array}{ll}\text { Figura } 4 \text { Aparato e princípio de funcionamento da anemometria laser-Doppler } & 19\end{array}$

$\begin{array}{lll}\text { Figura } 5 & \text { Disposição dos furos em sonda direcional de três furos } & 21\end{array}$

$\begin{array}{lll}\text { Figura } 6 & \text { Determinação do ângulo do escoamento } & 21\end{array}$

$\begin{array}{llll}\text { Figura } 7 & \text { Sondas de velocidade e direção de escoamento utilizadas no trabalho NACA TN } 2830 \quad 28\end{array}$

$\begin{array}{lll}\text { Figura } 8 & \begin{array}{l}\text { Sondas de velocidade e direção do escoamento utilizadas no trabalho NACA } 2830 . \\ \text { Sonda tipo piramidal e tipo prisma }\end{array}\end{array}$

$\begin{array}{lll}\text { Figura } 9 & \begin{array}{l}\text { Desenho esquemático de sondas de guinada, representada no trabalho NACA TN } \\ 2830\end{array}\end{array}$

Figura $10 \begin{aligned} & \text { Resultados de leituras de pressão de sondas de guinada. Resultados extraídos de } \\ & \text { NACA TN } 2830\end{aligned}$

$\begin{array}{lll}\text { Figura } 11 \text { Sonda tipo garra. Extraído de NACA TN } 2830 & 32\end{array}$

\begin{tabular}{lll} 
Figura 12 & $\begin{array}{l}\text { Resultados de sensibilidade a ângulo de guinada do escoamento para diversas } \\
\text { configurações de sondas tipo garra. NACA TN } 2830\end{array}$ \\
\hline 2
\end{tabular}

$\begin{array}{llll}\text { Figura } & 13 & \text { Sonda tipo A (NACA TN 2830) } & 33\end{array}$

$\begin{array}{llll}\text { Figura } 14 & \text { Sonda tipo B } & 34\end{array}$

$\begin{array}{llr}\text { Figura } 15 & \text { Sonda tipo C } & 34\end{array}$

$\begin{array}{lll}\text { Figura } 16 & \text { Sonda tipo D } & 34\end{array}$

$\begin{array}{llll}\text { Figura } 17 & \text { Sonda tipo E } & 34\end{array}$

$\begin{array}{lll}\text { Figura } 18 & \text { Sonda tipo F } & 35\end{array}$

$\begin{array}{lll}\text { Figura } 19 & \text { Sonda tipo G } & 35\end{array}$

$\begin{array}{lll}\text { Figura } 20 & \text { Sonda tipo } \mathrm{H} & 35\end{array}$ 
Figura 21 Sonda tipo prisma (NACA TN 2830)

Figura 22 Sonda tipo pirâmide (NACA TN 2830)

Variação na leitura de pressão dos tubos de guinada e diferenças nas leituras de

Figura 23 pressão total e estática da sonda prisma em relação a uma sonda padrão tipo Pitot, com respeito ao ângulo de guinada. $\mathrm{V}=60 \mathrm{~m} / \mathrm{s}$

Figura 24 Variação na leitura de pressão dos tubos de guinada e diferenças nas leituras de pressão total e estática da sonda prisma em relação a uma sonda padrão tipo Pitot, com respeito ao ângulo de guinada. $V=119 \mathrm{~m} / \mathrm{s}$

Sensores de pressão feitos de tubos abertos: (a) Sonda de 2 tubos; (b) Sonda

Figura 25 assimétrica de 2 tubos; (c) Sonda de 4 tubos; (d) Sonda tipo garra; (e) Sonda de 2 tubos divergente

Vários sensores de pressão: (a) Cilindro-transverso; (b) Cabeça hemisférica; (c) Cunha

Figura 26 em balanço; (d) Conrad; (e) Chisel; (f) Cônico; (g) Piramidal; (h) Hemisférico com feixe de tubos divergentes; (i) Seção de aerofólio

Figura 27 Sistema de coordenadas do medidor (ZILLIAC, 1989)

Figura 28 Sonda de 7 orifícios e esquema de numeração dos orifícios

Figura 29 Variação de pressão em uma sonda de 7 furos. (a) Variação de pressão medida. (b) Variação de pressão teórica Figura $30 \begin{aligned} & \text { Exemplo de resultado de medições de aumento de pressão total na direção radial do } \\ & \text { rotor }\end{aligned}$

Figura 31 Exemplo de posicionador mecânico para calibração utilizado no trabalho NACA TN 2830

$\begin{array}{ll}\text { Figura } 32 & \text { Esquema de montagem de posicionador mecânico utilizado no trabalho NACA TN } \\ 2830\end{array}$

Figura 33 Ventilador axial de aplicação em mineração

Figura 34 Curva do ventilador TJF11013075

Figura 35 Função das aletas de saída

Figura 36 Deslocamento do medidor devido à força de arrasto

Figura 37 Variação do coeficiente de arrasto de corpo cilíndrico inserido em um escoamento 
Figura 38 Esquema da haste da sonda direcional

Figura 39 Esquema da ponta da sonda tipo pirâmide

Figura 40 Esquema da ponta da sonda tipo prisma

Figura 41 Esquema da haste da sonda com suas divisões

Figura 42 Haste da sonda ao lado de uma régua de $50 \mathrm{~cm}$

Figura 43 Ponta tipo prisma fabricada

Figura 44 Ponta tipo pirâmide fabricada

Figura 45 Tubos de cobre colados na parte interna das pontas de sonda

Figura 46 Teste de vazamento

Figura 47 Sonda tipo prisma fabricada em latão

Figura 48 Dispositivo posicionador para sonda de pressão direcional

Figura 49 Montagem do dispositivo posicionador no cilindro de regulagem vertical de altura

Figura 50 Micro-manômetro FCO 510

Figura 51 Indicadores de temperatura e barômetro DHI

Figura 52 Indicações de pressão no programa Flowsense

Figura 53 Indicações ângulos de guinada e arfagem

Figura 54 Nivelamento da sonda antes dos ensaios

Figura 55 Ângulos de posicionamento da sonda pirâmide no escoamento

Figura 56 Numeração das tomadas de pressão na sonda pirâmide 
Figura 58 Ensaio de calibração da sonda tipo prisma. V=10,11 m/s. Coeficiente de arfagem definido segundo (TREASTER, et al., 1978)

Figura 59 Ensaio de calibração da sonda tipo prisma. V=10,11 m/s. Coeficiente de arfagem definido segundo (NOWACK, 1970)

Figura 60 Ensaio de calibração da sonda tipo prisma. $V=10,11 \mathrm{~m} / \mathrm{s}$. Coeficiente de arfagem definido segundo (NOWACK, 1970), região entre $-25^{\circ}$ e $+25^{\circ}$

Ensaio de calibração da sonda tipo prisma. V=10,11 m/s. Coeficiente de arfagem

Figura 61 definido com o denominador $\sqrt{\bar{p}^{2}}$

100

Ensaio de calibração da sonda tipo prisma. $V=10,11 \mathrm{~m} / \mathrm{s}$. Coeficiente de arfagem

Figura 62 definido com o denominador $\sqrt{\bar{p}^{2}}$. Faixa de ângulos entre $-25^{\circ} \mathrm{e}+25^{\circ}$

100

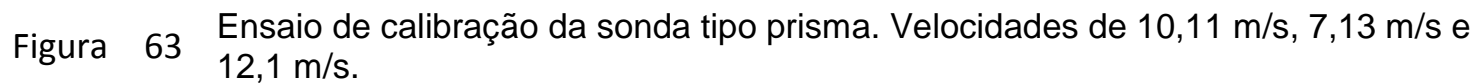

101

Ensaio de calibração da sonda tipo prisma. $V=10,11 \mathrm{~m} / \mathrm{s}$. Coeficiente de pressão total

Figura 64 definido segundo Treaster (TREASTER, et al., 1978)

102

Ensaio de calibração da sonda tipo prisma. V=10,11 m/s. Coeficiente de pressão

Figura 65 estática definido segundo Treaster (TREASTER, et al., 1978).

Ensaio de calibração da sonda tipo prisma. $V=10,11 \mathrm{~m} / \mathrm{s}$. Coeficiente de pressão total

Figura 66 definido com o denominador $\sqrt{\bar{p}^{2}}$

104

Ensaio de calibração da sonda tipo prisma. V=10,11 m/s. Coeficiente de pressão

Figura 67 estática definido com o denominador $\sqrt{\bar{p}^{2}}$

104

Figura 68 Ensaio de calibração da sonda tipo pirâmide. $V=10,03 \mathrm{~m} / \mathrm{s}$. Coeficiente de guinada definido segundo (NOWACK, 1970)

Figura 69 Ensaio de calibração da sonda tipo pirâmide. V=10,03 m/s. Coeficiente de arfagem definido segundo (NOWACK, 1970)

Ensaio de calibração da sonda tipo pirâmide. $V=10,03 \mathrm{~m} / \mathrm{s}$. Coeficiente de guinada

Figura 70 definido segundo (TREASTER et al. , 1978)

108

Figura 71 Ensaio de calibração da sonda tipo pirâmide. $V=10,03 \mathrm{~m} / \mathrm{s}$. Coeficiente de arfagem definido segundo (TREASTER et al. , 1978)

109

Ensaio de calibração da sonda tipo pirâmide. $V=10,11 \mathrm{~m} / \mathrm{s}$. Coeficiente de guinada

Figura 72 definido com o denominador $\sqrt{\bar{p}^{2}}$.

110

Ensaio de calibração da sonda tipo pirâmide. $V=10,11 \mathrm{~m} / \mathrm{s}$. Coeficiente de guinada

Figura 73 definido com o denominador $\sqrt{\bar{p}^{2}}$ e faixa de ângulos de -35 a +35 graus

Ensaio de calibração da sonda tipo pirâmide. $V=10,03 \mathrm{~m} / \mathrm{s}$. Coeficiente de arfagem

Figura 74 definido com o denominador $\sqrt{\bar{p}^{2}}$.

Ensaio de calibração da sonda tipo pirâmide. $V=10,03 \mathrm{~m} / \mathrm{s}$. Coeficiente de arfagem

Figura 75 definido com o denominador $\sqrt{\bar{p}^{2}}$ e faixa de ângulos de $-35 a+35$ graus

Figura 76 Ensaio de calibração da sonda tipo pirâmide. $V=10,03 \mathrm{~m} / \mathrm{s}$. Variação dos ângulos de guinada e arfagem na mesma proporção. 
Figura 77 Ensaio de calibração da sonda tipo pirâmide. V=10,03 m/s. Variação dos ângulos de guinada e arfagem na mesma proporção. Faixa de ângulos entre $-30^{\circ} \mathrm{e}+35^{\circ}$

Figura 78 Ensaio de calibração da sonda tipo pirâmide. V=10,03 m/s. Variação dos ângulos de guinada e arfagem na mesma proporção

Figura 79 Ensaio de calibração da sonda tipo pirâmide. V=10,03 m/s. Variação dos ângulos de guinada e arfagem na mesma proporção. Faixa de ângulos entre $-30^{\circ} \mathrm{e}+35^{\circ}$

Figura 80 Ensaio de calibração da sonda tipo pirâmide. $V=10,03 \mathrm{~m} / \mathrm{s}$. Coeficiente de pressão total definido conforme Treaster (TREASTER, et al., 1978) e Zilliac (ZILLIAC, 1989)

Figura 81 Ensaio de calibração da sonda tipo pirâmide. V=10,03 m/s. Coeficiente de pressão estática definido conforme Treaster (TREASTER, et al., 1978) e Zilliac (ZILLIAC, 1989)

Ensaio de calibração da sonda tipo pirâmide. $V=10,03 \mathrm{~m} / \mathrm{s}$. Coeficiente de pressão total

Figura 82 definido com o denominador $\sqrt{\bar{p}^{2}}$

Ensaio de calibração da sonda tipo pirâmide. $V=10,03 \mathrm{~m} / \mathrm{s}$. Coeficiente de pressão total

Figura 83 definido com o denominador $\sqrt{\bar{p}^{2}}$, faixa de ângulos entre $-35^{\circ} \mathrm{e}+35^{\circ}$

Ensaio de calibração da sonda tipo pirâmide. $V=10,03 \mathrm{~m} / \mathrm{s}$. Coeficiente de pressão

Figura 84 estática definido com o denominador $\sqrt{\bar{p}^{2}}$

Ensaio de calibração da sonda tipo pirâmide. $V=10,03 \mathrm{~m} / \mathrm{s}$. Coeficiente de pressão

Figura 85 estática definido com o denominador $\sqrt{\bar{p}^{2}}$, faixa de ângulos entre $-35^{\circ} \mathrm{e}+35^{\circ}$

Figura 86 Ensaio de calibração da sonda tipo pirâmide. V=10,03 m/s. Coeficiente de pressão total definido conforme Treaster (TREASTER, et al., 1978) e Zilliac (ZILLIAC, 1989)

Figura 87 Ensaio de calibração da sonda tipo pirâmide. $V=10,03 \mathrm{~m} / \mathrm{s}$. Coeficiente de pressão estática definido conforme Treaster (TREASTER, et al., 1978) e Zilliac (ZILLIAC, 1989) Ensaio de calibração da sonda tipo pirâmide. $V=10,03 \mathrm{~m} / \mathrm{s}$. Coeficiente de pressão total

Figura 88 definido com o denominador $\sqrt{\bar{p}^{2}}$

Ensaio de calibração da sonda tipo pirâmide. $V=10,03 \mathrm{~m} / \mathrm{s}$. Coeficiente de pressão total

Figura 89 definido com o denominador $\sqrt{\bar{p}^{2}}$, faixa de ângulos entre $-35^{\circ} \mathrm{e}+35^{\circ}$

Ensaio de calibração da sonda tipo pirâmide. $V=10,03 \mathrm{~m} / \mathrm{s}$. Coeficiente de pressão

Figura 90 estática definido com o denominador $\sqrt{\bar{p}^{2}}$

Ensaio de calibração da sonda tipo pirâmide. $V=10,03 \mathrm{~m} / \mathrm{s}$. Coeficiente de pressão

Figura 91 estática definido com o denominador $\sqrt{\bar{p}^{2}}$, faixa de ângulos entre $-35^{\circ} \mathrm{e}+35^{\circ}$

Figura 92 Ensaio de calibração da sonda tipo pirâmide. Variação do coeficiente de guinada com as variações dos ângulos de arfagem e guinada

124

Figura 93 Ensaio de calibração da sonda tipo pirâmide. Variação do coeficiente de arfagem com as variações dos ângulos de arfagem e guinada

Figura 94 Ensaio de calibração da sonda tipo pirâmide. Variação do coeficiente de pressão total com as variações dos ângulos de arfagem e guinada

Figura 95 Ensaio de calibração da sonda tipo pirâmide. Variação do coeficiente de pressão estática com as variações dos ângulos de arfagem e guinada 


\section{LISTA DE TABELAS}

Tabela 1 Resultados de medições de sondas tipo B a H. NACA TN 2830

Tabela 2 Comparação entre sensibilidades de medidores para escoamento incompressível

Tabela 3 Instrumentação utilizada nos ensaios 


\section{LISTA DE SÍMBOLOS}

a Ângulo de inclinação da sonda em relação ao plano horizontal

$\beta \quad$ Ângulo entre orifícios de tomada de pressão

$\delta \quad$ Ângulo de arfagem do medidor

$\zeta$ Ângulo entre eixo $x$ e a direção do escoamento não-perturbado

$\theta \quad$ Ângulo de ataque do escoamento

$\lambda \quad$ Posição ao longo do raio do rotor

$\mu \quad$ Viscosidade dinâmica

$v_{\text {eff }} \quad$ Graus de liberdade efetivos

$v_{i} \quad$ Grau de liberdade do elemento $i$

$\xi \quad$ Coordenada circunferencial transformada

$\rho \quad$ Massa específica do ar

$\varphi \quad$ Ângulo de separação entre orifícios

$\psi \quad$ Ângulo de guinada do medidor

$\Delta p_{\min } \quad$ menor diferença de pressão lida pelo manômetro

$\Phi \quad$ Potencial de velocidade do escoamento

$\Phi_{\text {ext }} \quad$ Diâmetro externo do tubo

$\Phi_{\text {int }} \quad$ Diâmetro interno do tubo

$X \quad$ Ângulo de rotação

A Ângulo de corte da ponta de sonda de guinada

$A_{\text {anular }} \quad$ Área do anel entre o cubo do rotor e as paredes do duto

B Ângulo de abertura entre tomadas de pressão

$\mathrm{C}_{\mathrm{C}}$ coeficiente de calibração de tubo de Pitot

$\mathrm{C}_{\mathrm{p} \psi} \quad$ Coeficiente de sensibilidade a guinada

$C_{P} \quad$ Coeficiente de pressão

$\mathrm{C}_{d} \quad$ Coeficiente de arrasto do cilindro

d Diâmetro interno do tubo

$d_{e} \quad$ Diâmetro externo da haste da sonda

d1 Deflexão da haste engastada

d2 Deflexão da haste engastada

D Diâmetro externo do tubo

Dx Arrasto na direção axial

E Módulo de Elasticidade

g aceleração da gravidade

h altura de coluna d'água

H Pressão total lida pelo sensor

$\mathrm{H}_{0} \quad$ Pressão total de referência

$\mathrm{I}_{0} \quad$ Momento de Inércia

k Fator de abrangência 


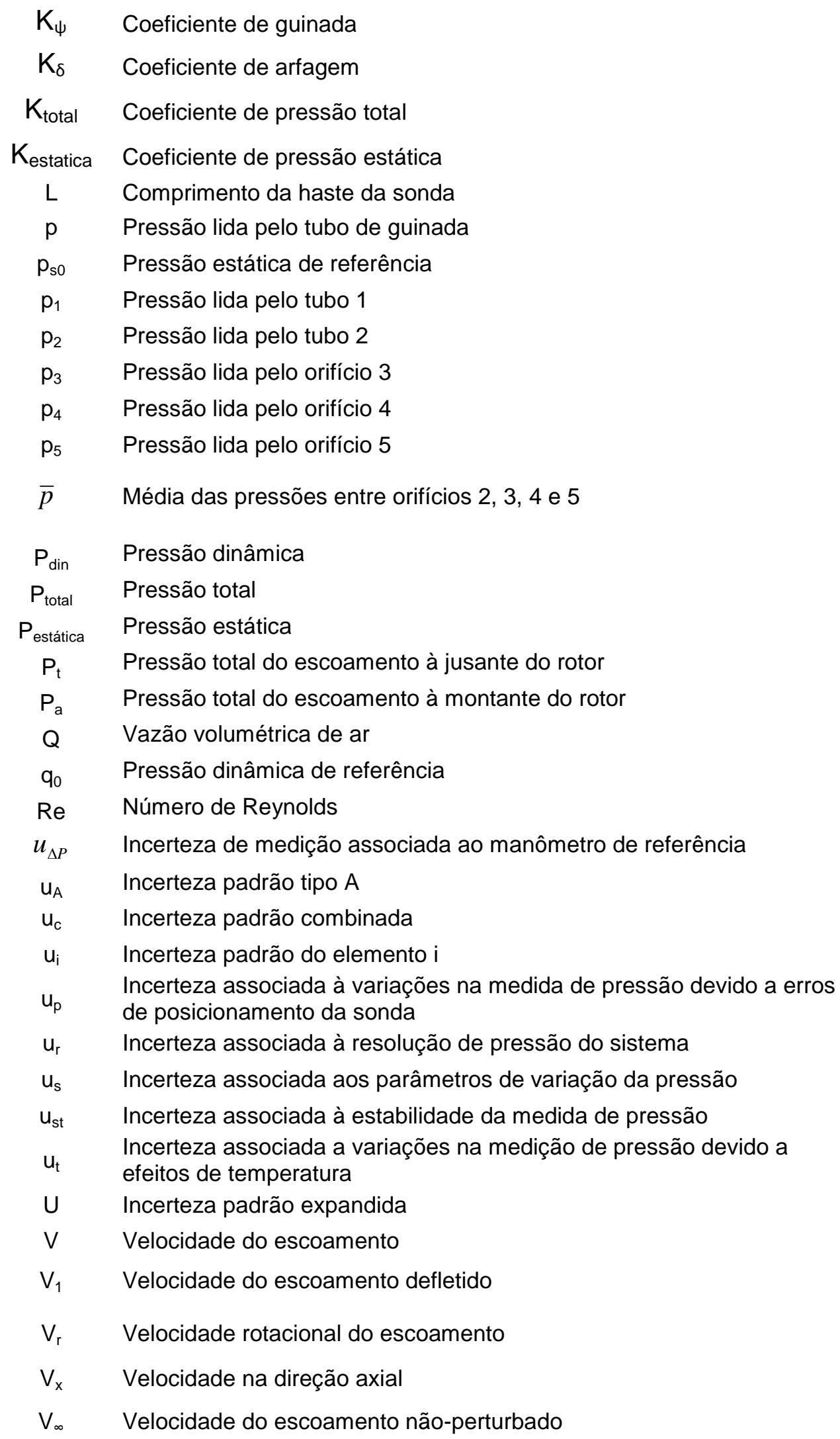




\section{SUMÁRIO}

1. INTRODUÇÃO

1.1 MEDIÇÃO DE VELOCIDADE DE ESCOAMENTOS $\quad 15$

1.2 METODOLOGIA DE TRABALHO

2. OBJETIVOS

3. REVISÃO DA LITERATURA 26

3.1 HISTÓRICO $\quad 26$

3.2 SONDAS DIRECIONAIS 28

3.3 APLICAÇÕES EM MEDIÇÃO DE ESCOAMENTOS À JUSANTE DE VENTILADORES AXIAIS $\quad 51$

4. DEFINIÇÃO DOS MEDIDORES E DO APARATO EXPERIMENTAL 53

4.1 ESCOLHA DO SENSOR

4.2 DEFINIÇÃO DO APARATO EXPERIMENTAL $\quad 54$

4.3 APLICAÇÃO DA MEDIÇÃO: ESTUDO DO ESCOAMENTO À JUSANTE DE ROTORES DE VENTILADORES AXIAIS $\quad 57$

5. PROJETO DOS SENSORES $\quad 60$

5.1 DEFINIÇÕES GERAIS $\quad 60$

5.2 PROJETO DETALHADO DOS SENSORES

5.3 FABRICAÇÃO E VALIDAÇÃO DOS PROTÓTIPOS

6. ENSAIOS EXPERIMENTAIS

6.1 DESCRIÇÃO GERAL E OBJETIVOS DO ENSAIO

6.2 APARATO EXPERIMENTAL $\quad 76$

6.3 PROCEDIMENTO EXPERIMENTAL PARA OS ENSAIOS

6.4 ANÁLISE DE INCERTEZAS $\quad 89$

6.5 SELEÇÃO E DEFINIÇÃO DE COEFICIENTES

6.6 RESULTADOS DOS ENSAIOS E ANÁLISE DE COEFICIENTES 96

6.7 DETERMINAÇÃO DOS PARÂMETROS DE VELOCIDADE E DIREÇÃO DO ESCOAMENTO $\quad 128$

7. ANÁLISE DOS RESULTADOS E CONCLUSÕES

8. REFERÊNCIAS BIBLIOGRÁFICAS $\quad 134$

APÊNDICE I - RESULTADOS DO ENSAIO DE VERIFICAÇÃO DA SONDA PRISMA 136

APÊNDICE II - RESULTADOS DO ENSAIO DE VERIFICAÇÃO DA SONDA PIRÂMIDE $\quad 140$

APÊNDICE III - CALIBRAÇÕES DOS TRANSDUTORES DE PRESSÃO 164 


\section{INTRODUÇÃO}

\subsection{MEDIÇÃO DE VELOCIDADE DE ESCOAMENTOS}

A medição de grandezas em escoamentos de gases encontra aplicações em diversas áreas da engenharia. O presente trabalho nasce da necessidade de avaliação do módulo do vetor velocidade de sua direção em pontos de um escoamento à jusante de um rotor de ventilador axial utilizado em ventilação de minas. Estes equipamentos são fundamentais para a operação da mina, uma vez que fornecem vazão de ar de modo a atingir os requisitos para condições de segurança e salubridade dos que trabalham no seu interior, bem como ventilar áreas que necessitem um controle específico de temperatura, como salas de máquinas.

A caracterização do campo de velocidades do ar em seções à jusante do rotor de um ventilador axial permite conhecer a forma que o equipamento de ventilação está acelerando o ar, fornecendo informações valiosas do ponto de vista de projeto deste equipamento. No entanto, os vetores velocidade do escoamento à jusante de um rotor possuem componentes nas direções axiais, tangenciais e radiais, exigindo um mapeamento e determinação do módulo, direção e sentido destes vetores, o que não pode ser obtido apenas com o uso de medidores que pressupõem um alinhamento do sensor com a direção do escoamento. Isto porque ao se realizar a medição não se conhece, a priori, a direção e o sentido do vetor velocidade do fluido em cada ponto de uma dada seção de escoamento.

Os ensaios de ventiladores industriais normalmente se limitam a determinar a capacidade de geração de vazão de ar, os ganhos de pressão e potências relacionadas ao movimento do fluido. Com o estudo de características do escoamento à jusante do rotor do ventilador, podem-se inferir aspectos importantes sobre a eficiência na aceleração da massa de ar, permitindo ao engenheiro avaliar melhores geometrias de pás e aletas difusoras para aperfeiçoamento do projeto do equipamento. Medições pontuais em seções de interesse podem detectar não-uniformidades no campo de 
velocidades e também indicar onde devem ocorrer intervenções para evoluir o ventilador.

Sendo assim, neste projeto é feita a investigação de medidores de velocidade com as seguintes características: facilidade de calibração e operação, capacidade de medir direção e sentido para ampla faixa de ângulos e módulos dos vetores velocidade, capacidade de realizar medições locais, fabricação com baixo custo, reduzida necessidade de manutenção e robustez. Certas características são decorrentes de que há aplicações em ambientes fabris com partículas de fibra de vidro em suspensão.

A partir das primeiras tentativas de medições de velocidade de escoamento no século XVIII, diversos tipos de medidores foram desenvolvidos. Os princípios de funcionamento destes medidores variam desde a aquisição de valores de pressão no escoamento até a medição de intervalos de tempo entre o choque de partículas do fluido com feixes de laser. O campo da medição de velocidades em fluidos evoluiu de tal forma que hoje é possível obter um alto nível de detalhamento sobre as características do escoamento. Muitas das técnicas desenvolvidas também permitem a obtenção de parâmetros com o uso de medidores e procedimentos que não representam custos elevados, o que também é um dos requisitos desta pesquisa.

Um dos instrumentos utilizados para a medição de velocidade em escoamentos de fluidos é o tubo de Pitot (PITOT, 1732). Este medidor, e também sua versão mais recente, o tubo Pitot-estático (FOLSOM, 1955; BRYER e PANKHURST, 1971), estiveram entre os primeiros sensores criados para a medição de velocidade de um fluido através de medições de pressão total e estática. Seu uso é bastante difundido em ambientes industriais e em laboratórios de pesquisa (figura 1). 


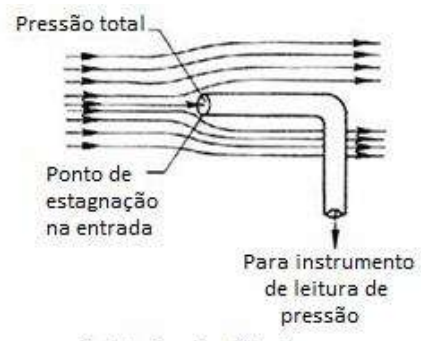

(a) Tubo de Pitot

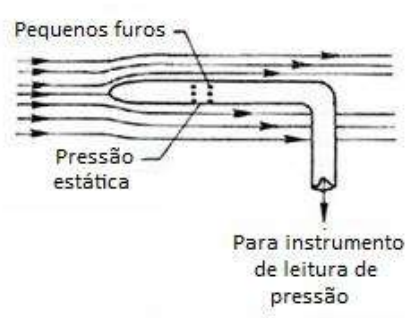

(b) Tubo estático

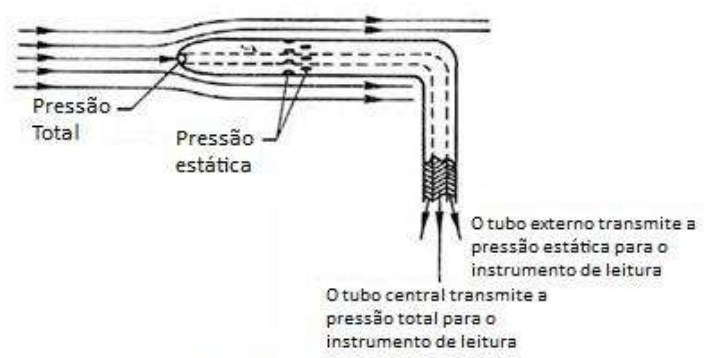

(c) Tubo de Pitot-estático

Figura 1 - Algumas configurações de sondas: Tubo de Pitot (a). Tubo estático (b). Tubo Pitot-estático (c). Fonte: NASA.

Outro medidor de velocidade em meios fluidos de ampla utilização é o anemômetro de fio quente (GJESSING, et al., 1969), que consiste basicamente em uma haste com um fio (ou conjunto de fios) de espessura da ordem de micrômetros aquecido eletricamente (figura 2). Um material de uso comum para esse tipo de fio é o tungstênio. Este medidor apresenta também a capacidade de determinar a magnitude da velocidade. Há modelos que possibilitam medir a direção do escoamento através da determinação de até três componentes do vetor velocidade. Há a possibilidade de ser utilizado para medições em alta freqüência de taxas de aquisição, quando é importante medir o comportamento transiente do escoamento.

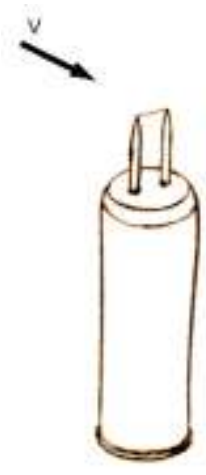

Figura 2 - Representação de um anemômetro de fio quente 
Para medições em ventilação industrial, em particular, é comum o uso de um anemômetro de pás, que consiste em um rotor com pás de metal ou plástico (ver figura 3) que giram a uma rotação proporcional à velocidade de passagem do escoamento de ar no sentido normal ao plano do rotor.

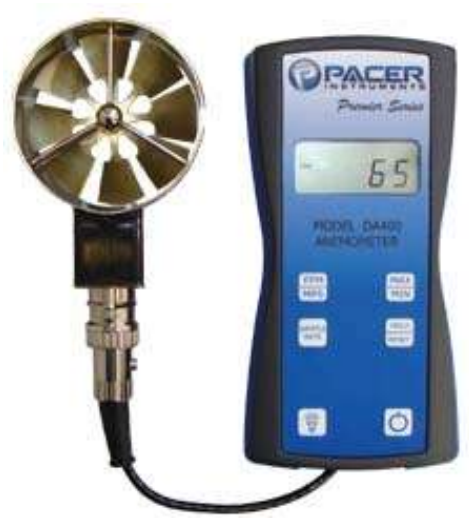

Figura 3 - Exemplo de anemômetro de pás (modelo Pacer DA400)

Técnicas mais recentes desenvolvidas a partir dos anos 80 , como anemometria a laser por efeito Doppler, cujo aparato está representado na figura 4, permitem a caracterização do campo de velocidades de fluidos com o uso de feixes de laser direcionados à região do escoamento que se deseja medir. Partículas podem ser inseridas no escoamento por meio de um processo de atomização, são chamadas de traçadores e devem possuir comportamento no escoamento similar ao dos fluidos predominantes. Uma grande vantagem desta técnica é não haver a necessidade de inserir algum medidor no escoamento, mas sim feixes de laser, sendo assim uma técnica não-intrusiva. 


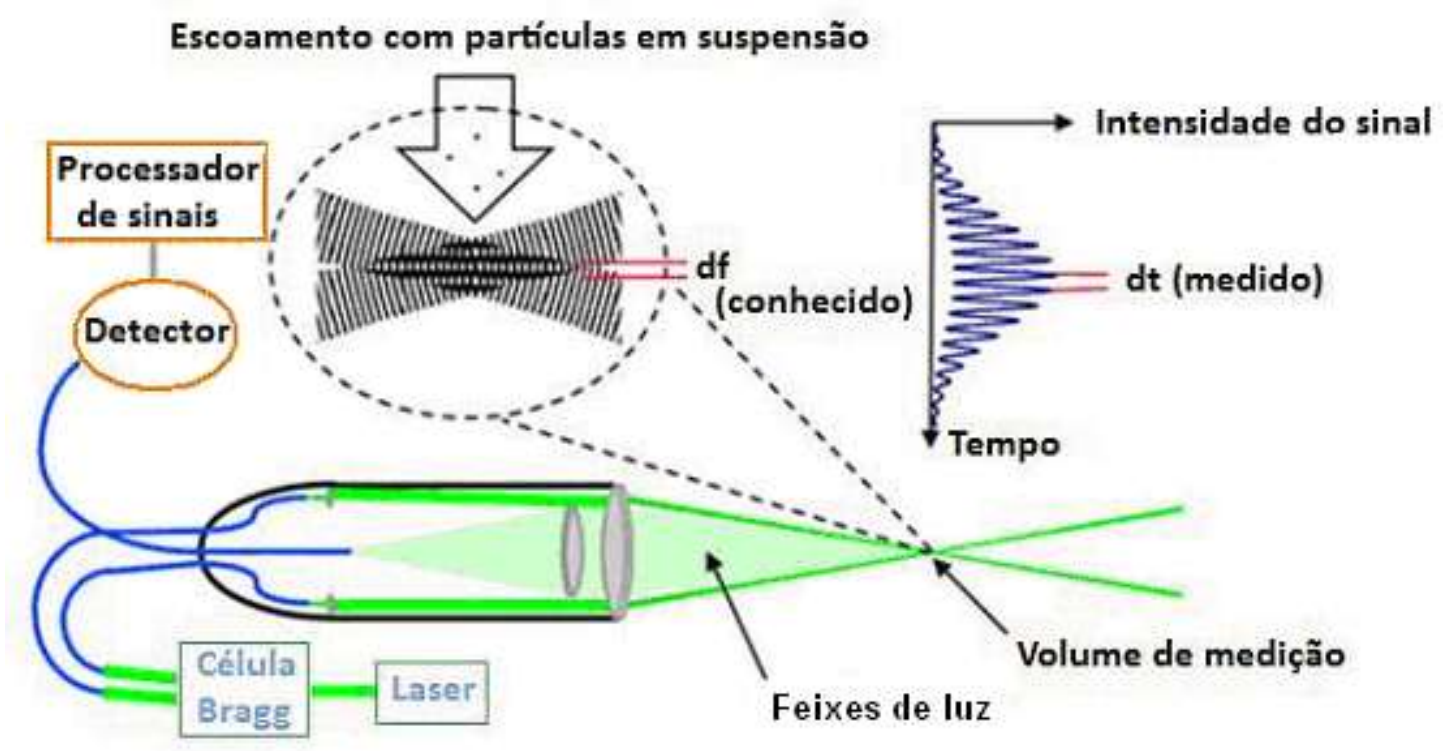

Figura 4 - Aparato e princípio de funcionamento da anemometria laser Doppler. (ENER, 2009)

Desta maneira, existe uma vasta gama de técnicas de medição e medidores para velocidade de fluidos em diferentes aplicações e requisitos de exatidão de resultados, freqüência de aquisição de dados, aparato experimental necessário, seu custo e rapidez em se obter as medições.

Dadas as características do escoamento a ser avaliado, pode-se iniciar a escolha do tipo de medidor de velocidade e verificar quais apresentam as características necessárias para se realizar a medição.

Considerando o propósito deste trabalho e os requisitos relacionados à área de ventilação, não são investigados medidores do tipo anemometria laser Doppler ou demais métodos óticos, pelo grande investimento necessário nesses casos. A análise de alternativas inicialmente estabelecidas fica entre os medidores portáteis pontuais e intrusivos, como anemômetros de fio quente, anemômetros de pás e sensores de pressão fabricados a partir do tubo de Pitot, com orifícios adicionais permitindo a determinação da direção do escoamento.

Os anemômetros de fio quente apresentam uma grande vantagem que é sua resposta em freqüência e sua resolução espacial (quando comparada às dos tubos de Pitot convencionais), e podem servir para medir a direção e velocidade do vento, utilizando fios orientados em 2 ou mais eixos distintos. Por outro lado, estes medidores 
são bastante frágeis e caros quando comparados aos medidores derivados do tubo de Pitot.

Ainda que os anemômetros de fio quente possuam propriedades bastante interessantes, na aplicação deste projeto, não necessitamos de uma resposta em freqüência muito alta para esse primeiro estudo. Além, disso, a robustez do aparelho em termos de resistência a choques e resíduos presentes no escoamento é muito importante, uma vez que as estações de ensaios são localizadas em ambiente fabril e estão sujeitas a esbarrar em peças, a ambiente hostil, como por exemplo pó de fibra de vidro.

Embora este medidor não seja o mais apropriado para esta medição específica, deve-se considerá-lo essencial para estudos de turbulência e camada-limite, por sua ótima resolução espacial e resposta em freqüência.

Os anemômetros de pás medem a velocidade do escoamento da seguinte maneira: as pás associadas a um rotor, ao passar por um ímã ou um sensor de proximidade posicionado no copo do rotor (a peça que envolve o rotor), fecham (ou abrem) um contato, resultando em um fornecimento de uma saída em voltagem em pulsos, de amplitude proporcional à alimentação do aparelho e freqüência igual à freqüência de passagem das pás do rotor. $A$ freqüência de passagem é simplesmente a rotação do rotor multiplicada pelo número de pás, e a rotação é determinada por um sensor tipo pick-up magnético.

Estes anemômetros são bastante utilizados para medições em ventiladores industriais por serem robustos e apresentarem intervalos de medição de velocidade do ar de 0,2 a $30 \mathrm{~m} / \mathrm{s}$. No entanto, o menor destes medidores encontrado comercialmente possui uma pequena ventoinha com pás, limitando dessa forma a capacidade de realização de medições pontuais, embora tenha sua utilidade para outros tipos de medições menos detalhadas e para ventiladores maiores, como os de torres de resfriamento.

Uma família de medidores que realizam a medição da pressão do escoamento e determinam, além da velocidade, a direção do escoamento, são as chamadas sondas direcionais. Estas sondas consistem em tubos cilíndricos com um ou mais furos, 
captando a pressão total do escoamento e comparando-a com a pressão estática ou pressão de esteira do medidor.

Há basicamente duas maneiras para se determinar a direção do escoamento utilizando este tipo de sonda. Uma com base em leituras nulas de tomadas dispostas simetricamente no sensor, e outra com base em uma calibração que relacione a diferença entre as pressões lidas e o ângulo do escoamento.

A primeira maneira, que ocorre, por exemplo, na determinação da direção do ângulo do escoamento por um tubo com três orifícios, consiste em igualar a leitura de pressão nos dois furos em ângulo, como mostra o detalhe da figura 5 (BRYER e PANKHURST, 1971). Quando isso acontece, significa que o tubo cilíndrico está no plano do escoamento e o ângulo em que a sonda está posicionada é o ângulo do escoamento no plano de medição do tubo com orifícios, como mostra a figura 6. Para igualar-se a pressão nos dois orifícios ( 1 e 3 na figura 5), deve-se mover o medidor. Dessa forma, para se fazer uma medição automatizada, seria necessário um controle que ajustasse a posição do medidor de acordo com a diferença de pressão entre as tomadas 1 e 3 .

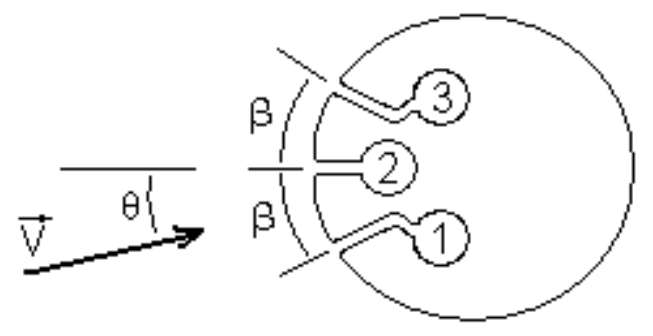

Figura 5 - Disposição dos furos em sonda direcional de três furos.

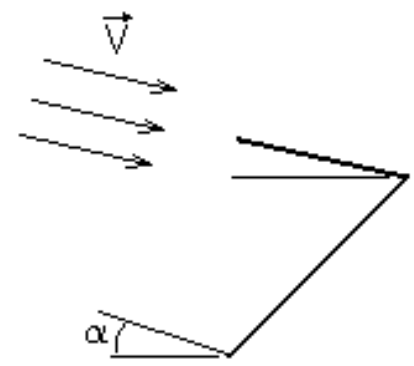

Figura 6 - Determinação do ângulo do escoamento. 
Já a segunda maneira de se determinar a direção do escoamento utilizando este tipo de medidor consiste em calibrar o instrumento de modo que a pressão lida (ou diferenças de pressão) seja proporcional ao ângulo que o escoamento faz com o plano que contém a haste dos furos. Neste último método, o medidor fica estacionário, dessa forma, tem-se a vantagem de não necessitar de algum servomecanismo para o caso de automatização do sistema, sendo, contudo, necessário fazer calibrações periódicas do medidor em uma maior freqüência em relação ao sensor que utiliza o método nãoestacionário.

Para estes tipos de sensores, a resolução da medição de ângulo que se pode atingir está ligada à menor diferença de pressão que pode ser lida pelo conjunto sensor-manômetro.

Considerando a capacidade de medição de velocidade e direção de escoamento de ar verificada para as sondas direcionais, bem como sua capacidade de medição pontual, diferentemente do verificado com os anemômetros de pá, e fabricação robusta, ao contrário dos anemômetros de fio quente, opta-se por investigar e focar esta pesquisa neste tipo de medidor.

\subsection{METODOLOGIA DE TRABALHO}

Nesta seção discutem-se as etapas seguidas para o desenvolvimento do trabalho.

Inicialmente, foi feita uma revisão da literatura sobre medidores de velocidade por diferença de pressão em escoamentos e particularmente sobre medições desta natureza que podem ser aplicadas a ventiladores axiais. Desta forma, ficaram claras quais técnicas são utilizadas para cada conjunto de dados que se deseja obter. Verificou-se que os medidores de pressão desenvolvidos a partir dos tubos de Pitot, bem como configurações de anemômetros de fio quente, são bastante utilizados em medições em escoamentos à jusante de rotores de ventiladores axiais, como mostram os trabalhos de Li et al. (2007), Zilliac (1989) e Gjessing et al. (1969). 
A segunda etapa do projeto foi a escolha da família de medidores, com base nas informações coletadas na revisão da literatura e conhecendo os requisitos do medidor, tanto em faixa de velocidades e ângulos de escoamento, como a necessidade de fabricação de baixo custo, robustez do medidor e capacidade de realizar medições pontuais, tendo em vista o gradiente elevado de velocidades na seção em questão.

Escolhida a família de medidores, definiram-se dois modelos de sensores em particular para fabricação e realização de ensaios. Estes dois medidores podem determinar a velocidade e direção do escoamento de ar, no entanto, um dos sensores é capaz de determinar o ângulo do escoamento em apenas um plano (ou apenas o ângulo de guinada do escoamento), e o outro é capaz de realizar uma medição de ângulo em dois planos, o que em outras palavras, permite a determinação dos ângulos de guinada e arfagem do escoamento. Ou seja, um deles tem aplicação a escoamentos bidimensionais e o outro a tridimensionais.

Após a determinação dos dois tipos de medidores de velocidade, foi realizado o projeto com o desenho detalhado e fabricação, seguido do planejamento dos ensaios de validação dos medidores. Em seguida foram verificadas as faixas de ângulo do vetor velocidade do escoamento que cada sensor é capaz de determinar e as incertezas de medições em termos de magnitude de direção da velocidade do escoamento.

Após a análise de resultados e incertezas de medição, foram constatadas as diferenças entre os dois medidores, no que diz respeito a capacidade de determinação de valores para os ângulos das componentes do vetor velocidade associadas ao escoamento bidimensional, caso da sonda prisma, e tridimensional, caso da sonda pirâmide. 


\section{OBJETIVOS}

O objetivo central deste trabalho é realizar um estudo experimental que desenvolva e analise alternativas de sensores capazes de realizar medições da magnitude e direção da velocidade do escoamento.

Uma das principais metas para aplicação de tais medidores é a caracterização de escoamentos encontrados na descarga de ventiladores industriais. Ou seja, os sensores podem ser utilizados em laboratórios de testes e desenvolvimento de ventiladores e seus componentes, como aletas de estatores, de empresas fabricantes destes equipamentos. Assim, estes medidores devem atender a requisitos como facilidade de operação e calibração, bem como baixo custo de fabricação e robustez.

Inicialmente o trabalho deve determinar os melhores tipos de medidores que atendem aos requisitos propostos, sendo assim realizada uma pesquisa bibliográfica e comparando diversos sensores direcionais e as várias técnicas de medição de velocidade em escoamentos de fluidos bidimensionais e tridimensionais.

Uma vez definidos os medidores a serem projetados e fabricados, como objetivos secundários do trabalho estão: o desenvolvimento do projeto de sondas bidimensionais e tridimensionais com seu dimensionamento, a fabricação e validação de protótipos. No processo de fabricação das sondas, especialmente das ponteiras sensoras, são comparados dois métodos: prototipagem rápida em material plástico tipo ABS (Acrilonitrila-butadieno-estireno) e usinagem em material metálico, sendo definido o latão.

Definidos, projetados, fabricados e validados os protótipos dos sensores, são analisados em ensaios em túnel de vento, de forma que seja possível avaliar a capacidade de medição de cada sensor em termos de determinação da faixa de ângulos do vetor velocidade nos planos identificados por arfagem e guinada através das medições de pressão.

Os ensaios em túnel de vento exigiram que fossem estudados e definidos mecanismos e dispositivos para realizar o posicionamento dos sensores. Eles têm 
como objetivo determinar as curvas de calibração dos sensores e também avaliar as incertezas de medição de todo o sistema. Desta forma, ao final do trabalho, é possível conhecer as capacidades e limitações das sondas, estando as mesmas prontas para uso, de posse de suas curvas de calibração. 


\section{REVISÃO DA LITERATURA}

\subsection{HISTÓRICO}

O estudo experimental de medições de velocidade de um fluido teve origem em um artigo de 1732 (PITOT, 1732) com as medições realizadas por Henri Pitot no rio Sena. Neste artigo, Pitot propõe uma relação quadrática entre a pressão em coluna d'água medida pelo seu instrumento e a velocidade do fluido.

A partir do trabalho de Pitot, muitos desenvolvimentos foram feitos no tubo que foi batizado com seu nome. Em 1854 e 1858, Darcy publica artigos respectivamente sobre o movimento de água no interior de tubos e sobre modificações realizadas nos tubos de Pitot. Com estes desenvolvimentos, Darcy concluiu que um tubo com tomadas de pressão na parte de trás e nas laterais apresentava medidas de pressão estática com melhor precisão. Também obteve redução da influência das vibrações através da utilização de orifícios de diâmetros menores que o do tubo (DARCY, 1854, 1858; MARIANI, 2000).

Ainda no final do século XIX, o tubo de Pitot era pouco utilizado por engenheiros e apenas no início do século $X X$, com o rápido desenvolvimento de campos como a aerodinâmica e com a necessidade de medições de campos de escoamento foi que esse instrumento desenvolveu-se até a forma parecida com a que se conhece atualmente (FOLSOM, 1955).

Em 1901 houve um importante desenvolvimento na forma da equação até então utilizada para medições da velocidade por meio da obtenção da pressão em coluna d'água. Até esta época, era comum utilizar-se a forma:

$$
V=\sqrt{g h}
$$

E com os estudos de White, reportados por Folsom em seu artigo de revisão sobre o desenvolvimento dos tubos de Pitot (FOLSOM, 1955), chegou-se a uma expressão melhor ajustada:

$$
V=\sqrt{2 g h}
$$


Em 1914, houve importante desenvolvimento na teoria para a pressão dinâmica medida por um tubo de Pitot, com os trabalhos de Moody et al. (1914). Neste momento, apresentou-se o equacionamento:

$$
V=C_{C} \sqrt{2 g h}
$$

Em que $\mathrm{C}_{c}$ é o coeficiente para o tubo de Pitot e $\mathrm{h}$ representa a diferença de pressão em termos da altura da coluna de fluido (MARIANI, 2000).

Durante a década de 1930 houve um interesse renovado em estudar os fundamentos do tubo de Pitot e outros tubos medidores de velocidade aplicados à medição de vazão de água (FOLSOM, 1955). No trabalho de Allen e Hooper (1932), procurou-se estabelecer uma metodologia para a avaliação da pressão estática realizando a medição através das paredes de um conduto com um piezômetro. Esta metodologia, embora simples, não apresentou bons resultados (ALLEN, HOOPER, 1932). Trabalhos de Hubbard (1939) e Cole (1935) também realizaram discussões sobre os fundamentos das medições utilizando tubo de Pitot

No trabalho de Hubbard, em especial, investigam-se os erros que influenciam os resultados das medições realizadas com os tubos de Pitot, como a influência da presença do suporte do tubo de Pitot e sua distância entre este e o ponto onde a pressão estática é medida. A presença do suporte do tubo diminui a área da seção transversal ocupada pelo fluido. A conclusão do trabalho de Hubbard é que, para se medir a pressão estática fazendo uso do tubo de Pitot, dois fatores podem afetar a medição: a geometria do tubo e a distância entre os planos dos orifícios e a extremidade deste tubo.

A partir de 1930, houve uma grande variedade de desenvolvimentos dos tubos de Pitot para várias aplicações em ciência e engenharia (FOLSOM, 1955). Estudos sobre escoamentos compressíveis, estudos da camada limite, escoamentos multifásicos e medições em alta troposfera são algumas das ramificações das medições de escoamentos originadas com o tubo de Pitot. 


\subsection{SONDAS DIRECIONAIS}

Aplicações mais específicas de medidores de pressão que pretendem determinar não só a velocidade do escoamento de ar, mas também a direção do mesmo, são tratadas no NACA TN 2830 (SCHULZE et al., 1952), que é um estudo detalhado sobre este tipo de medidor. Esta é uma das principais referências para este trabalho no que diz respeito à escolha das propriedades geométricas do medidor. No trabalho de Schulze, foi utilizada uma estação de ensaio cuja seção de teste, circular, possui 0,2 metros de diâmetro e foram feitos ensaios com velocidades nesta seção de até $135,6 \mathrm{~m} / \mathrm{s}$. Observou-se que as medições realizadas pela sonda podem ser influenciadas: por alterações locais no escoamento causadas pela própria inserção da sonda, pela incapacidade de tomar várias medidas simultaneamente no mesmo ponto, por mudanças em fatores de calibração que são funções do Número de Mach e do número de Reynolds, bem como pela deformação da sonda.

Levando em consideração a necessidade de se fabricar uma sonda de seção transversal pequena, interferindo o mínimo possível nas características do escoamento, o trabalho descrito no NACA TN 2830 utilizou sondas de diâmetros $3,17 \mathrm{~mm}$ e 6,34 mm, como as mostradas nas figuras 7 e 8 a seguir.

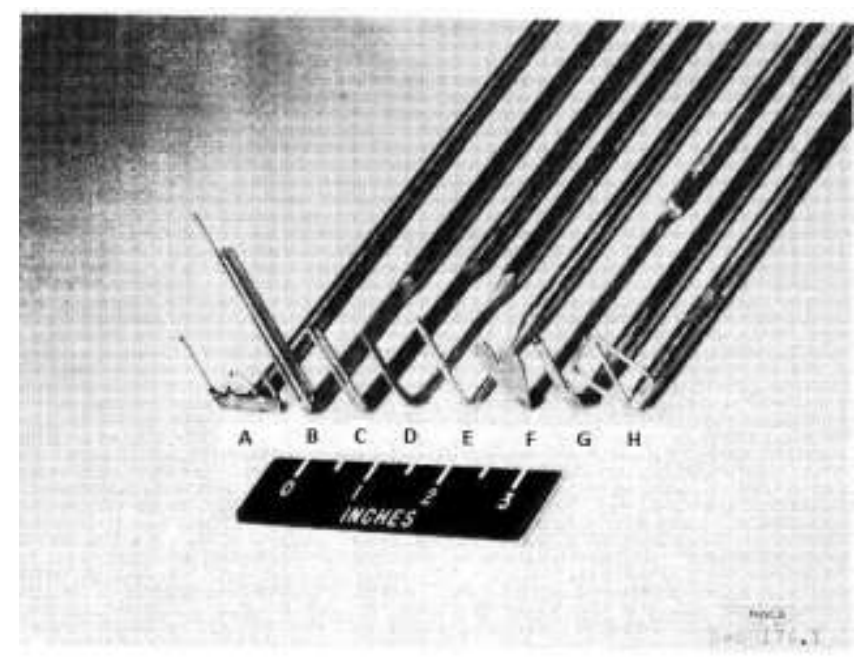

Figura 7 - Sondas de velocidade e direção de escoamento utilizadas no trabalho NACA TN 2830.

(SCHULZE et al., 1952) 

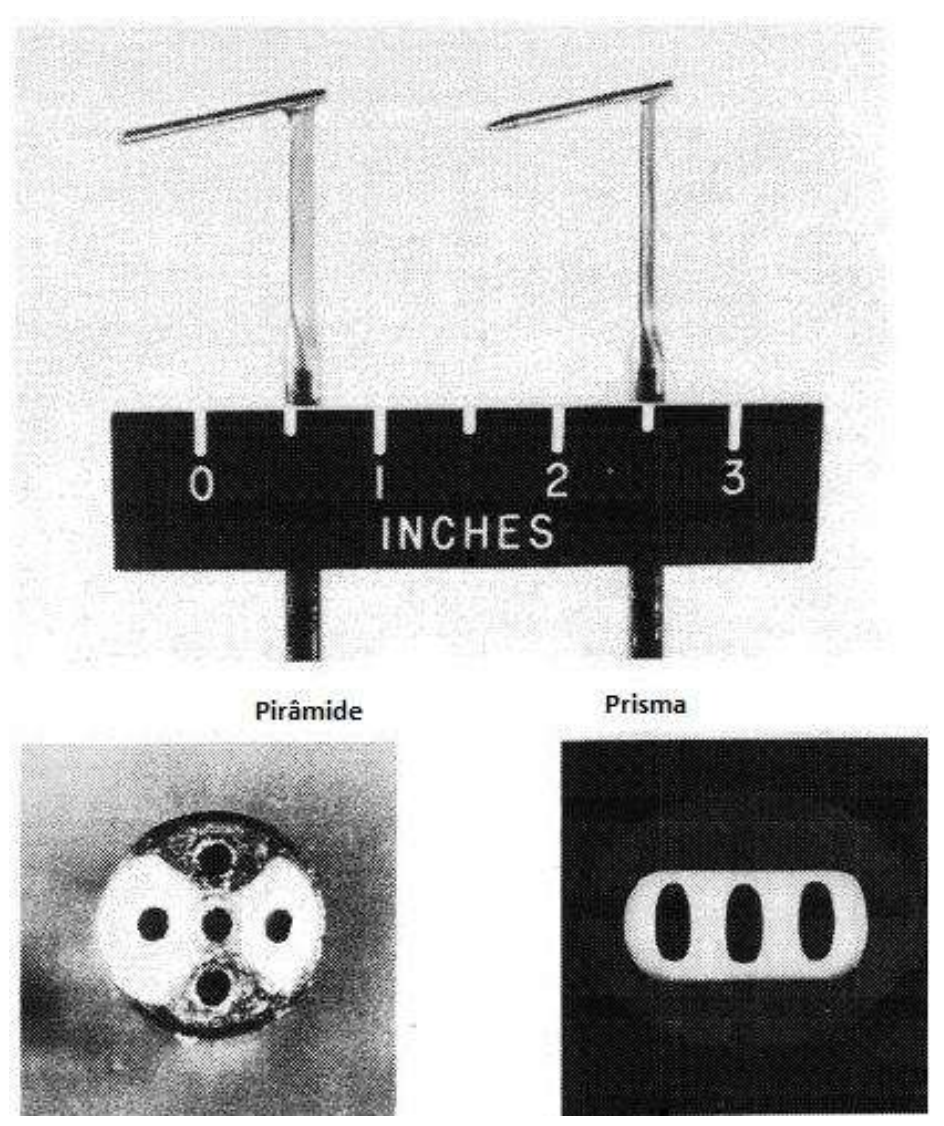

Figura 8 - Sondas de velocidade e direção do escoamento utilizadas no trabalho NACA 2830. Sonda tipo piramidal e tipo prisma. (SCHULZE et al., 1952)

Com os resultados do trabalho NACA TN 2830, verificou-se que as sondas mostradas na figura 7 não apresentaram resultados satisfatórios em termos de exatidão nas medidas de ângulo de escoamento. No entanto, as sondas representadas na figura 8 se mostraram melhores em termos de exatidão. A sonda tipo prisma é capaz de medir a direção do escoamento em um plano, assim como pressão estática e pressão total. A sonda tipo pirâmide é capaz de medir a direção do escoamento em dois planos, assim como pressão estática e pressão total.

Para as sondas de guinada (yaw-element probes), as quatro sondas ensaiadas neste trabalho, mostradas na figura 9 a seguir para ângulos de cortes na ponta do tubo de $30^{\circ}, 45^{\circ}, 60^{\circ}$ e $90^{\circ}$ mostraram alta sensibilidade a ângulo de escoamento. Cada uma das sondas indica uma leitura de pressão total quando a inclinação da face do tubo está orientada na direção normal ao escoamento. Para outros ângulos de guinada, a 
inclinação da face da abertura influencia a leitura de pressão. As figuras 9 e 10 a seguir mostram, respectivamente, um desenho esquemático destas sondas e os resultados de leituras de ângulos obtidos no trabalho NACA TN 2830, para uma velocidade de escoamento na seção de testes de $89,9 \mathrm{~m} / \mathrm{s}$.

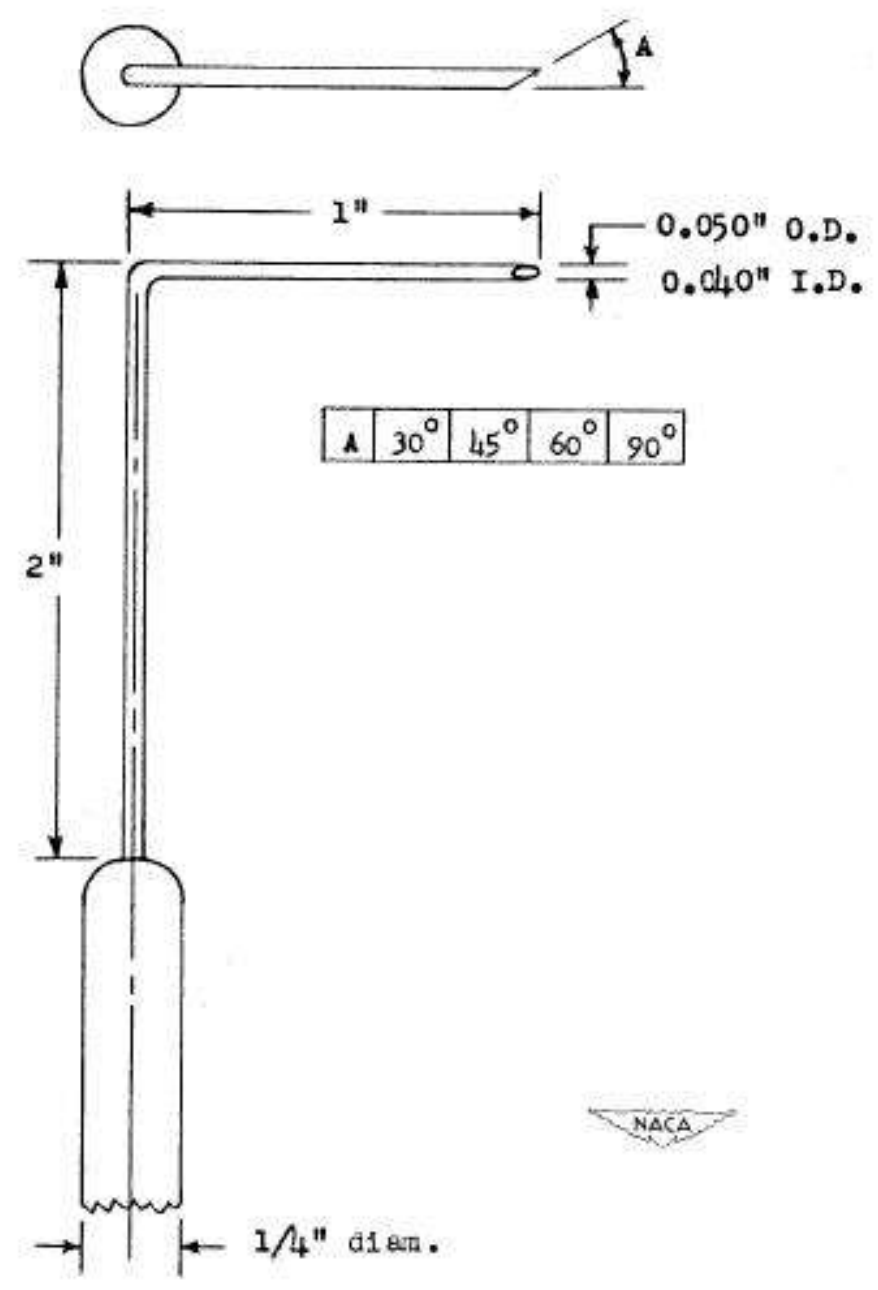

Figura 9 - Desenho esquemático de sondas de guinada, representada no trabalho NACA TN 2830.

(SCHULZE et al., 1952) 


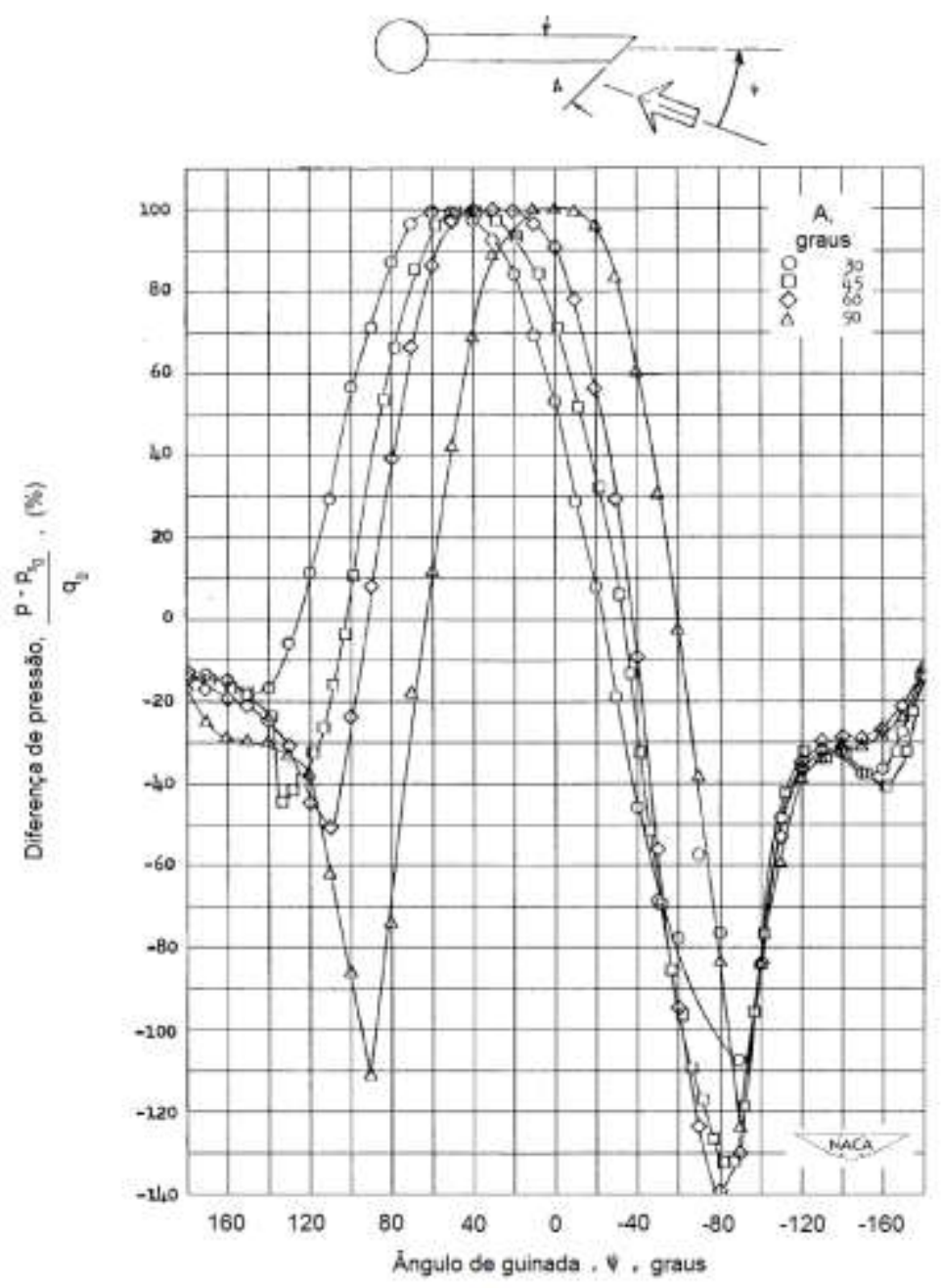

Figura 10 - Resultados de leituras de pressão de sondas de guinada. Resultados extraídos de NACA TN 2830. (SCHULZE et al., 1952)

Como pode ser observado na figura 10 acima, todas as quatro sondas de guinada ensaiadas apresentaram alta sensibilidade em respeito ao ângulo do escoamento. Desta maneira, este tipo de sonda é altamente recomendável para determinação de direção do escoamento.

Além das sondas tipo guinada, também foi investigada a sensibilidade a direção de escoamento para as sondas tipo garra, mostradas na figura 11 a seguir. Para as 35 diferentes configurações de sondas tipo garra que o autor investigou, a que apresentou a maior sensibilidade angular foi aquela com ângulo de encontro entre os tubos de $120^{\circ}$ 
tendo as faces do tubo com abertura de $15^{\circ}$, ou seja, $B=30^{\circ}$ (ver figura 11). Para esta configuração, uma mudança de $1^{\circ}$ no ângulo de guinada do escoamento produziu uma diferença de 9,5\% na leitura de pressão dinâmica entre as duas tomadas de pressão do medidor. A figura 6 mostra os resultados da investigação de sensibilidade a ângulo de guinada para diversas configurações de ângulos $\mathrm{A}$ e $\mathrm{B}$.
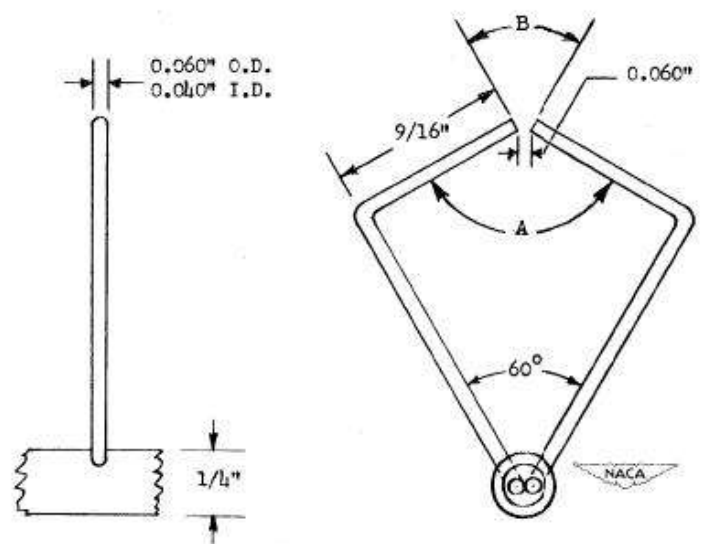

Figura 11 - Sonda tipo garra. Extraído de NACA TN 2830. (SCHULZE et al., 1952)
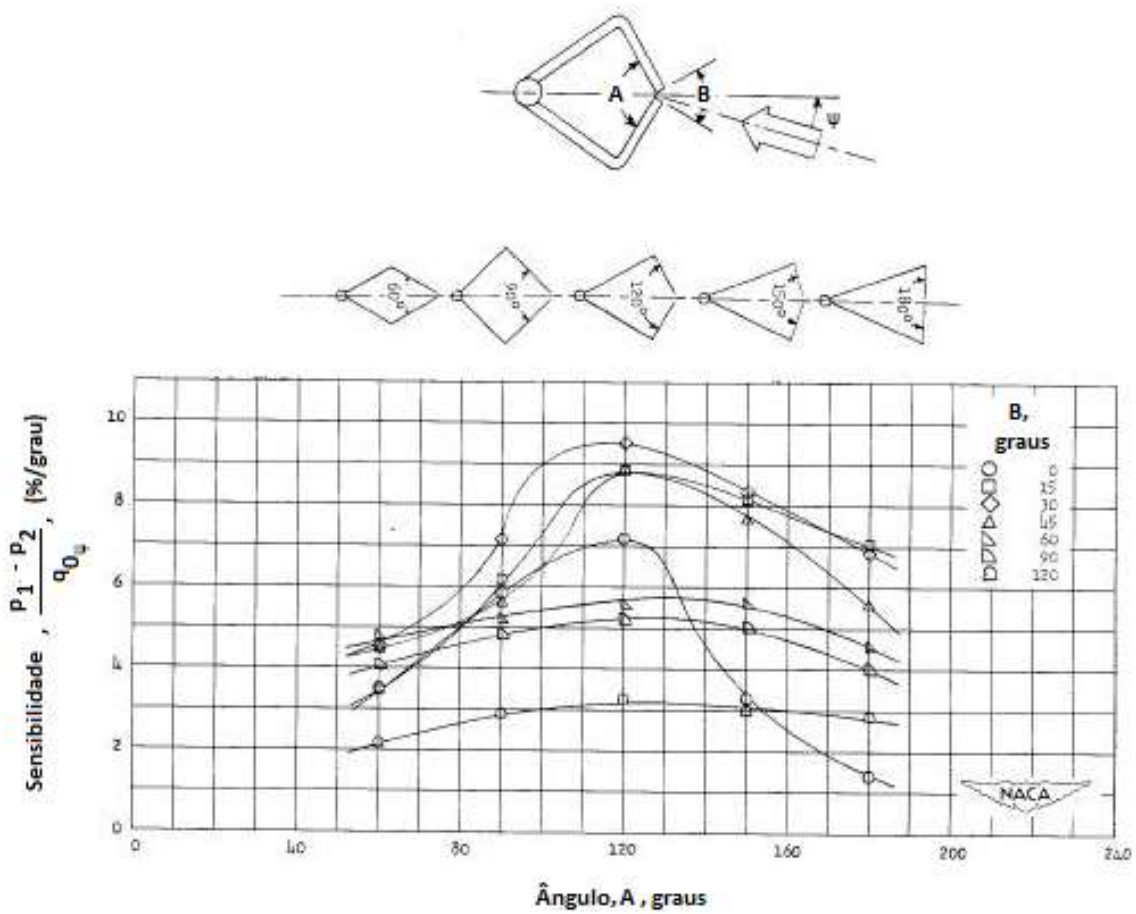

Figura 12 - Resultados de sensibilidade a ângulo de guinada do escoamento para diversas configurações de sondas tipo garra. NACA TN 2830. (SCHULZE et al., 1952) 
Para a determinação de uma configuração final de sonda capaz de medir ângulo de escoamento, pressão estática e pressão total, muitas outras configurações foram investigadas no estudo NACA TN 2830. As sondas representadas na figura 13, denominadas sondas tipo $\mathrm{A}$, se mostraram adequadas para medições em campos de escoamento uniforme caso seja feita uma correção de pressão estática. No entanto, os finos tubos são facilmente defletidos pelo escoamento de forma que as calibrações de pressão estática e ângulo de escoamento são afetadas. Além disso, como os elementos da sonda estão relativamente distantes entre si, esta sonda não deve ser utilizada em medições em campos de escoamento não-uniformes.

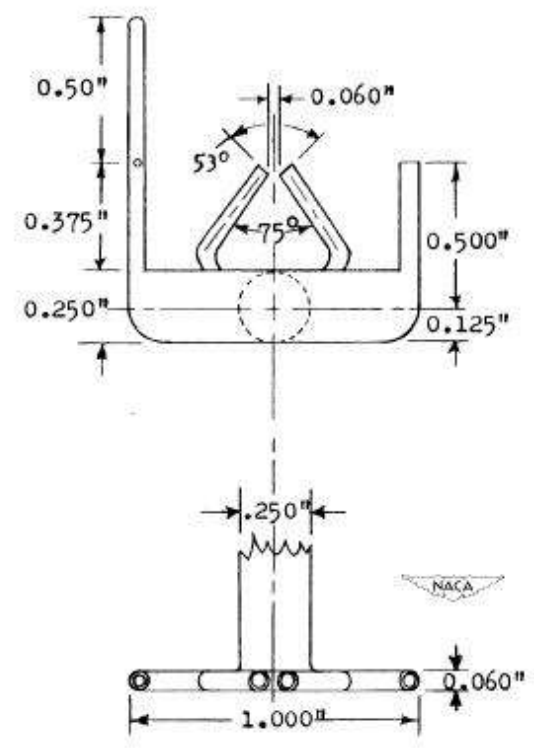

Figura 13 - Sonda tipo A. NACA TN 2830 (SCHULZE et al., 1952)

As sondas representadas nas figuras 14 a 20 a seguir foram rejeitadas pelo estudo NACA TN 2830 devido a altos erros na medição de pressão estática, alto erro na indicação de ângulo de guinada do escoamento ou baixa sensibilidade a ângulo de guinada do escoamento. Os resultados das medições realizadas com estes tipos de sondas estão compilados na tabela 1 a seguir, também retirada do estudo NACA TN 2830. 


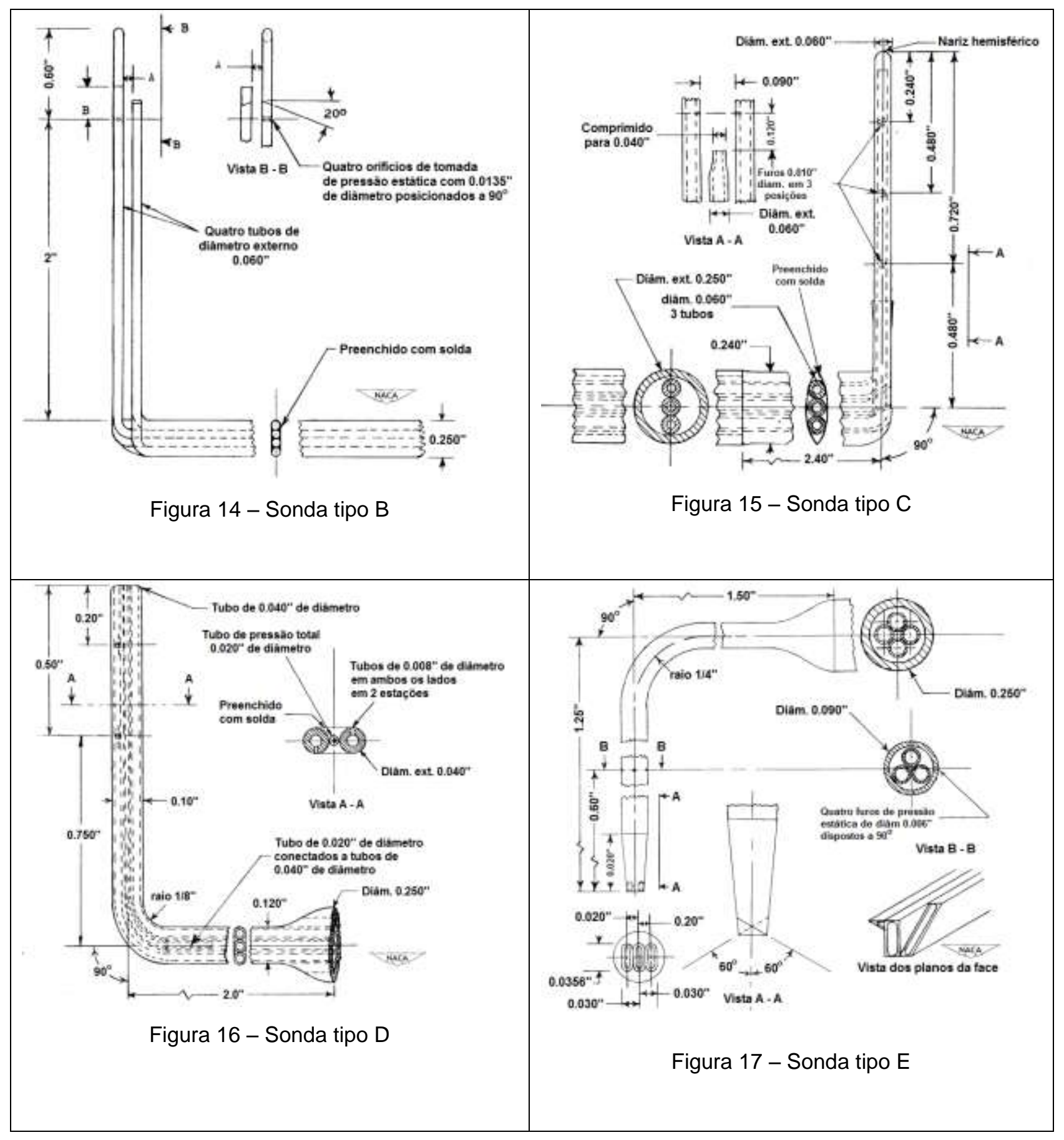




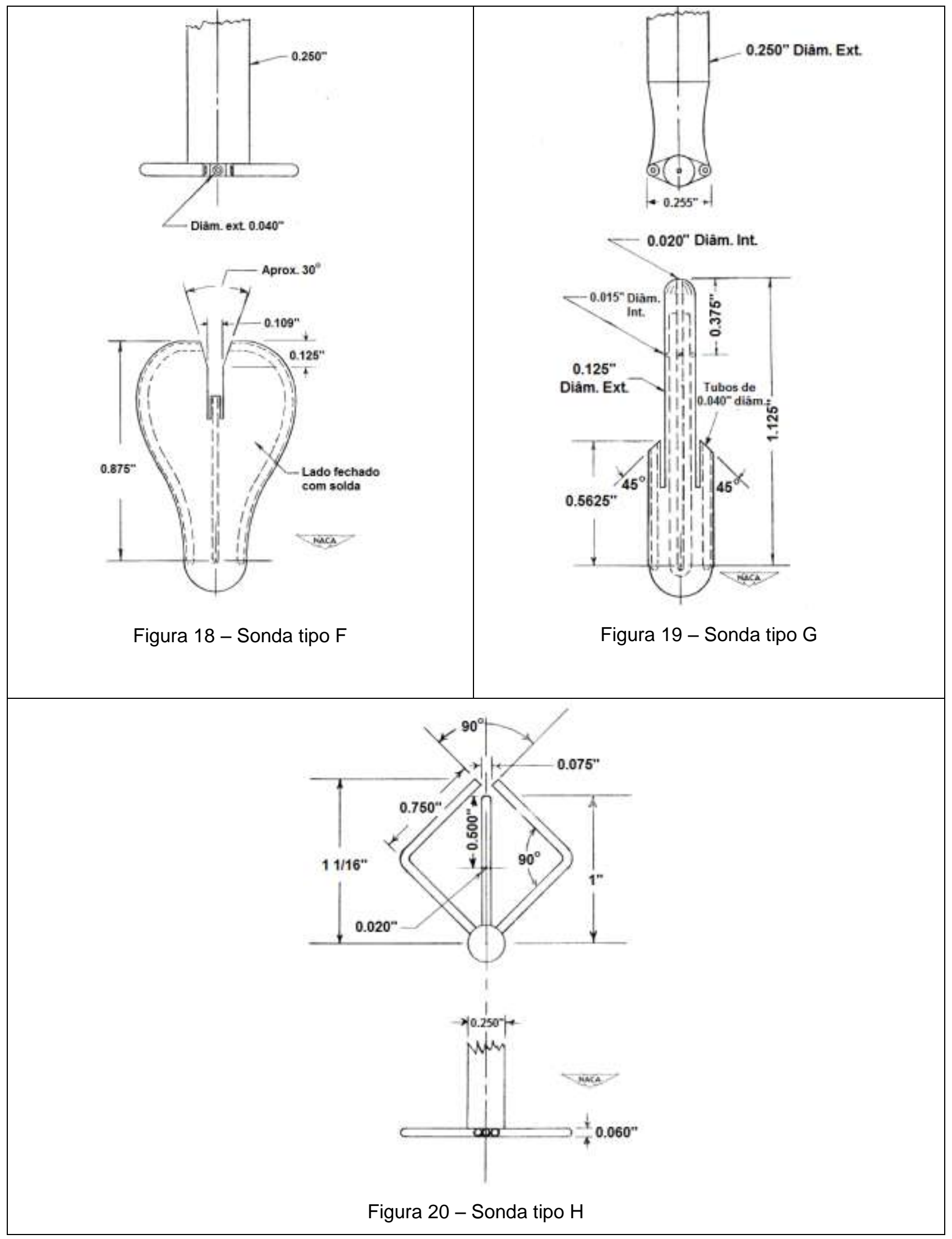


Tabela 1 - Resultados de medições de sondas tipo B a H. NACA TN 2830. (SCHULZE et al., 1952)

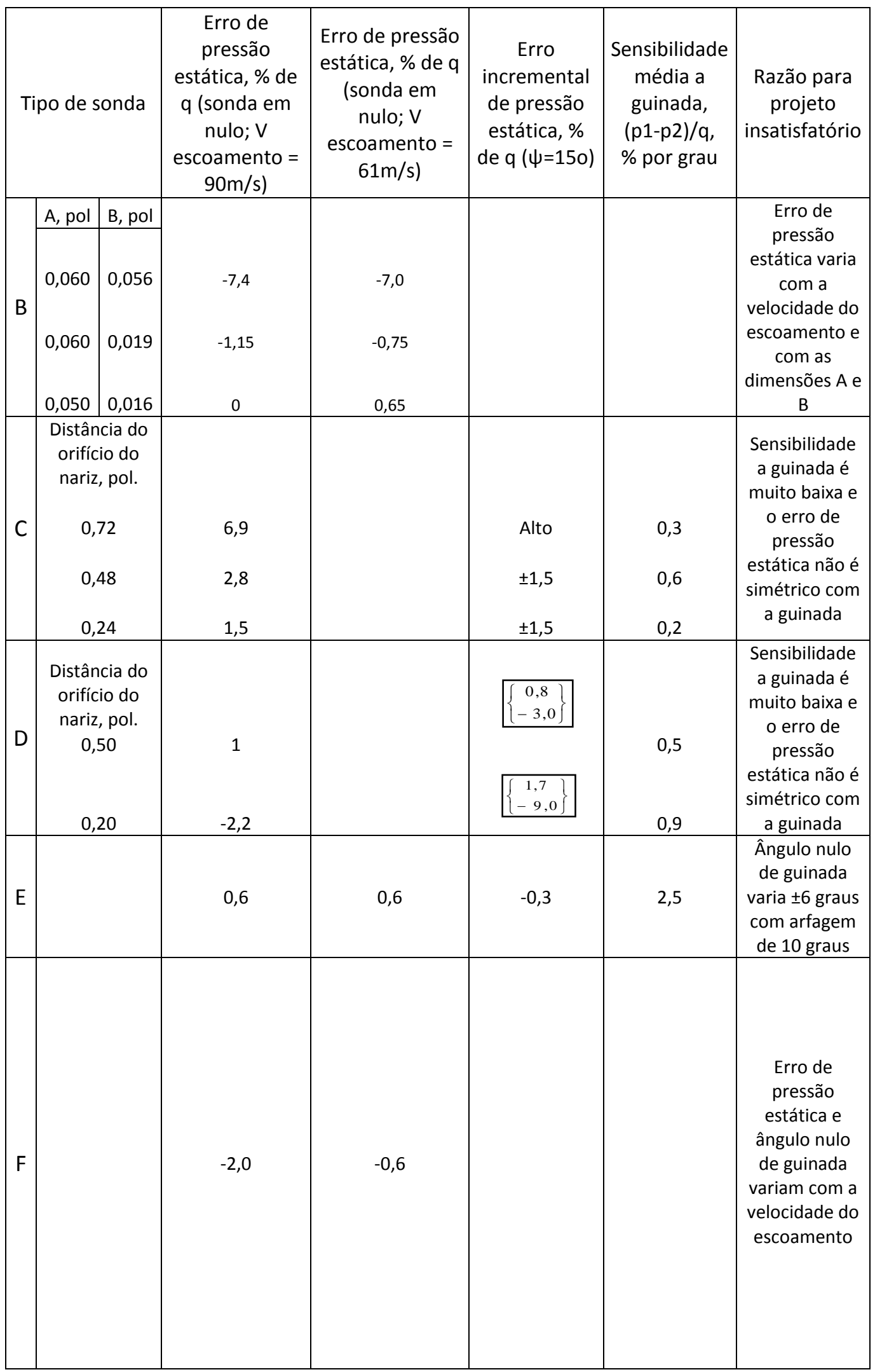




\begin{tabular}{|c|c|c|c|}
\hline G & 2,1 & 1,5 & $\begin{array}{c}\text { Erro de } \\
\text { pressão } \\
\text { estática varia } \\
\text { com a } \\
\text { velocidade do } \\
\text { escoamento e } \\
\text { a sonda divide } \\
\text { o escoamento } \\
\text { antes do } \\
\text { ângulo do } \\
\text { escoamento } \\
\text { ser captado }\end{array}$ \\
\hline $\mathrm{H}$ & 8,3 & 7,7 & $\begin{array}{c}\text { O erro de } \\
\text { pressão } \\
\text { estática é } \\
\text { expressivo e } \\
\text { varia com a } \\
\text { velocidade do } \\
\text { escoamento }\end{array}$ \\
\hline
\end{tabular}

Os resultados representados na tabela 1 apontam a necessidade de um projeto aerodinamicamente limpo para os medidores, no sentido de evitar interferências mútuas entre os elementos da sonda. Se as aberturas da sonda forem instaladas no nariz de um tubo de Pitot, a exatidão da indicação de pressão total e estática será mantida e o ângulo de guinada pode ser adquirido em um escoamento não-perturbado (SCHULZE et al., 1952). Esta consideração levou ao projeto das sondas tipo prisma e piramidal, representadas nas figuras 8,21 e 22 . 


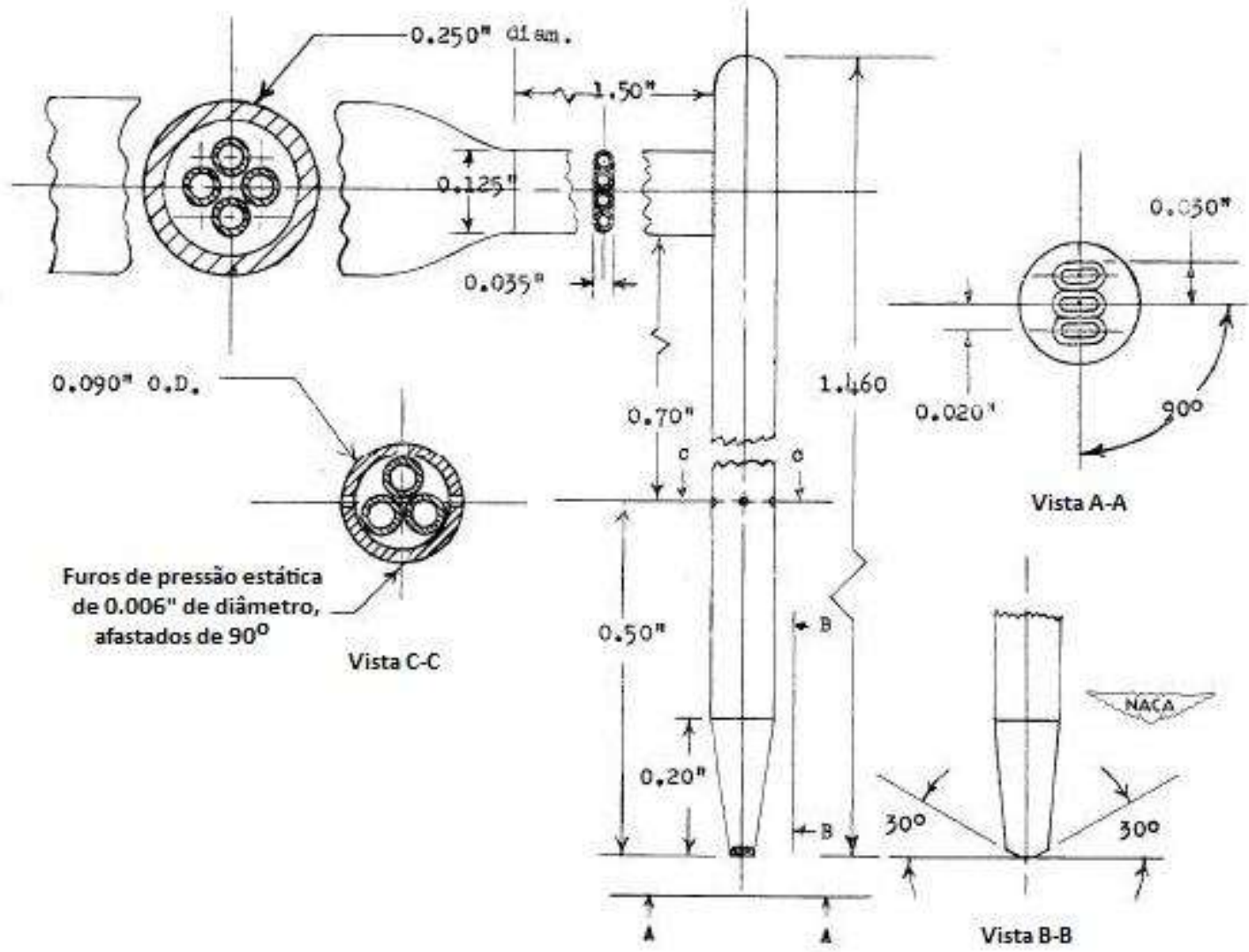

Figura 21 - Sonda tipo prisma. NACA TN 2830. (SCHULZE et al., 1952) 


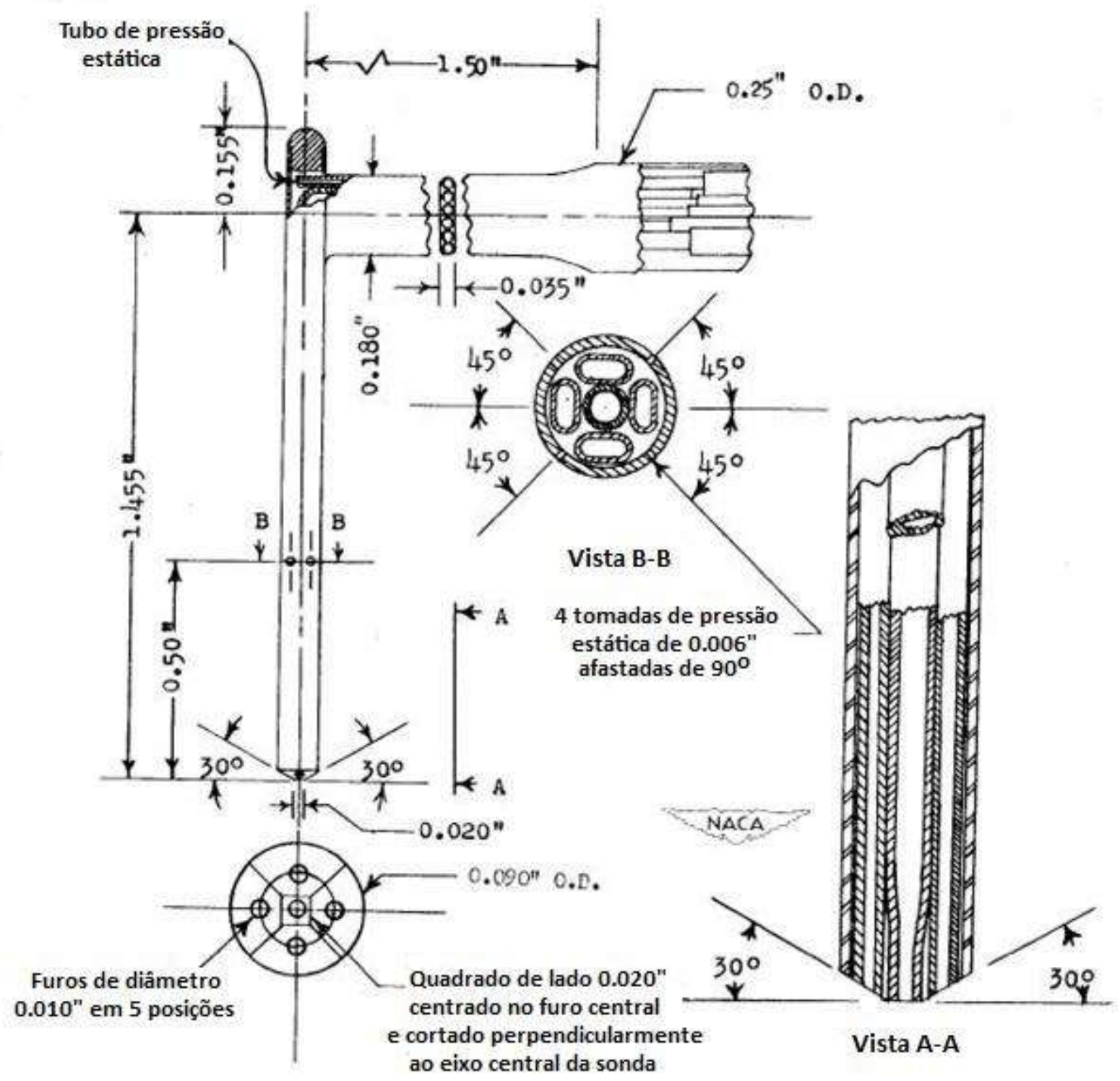

Figura 22 - Sonda tipo pirâmide. NACA TN 2830. (SCHULZE et al., 1952)

Nestes tipos de sonda, há cinco tomadas de pressão, sendo uma no centro da seção frontal da sonda e as outras quatro, inclinadas em $30^{\circ}$ em relação à direção normal ao escoamento já que, em estudos em outros tipos de sonda, este ângulo mostrou fornecer boa sensibilidade a ângulo de guinada de escoamento. As superfícies em que os orifícios são usinados são planas, de forma que se houver pequenos erros no posicionamento do orifício no momento de fabricação da sonda, não se verificam grandes alterações nos dados de calibração do instrumento. Há também tomadas de 
pressão de referência localizadas a mais de três diâmetros de sonda à jusante do nariz da sonda, em uma região em que os erros nas leituras de pressão de referência foram verificados como sendo muito pequenos da ordem de $0,5 \%$ para uma velocidade na seção de teste de 135,6 m/s (SCHULZE, et al., 1952). As tomadas de pressão para este tipo de sensor estão muito próximas entre si, estando separadas em apenas $1 \mathrm{~mm}$. Sendo assim, estas sondas são pouco afetadas por escoamentos não uniformes, salvo em regiões do escoamento com um alto gradiente de pressão. A sonda é pequena de forma a permitir a medição simultânea de pressões e ângulo do escoamento em distâncias axiais e radiais de $12,7 \mathrm{~mm}$ e 2,3 mm, respectivamente. A sensibilidade desta sonda ao ângulo de guinada foi obtida para duas velocidades, $60 \mathrm{~m} / \mathrm{s}$ e 118,8 m/s (SCHULZE, et al., 1952). Estes resultados estão representados nas figuras 23 e 24 a seguir.

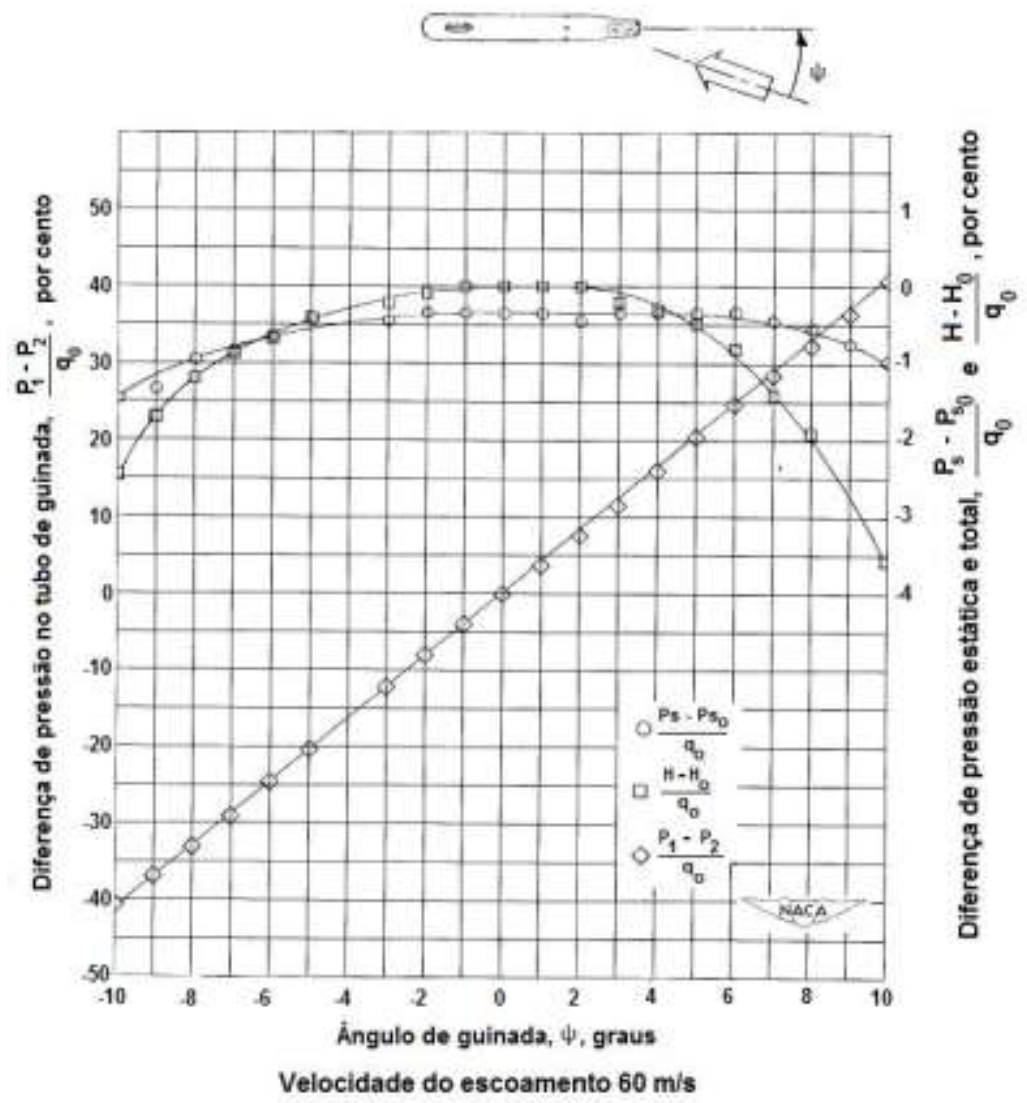

Figura 23 - Variação na leitura de pressão dos tubos de guinada e diferenças nas leituras de pressão total e estática da sonda prisma em relação a uma sonda padrão tipo Pitot, com respeito ao ângulo de guinada. $\mathrm{V}=60 \mathrm{~m} / \mathrm{s}$. (Fonte: NACA TN 2830) 


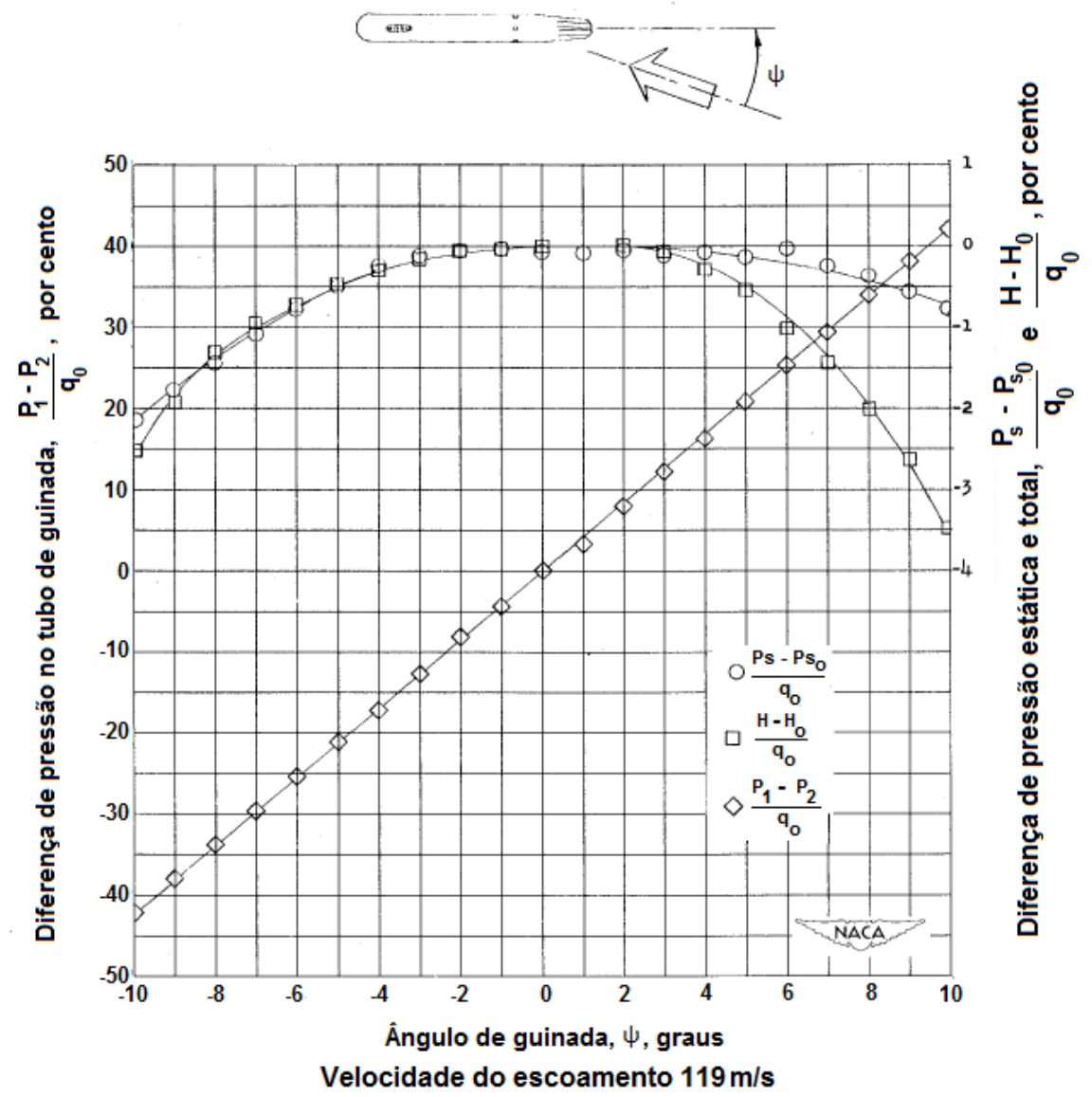

Figura 24 - Variação na leitura de pressão dos tubos de guinada e diferenças nas leituras de pressão total e estática da sonda prisma em relação a uma sonda padrão tipo Pitot, com respeito ao ângulo de guinada. $V=119 \mathrm{~m} / \mathrm{s}$. (Fonte: NACA TN 2830)

A referência NACA TN 2830 concluiu que a sonda tipo prisma, e sua variação para medidas em duas dimensões, a sonda pirâmide (figura 8) são consideradas adequadas para a medição de pressão estática, pressão total e direção do escoamento.

O trabalho de Bryer e Pankhurst (BRYER, PANKHURST, 1971) também é uma referência importante para o estudo de medidores de direção de escoamento e também serve de base para a escolha do medidor mais adequado à aplicação deste trabalho.

Para as sondas de pressão direcionais, capazes de medir direção de escoamento, a resolução da medição de ângulo que se pode atingir está ligada à menor diferença de pressão que pode ser lida pelo conjunto medidor-manômetro. Para escoamento incompressível, a sensibilidade de um medidor de direção do escoamento pode ser expressa por (BRYER, PANKHURST, 1971): 


$$
\left(C_{p}\right)_{\psi}=\frac{p_{1}-p_{2}}{\frac{1}{2} \rho V^{2} \psi}
$$

Nesta equação, a sensibilidade do medidor é expressa em termos da diferença de pressão entre dois tubos (ou furos) sensores por grau, em termos da pressão dinâmica do escoamento.

A menor variação de ângulo que pode ser detectada por um dado sistema pode ser expressa pela equação:

$$
\Delta \psi=\frac{\Delta p_{\min }}{\left(C_{p}\right)_{\psi} \times \frac{1}{2} \rho V^{2}}
$$

Nesta equação, $\Delta p_{\min }$ é a menor diferença de pressão que pode ser lida pelo manômetro.

Um exemplo citado no livro de Bryer e Pankhurst (BRYER, PANKHURST, 1971), para efeito de ordens de grandeza consiste em um manômetro de coluna d'água em $U$, que pode ser lido em intervalos de $1 \mathrm{~mm}$ e uma sonda com uma sensibilidade típica de 0,05, o ângulo do escoamento é detectável com uma resolução de 0,4 graus a uma velocidade de escoamento de $30 \mathrm{~m} / \mathrm{s}$.

Observando a equação 5 , pode-se concluir que há a necessidade de manômetros com boa resolução quando se quer medir velocidades mais baixas de escoamento, para se obter a mesma resolução em ângulo.

O trabalho de Bryer e Pankhurst, assim como o trabalho de Schulze (SCHULZE et al., NACA TN 2830, 1952) citado anteriormente, também investigou uma série de sondas de pressão capazes de medir velocidade e direção do escoamento. Estas sondas estão mostradas nas figuras 25 e 26. 
a

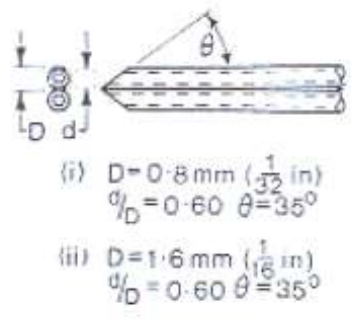

b

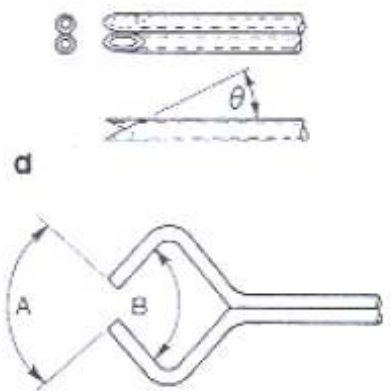

c
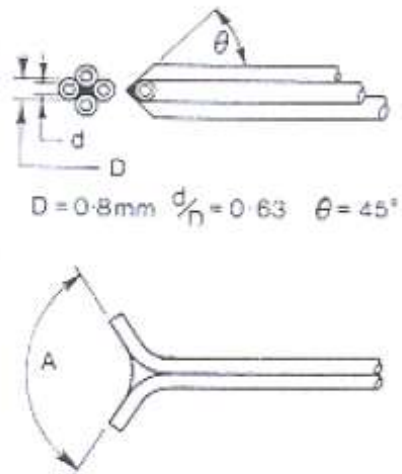

Figura 25 - Sensores de pressão feitos de tubos abertos: (a) Sonda de 2 tubos; (b) Sonda assimétrica de 2 tubos; (c) Sonda de 4 tubos; (d) Sonda tipo garra; (e) Sonda de 2 tubos divergente. (BRYER, PANKHURST, 1971)

a

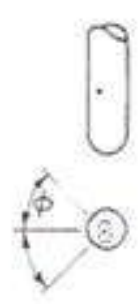

d

(0.)

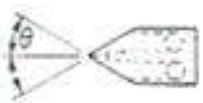

9

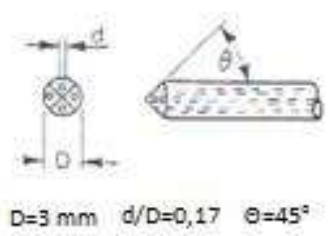

b

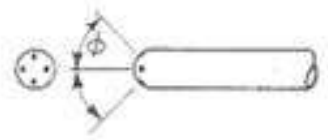

c

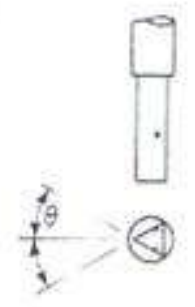

e

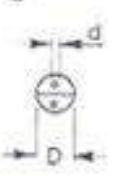

$\mathrm{D}=1,5 \mathrm{~mm}$

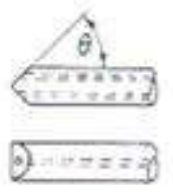

$d / D=0,19 \quad \theta=45^{\circ}$

h

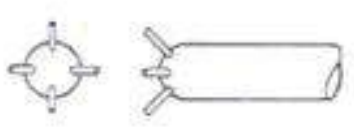

f

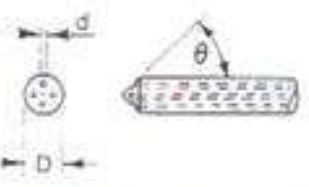

$D=3 \mathrm{~mm} \quad d / D=0,17 \quad \theta=45^{\circ}$

i

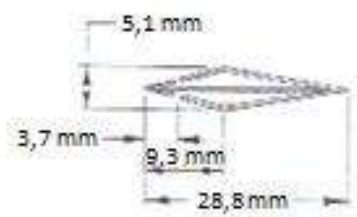

Figura 26 - Vários sensores de pressão: (a) Cilindro-transverso; (b) Cabeça hemisférica; (c) Cunha em balanço; (d) Conrad; (e) Chisel; (f) Cônico; (g) Piramidal; (h) Hemisférico com feixe de tubos divergentes; (i) Seção de aerofólio. (BRYER, PANKHURST, 1971) 
O efeito do gradiente de pressão na exatidão do sensor pode ser grande, sobretudo quando existe grande separação dos furos ou tubos sensores, como no caso dos sensores 25-d, 25-e e 26-h. Na prática (BRYER, PANKHURST, 1971), vê-se que os erros na medição de ângulo em gradientes de pressão total com pequena variação de pressão estática também dependem do tipo de sonda a ser usada e para uma dada separação de furos ou tubos sensores. Os sensores tipo cunha (26-c e 26-i) são menos sujeitos a erro. No caso em questão, não esperamos grandes variações de pressão estática para uma mesma seção de medição (entre o rotor e as aletas de um ventilador axial, por exemplo).

Sensores do tipo cilindro-transverso 26 -a, são bastante úteis para medidores de direção do vento em que se aplica o princípio de leitura nula, ou seja, para a família de medidores em que se posiciona o sensor de modo a fornecer a mesma leitura para as duas tomadas de pressão. Os furos podem ser executados na posição de máximo gradiente de pressão e, para baixos números de Mach, este ângulo de separação entre os dois orifícios se encontra em torno de 90 graus (BRYER, PANKHURST, 1971).

Os sensores dos tipos Cunha, Chisel, cônico, piramidal e Conrad, são mais sensíveis do que os que possuem uma cabeça esférica e a sensibilidade destas sondas cresce à medida que aumenta o ângulo de seu nariz, entre 15 e 90 graus, dependendo do número de Mach do escoamento a ser medido. Outra vantagem destes tipos de sensores é a sua facilidade de construção, pois o posicionamento dos furos é menos crítico do que em sensores de seção circular ou elipsoidal.

O efeito do ângulo de arfagem na medição do ângulo de guinada é menor nos medidores tipo cunha, piramidal e Conrad do que nos medidores tipo cônico e Chisel, sendo assim, tem-se mais um critério para a escolha do medidor. Comparando-se esses três medidores, segundo a referência (BRYER, PANKHURST, 1971), temos as sensibilidades representadas na tabela 2, para escoamento incompressível e para os dados ângulos de separação dos furos. 
Tabela 2: Comparação entre sensibilidades de medidores para escoamento incompressível. (BRYER, PANKHURST, 1971)

\begin{tabular}{|c|c|c|}
\hline Medidor & $\begin{array}{c}\text { Ângulo de separação } \\
\text { (graus) }\end{array}$ & Sensibilidade \\
\hline Cunha & 30 & 0,053 \\
\hline Piramidal & 45 & 0,042 \\
\hline Conrad & 30 & 0,049 \\
\hline
\end{tabular}

O trabalho de Zilliac (ZILLIAC, 1989) consiste em um estudo experimental e analítico sobre sondas de 7 orifícios. Estas sondas funcionam segundo o mesmo princípio das sondas tipo pirâmide citadas no trabalho de Schulze, citadas anteriormente, com a vantagem de permitir medições em uma maior faixa de ângulos. Este trabalho discute um modelo analítico fundamentado na teoria de escoamento em torno de corpos rombudos e também em métodos dos painéis, fazendo uso das formulações desenvolvidas nos trabalhos de Smith (SMITH et. al., 1970) e Huffman (HUFFMAN et. al., 1980). O programa de método dos painéis PANAIR foi utilizado no trabalho de Zilliac para resolver as equações potenciais do fluido para o modelo da sonda. Este método de painéis resolve a equação de Laplace para o potencial de velocidade $\Phi$ fazendo a superposição de um dipolo variando quadraticamente e singularidades tipo fonte variando linearmente em painéis mapeados na superfície do modelo da sonda. As equações que regem o problema, bem como as condições de contorno são (ZILLIAC, 1989):

$$
\begin{aligned}
\vec{\nabla}^{2} \Phi & =0 \\
\vec{\nabla} & \\
\vec{\nabla} & =\vec{V}_{\infty} \quad \text { em } \infty \\
\vec{\nabla} & \qquad \cdot \vec{\nabla} F=0 \quad \text { em } \mathrm{F}(\mathrm{r}, \theta, \mathrm{z})=0
\end{aligned}
$$

Em que

$$
\vec{V}=\vec{\nabla} \Phi
$$


É a solução para um corpo em ângulo de ataque e guinada arbitrários. Esta solução pode ser encontrada pela combinação linear da solução em $\alpha=0^{\circ}$ e $\alpha=90^{\circ}$. Se $\Phi_{1}$ é a solução em $\alpha=0^{\circ}$ e $\Phi_{2}$ é a solução em $\alpha=90^{\circ}$, então a solução em qualquer $\alpha$ é dada por:

$$
\Phi=\Phi_{1} \cos (\alpha)+\Phi_{2} \operatorname{sen}(\alpha)
$$

Como pode se verificar via substituição, essa expressão satisfaz as equações e as condições de contorno para um corpo de revolução sob ângulo de ataque. Para determinar $\Phi$, dados $\alpha$ (ângulo de ataque) e $\beta$ (ângulo de guinada), para um corpo de revolução, pode-se utilizar uma transformação de coordenadas. Essa transformação é equivalente à rotação de um ângulo $x$ em torno do plano $x-z$ do vetor velocidade do escoamento não-perturbado, conforme mostrado no sistema de coordenadas representado na figura 26 a seguir.

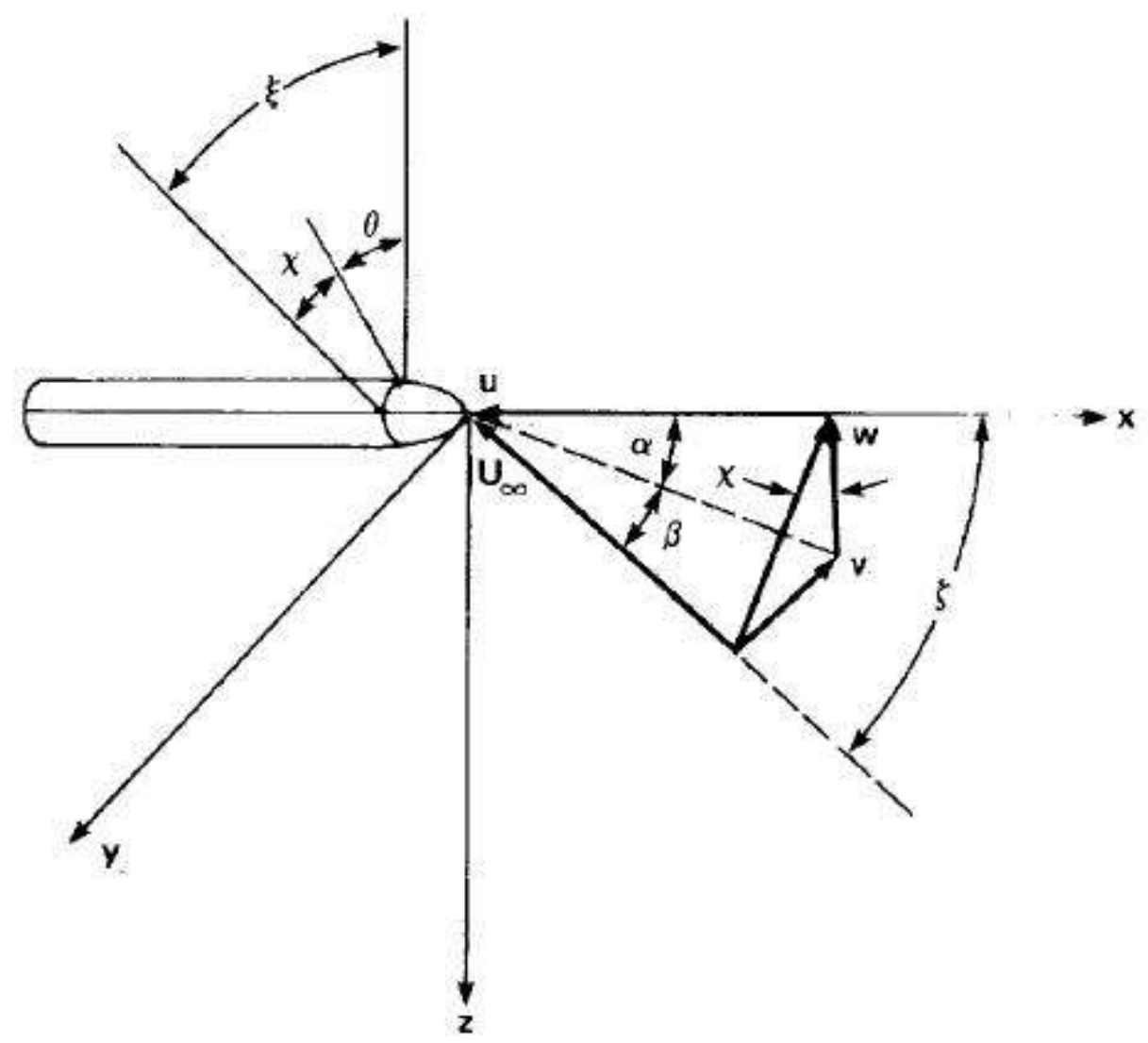

Figura 27 - Sistema de coordenadas do medidor. (ZILLIAC, 1989) 
A transformação do sistema $(r, \theta, z)$ para o sistema $(r, \xi, z)$ é definida por:

$$
\xi=\theta+\chi
$$

Em que:

$$
\chi=\tan ^{-1}\left(\frac{\operatorname{sen}(\beta)}{\cos (\beta) \operatorname{sen}(\alpha)}\right)
$$

Dessa forma, o novo ângulo de ataque $x$ é usado junto com a expressão para $\Phi$ para determinar o potencial de velocidade para um sólido de revolução sob ângulo de ataque e guinada.

$$
\varsigma=\cos ^{-1}[\cos (\alpha) \cos (\beta)]
$$

E o coeficiente de pressão é dado por:

$$
C_{P}=\frac{P-P_{\infty}}{\frac{1}{2} \rho U_{\infty}^{2}}=1-\frac{|\vec{V}|^{2}}{V_{\infty}^{2}}=1-\frac{|\vec{\nabla} \Phi|^{2}}{V_{\infty}^{2}}
$$

Essa técnica é aplicável de uma forma geral a corpos de revolução em que se deseja a solução do escoamento potencial em um certo par ângulo de ataque e guinada arbitrários (ZILLIAC, 1989). O trabalho de Zilliac apresenta uma comparação dos resultados calculados analiticamente com medições realizadas com uma sonda de 7 furos. A figura 26b representa a sonda de 7 orifícios discutida no trabalho de Zilliac enquanto a figura 27 a mostra uma comparação dos resultados analíticos e de medição para a variação de pressão com ângulo de guinada $\theta=0^{\circ}$. 


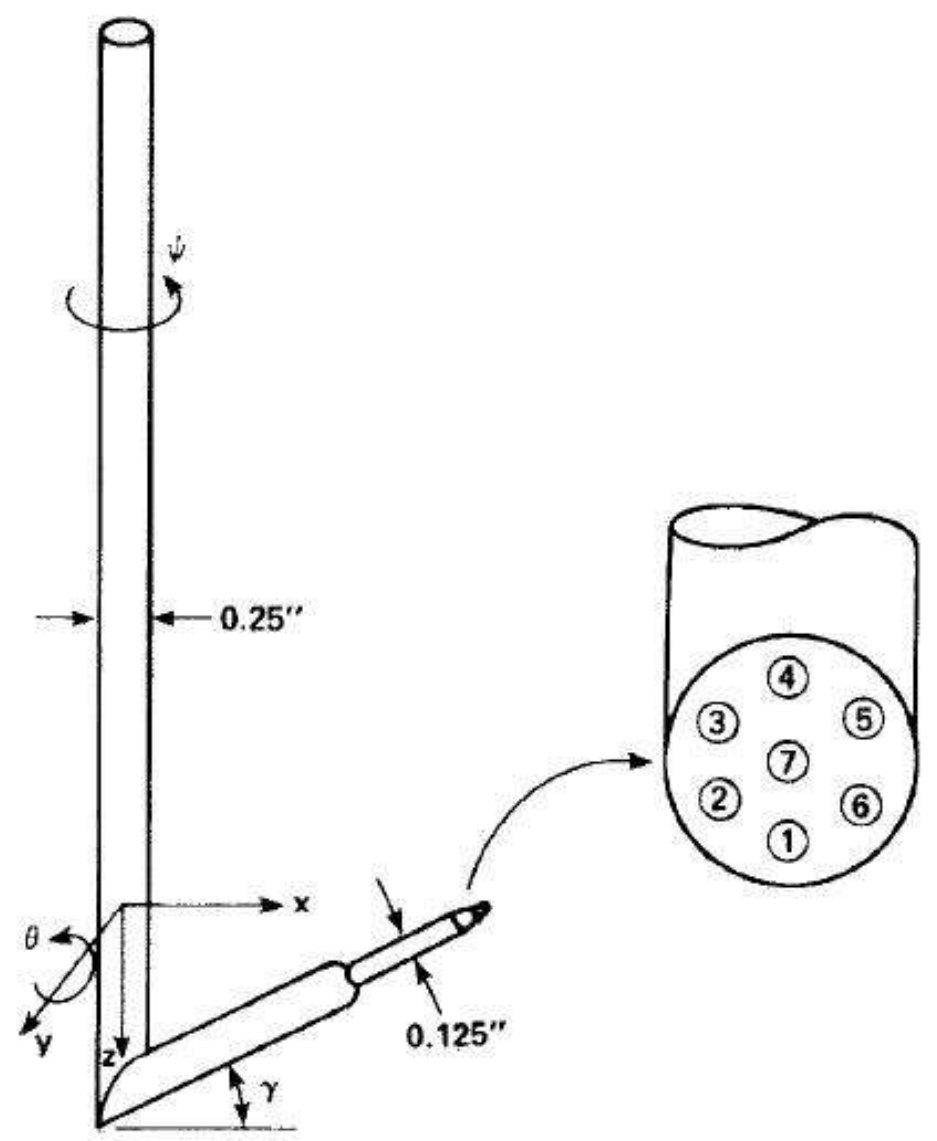

Figura 28 - Sonda de 7 orifícios e esquema de numeração dos orifícios (ZILLIAC, 1989) 


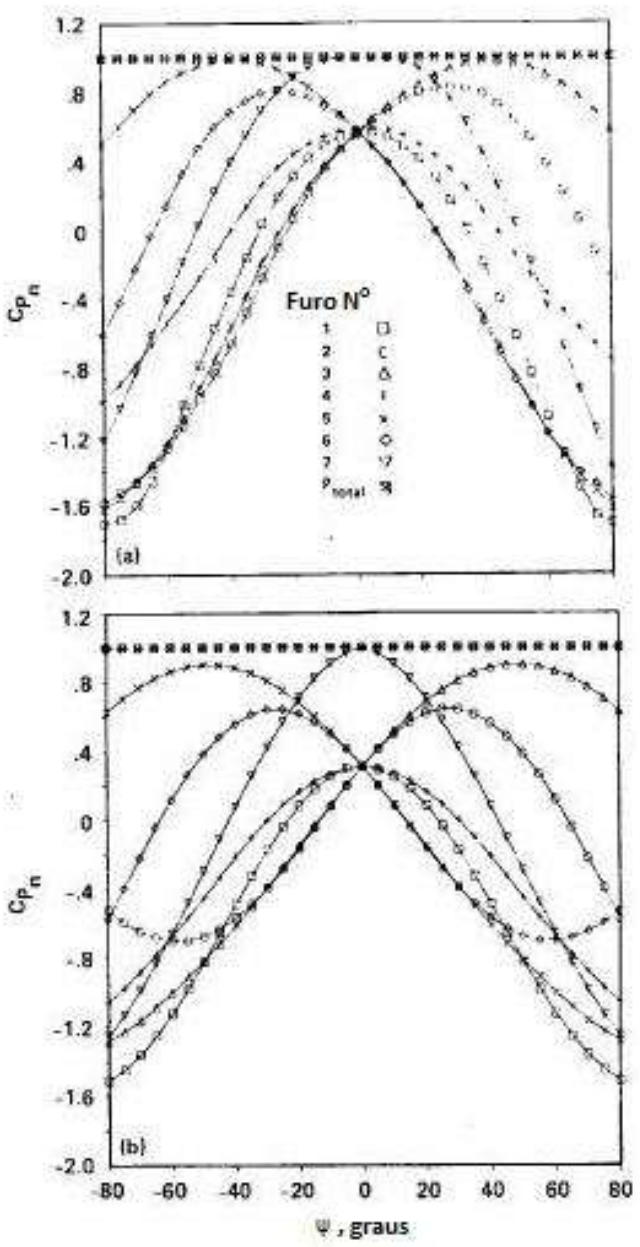

Figura 29 - Variação de pressão em uma sonda de 7 furos. (a) Variação de pressão medida. (b) Variação de pressão teórica. (ZILLIAC, 1989).

Como pode ser visto pela comparação na figura 29, as tendências e ordens de grandeza mostram grande nível de correspondência. De acordo com o trabalho de Zilliac, as maiores diferenças entre os resultados são devidas a:

a) A queda na distribuição de pressão experimental diminui com $\circ \beta$ na ponta da sonda (tubo 7) mas não é tão dramática como a queda calculada computacionalmente. Possivelmente, isso pode ser causado por pequenas diferenças entre $o$ modelo de sonda fabricado $e$ modelado computacionalmente. 
b) Os picos de pressão computados no furo 5 perto de $\beta=-40^{\circ}$ e no furo 3 perto de $\beta=40^{\circ}$ são um pouco menores que o valor medido. Considerando que o ângulo da geratriz do cone na ponta da sonda é $45^{\circ}$, é esperado que esses picos estejam perto da pressão de estagnação, assim como é o caso dos dados experimentais.

c) Quando em grandes ângulos de guinada negativos, a pressão calculada no tubo 2 é substancialmente maior que os resultados experimentais. Essa discrepância é uma evidência de separação do escoamento nesta parte da sonda. Tipicamente, quando o escoamento se separa em um sólido de revolução, a sucção desenvolvida pela parte da sonda onde o escoamento está separado é maior do que aquela prevista pelo escoamento potencial, devido à presença de vórtices na região de escoamento separado. Situações similares ocorrem no tubo 6 em grandes ângulos de guinada e também para outros furos em diferentes ângulos de ataque.

O trabalho de Zilliac ainda apresenta uma comparação entre os valores calculados e determinados experimentalmente dos coeficientes de calibração da sonda para cada uma das 7 tomadas de pressão. Há diferenças, mas as tendências gerais e as magnitudes dos resultados são próximas o suficiente para serem capazes de ajudar na etapa de projeto de sondas desse tipo. Esses resultados serão usados neste trabalho para a escolha da geometria e configuração da sonda.

O trabalho de Nowack (NOWACK, 1970) apresenta uma maneira para efetuar a calibração de sondas direcionais de pressão com 5 orifícios. É apresentado um método de calibração que consiste em posicionar a sonda de 5 orifícios na frente de um soprador de ar calibrado para fornecer um escoamento alinhado com o eixo da sonda e com velocidade conhecida. Um dispositivo posicionador rotaciona a sonda em torno de dois eixos, um de guinada e um de arfagem. Durante a calibração, foram tomadas leituras de pressão para incrementos de ângulo de 5 graus para um dado ângulo de arfagem constante. Dessa forma, foram feitas variações angulares nas direções identificadas como arfagem e guinada, sendo medidas das pressões para uma faixa 
entre -90 e +90 graus em incrementos de 5 graus. Com estes valores, foram traçadas curvas de calibração em um diagrama ângulo de guinada versus ângulo de arfagem, para diversos valores de coeficientes de guinada $\mathrm{K}_{\psi}$ e arfagem $\mathrm{K}_{\delta}$ em que:

$$
K_{\psi}=\frac{p_{1}-p_{3}}{p_{1}-p_{5}} \text { e } K_{\delta}=\frac{p_{1}-p_{2}}{p_{1}-p_{4}}
$$

Sendo $p_{1} \circ$ valor da pressão lida pelo orifício central, $p_{3}$ e $p_{5}$ são leituras das pressões dos orifícios localizados no plano de guinada e $p_{2}$ e $p_{4}$ são as leituras de pressões nos orifícios no plano de arfagem.

O trabalho de Nowack realizou esta calibração para diferentes valores de velocidade de escoamento e em diferentes condições climáticas (temperatura e umidade do ar), verificando que os fatores $\mathrm{K}_{\psi}$ e $\mathrm{K}_{\delta}$ apresentaram praticamente os mesmos valores (NOWACK, 1970).

\subsection{APLICAÇÕES EM MEDIÇÃO DE ESCOAMENTO À JUSANTE DE VENTILADORES AXIAIS}

Um estudo sobre o campo de velocidades à jusante de rotores de ventiladores axiais foi realizado, tomando como base os experimentos conduzidos por $\mathrm{Li}$ et. al. ( $\mathrm{Li}$ et al., 2007). Este estudo sobre o desempenho aerodinâmico em ventiladores axiais realizou dois tipos de experimentos.

A primeira série de experimentos consistiu na utilização de uma sonda por medição de pressão com 5 furos para a caracterização do escoamento na saída do rotor. Esta sonda foi posicionada em 21 estações ao longo do raio do rotor e foi fixada a $15 \mathrm{~mm}$ atrás da pás do rotor. Este tipo de medição permitiu determinar a distribuição radial de aumento pressão total e a distribuição radial do coeficiente de perda de pressão total do rotor. Alguns resultados desta série de experimentos estão representados na figura 30 a seguir, e permite ter uma idéia do tipo de resultado que se espera obter em medições deste tipo. 


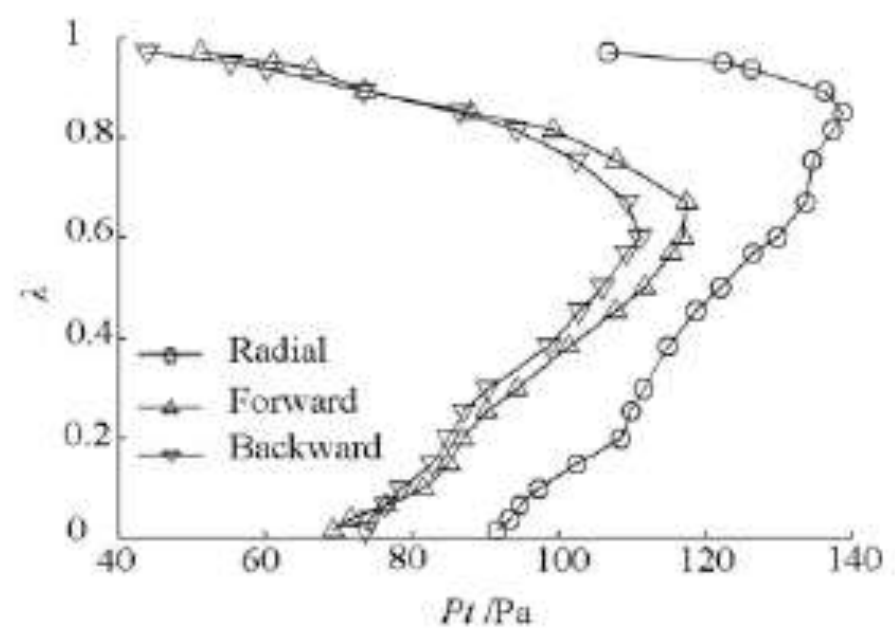

Figura 30 - Exemplo de resultado de medições de aumento de pressão total na direção radial do rotor. (Li et al., 2007)

$\mathrm{Na}$ figura 30, o parâmetro $\lambda$ representa a estação ao longo do raio em que foi realizada a medição. A razão $\mathrm{P}_{\mathrm{t}} / \mathrm{P}_{\mathrm{a}}$ representa 0 aumento de pressão total naquela estação, sendo $\mathrm{P}_{\mathrm{a}}$ a pressão total do escoamento à montante do rotor e $\mathrm{P}_{\mathrm{t}}$ a pressão total do escoamento à jusante de rotor.

A segunda série de experimentos utilizou um anemômetro de fio quente acoplado a um posicionador que permite rotacionar o anemômetro e deslocá-lo no sentido radial do ventilador - da ponta das pás até o centro do ventilador. Dessa forma, realizando medições em 10 estações ao longo do raio e 417 pontos ao longo da circunferência do rotor, foi possível realizar um mapeamento do campo de velocidade num plano localizado $15 \mathrm{~mm}$ a jusante do rotor. Um sistema de gatilho via reflexão fotoeletrônica foi utilizado para que a placa de aquisição interpretasse quando uma das pás (que continha uma fita refletora) passasse em frente a um sensor infravermelho. A aquisição de sinais era realizada por um gatilho externo que recebeu um sinal deste sensor infravermelho. 


\section{DEFINIÇÃO DOS MEDIDORES E DO APARATO EXPERIMENTAL}

Neste item são apresentados os fundamentos para a escolha do sensor, valendo-se das pesquisas apresentadas no capítulo de revisão da literatura, e em especial o levantamento referente a sondas direcionais. Conforme já mencionado na introdução, as sondas direcionais possuem requisitos que levam à sua escolha, considerando o contexto de aplicação em questão, que é a medição de escoamento à jusante de ventiladores axiais. Estes requisitos são: construção robusta, capacidade de realização de medição em um ponto do escoamento, baixo custo de fabricação e relativa facilidade de calibração.

Após definido o medidor, procede-se à determinação do aparato experimental necessário para as etapas de calibração do medidor e realização dos experimentos, encerrando a seção com o estudo em mais detalhe do escoamento à jusante de rotores de ventiladores axiais.

\subsection{ESCOLHA DO SENSOR}

Partindo do conjunto de diferentes tipos de sondas direcionais descrito na revisão da literatura, os tipos de sondas direcionais selecionados preliminarmente foram: do tipo garra (figura 12), tipo prisma (figura 21), tipo piramidal (figura 22), e a sonda de 7 orifícios (figura 28).

Devido à necessidade de realização de medições pontuais, de forma a ser possível a captação de gradientes elevados de velocidade ou direção de escoamento, as sondas tipo garra se mostraram menos adequadas, pois suas tomadas de pressão possuem um espaçamento entre si da ordem de $15 \mathrm{~mm}$ em comparação com espaçamentos da ordem de $5 \mathrm{~mm}$ ou menos para as sondas tipo piramidal, prisma e de 7 orifícios.

Os procedimentos de calibração para estas diferentes sondas foram analisados com base no artigo NACA TN2830 (SCHULZE et al., 1952) que estuda as sondas tipo prisma, pirâmide e garra, enquanto que para o tubo de 7 orifícios, os procedimentos são detalhados no trabalho NASA TM102200 (ZILLIAC, 1989). 
Desta comparação, verificou-se que o processo de calibração das sondas de 7 orifícios é longo, uma vez que devem ser calibradas em escoamentos tridimensionais e o número de pontos de posicionamento da sonda no espaço é da ordem de 2000 pontos. O procedimento de calibração da sonda tipo prisma é mais simples, considerando medições de ângulo em apenas em um plano. Em seguida está o processo de calibração da sonda tipo pirâmide que, apesar de consumir um tempo pelo menos três vezes maior do que o necessário para a calibração da sonda tipo prisma e necessitar de aparatos de calibração com maior grau de liberdade de rotação, ainda assim pode ser viável para a aplicação neste projeto de experimentos.

A sonda de 7 orifícios, apesar de possuir um grau mais alto em termos de precisão, resolução e faixa de ângulos de medição (até 80 graus em relação a um plano que contém o eixo do orifício central), não possui um procedimento de calibração simples, adequado às possibilidades experimentais dos laboratórios utilizados, somando ao fato de sua fabricação ser mais suscetível a erros, o que pode aumentar significativamente os custos de desenvolvimento deste tipo de medidor.

Pelas razões apresentadas, optou-se pelo projeto e fabricação de protótipos de duas sondas direcionais, uma tipo prisma e outra tipo pirâmide.

\subsection{DEFINIÇÃO DO APARATO EXPERIMENTAL}

Definidos os protótipos a ser fabricados, há necessidade de instrumentos que viabilizem a calibração e execução de experimentos atendendo aos requisitos de amplitude da faixa de medição e resolução das medidas, tanto para a pressão quanto para o posicionamento angular.

Para a calibração, o dispositivo para posicionamento do sensor deve possuir liberdade de rotação em dois eixos, que são relacionados aos ângulos de guinada e arfagem. Um possível dispositivo que contém apenas partes mecânicas está representado nas figuras 31 e 32 a seguir. 


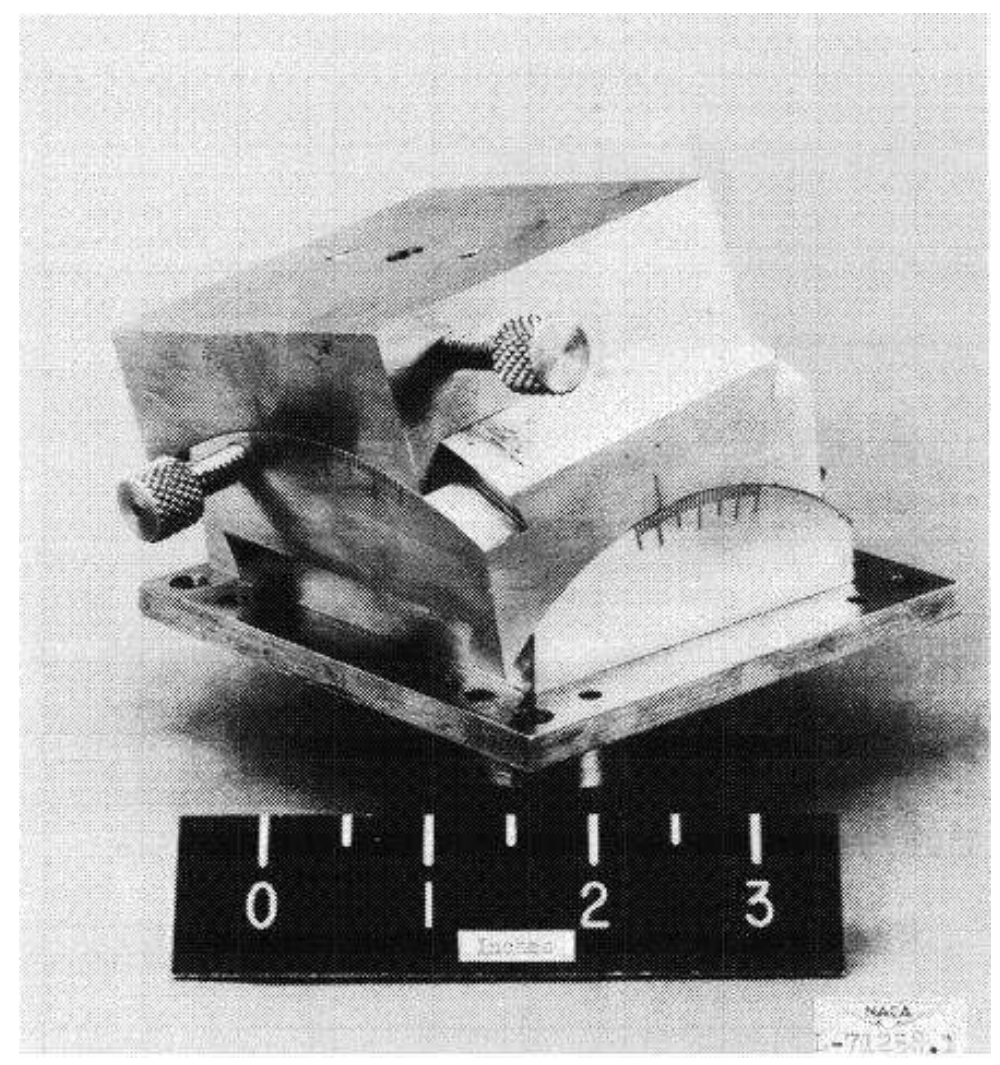

Figura 31 - Exemplo de posicionador mecânico para calibração utilizado no trabalho NACA TN 2830.

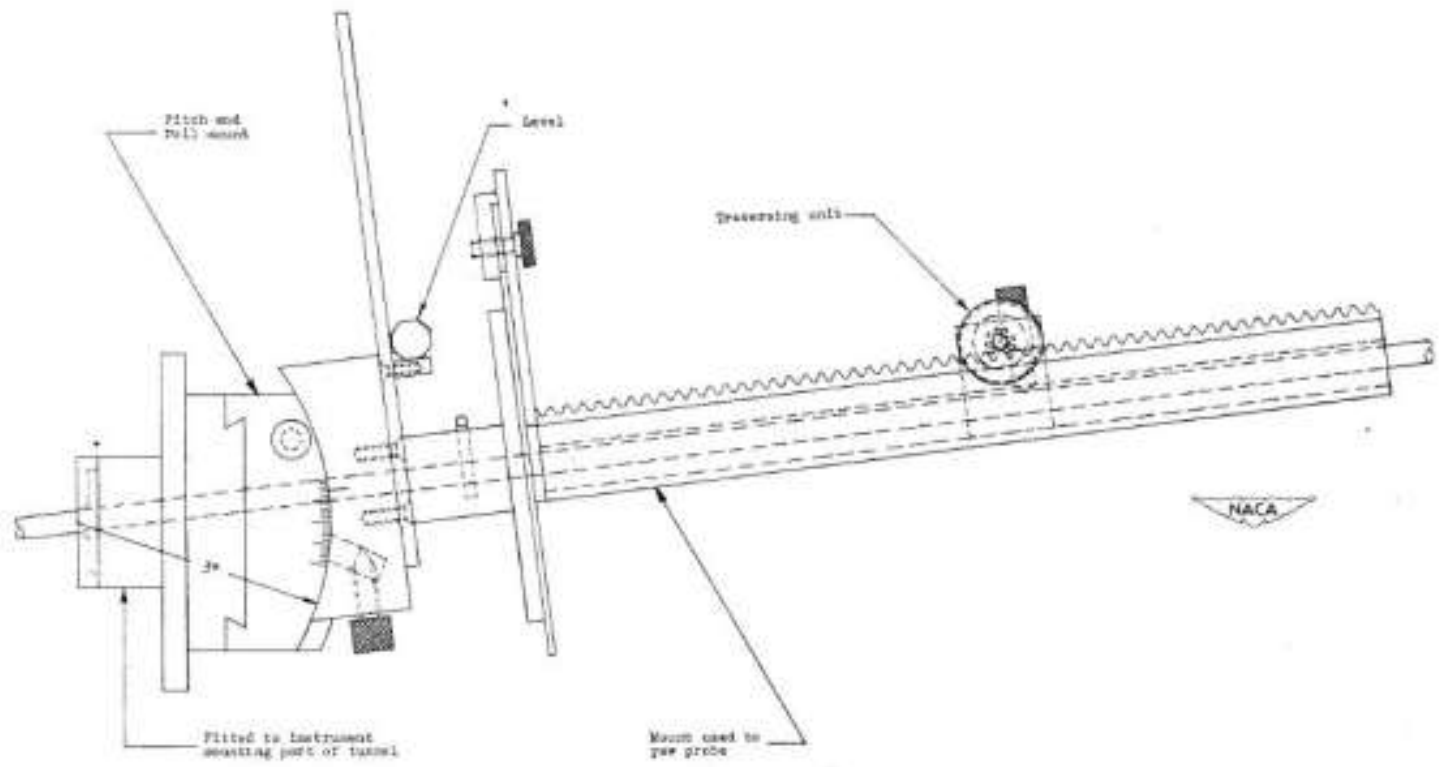

Figura 32 - Esquema de montagem de posicionador mecânico utilizado no trabalho NACA TN 2830. 
$\mathrm{Na}$ etapa de calibração, são necessários manômetros capazes de medir valores de pressão na faixa pretendida e com a resolução mínima de $1 \mathrm{~Pa}$, a fim de que o manômetro não seja um limitante quanto à resolução da medição da velocidade do escoamento. Para medir velocidades de escoamento na faixa de 0 a $15 \mathrm{~m} / \mathrm{s}$ com resolução da ordem de $1 \mathrm{~m} / \mathrm{s}$ utiliza-se a equação (15) a seguir para relacionar pressão e velocidade:

$$
V=\sqrt{\frac{2 P_{d i n}}{\rho}}
$$

Uma variação na velocidade significa esta variação ao quadrado para a pressão dinâmica. Sendo assim, se o manômetro possuir uma resolução de $1 \mathrm{~Pa}$ e uma faixa de medição de $-125 \mathrm{~Pa}$ a $+125 \mathrm{~Pa}$ do valor da pressão diferencial, garante-se a possibilidade de determinar a velocidade em uma faixa a partir de 1,3 m/s até 14,4 m/s e uma resolução de velocidade da ordem de $0,6 \mathrm{~m} / \mathrm{s}$, o que atende o requisito de pelo menos $1 \mathrm{~m} / \mathrm{s}$ de resolução dentro da faixa de medições pretendida. A maior dificuldade desta medição ocorre em velocidades menores, em que a diferença de pressão entre as tomadas de pressão da sonda são pequenas. Para eliminar este problema, pode-se utilizar micro-manômetros, com resolução da ordem de $0,001 \mathrm{~Pa}$ e faixa de medição entre -100 $\mathrm{Pa}$ e $+200 \mathrm{~Pa}$, o que resulta na possibilidade de determinar a velocidade do escoamento em uma faixa entre $0,05 \mathrm{~m} / \mathrm{s}$ e $20 \mathrm{~m} / \mathrm{s}$ com resolução da ordem de $0,02 \mathrm{~m} / \mathrm{s}$.

Outros instrumentos necessários são termo-higrômetro e medidor de pressão atmosférica para a determinação da massa específica do ar ambiente, bem como termopares na região de interesse das medições, para uma correção da massa específica do ar local usando como referência a temperatura naquele ponto (AMCA 210). Finalmente, é desejável usar um sistema de aquisição de dados para a execução do experimento, considerando o grande número de medidas a fazer. 


\subsection{APLICAÇÃO DA MEDIÇÃO: ESTUDO DO ESCOAMENTO À JUSANTE DE ROTORES DE VENTILADORES AXIAIS}

Outro aspecto que auxiliou a definição do medidor foram as medições de características de velocidade nos escoamentos em dutos associados a turbomáquinas ou ventiladores axiais. Algumas particularidades, como o escoamento estar confinado em pequenas passagens e passar por mudanças bruscas de direção e velocidade, motivam a inserção de uma sonda neste escoamento para avaliar suas propriedades.

Para escolher o tipo de sensor adequado, é necessário antes conhecer as características do escoamento que se quer estudar com o uso deste. A figura 33 a seguir apresenta uma ilustração do ventilador de mineração.

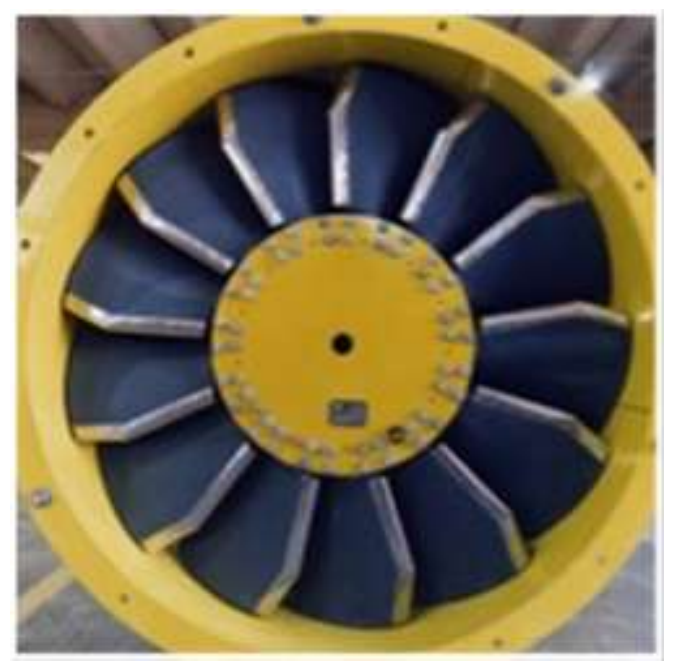

Figura 33 - Ventilador axial de aplicação em mineração. Fonte: Tecsis

A título de exemplo, e para estimar intervalos de velocidade em que as sondas irão operar, foi selecionado um modelo. Este equipamento possui uma rotação nominal de 1780 rpm e sua curva característica, em termos de pressão e vazão, de acordo com o passo da pá é dada na figura 34. Para este caso, o ponto de operação do ventilador é de uma vazão de $16,4 \mathrm{~m}^{3} / \mathrm{s}$ a uma pressão estática de $2128 \mathrm{~Pa}$ e massa específica do ar de $1.1 \mathrm{~kg} / \mathrm{m}^{3}$. A massa específica do ar considerada nesta curva é aquela considerada para as condições usuais em ambientes da mina. 


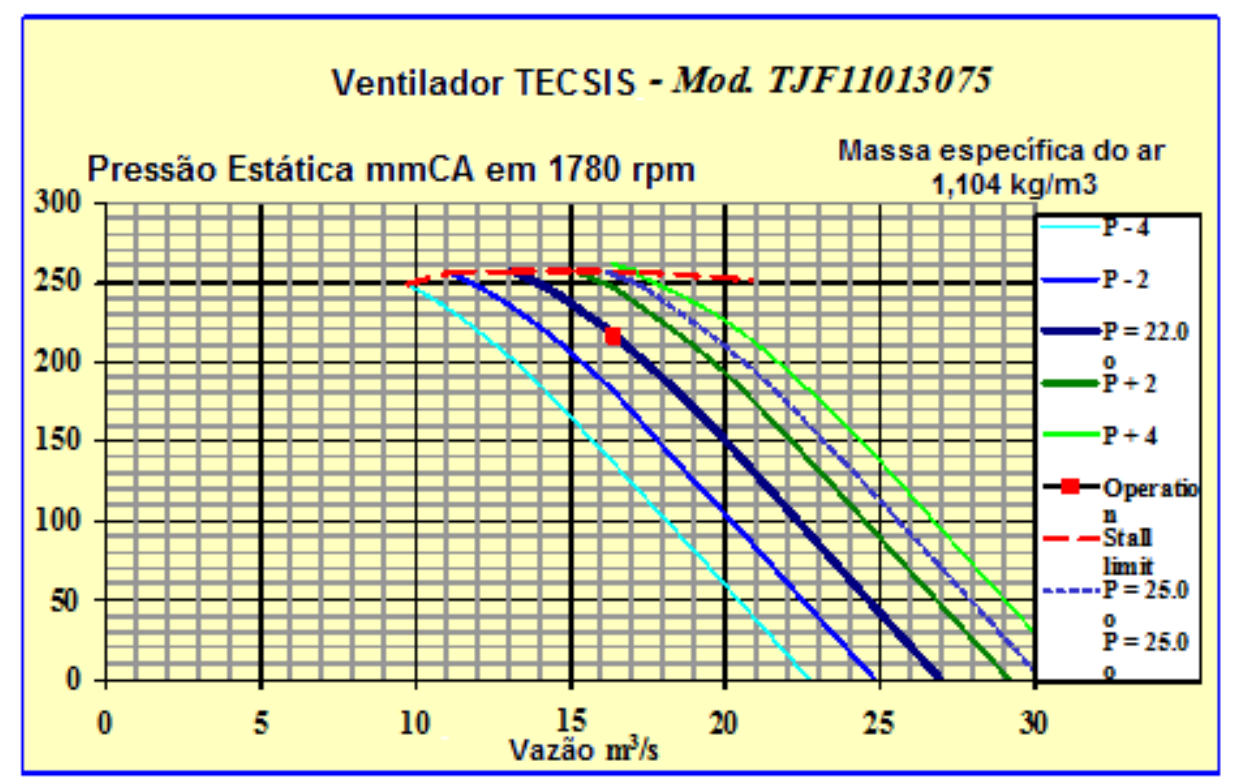

Figura 34 - Curva do ventilador TJF11013075 (Fonte: TECSIS - Divisão de Ventilação Industrial)

Sendo assim, para uma vazão $Q$ de $16,4 \mathrm{~m}^{3} / \mathrm{s}$ em um duto de diâmetro interno de $1 \mathrm{~m}$ e área $\mathrm{A}$, tem-se uma velocidade média na direção axial do escoamento de:

$$
V=\frac{Q}{A}=\frac{16,4 \mathrm{~m}^{3} / \mathrm{s}}{\pi \times\left(\frac{1,1 \mathrm{~m}}{2}\right)^{2}}=17,2 \mathrm{~m} / \mathrm{s}
$$

Contudo, o interesse da medição é de obter características mais específicas sobre o campo de velocidades nas condições de escoamento, e para tal, é necessário observar como se dá o escoamento na interface com as pás do ventilador.

O equipamento de ventilação em questão apresenta aletas atrás do rotor. Conforme representado na figura 35, o escoamento de ar se aproxima das pás do ventilador com velocidade $V_{0}=Q / A_{\text {anular }}(B L E I E R, 1997)$ onde $A_{\text {anular é a área da seção }}$ anular entre a carcaça do duto e o cubo onde são fixas as pás do rotor. O escoamento então é defletido pelas pás e as deixa a uma velocidade $V_{1}$. Esta velocidade $V_{1}$ possui uma componente axial $\mathrm{V}_{0}$, que deve ser mantida pela continuidade, e uma componente rotacional $\mathrm{V}_{\mathrm{r}}$, tais que:

$$
V_{1}=\sqrt{V_{0}^{2}+V_{r}^{2}}
$$




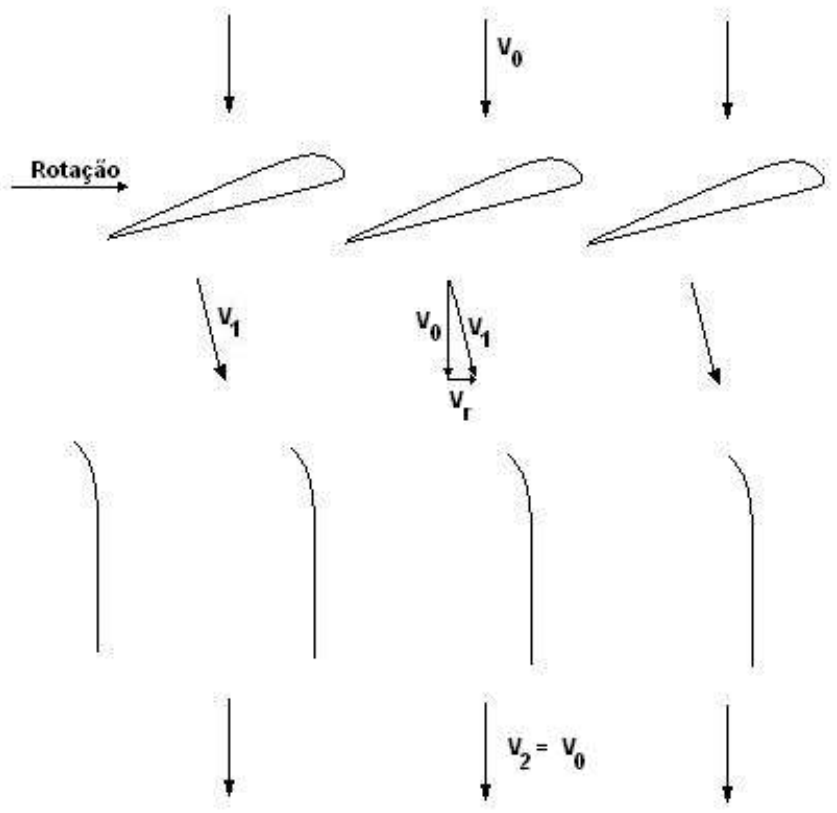

Figura 35 - Função das aletas de saída

Sendo assim, deseja-se ter a possibilidade de posicionar o medidor no plano entre as pás do rotor e as aletas, e também à jusante das aletas, a fim de se medir a velocidade e o ângulo do escoamento em cada seção. Além da determinação da velocidade média em cada seção, pretende-se mapear o perfil de velocidades locais em cada seção, a fim de entender a distribuição de pressões e estudar formas de aperfeiçoar o desempenho de pás e aletas do sistema de ventilação.

Uma das principais restrições para este tipo de medição é o pouco espaço disponível na seção entre o rotor e as aletas de saída, da ordem de 500 mm. Outra peculiaridade é o acentuado gradiente no campo de velocidade local presente na seção, já que o escoamento mudará de direção de maneira abrupta, e sua velocidade varia a grandes taxas no sentido radial, da raiz para as pontas das pás. 


\section{PROJETO DOS SENSORES}

\subsection{DEFINIÇÕES GERAIS}

As diretrizes que determinam parâmetros geométricos dos medidores como diâmetros de tomadas de pressão, espaçamento ideal entre orifícios, diâmetros de hastes (corpo do medidor) e distância entre tomada de pressão total e haste principal serão discutidas neste capítulo, com o auxílio, principalmente, das referências NACA TN 2830 e NASA TM 102200 que tratam dos efeitos destes parâmetros nos resultados de medição.

No tópico 4.1 - Processo de escolha do sensor - foram explicados os motivos pelos quais as sondas tipo prisma e tipo pirâmide foram escolhidas. Cabe agora definir parâmetros geométricos destas sondas e apresentar o fundamento da escolha destas dimensões.

Parâmetros geométricos a serem definidos, tanto para as sondas tipo prisma quanto para as sondas tipo pirâmide são (ver figura 36):

a) Comprimento da haste;

O comprimento da haste do medidor deverá ter no mínimo o comprimento do raio do ventilador axial a ser ensaiado, já que o medidor deve ser posicionado radialmente com sua haste na direção do centro do ventilador, sendo necessário que a haste do medidor tenha um comprimento pelo menos igual ao raio do ventilador para que se possa medir todo o campo de velocidades. Como valor típico para o diâmetro destes ventiladores é de $800 \mathrm{~mm}$, decidiu-se por fabricar um medidor com $600 \mathrm{~mm}$ de comprimento de haste, possibilitando o uso do mesmo medidor para ventiladores maiores.

b) Diâmetro da haste;

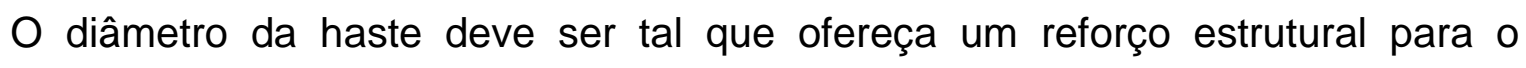
medidor, que pode ser tratado como uma viga em balanço inserida no escoamento. Ao mesmo tempo, o diâmetro da haste não pode ser grande o bastante de modo a influenciar o valor da velocidade.

Conforme é mostrado no desenho esquemático a seguir, a sonda é submetida a um escoamento cujo vetor velocidade na direção axial $\vec{V}_{x}$ é representado na figura a 
seguir. A sonda, sendo um corpo rombudo inserido em um escoamento, sofre uma pressão distribuída cuja resultante é uma força de arrasto na direção axial $\vec{D}_{x}$ aplicada no centro aerodinâmico da sonda.

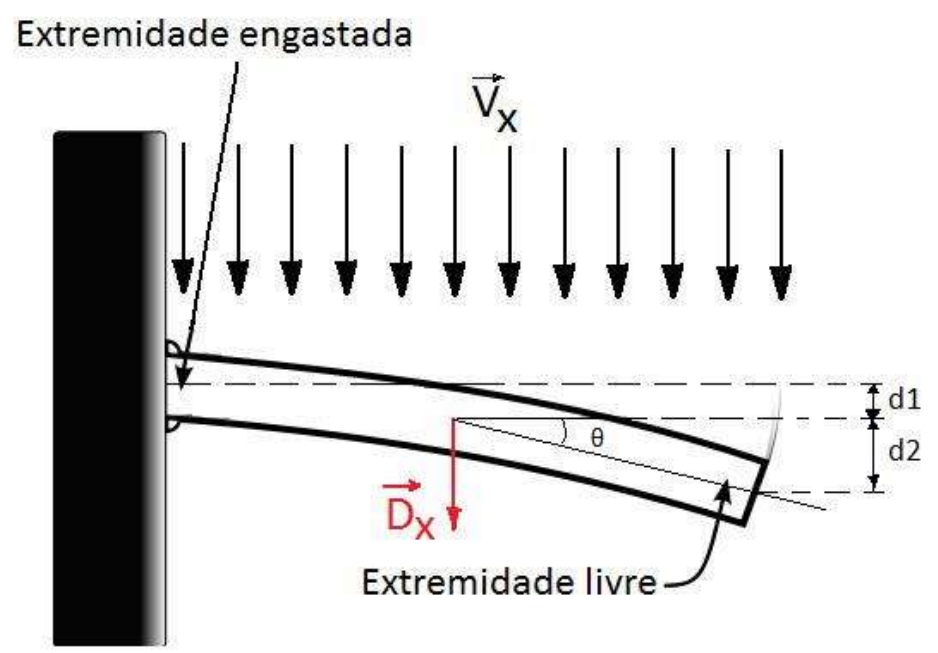

Figura 36 - Deslocamento do medidor devido à força de arrasto.

O deslocamento da ponta do medidor (um tubo cilíndrico), devido à força descrita é dada por:

$$
d=d 1+d 2
$$

em que:

e

$$
d 1=\frac{D_{x}\left(\frac{L}{2}\right)^{3}}{3 E I_{0}}
$$

onde

$$
d 2=\frac{L}{2} \operatorname{sen} \theta
$$

$$
\theta=\frac{D_{x}\left(\frac{L}{2}\right)^{2}}{2 E I_{0}}
$$

Em que $\boldsymbol{E}$ é o módulo de elasticidade do material da haste e $I_{0}$ é o momento de inércia da seção. 
O módulo da força de arrasto a que o corpo cilíndrico do medidor é submetido é dado por:

$$
D_{x}=\frac{1}{2} \rho V_{x}^{2} A C_{d}
$$

Onde $\rho$ é a massa específica do $a r, V_{x}$ é a velocidade do escoamento na direção axial (conforme figura 36), A é a área de referência, igual a $L \times d_{\theta}$ (comprimento $\mathrm{x}$ diâmetro externo da haste da sonda) e $\mathrm{C}_{d}$ é o coeficiente de arrasto do cilindro.

O coeficiente de arrasto de um corpo rombudo em forma de cilindro é uma função do número de Reynolds do escoamento, como mostra o gráfico a seguir, retirado da referência (Scienceworld, 2009).

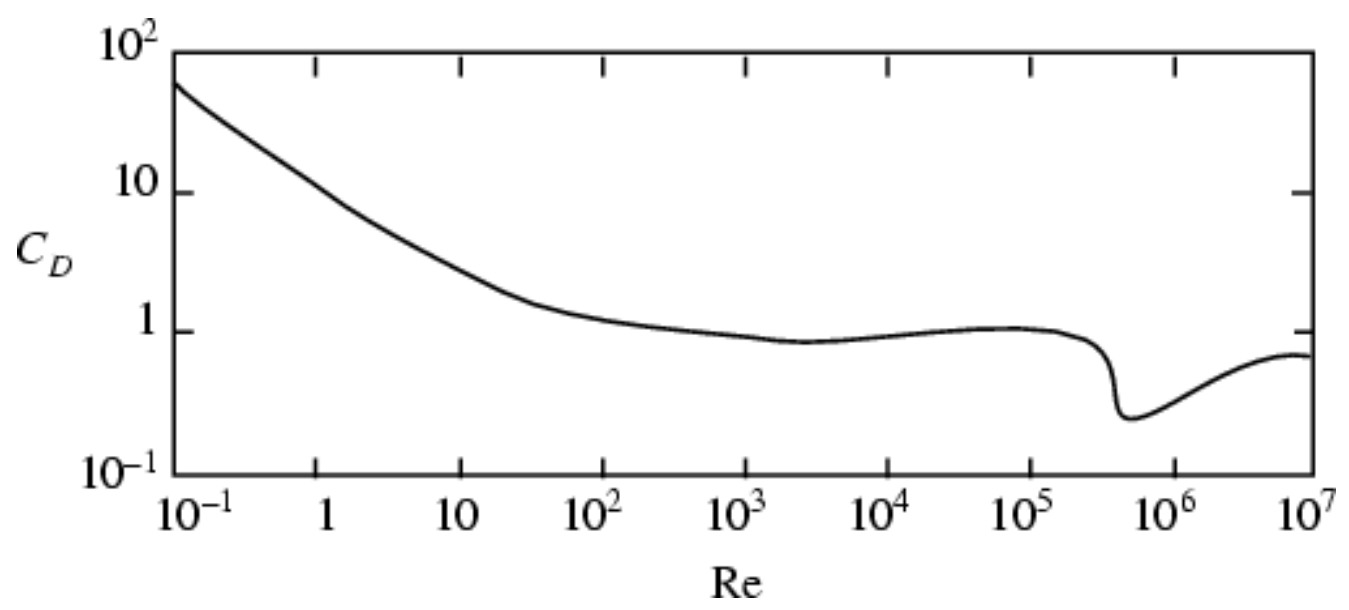

Figura 37 - Variação do coeficiente de arrasto de corpo cilíndrico inserido em um escoamento.

Para o escoamento em que se deseja realizar os ensaios, o módulo da velocidade atingirá o valor máximo de $30 \mathrm{~m} / \mathrm{s}$. Dessa maneira, teremos (para um diâmetro externo de haste de $25 \mathrm{~mm}$ ):

$$
\mathrm{Re}=\frac{\rho V_{x} d_{e}}{\mu}=\frac{1,0 \times 30 \times 0,025}{1,78 \times 10^{-5}}=4,2 \times 10^{4}
$$

Sendo assim, pelo gráfico da figura 37 , teremos um $C_{d}$ da ordem de $1,0$. Na equação 24, $\mu$ é a viscosidade dinâmica do fluido.

Para a seção da haste, que é uma casca cilíndrica, temos o momento de inércia $I_{0}$ da seção dado por $\left(d_{e}=25 \mathrm{~mm}\right.$ e $\left.d_{i}=23 \mathrm{~mm}\right)$ : 


$$
I_{0}=\frac{\pi}{4}\left(\left(\frac{d_{e}}{2}\right)^{4}-\left(\frac{d_{i}}{2}\right)^{4}\right)=5,44 \times 10^{-9} m^{4}
$$

Inserindo o resultado do Reynolds do escoamento na equação (23), temos que $D_{x}=13,5 \mathrm{~N}$, com o material da haste sendo aço inox 304 , o valor do módulo de elasticidade $E$ é igual a $200 \mathrm{GPa}$.

Inserindo esse valor nas equações (20) e (21), temos:

$\mathrm{d} 1 \approx 0,1 \mathrm{~mm}$ e $\theta \approx 0,01$ graus, o que leva a $\mathrm{d} 2 \approx 0,16 \mathrm{~mm}$..

Logo, pela equação (16), $d \approx 0,26 \mathrm{~mm}$ é a deflexão na ponta do instrumento. Sabendose que $L=0,6 \mathrm{~m}$, pode-se dimensionar por iteração as paredes da haste cilíndrica do sensor para que a deflexão na ponta não seja superior a $1 \mathrm{~mm}$. Dessa maneira, a opção de $\mathrm{d}_{\mathrm{e}}=25 \mathrm{~mm}$ e $\mathrm{d}_{\mathrm{i}}=23 \mathrm{~mm}$ gera um deslocamento máximo de 0,26 $\mathrm{mm}$ na ponta da haste em engaste.

C) Comprimento do eixo do sensor;

O comprimento do eixo do sensor funciona como um espaçador entre a haste de suporte e as tomadas de pressão, de forma que estas meçam um escoamento o mais limpo possível, sem sofrer interferências de uma eventual proximidade da haste. Conforme a norma AMCA 210 para medições em ventilação industrial, a recomendação é que o comprimento do eixo do sensor seja de 24 vezes o diâmetro da haste (AMCA, 2007) e foi este o comprimento adotado.

d) Diâmetro das tomadas de pressão;

A escolha do diâmetro das tomadas de pressão são uma solução de compromisso entre dificuldade de fabricação e exatidão das medidas (TAVOULARIS, 2005). Necessita-se atender aos requisitos de $1 \mathrm{~Pa}$ de resolução nas medições de pressão pelo conjunto medidor-manômetro. Dessa maneira, com base nas medições conduzidas por Shaw (SHAW,1959) para determinação da influência de diâmetro do orifício de tomada de pressão estática nos resultados de medições desta pressão, optou-se por um diâmetro de 1,0 mm para estas tomadas de pressão.

e) Ângulo da face do prisma/pirâmide $(\theta)$.

A escolha do ângulo da face do prisma (ou pirâmide) foi feita visando a maior faixa de medição de ângulos possível. A referência NACA TN 2830 descreve sensores 
com ângulo de face do prisma (ou pirâmide) de 30 graus, conforme visto nas figuras 21 e 22. No entanto, o trabalho de Bryer e Pankhurst descreve sensores tipo pirâmide com ângulo de face de prisma (ou pirâmide) de 45 graus, apontando para uma faixa maior de ângulos de medição. Dessa maneira, embasando-se em resultados já obtidos com a fabricação de medidores tipo pirâmide e prisma em outros trabalhos como os citados anteriormente, optou-se por um ângulo de face do prisma (ou pirâmide) de 45 graus.

\subsection{PROJETO DETALHADO DOS SENSORES}

Com base nas propostas apresentadas, foram projetados dois protótipos de sensores, um para sonda prisma e outro para sonda pirâmide. As dimensões das sondas foram escolhidas levando em consideração restrições de fabricação e os requisitos de comprimento de hastes e diâmetros de orifícios de forma a realizar medições com exatidão.

A fim de reduzir a necessidade de fabricação, foi projetada uma haste única para os medidores e a ponta do medidor podendo ser tipo pirâmide ou tipo prisma. Desta forma, é possível intercambiar as sondas apenas substituindo a ponta a ser acoplada à haste, como mostrado nas figuras 38 a 40 a seguir. 

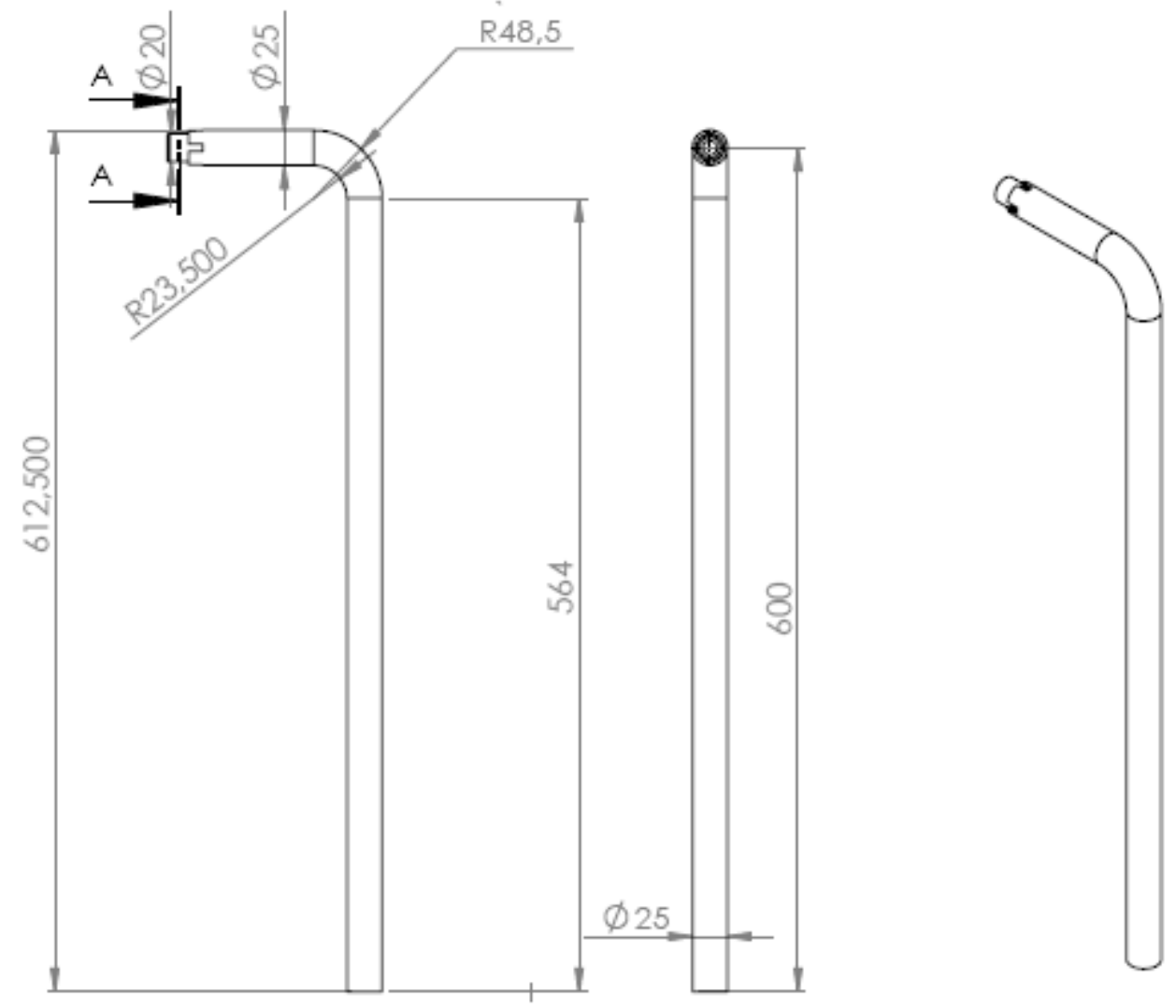

Figura 38 - Esquema da haste da sonda direcional 

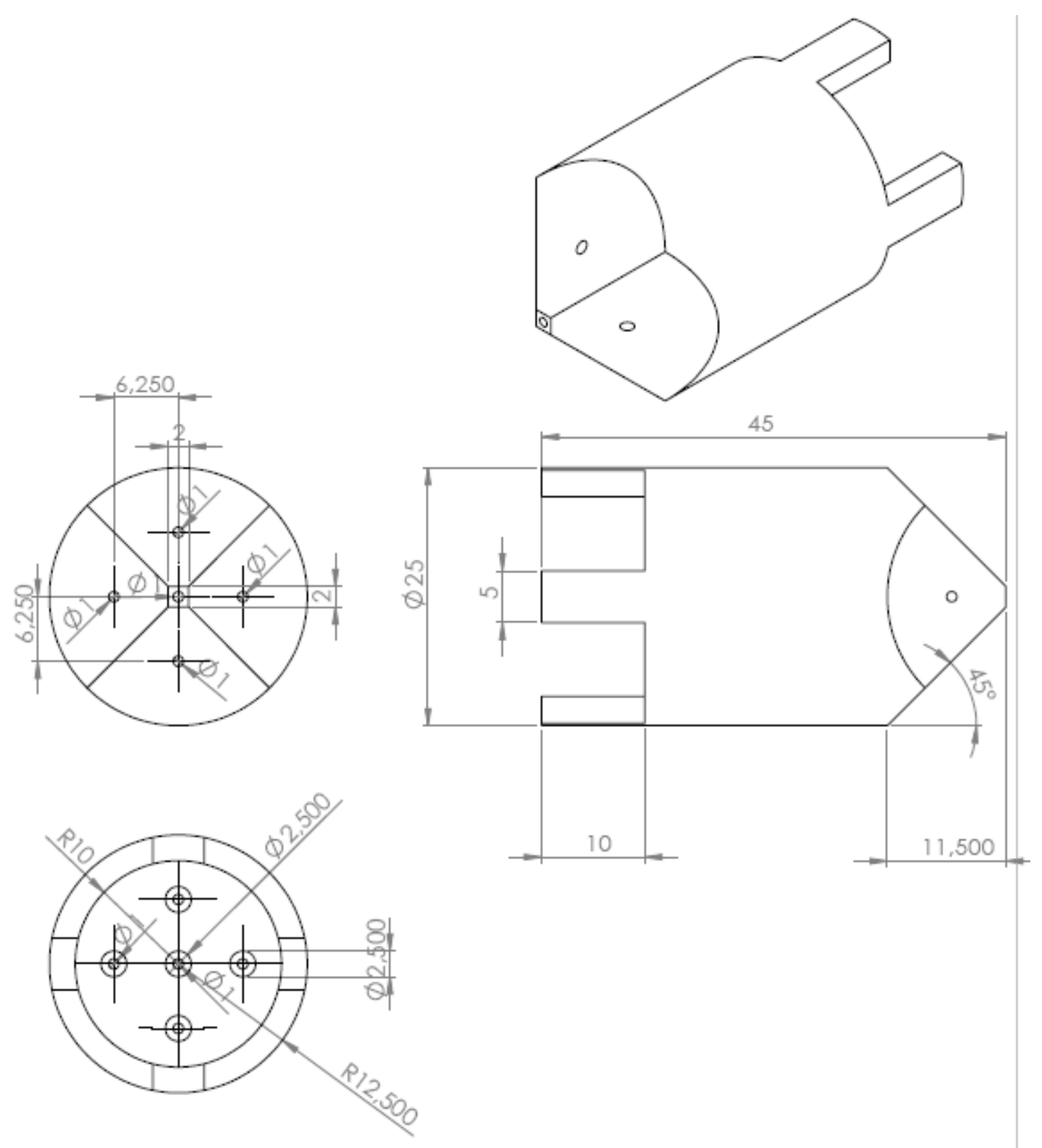

Figura 39 - Esquema da ponta da sonda tipo pirâmide 

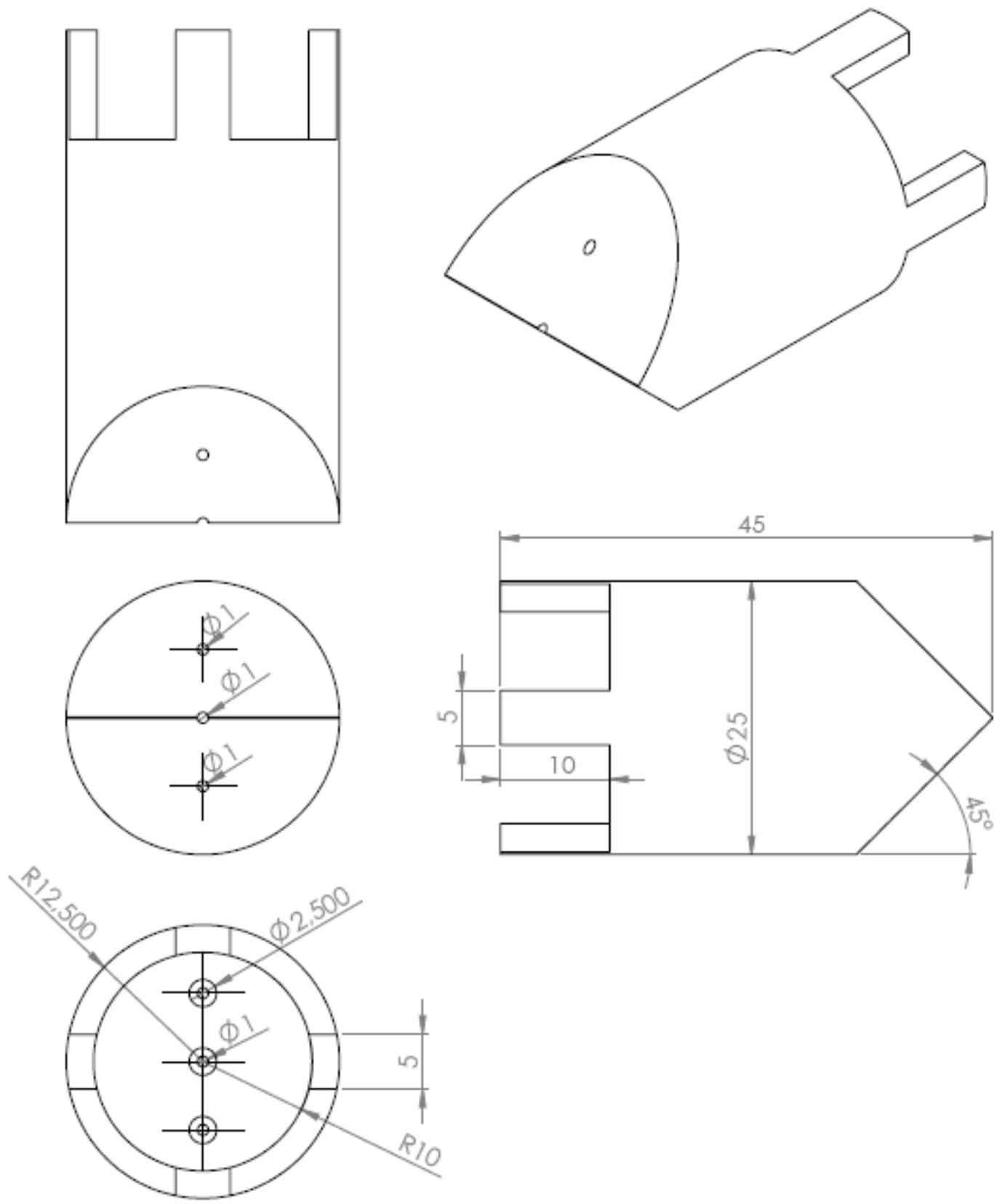

Figura 40 - Esquema da ponta da sonda tipo prisma

Como pode ser visto na figura 39, a sonda tipo pirâmide possui cinco orifícios, sendo um deles central e os demais dispostos em faces que formam 45 graus com o plano do furo central. Todos os orifícios possuem diâmetro de $1 \mathrm{~mm}$. 
A sonda tipo prisma, representada na figura 40, possui três orifícios, sendo um deles central e os outros dois em planos que formam um ângulo de 45 graus com o plano normal ao eixo da sonda. Os três orifícios possuem diâmetro de $1 \mathrm{~mm}$.

\subsection{FABRICAÇÃO E VALIDAÇÃO DOS PROTÓTIPOS}

O procedimento de fabricação e validação com testes de estanqueidade e verificação geométrica dos protótipos das pontas das sondas, tipo pirâmide e tipo prisma está apresentada a seguir.

Após estar definida a geometria e o dimensionamento das sondas, partiu-se para a definição do material utilizado na fabricação. Devido ao requisito de resistência à corrosão, optou-se pelo aço inox 306 para a peça da haste maior da sonda. Escolhido o material, verificou-se que seria mais viável dividir a haste em três peças: uma haste maior, um cotovelo também em aço inox e uma peça intermediária em alumínio para ligar o cotovelo da haste à ponta da sonda. Com esta montagem, não foi necessário realizar a dobra de um tubo de aço, o que se mostrou difícil operacionalmente. 


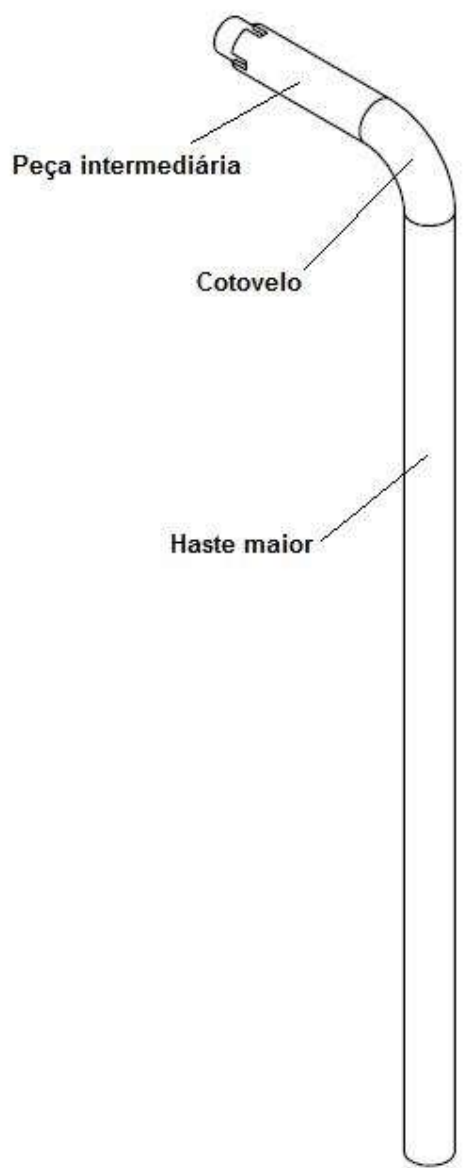

Figura 41 - Esquema da haste da sonda com suas divisões

O acoplamento entre as partes da haste foi feito por parafusos de cabeça cônica em furos com acabamento escareado, de forma a não formar ressaltos na superfície da haste e ainda assim possibilitando fácil montagem e desmontagem. A conexão entre haste e ponta se deu também pelo uso de parafuso de cabeça cônica e foi feita de forma a impedir qualquer movimento de rotação da ponta em relação à haste. 


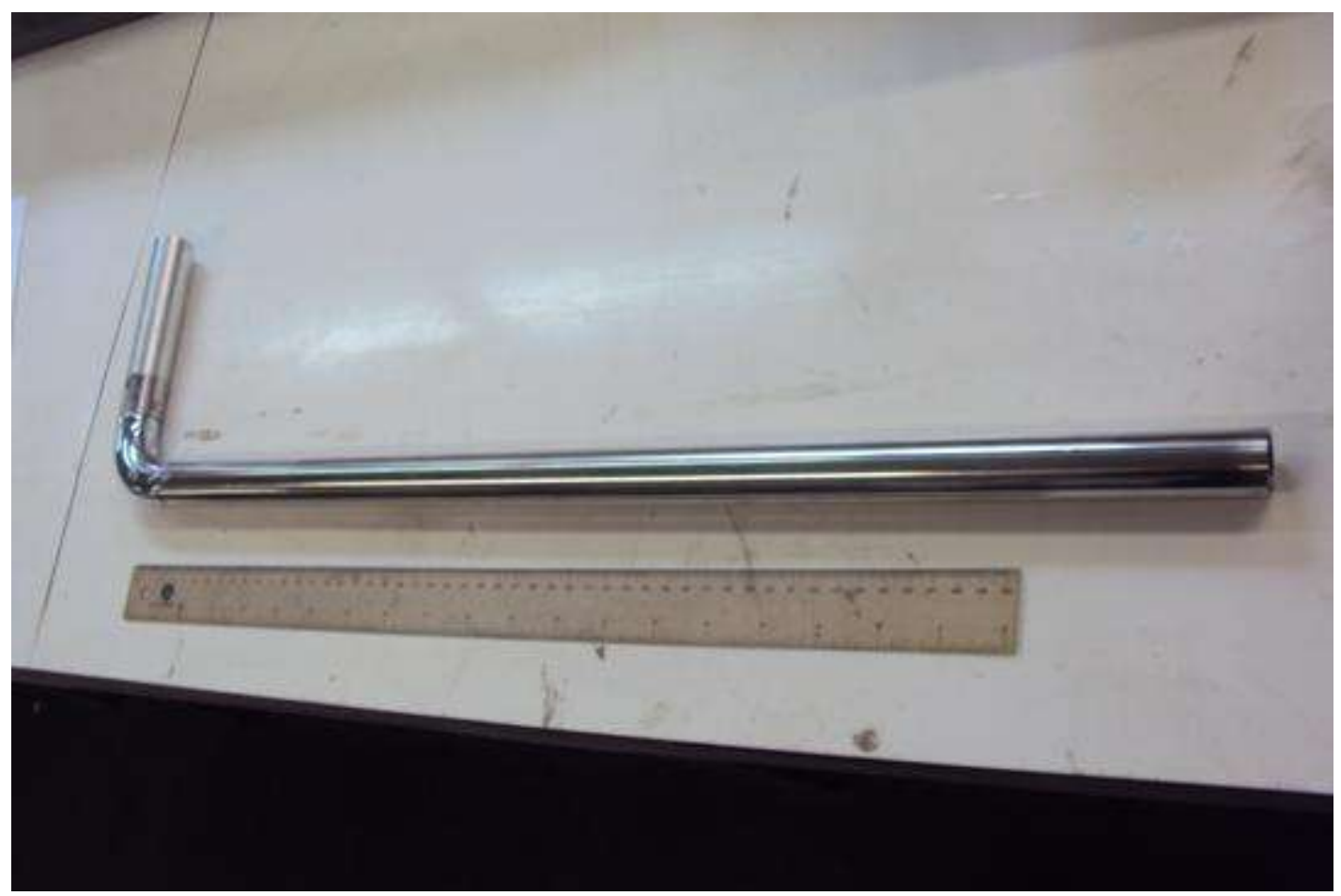

Figura 42 - Haste da sonda ao lado de uma régua de $50 \mathrm{~cm}$.

\subsubsection{FABRICAÇÃO DAS PONTAS DAS SONDAS POR PROTOTIPAGEM RÁPIDA}

Para as pontas de sondas, cogitou-se inicialmente o uso do alumínio 7075T651 de uso aeronáutico, sendo descartado pela dificuldade em se encontrar esse material comercialmente nas dimensões desejadas e pela necessidade de usinar com grande precisão um tarugo de alumínio para se obter a geometria das pontas das sondas. Decidiu-se então pela fabricação em prototipagem rápida usando material plástico identificado por ABS (Acrilonitrila-butadieno-estireno), que fornece como produto final um sólido já com as dimensões de projeto da ponta.

Após a fabricação de cada ponta, deu-se um acabamento superficial nas faces da sonda usando lixas de gramaturas 320, 400,600, 1000 e 1200, e também aplicou-se uma fina camada de cianoacrilato para vedação da superfície porosa que é característica do plástico ABS. 


\subsubsection{VALIDAÇÃO DOS PROTÓTIPOS DAS PONTAS DE SONDA EM MATERIAL ABS}

A análise dos protótipos em plástico ABS preocupou-se com várias características da sonda e de seu material. Inicialmente foi considerada a hipótese de realizar a medição da rugosidade das superfícies das sondas utilizando o rugosímetro, porém optou-se por não realizar esta medição pelo fato de o instrumento ter de riscar a face com uma ponta diamante durante a medição. As superfícies com tratamento de cianoacrilato e lixamento dispensaram esta avaliação.

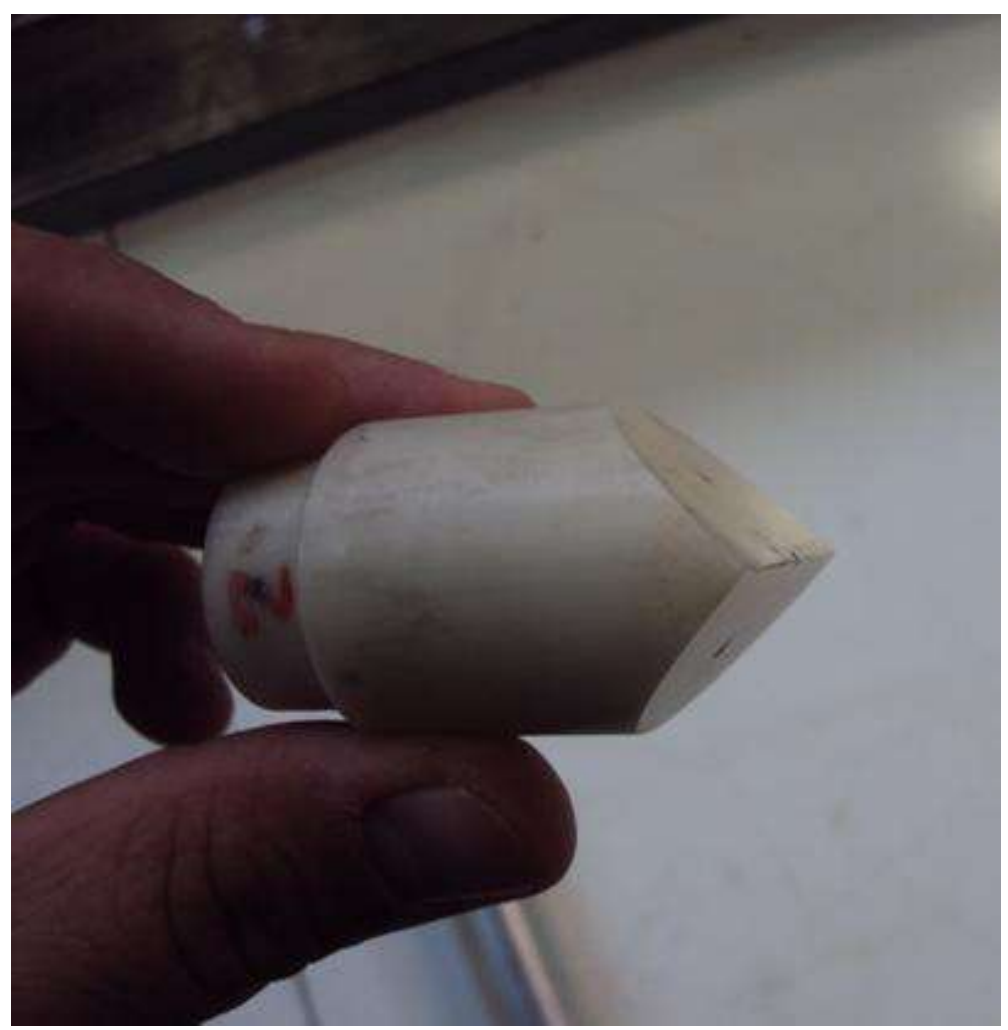

Figura 43 - Ponta tipo prisma fabricada 


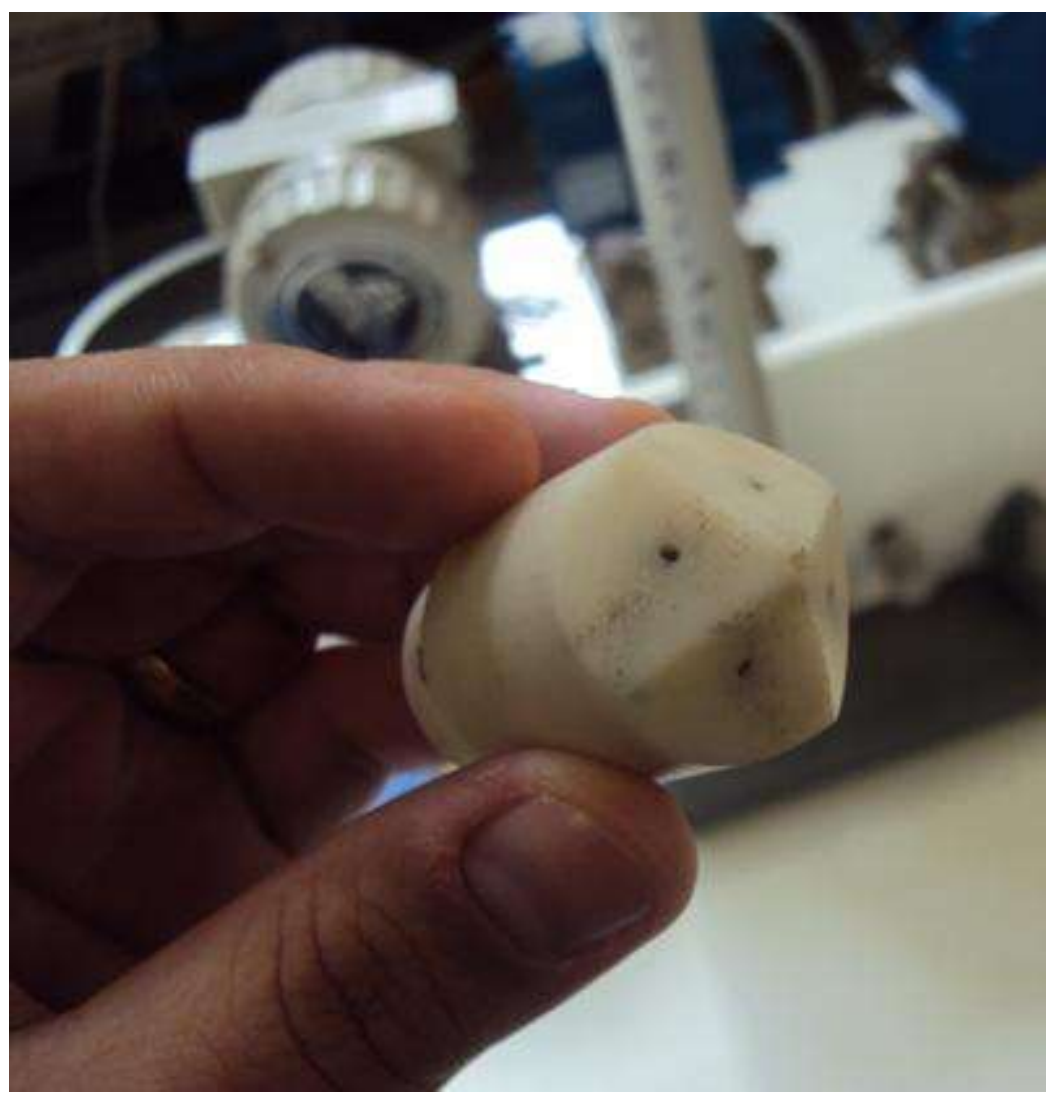

Figura 44 - Ponta tipo pirâmide fabricada

Verificadas as dimensões das pontas de sondas, são fixados tubos de cobre na parte interna das pontas, para facilitar o acoplamento dos tubos de silicone que correm no interior da haste. Os tubos de cobre são colados a cada ponta de sonda usando silicone.

Um teste de estanqueidade em cada canal e orifício de cada sonda é realizado para verificar a qualidade da vedação dos tubos. O teste de vazamento consiste em acoplar um tubo de silicone ao tubo de cobre colado na ponta de sonda, pressurizar este tubo com o auxílio de uma seringa e tampando a tomada de pressão na face da ponta de sonda. Em seguida, insere-se o conjunto em um béquer com água para verificar vazamento através da presença de bolhas.

$\mathrm{Na}$ realização dos testes para as pontas de sonda fabricadas por prototipagem rápida utilizando material plástico tipo $A B S$, verifica-se o vazamento de ar devido a comunicação entre as tomadas de pressão da sonda. Conclui-se que havia porosidade no material que interligava as tomadas de pressão da sonda, permitindo a passagem de 
ar. Sendo assim, avaliou-se que estas sondas fabricadas pelo método de prototipagem rápida não são adequadas para os objetivos deste trabalho.

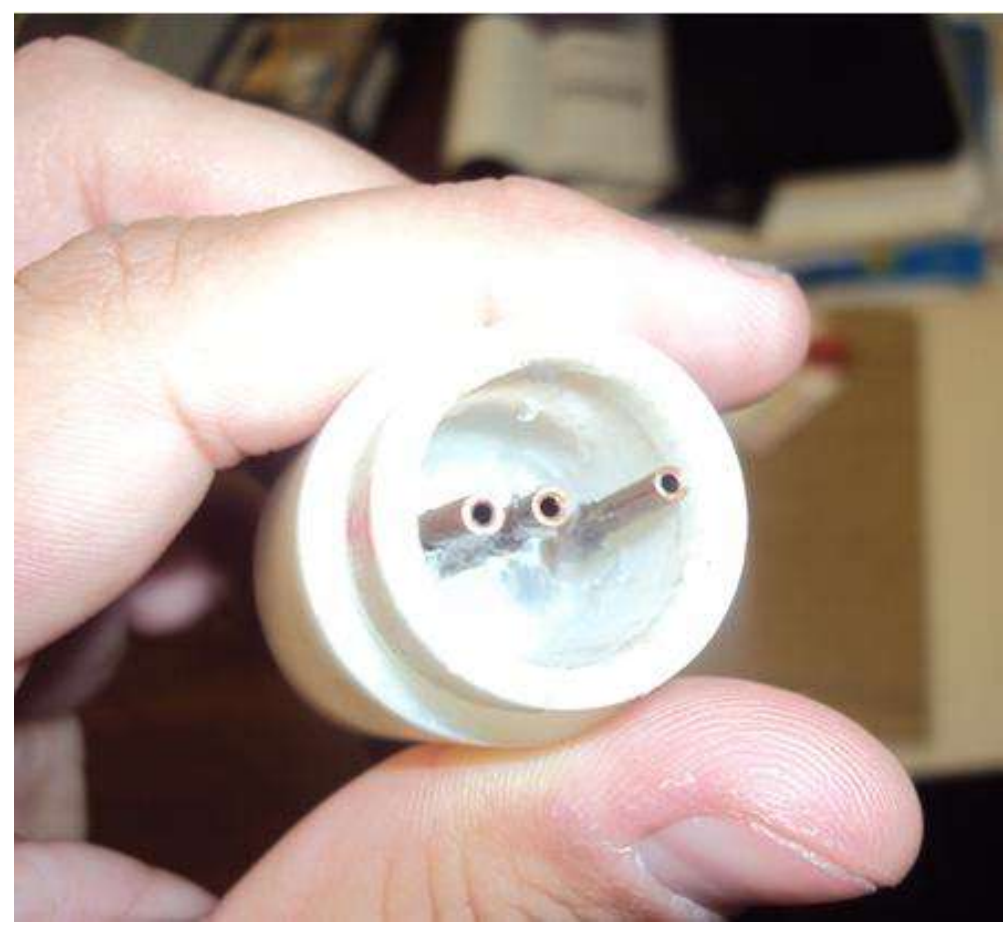

Figura 45 - Tubos de cobre colados na parte interna das pontas de sonda.

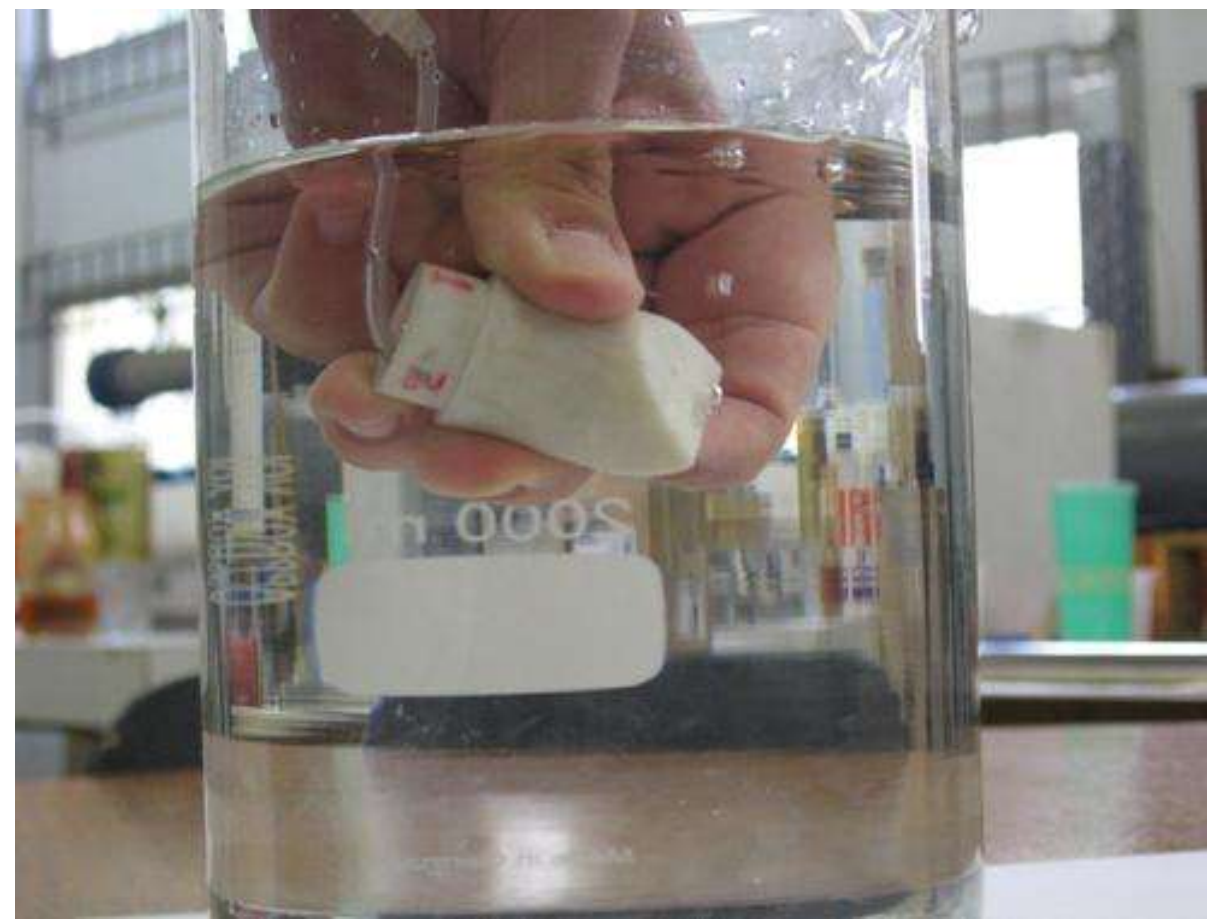

Figura 46 - Teste de vazamento 


\subsubsection{FABRICAÇÃO DAS PONTAS DAS SONDAS POR USINAGEM}

O resultado do teste de estanqueidade das pontas fabricadas em material plástico tipo ABS desqualificou aqueles protótipos, sendo feita a opção pela fabricação de novos protótipos de pontas de sondas através de processo de usinagem de material metálico.

Foram considerados o aço inox, o alumínio e o latão para este propósito. Analisando as propriedades dos materiais, conclui-se que haveria maior dificuldade na usinagem do aço inox devido à sua resistência ao desbaste, especialmente na fabricação dos detalhes de dimensões reduzidas nas furações. O uso do alumínio poderia dificultar os detalhes por se tratar de um material que poderia sofrer deformações plásticas nas regiões de atuação das ferramentas de usinagem, o que poderia prejudicar o processo de fabricação. Assim, optou-se pelo latão, que atende aos requisitos para uma boa usinagem. Após a usinagem, as superfícies sofreram acabamento com lixas de gramaturas 320, 400,600, 1000 e 1200. Após sua fabricação, também foi realizado o teste de estanqueidade com estas pontas de sonda usinadas em latão, em que foi verificada a ausência de vazamentos.

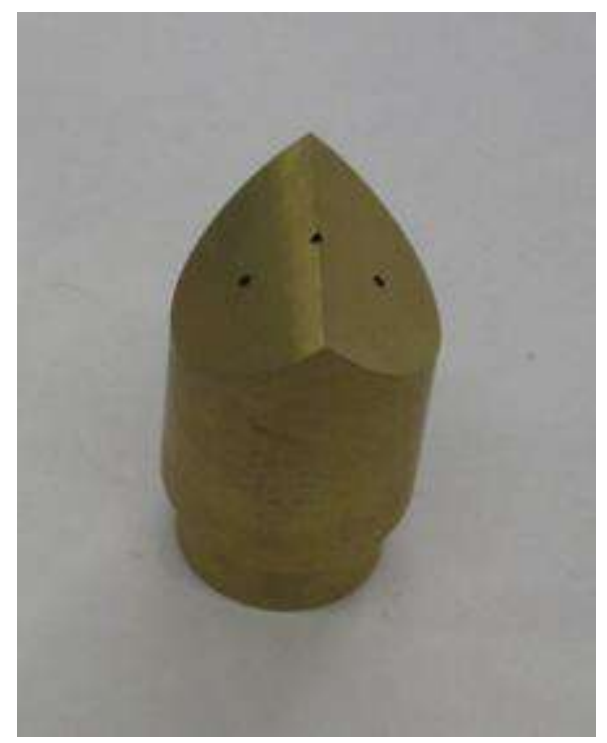

Figura 47 - Sonda tipo prisma fabricada em latão 


\section{ENSAIOS EXPERIMENTAIS}

\subsection{DESCRIÇÃO GERAL E OBJETIVOS DOS ENSAIOS}

O ensaio experimental para a calibração e avaliação das sondas consiste em verificar se estas são efetivamente capazes de medir a velocidade e a direção do escoamento de ar que incide na sonda. Para isso, é necessário que haja um escoamento de referência, não-perturbado, com pressão dinâmica, pressão estática e condições psicrométricas conhecidas. Neste escoamento de referência, as sondas são posicionadas em determinados ângulos. Como as sondas possuem múltiplas tomadas de pressão, relações entre medidas de pressão determinam a magnitude e a direção do vetor velocidade do escoamento de ar que incide na sonda, além da pressão estática e da pressão total associada a uma linha de corrente do escoamento. Uma das complexidades deste ensaio é a fixação da sonda e seu posicionamento, uma vez que ela deve rotacionar em torno de 2 eixos perpendiculares para a calibração. Dessa forma, um dispositivo de posicionamento próprio para esta aplicação é utilizado.

Os ensaios experimentais consistem em posicionar a sonda em um escoamento de ar com velocidade e direção conhecidas. É utilizado para este fim um túnel de vento. Com o auxílio de um tubo de Pitot de referência, é medida a pressão dinâmica em uma linha de corrente do escoamento e calculada a velocidade do ar. O ar é utilizado como fluido e o regime de escoamento é variado na faixa de Reynolds de $1 \times 10^{4}$ a $2 \times 10^{4}$, utilizando como comprimento característico o diâmetro da sonda $25,4 \mathrm{~mm}$ e velocidades do escoamento de 7 a $12 \mathrm{~m} / \mathrm{s}$.

A sonda é posicionada em vários ângulos em relação à linha de corrente de referência, tomando medidas de pressão para os diversos orifícios da sonda. Conhecendo-se os ângulos em que a sonda foi posicionada e os valores medidos nas tomadas de pressão desta, determina-se uma curva de calibração que relaciona as leituras de pressão com a magnitude do vetor velocidade do escoamento e com os ângulos entre o vetor velocidade e os eixos associados à sonda. 
Para a sonda tipo prisma, são variados ângulos de posicionamento apenas no plano dos 3 orifícios da ponta da sonda, por se tratar de uma sonda para escoamento bidimensional.

A sonda tipo pirâmide é posicionada no escoamento e são variados ângulos de guinada e arfagem, uma vez que esta sonda é capaz de detectar as componentes do vetor velocidade do ar em dois planos.

\subsection{APARATO EXPERIMENTAL}

\subsubsection{Equipamentos utilizados}

Para a realização dos ensaios de calibração das sondas, são necessários os seguintes equipamentos:

a) Túnel de vento

b) Posicionador das sondas

a) Túnel de vento

Foi utilizado o túnel de vento do Laboratório de Anemometria do IPT, que é do tipo aberto e possui uma seção de teste de $500 \mathrm{~mm} \times 500 \mathrm{~mm}$. A movimentação do ar é realizada por um ventilador centrífugo acionado por um motor elétrico de $50 \mathrm{cv}$. $\mathrm{O}$ ajuste da condição de vazão é obtido através de um inversor estático de freqüência que estabelece a rotação do motor. Para selecionar a vazão pode-se utilizar também um registro radial instalado na entrada do ventilador. fornece um escoamento permanente com velocidade de até $40 \mathrm{~m} / \mathrm{s}$. As sondas são posicionadas ao longo da seção de testes, na saída do túnel de vento. As velocidades ensaiadas foram de $7 \mathrm{~m} / \mathrm{s}, 10 \mathrm{~m} / \mathrm{s}$ e $12 \mathrm{~m} / \mathrm{s}$. 
b) Posicionador das sondas

Para a variação dos ângulos de posicionamento da sonda em relação ao escoamento de referência, é utilizado o posicionador angular representado na figura 48 a seguir:

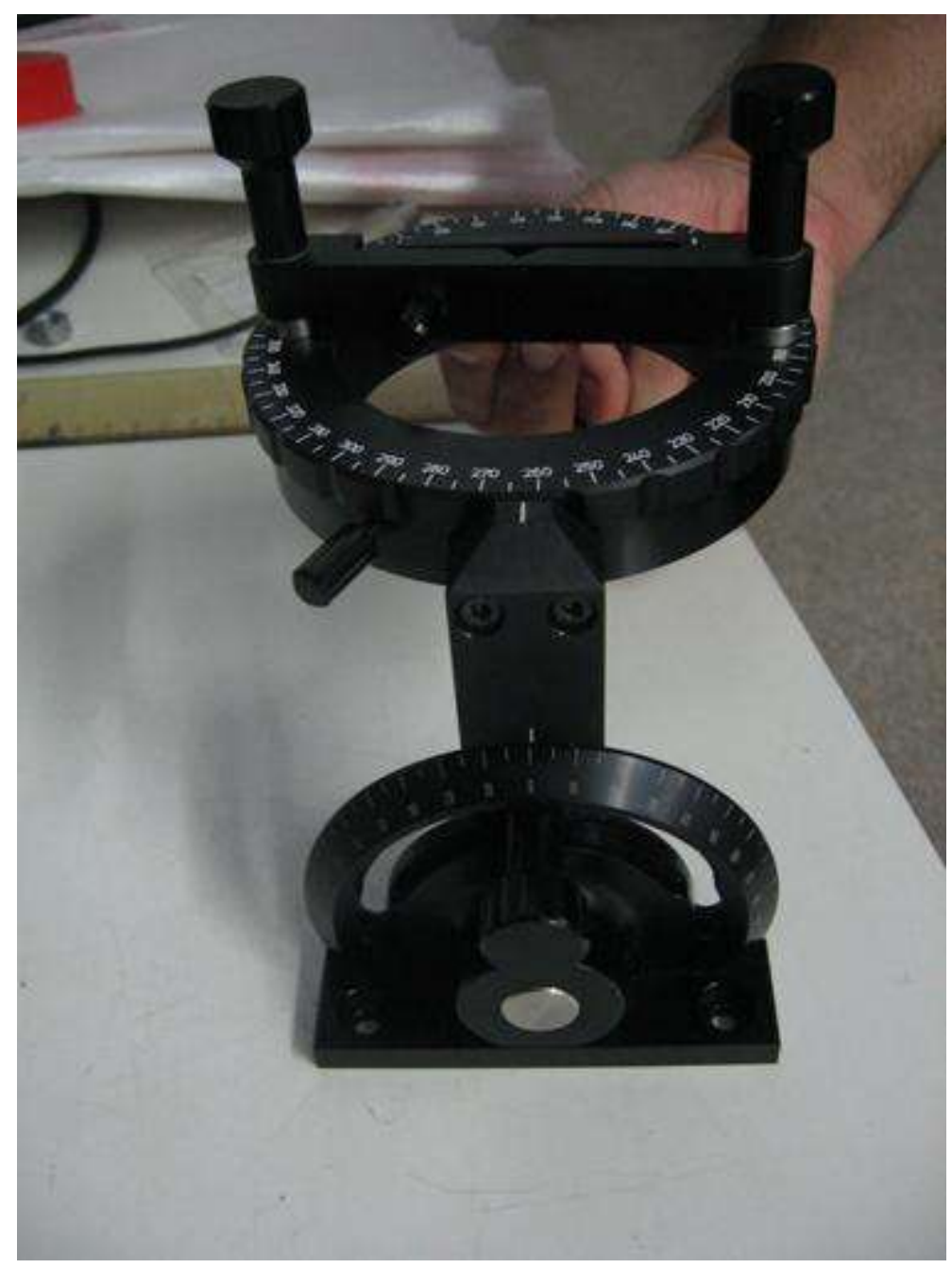

Figura 48 - Dispositivo posicionador para a sonda direcional

Este dispositivo é capaz de posicionar cada sonda efetuando rotações em torno de dois eixos. Ele permite rotação de $180^{\circ}$ em torno de um dos eixos e $360^{\circ}$ em torno do outro eixo. A resolução no posicionamento angular é de $5^{\circ}$ para ambos os eixos.

A figura 49 a seguir mostra a montagem do dispositivo posicionador acoplado a um cilindro de regulagem vertical de altura que está preso a uma base e pode ser movido, 
permitindo o posicionamento da sonda para uma faixa de ângulos entre +60 e -60 graus.

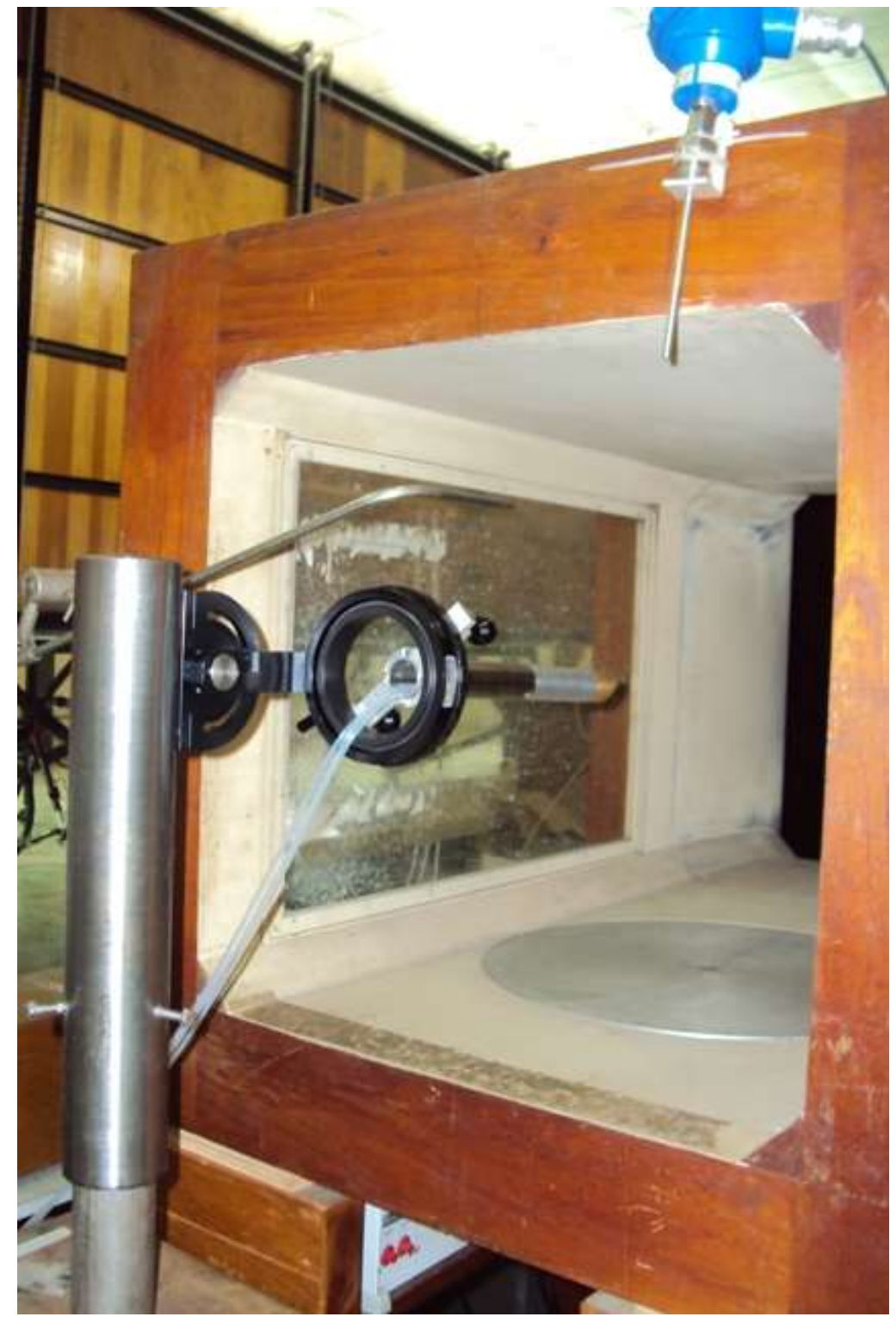

Figura 49 - Montagem do dispositivo posicionador no cilindro de regulagem vertical de altura no túnel de vento do laboratório de anemometria do IPT. 


\subsubsection{Instrumentação utilizada}

Para as medições realizadas, utiliza-se a seguinte instrumentação:
a) Transdutores de pressão
b) Micro-manômetro
c) Termopar
d) Psicrômetro
e) Barômetro
f) Sistema monitor de pressões

As grandezas medidas e as características dos instrumentos estão representados na tabela 3 a seguir.

Tabela 3: Instrumentação utilizada nos ensaios

\begin{tabular}{|c|c|c|c|}
\hline Instrumento & Grandeza & $\begin{array}{c}\text { Faixa de } \\
\text { Operação }\end{array}$ & Resolução \\
\hline $\begin{array}{c}\text { Transdutores de } \\
\text { Pressão }\end{array}$ & Pressão & $-125 \mathrm{~Pa} \mathrm{a}+125 \mathrm{~Pa}$ & $0,24 \mathrm{~Pa}$ \\
\hline Micro-manômetro & Pressão & $-200 \mathrm{a}+200 \mathrm{~Pa}$ & $0,001 \mathrm{~Pa}$ \\
\hline Termopar tipo J & $\begin{array}{c}\text { Temperatura de } \\
\text { Bulbo Seco do } \\
\text { jato de ar }\end{array}$ & 0 a $50^{\circ} \mathrm{C}$ & $0,1^{\circ} \mathrm{C}$ \\
\hline Psicrômetro & $\begin{array}{c}\text { Temperatura de } \\
\text { Bulbo Úmido } \\
\text { Pressão } \\
\text { atmosférica }\end{array}$ & 0 a $50^{\circ} \mathrm{C}$ & $0,1^{\circ} \mathrm{C}$ \\
\hline até $110 \mathrm{kPa}$ & $0,1 \mathrm{~Pa}$ \\
\hline Sistema monitor \\
de pressões
\end{tabular}


a) Transdutores de pressão

Os transdutores de pressão utilizados são modelo Autotran série 850 com uma faixa de medição de pressão diferencial de $-125 \mathrm{~Pa}$ até $+125 \mathrm{~Pa}$. Esta faixa de leitura de pressões é adequada para a realização dos ensaios, já que a maior diferença de pressão que poderia ser medida seria a de um escoamento com velocidade de $12 \mathrm{~m} / \mathrm{s}$ (condição de maior velocidade a ser ensaiada), o que corresponde a uma pressão dinâmica da ordem de $80 \mathrm{~Pa}$.

A incerteza de medição deste instrumento informada pelo fabricante é de $1 \%$ do fundo de escala, o que corresponde a $\pm 1,25 \mathrm{~Pa}$. $O$ microprocessador utilizado na medição é do tipo PIC 16F877. Este microprocessador transmite os sinais analógicos de voltagem do transdutor ( 1 a $5 \mathrm{~V}$ ) ao computador em sinais digitais. A resolução deste microprocessador é de 1024 dígitos. Desta forma, tem-se uma faixa de $4 \mathrm{~V}$ ( 1 a $5 \mathrm{~V}$ ) dividida em 1024 intervalos. Desta forma, os sinais enviados ao computador são discretizados a cada $3,0625 \times 10^{-3} \mathrm{~V}$, que equivalem a uma resolução de $0,24 \mathrm{~Pa}$.

Todos os transdutores utilizados nos ensaios e instalados no sistema monitor de pressão foram calibrados previamente. O padrão para esta calibração foi o manômetro inclinado modelo type 4 do fabricante Airflow, que é a referência de pressão adotada no Laboratório de Instrumentação em Mecânica dos Fluidos, cuja resolução é 0,05 Pa. Para esta calibração também foi usado o multímetro HP padrão com resolução de $10^{-4} \mathrm{mV}$. Os resultados destas calibrações estão apresentados no apêndice III.

b) Micro-manômetro

O micro-manômetro é utilizado para as medições de pressão total, pressão dinâmica e pressão estática pelo tubo de Pitot de referência. O micro-manômetro modelo FCO 510 do fabricante Furness Controls tem uma incerteza associada ao instrumento inferior a $0,5 \%$ do valor indicado, com resolução de 0,001 Pa e faixa de medição de $-200 \mathrm{a}+200 \mathrm{~Pa}$. 


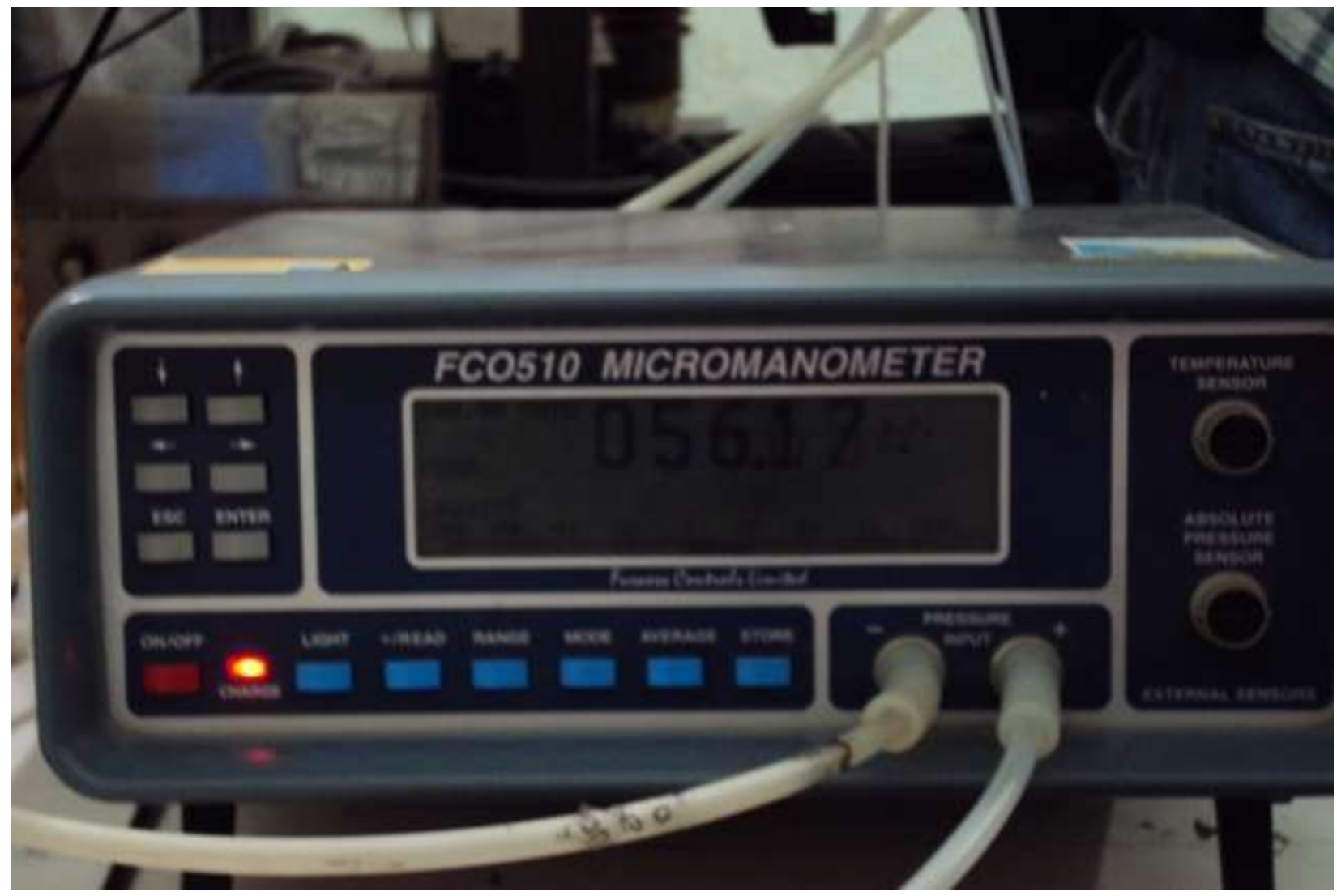

Figura 50 - Micro-manômetro FCO 510.

c) Termopar

No experimento em questão é utilizado um termopar tipo $\mathrm{J}$ para medir a temperatura de bulbo seco do ar no escoamento da seção de testes. O termopar utilizado possui resolução de $0,1^{\circ} \mathrm{C}$ e faixa de medição entre 0 e $50^{\circ} \mathrm{C}$. Esta medição é necessária para a determinação da massa específica do ar.

d) Psicrômetro

O psicrômetro é utilizado para a medição da temperatura de bulbo úmido. A resolução deste instrumento é de $0,1^{\circ} \mathrm{C}$ e a faixa de medições de temperatura está entre 0 e $50^{\circ} \mathrm{C}$. Com esta medição, a pressão atmosférica e a temperatura de bulbo seco do ar no escoamento, pode-se determinar a massa específica do ar. 
e) Barômetro

Um barômetro é utilizado no experimento para a determinação da pressão atmosférica e este valor é utilizado no cálculo da massa específica do ar. O barômetro utilizado na medição é capaz de registrar pressões atmosféricas com resolução de 0,1 Pa. A figura 51 a seguir mostra este aparelho, assim como os indicadores de temperatura de bulbo seco ambiente, temperatura de bulbo úmido e temperatura de bulbo seco do ar no escoamento.

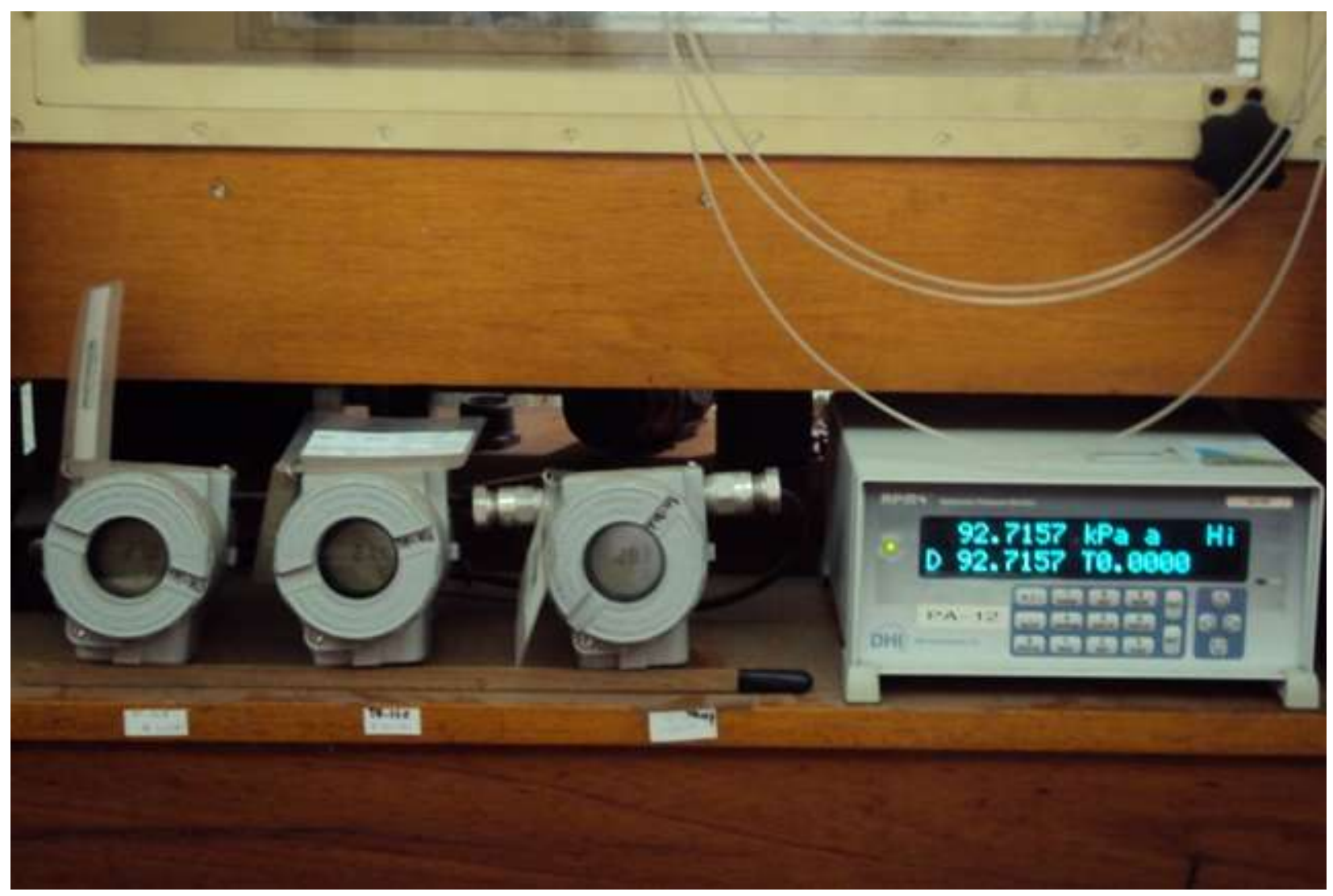

Figura 51 - Indicadores de temperatura e barômetro DHI.

f) Sistema monitor de pressões

A fim de facilitar o procedimento experimental, é utilizado um sistema monitor de pressões que faz a aquisição de dados dos transdutores de pressão descritos 
anteriormente. Trata-se de um sistema microprocessado que faz a leitura e a transformação analógica-digital possibilitando o registro das pressões em um arquivo de computador.

O programa de computador Flowsense (MARIANI, 2000) interpreta os sinais digitais e, usando coeficientes de calibração para cada um dos transdutores, mostra em uma tela até 16 valores simultâneos de pressão. Estes valores correspondem à média de 10 amostras tomadas a cada $150 \mathrm{~ms}$, ou seja, a cada 1,5 s uma nova média é mostrada para cada tomada de pressão. O programa possui a vantagem de indicar e salvar até 16 valores de pressão simultaneamente, o que facilita as medições. Caso não houvesse tal possibilidade, seria necessário realizar a medição de pressão em cada tomada da sonda individualmente uma após a outra.

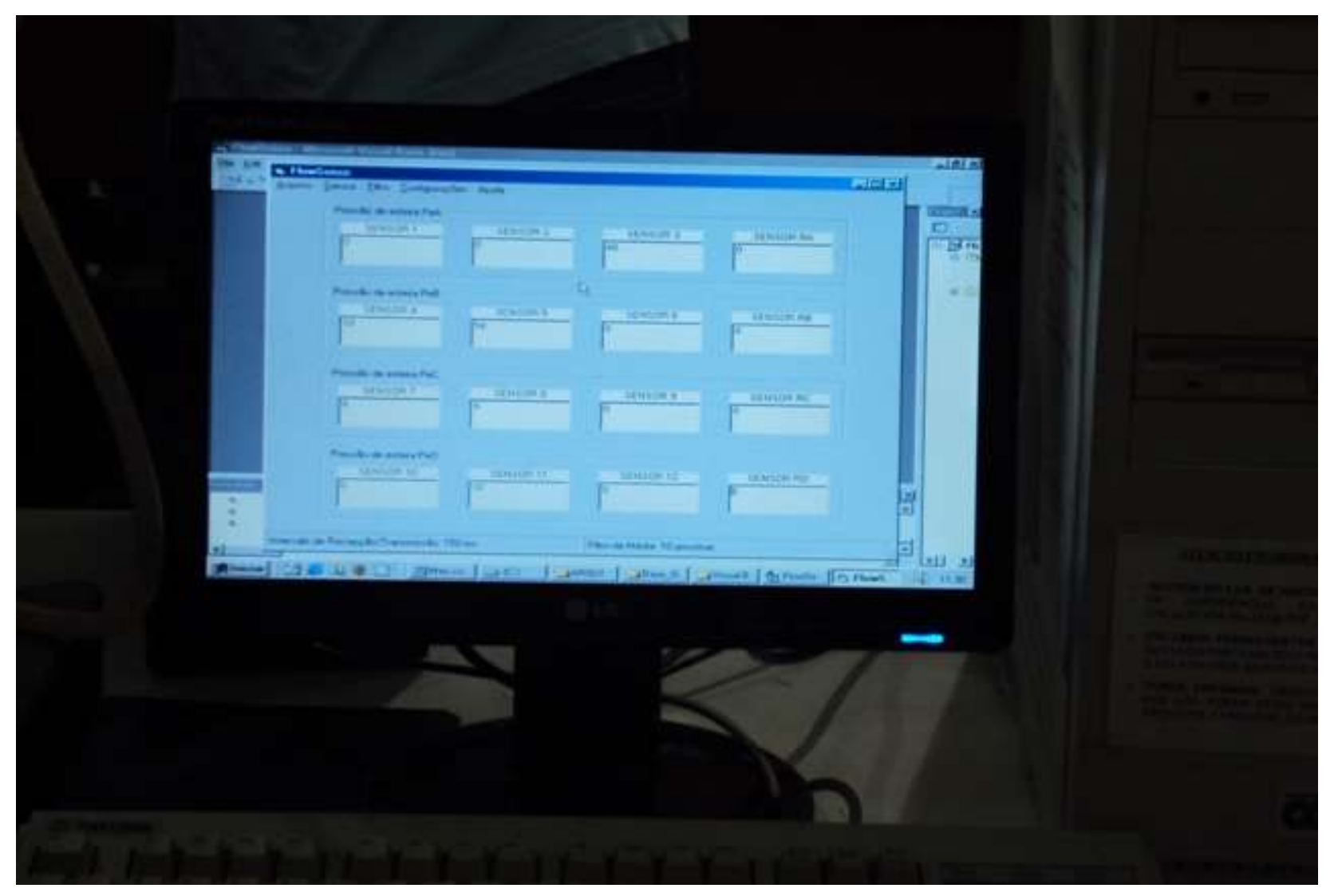

Figura 52 - Indicações de pressão no programa Flowsense. 
Para este sistema, verifica-se que o valor de pressão lido varia em $\pm 1 \mathrm{~Pa}$ devido a instabilidades do escoamento e também devido ao fato de a resolução do sistema monitor de pressão ser de $1 \mathrm{~Pa}$.

\subsection{PROCEDIMENTO EXPERIMENTAL PARA ENSAIOS EM TÚNEIS DE VENTO}

A principal meta dos ensaios é medir valores nas tomadas de pressão das sondas direcionais para cada posição da sonda em relação à linha de corrente de referência do escoamento.

O escoamento de ar unidimensional com velocidade conhecida estabelece a referência desejada. Os sensores são posicionados em diversas combinações de ângulos de guinada $(\psi)$ e arfagem $(\delta)$ em relação à direção do escoamento, conforme mostrado na figura 54 a seguir, para o caso da sonda tipo pirâmide.

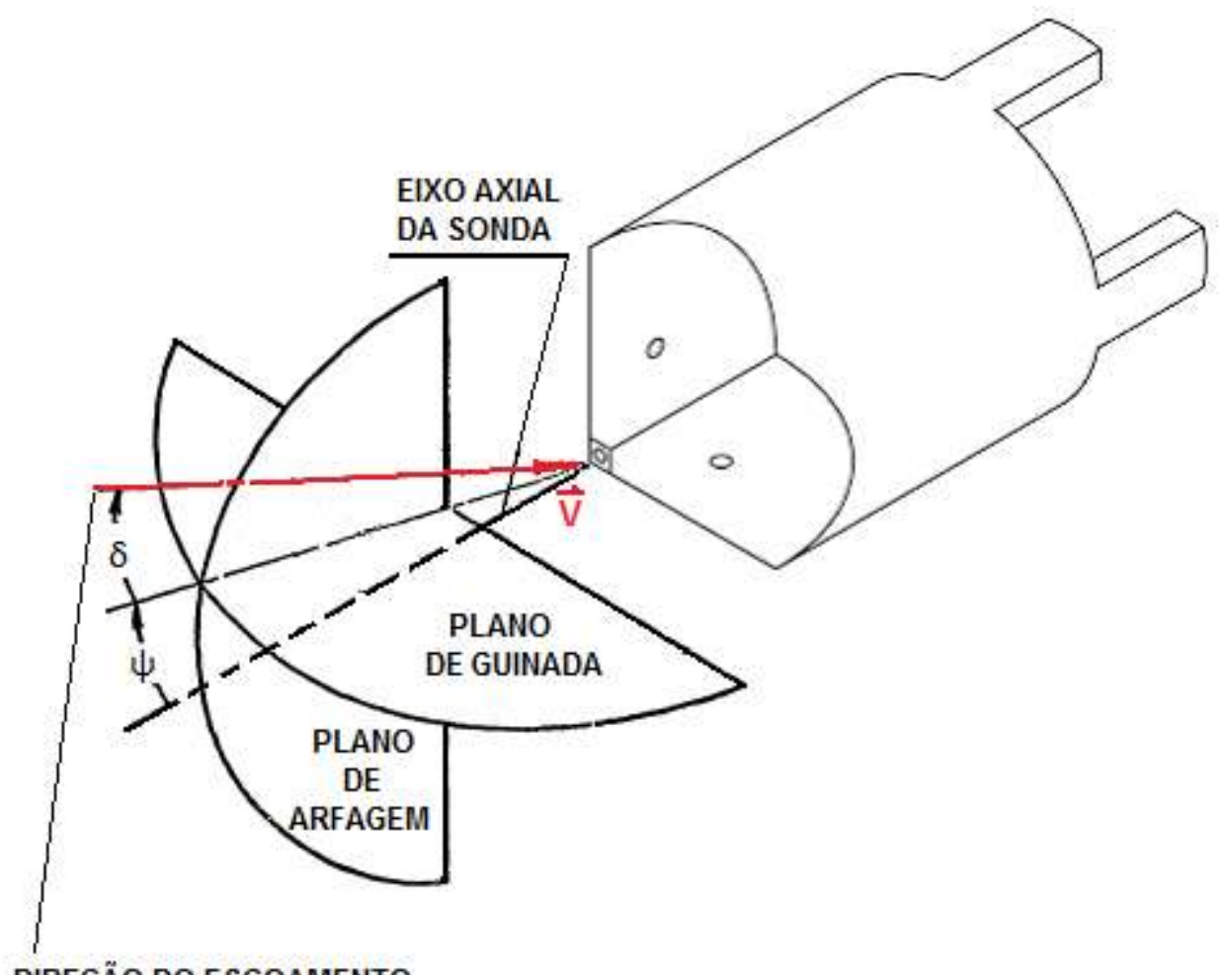

DIREÇÃO DO ESCOAMENTO

Figura 53 - Indicações ângulos de guinada e arfagem 


\subsubsection{Ensaios de verificação na EPUSP (Escola Politécnica da Universidade de São Paulo)}

Antes da realização dos ensaios no túnel de vento do IPT (Instituto de Pesquisas Tecnológicas), são realizados ensaios em um túnel de vento de menor seção e potência, do Laboratório de Instrumentação em Mecânica dos Fluidos da EPUSP, para verificação da operação do sistema de aquisição e do processo de medição.

Neste teste, a sonda foi posicionada em um escoamento de velocidade de $10 \mathrm{~m} / \mathrm{s}$ em três combinações de ângulos de arfagem e guinada. Sendo assim, percebese a variação das medições de pressão nas diferentes tomadas da sonda quando é variada sua posição em relação ao escoamento de referência.

O teste permite estimar o tempo de ensaio necessário para a calibração completa da sonda, considerando os procedimentos de medição, registro dos dados no computador e posicionamento da sonda.

Este teste é considerado essencial já que o tempo disponível para ensaio no túnel de vento de anemometria do IPT era limitado e deveriam ser minimizadas as possibilidades de falha no sistema de medição.

\subsubsection{Ensaios de avaliação e calibração de sondas no IPT}

\subsubsection{Sonda tipo prisma}

A sonda tipo prisma é posicionada no túnel de vento e é realizado um nivelamento e alinhamento da sonda em relação à seção de ensaio, conforme representado na figura 54 a seguir. 


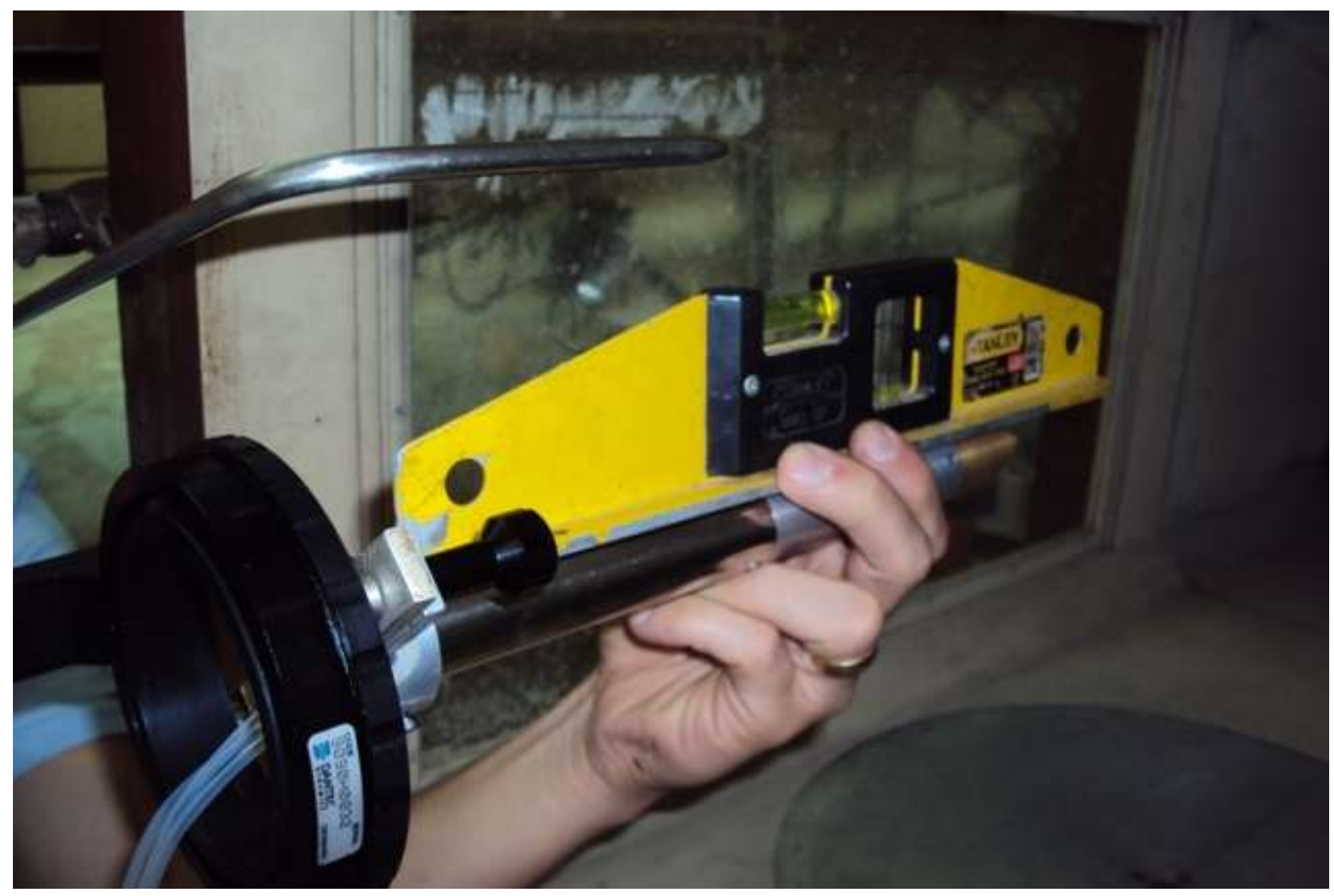

Figura 54 - Nivelamento da sonda antes dos ensaios.

Na figura 54 pode ser visto o tubo de Pitot usado como referência para medições de pressões estática e total. Ao se posicionar a sonda na seção de teste, há um nivelamento da sua haste no plano vertical, que é paralelo à direção do escoamento de referência. Este nivelamento foi realizado com um nível de bolha, conforme mostrado na figura 54. Este procedimento é necessário para que o eixo axial da sonda fique alinhado com o escoamento de referência quando o posicionador indica zero graus para o ângulo de arfagem.

O alinhamento do eixo axial da sonda no plano horizontal também é necessário, já que este eixo deve estar com ângulo de guinada nulo na condição inicial dos ensaios. Este alinhamento é realizado tomando-se medições de distância entre a haste e a parede lateral do túnel em duas posições da sonda, uma na ponta e outra próxima à acoplagem entre sonda e dispositivo posicionador. Igualando-se estas distâncias, garante-se o paralelismo entre a sonda e a parede lateral do túnel. 
A sonda prisma é ensaiada para três velocidades de escoamento: $7,1 \mathrm{~m} / \mathrm{s}, 10,1$ $\mathrm{m} / \mathrm{s}$ e $12,1 \mathrm{~m} / \mathrm{s}$ e a faixa de ângulo de arfagem varia de $-60^{\circ} \mathrm{a}+60^{\circ}$, com incrementos de $5^{\circ}$. Os valores de pressão medidos e as condições ambientes de ensaio encontramse no apêndice I.

\subsubsection{Sonda tipo pirâmide}

A sonda tipo pirâmide foi posicionada no túnel seguindo o procedimento descrito no item 6.2.2.1 para o alinhamento do eixo axial da sonda com o eixo do escoamento de referência. Esta sonda é ensaiada para uma velocidade de escoamento de $10,03 \mathrm{~m} / \mathrm{s}$. O dispositivo posicionador permite que a sonda seja rotacionada em torno de seu eixo e também em torno de um eixo perpendicular ao eixo axial da sonda, conforme representado na figura 55 .
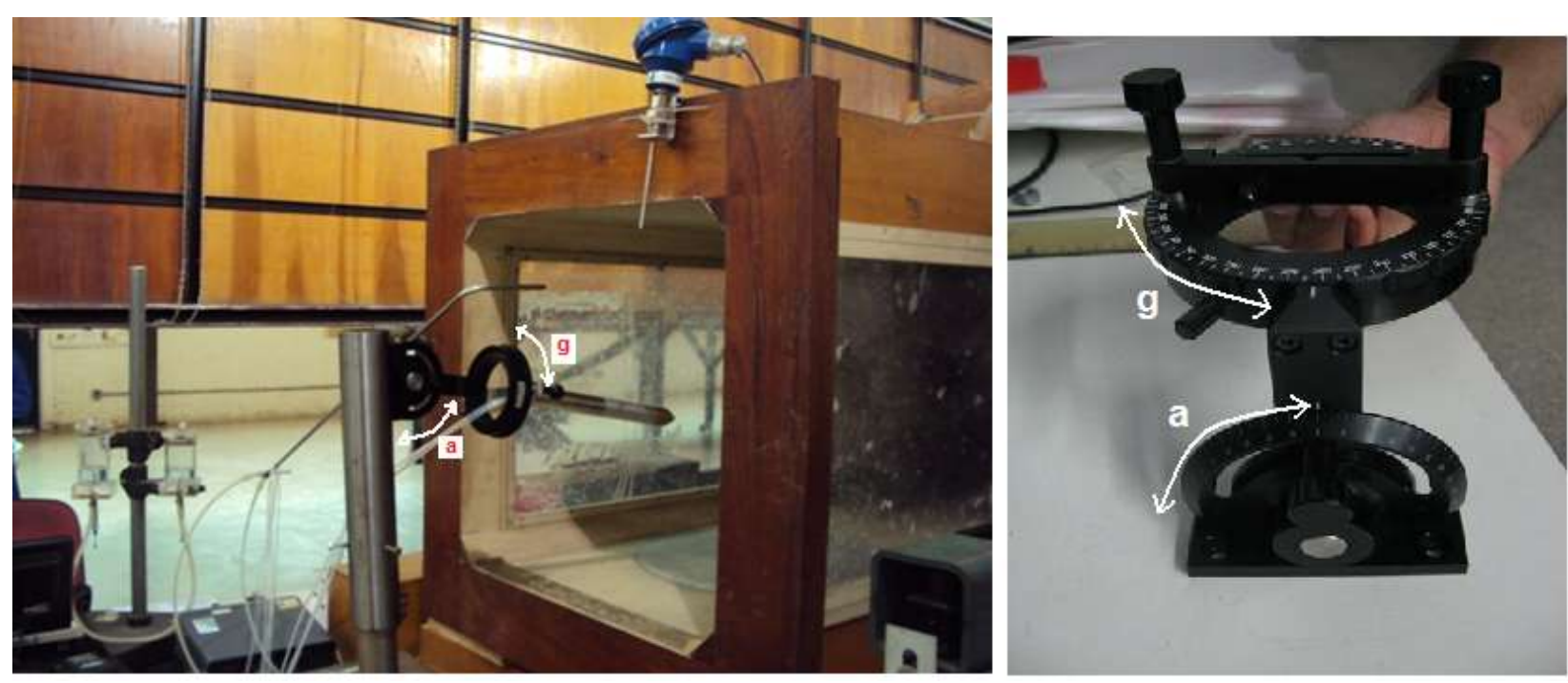

Figura 55 - Ângulos de posicionamento da sonda pirâmide no escoamento.

São definidos os ângulos " $a$ " e " $g$ " para auxiliar a identificação do posicionamento da sonda. O ângulo a é formado entre o eixo axial da sonda e o eixo vertical do cilindro de regulagem de altura. $O$ ângulo $g$ fica estabelecido pela rotação em torno do eixo axial da sonda. 
Os ângulos de arfagem $\delta$ e de guinada $\psi$ relacionam-se com os ângulos a e $g$ pelas expressões:

$$
\begin{aligned}
\delta & =a \times \cos (g) \\
\psi & =a \times \operatorname{sen}(g)
\end{aligned}
$$

Na figura 55 estão representados os ângulos a e $g$.

Nos ensaios o ângulo $g$ é variado entre $0^{\circ}$ e $175^{\circ} \mathrm{em}$ intervalos de $5^{\circ}$. Para cada valor de ângulo $g, o$ ângulo a é variado de $-60^{\circ} \mathrm{e}+60^{\circ} \mathrm{em}$ intervalos de $5^{\circ}$. Desta forma, a combinação dos ângulos a e $g$ resultam em 900 posições diferentes da sonda. Para cada uma dessas posições, são feitas medições das cinco pressões da sonda pirâmide.

O procedimento de medição adotado não considera que a sonda seja perfeitamente simétrica. Eventuais ausências de simetria decorrentes do processo de fabricação indicam que a calibração é válida apenas aquela sonda ensaiada.

A convenção de numeração das tomadas de pressão na sonda segue o representado na figura 56.

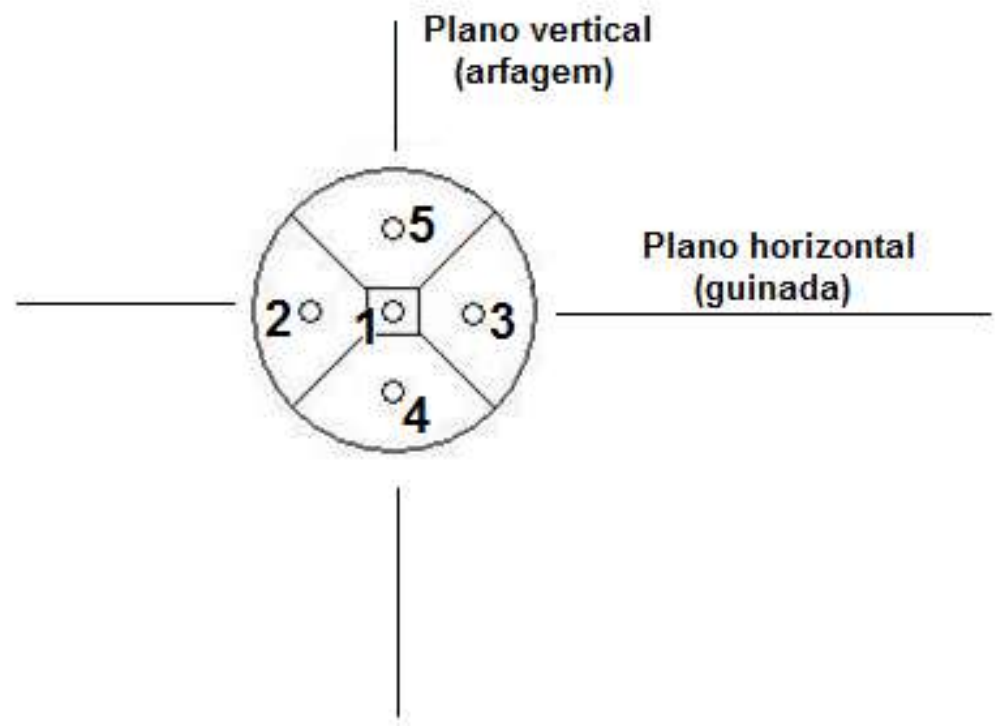

Figura 56 - Numeração das tomadas de pressão na sonda pirâmide

Os resultados deste ensaio encontram-se no apêndice II.

Um procedimento importante para ensaios com medições de baixas pressões, como o presente caso, é a verificação do zero nos medidores de pressão. Isto deve ser 
feito antes de iniciar as medições e periodicamente durante o ensaio. Para tanto, são verificadas as indicações de pressão quando os transdutores não estão conectados à sonda, de forma a calibrar o zero do transdutor. Nos casos em que a indicação não é nula, é realizado o ajuste do zero no programa Flowsense.

\subsection{ANÁLISE DE INCERTEZAS}

Este item da etapa de ensaios experimentais refere-se à análise de incerteza de todo o sistema de medição. Informações sobre as resoluções de instrumentos utilizados já foram apresentadas na descrição do aparato experimental, item 3.2.

O objetivo é determinar as incertezas dos resultados para os ângulos das componentes do vetor velocidade, para a magnitude da velocidade do escoamento e para a pressão estática.

Todas estas grandezas dependem da incerteza das medições de pressão nas tomadas de pressão da sonda, bem como da massa específica do ar.

A análise de incerteza segue as recomendações do Guia para expressão da incerteza de medição do INMETRO (INMETRO, 1998). Foi utilizado como referência para análise de incerteza de medições de pressão o trabalho de Ferreira (FERREIRA, et al., 2009).

São determinadas a seguir as incertezas tipo A, tipo B, a incerteza padrão combinada e a incerteza expandida para as medições de pressão.

\subsubsection{Incerteza tipo A}

Conforme sugerido pelo guia para expressão da incerteza de medição (INMETRO, 1998), estabeleceu-se uma relação entre uma grandeza de entrada e o mensurando. Para o caso da pressão, isto é feito através das curvas de calibração dos transdutores de pressão. Esta calibração relaciona uma pressão aplicada ao transdutor a um sinal de tensão elétrica medido por um multímetro de laboratório. $O$ transdutor possui uma faixa de tensão elétrica entre $1 \mathrm{~V}$ e $5 \mathrm{~V}$. 


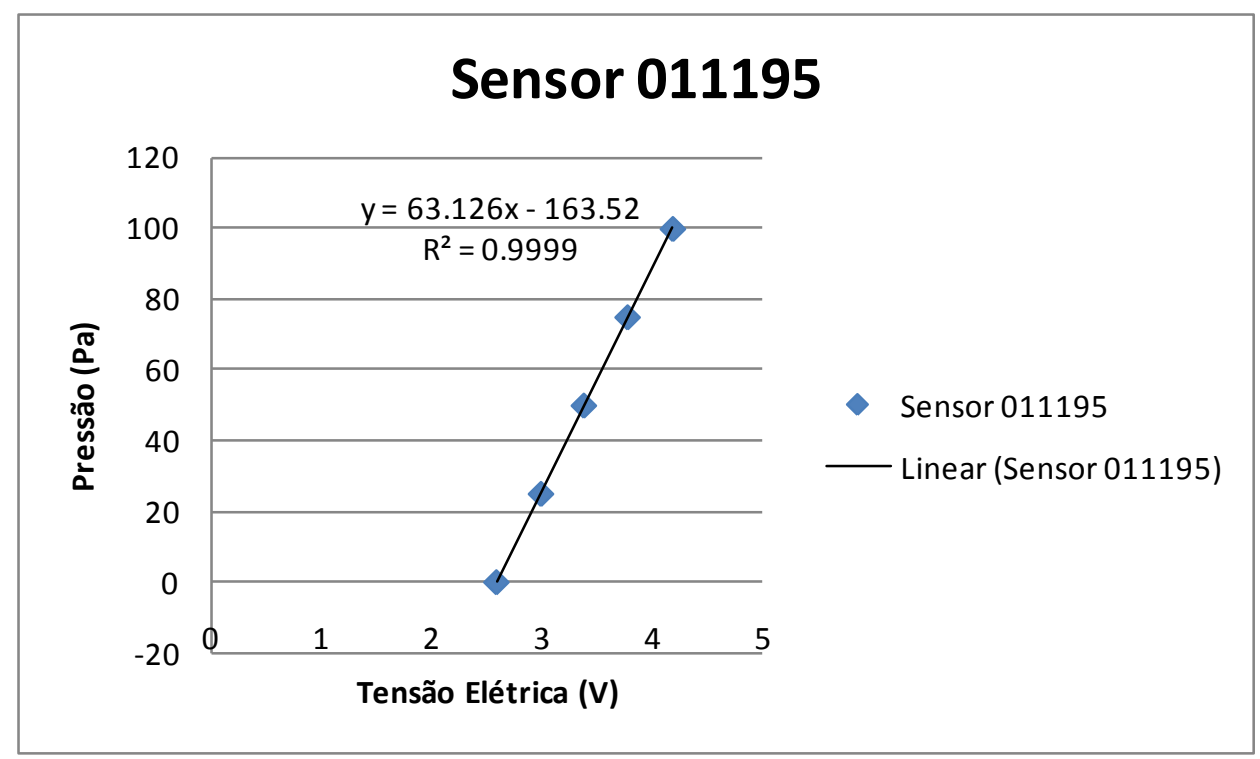

Figura 57 - Curva de calibração do transdutor de pressão \#011195.

Desta maneira, para este transdutor foi estabelecida a relação da pressão medida com a tensão elétrica descrita a seguir:

$$
P=63,126 \times V-163,52
$$

Considerando a incerteza de medição correspondente à variação $\Delta \mathrm{P}$ na pressão de referência, temos a expressão:

$$
P=63,126 \times V-163,52+\Delta P
$$

Durante a medição de cada ponto da curva, observou-se uma variação similar nos valores de tensão elétrica lidos. Para o exemplo do ponto correspondente à pressão de $75 \mathrm{~Pa}$ obtiveram-se 5 valores de tensão elétrica, com média de $3,772 \mathrm{~V}$ e um desvio padrão de $0,007 \mathrm{~V}$. Desta forma, a incerteza tipo $\mathrm{A}$ associada à variação do sinal de tensão do transdutor é dada por:

$$
u_{A}=\frac{u_{V}}{\sqrt{n}}=\frac{0,007}{\sqrt{5}}=0,003 \mathrm{~V}
$$




\subsubsection{Incerteza tipo B}

Para a determinação da incerteza tipo $B$, três parâmetros que influenciam na medição de pressão são observados. Estes parâmetros são:

- Resolução da leitura de pressão do sistema $\left(u_{r}\right)$;

- Variações na medição devido a efeitos de temperatura $\left(\mathrm{u}_{\mathrm{t}}\right)$;

- Estabilidade da medida de pressão ( $\left.\mathrm{u}_{\mathrm{st}}\right)$.

- Variação na medição devido a erros de posicionamento da sonda $\left(u_{p}\right)$.

Conforme apontado na descrição do aparato experimental, o sistema de medição possui uma resolução de $1 \mathrm{~Pa}$ em sua leitura, o que corresponde a 0,016 V. Dessa maneira, considerando uma distribuição normal de probabilidade para as medições, temos $u_{r}=\frac{0,016 \mathrm{~V}}{\sqrt{3}}=0,009 \mathrm{~V}$.

Segundo o fabricante, para a faixa de temperatura entre $5^{\circ} \mathrm{C}$ e $60^{\circ} \mathrm{C}$ a estabilidade da medição de $\pm 0,5 \%$ do fundo de escala é garantida, o que corresponde a uma variação de $\frac{0,5}{100} \times(5 V-1 V)=0,02 V$. Considerando uma distribuição normal de probabilidade para estes dados, tem-se $u_{s t}=\frac{0,02 \mathrm{~V}}{\sqrt{3}}=0,011 \mathrm{~V}$.

Da mesma forma, o fabricante informa que a variação na medição devido a efeitos de temperatura corresponde $a \pm 0,01 \%$ do fundo de escala, o que corresponde a $\frac{0,01}{100} \times(5 V-1 V)=0,0004 V$. Considerando uma distribuição normal de probabilidade para estes dados, tem-se $u_{t}=\frac{0,0004 \mathrm{~V}}{\sqrt{3}}=0,0002 \mathrm{~V}$.

A variação nas medições de pressão devido a erros de posicionamento da sonda foram estimadas durante as medições como sendo a variação da pressão observada quando a sonda era ajustada para sua posição de alinhamento e essa variação corresponde a $1 \mathrm{~Pa}$, o que corresponde a uma variação de 0,016 V. Considerando uma distribuição normal de probabilidades para esta medição, tem-se $u_{p}=\frac{0,016 \mathrm{~V}}{\sqrt{3}}=0,009 \mathrm{~V}$. 
Adicionalmente a estes fatores, adiciona-se a incerteza de medição associada ao manômetro de referência utilizado, que possui uma incerteza de $0,5 \mathrm{~Pa}$, sendo então expresso como esta incerteza, quando expressa em termos de tensão, $u_{\triangle P}=0,5 P a$.

Os valores de $u_{r}, u_{s t}, u_{t}$ e $u_{p}$ somados ao valor de $u_{\Delta P}$ constituem a incerteza tipo B para o modelo proposto.

\subsubsection{Incerteza padrão combinada}

Para a determinação da incerteza padrão combinada $\left(u_{c}\right)$, são feitas as derivadas parciais da função que relaciona a pressão medida com a tensão de saída, dada pela curva de calibração cuja equação é reproduzida abaixo.

$$
P=63,126 \times V-163,52+\Delta P
$$

As grandezas que influenciam na medição da tensão elétrica podem ser consideradas não-correlacionadas, uma vez que os efeitos de cada uma delas já possui sua própria influência na exatidão das medições conforme informado pelo fabricante. Desta forma, as derivadas parciais da função $P(V)$ com relação às variáveis de entrada descritas anteriormente são mostradas a seguir:

$$
u_{C}^{2}=\left(\frac{\partial P}{\partial V}\right)^{2} u_{S}^{2}+\left(\frac{\partial P}{\partial \Delta P}\right)^{2} u_{\Delta P}^{2}
$$

Em que:

$$
u_{S}^{2}=u_{r}^{2}+u_{t}^{2}+u_{s t}^{2}+u_{p}^{2} \rightarrow u_{S}=0,017 V
$$

$$
\begin{gathered}
\left(\frac{\partial P}{\partial V}\right)=63,126 P a / V,\left(\frac{\partial P}{\partial \Delta P}\right)=1 \\
u_{\Delta p}=0,5 P a
\end{gathered}
$$


Dessa forma:

$$
u_{C}=1,17 P a
$$

\subsubsection{Incerteza padrão expandida}

A incerteza padrão expandida foi calculada considerando um intervalo de confiança de $95,45 \%$. A fórmula de Welch-Sattertwaite (INMETRO, 1998) foi utilizada para a determinação dos graus de liberdade efetivos $v_{\text {eff. }}$.

$$
v_{\text {eff }}=\frac{u_{c}^{4}(y)}{\sum_{i=1}^{N} \frac{u_{i}^{4}(y)}{v_{i}}}
$$

Da mesma forma que sugerido pela referência (FERREIRA, et al., 2009), os graus de liberdade associados a $u_{r}, u_{s t}, u_{t}$ e $u_{p}$ foram considerados como $\rightarrow \infty$. Para $u_{A}$ temos $v=n-1=5-1=4$. Sendo assim,

$$
v_{\text {eff }}=\frac{(1,17)^{4}}{\frac{(0,186)^{4}}{4}}=6262,55 \rightarrow \infty
$$

Desta maneira, para o intervalo de confiança considerado, com o valor de $v_{\text {eff }}$ pode-se assumir um fator de abrangência $k=2$. Sendo assim, a incerteza padrão expandida $U$ é descrita por:

$$
U=k \times u_{C}(P)=2 \times 1,17 P a=2,34 P a
$$

De posse da incerteza expandida das medições de pressão, pode-se calcular o impacto desta variação nos coeficientes de arfagem, guinada, pressão estática e pressão total e conseqüentemente, o impacto desta variação na determinação do ângulo e da magnitude do vetor velocidade e da pressão total do escoamento.

Uma variação de 2,34 Pa nas leituras de pressão gera as seguintes variações nos coeficientes:

$$
\Delta K_{\delta}=0,0106, \Delta K_{\psi}=0,0106, \Delta K_{\text {estática }}=0,023 \mathrm{e} \Delta K_{\text {total }}=0,047
$$


Estes valores representam uma variação da ordem de $\pm 0,5^{\circ}$ no ângulo de escoamento (tanto em guinada quanto em arfagem), uma variação de $\pm 4 \%$ no valor da velocidade do escoamento e uma variação de $\pm 1 \mathrm{~Pa}$ no valor da pressão estática do escoamento.

\subsection{SELEÇÃO E DEFINIÇÃO DOS COEFICIENTES}

\subsubsection{Sonda pirâmide}

Os coeficientes adimensionais definidos a partir das medições de pressão permitem a determinação do ângulo e magnitude do vetor velocidade do escoamento, assim como a pressão estática, conforme descrito a seguir.

Os coeficientes de guinada $\mathrm{K}_{\psi}$ e arfagem $\mathrm{K}_{\bar{\delta}}$, definidos conforme Treaster et al., (1978) são:

$$
K_{\psi}=\frac{p 4-p 5}{p 1-\bar{p}} \text { e } K_{\delta}=\frac{p 2-p 3}{p 1-\bar{p}}, \operatorname{com} \bar{p}=\frac{p 2+p 3+p 4+p 5}{4}
$$

É também considerada a definição dos coeficientes de arfagem e guinada segundo Nowack (1970), em que a numeração das tomadas de pressão p1, p2, p3, p4 e p5 está mostrada na figura 56.

$$
K_{\psi}=\frac{p 1-p 4}{p 1-p 5} \text { e } K_{\delta}=\frac{p 1-p 3}{p 1-p 5}
$$

De posse da curva de calibração, podem-se relacionar as leituras de pressão dos cinco orifícios com o par (ângulo de guinada; ângulo de arfagem) do vetor velocidade.

Para a determinação da magnitude do vetor velocidade do escoamento através das medições de pressão nos 5 orifícios, definem-se os coeficientes de pressão total e pressão estática dados por Treaster et al., (1978):

$$
K_{\text {total }}=\frac{p 1-p_{\text {total }}}{p 1-\bar{p}} \text { e } K_{\text {estatica }}=\frac{\bar{p}-p_{\text {estatica }}}{p 1-\bar{p}}
$$

Uma outra definição de coeficientes de pressão estática e pressão dinâmica é proposta neste trabalho: 


$$
K_{\text {total }}=\frac{p 1-p_{\text {total }}}{\sqrt{\bar{p}^{2}}} \text { e } K_{\text {estatica }}=\frac{p 1-p_{\text {estatica }}}{\sqrt{\bar{p}^{2}}}
$$

Com $\bar{p}=\frac{p 1+p 2+p 3+p 4+p 5}{5}$.

Dessa forma, nos ensaios de avaliação da sonda de 5 orifícios, deve-se conhecer também a pressão total e pressão estática do escoamento, com o uso de um tubo de Pitot calibrado.

\subsubsection{Sonda prisma}

Para a calibração da sonda de 3 orifícios (prisma), o procedimento é análogo, sendo determinado no entanto o ângulo do escoamento em apenas um dos planos. Sendo p1 a pressão referente ao orifício central da sonda e p2 e p3 as pressões referentes aos orifícios dos planos inclinados.

Desta forma, o coeficiente de arfagem proposto por Treaster et al., (1978) tornase:

$$
K_{\delta}=\frac{p 2-p 3}{p 1-\bar{p}} \operatorname{com} \bar{p}=\frac{p 2+p 3}{2}
$$

O coeficiente de arfagem definido por Nowack (1970) é:

$$
K_{\delta}=\frac{p 1-p 2}{p 1-p 3}
$$

É definido ainda, neste trabalho, um terceiro coeficiente de arfagem:

$$
K_{\delta}=\frac{p 2-p 3}{\sqrt{\bar{p}^{2}}} \operatorname{com} \bar{p}=\frac{p 1+p 2+p 3}{3}
$$

Os coeficientes de pressão total e pressão estática para esta sonda de 3 orifícios são definidos da mesma maneira que para a sonda de 5 orifícios, ou seja (TREASTER et al., 1978): 


$$
K_{\text {total }}=\frac{p 1-p_{\text {total }}}{p 1-\bar{p}} \text { e } K_{\text {estatica }}=\frac{\bar{p}-p_{\text {estatica }}}{p 1-\bar{p}}
$$

Para a determinação da pressão estática e da pressão total, também foi proposto por este trabalho um outro par de coeficientes dado por:

$$
K_{\text {total }}=\frac{p 2-p 3+p_{\text {total }}}{\sqrt{\bar{p}^{2}}} \text { e } K_{\text {estatica }}=\frac{p 2-p 3+p_{\text {estatica }}}{\sqrt{\bar{p}^{2}}}
$$

Com $\bar{p}=\frac{p 1+p 2+p 3}{3}$.

A comparação dos coeficientes apresentados é feita na etapa de análise dos resultados.

\subsection{RESULTADOS DOS ENSAIOS E ANÁLISE DE COEFICIENTES}

Com as medições de pressão realizadas para as diferentes posições da ponta da sonda em relação ao escoamento, calculam-se coeficientes adimensionais para estabelecer uma relação entre as pressões medidas e o ângulo de posicionamento da sonda em relação ao escoamento. Com o uso de um tubo de Pitot calibrado, é possível também relacionar as medidas de pressão estática e pressão total do escoamento com as indicações de pressão da sonda.

\subsubsection{Sonda Prisma}

Foram definidos coeficientes de arfagem de três maneiras para a análise dos dados, conforme apresentado no item 6.5. Os gráficos a seguir representam os resultados dos ensaios realizados com a sonda prisma. 


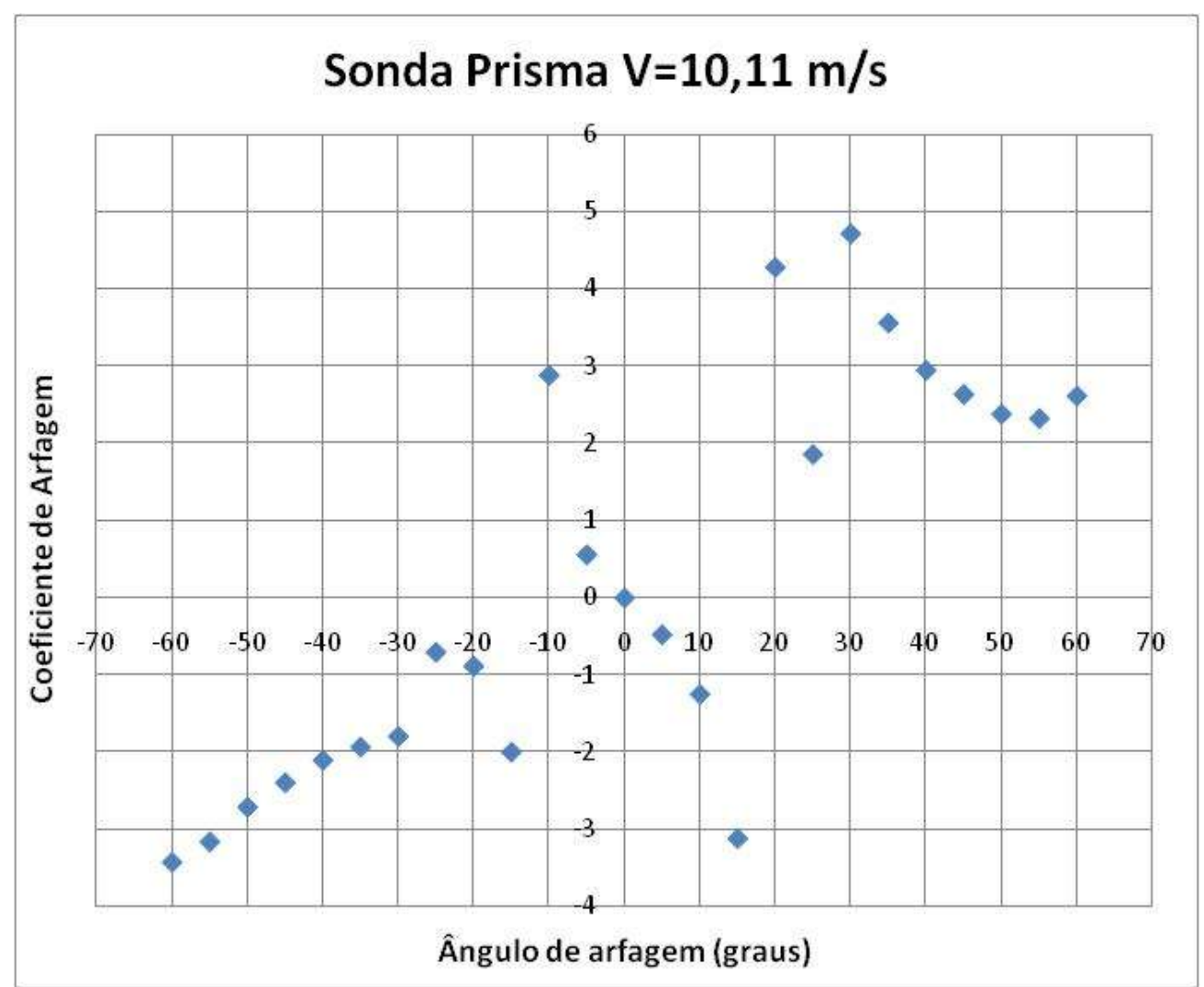

Figura 58 - Ensaio de calibração da sonda tipo prisma. $V=10,11 \mathrm{~m} / \mathrm{s}$. Coeficiente de arfagem definido segundo (TREASTER, et al., 1978)

Como pode ser observado por estes resultados, esta definição de coeficiente não é muito interessante para a análise, já que os valores do coeficiente de arfagem possuem uma relação unívoca com o ângulo de arfagem apenas para a faixa de ângulos entre $-10^{\circ} \mathrm{e}+15^{\circ}$.

A figura a seguir mostra os resultados utilizando a definição de coeficiente de arfagem estabelecida pela referência (NOWACK, 1970). 


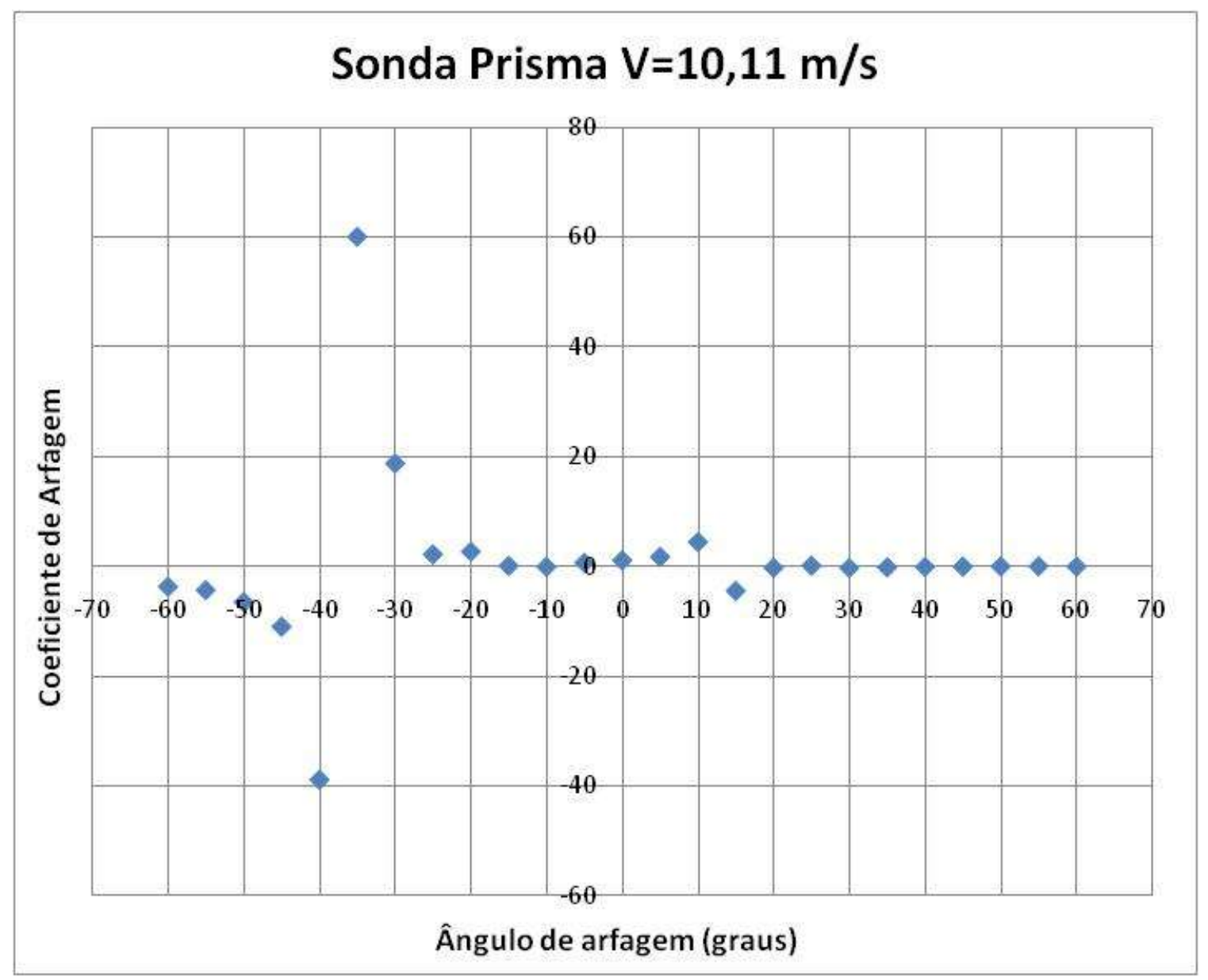

Figura 59 - Ensaio de calibração da sonda tipo prisma. $V=10,11 \mathrm{~m} / \mathrm{s}$. Coeficiente de arfagem definido segundo (NOWACK, 1970)

Com a definição de coeficientes de arfagem segundo a referência (NOWACK, 1970), pode-se verificar a incapacidade de relacionar o coeficiente com o ângulo de arfagem, mesmo para ângulos mais próximos ao zero grau. Na figura a seguir está representada uma região do gráfico entre $-25^{\circ} \mathrm{e}+25^{\circ}$. 


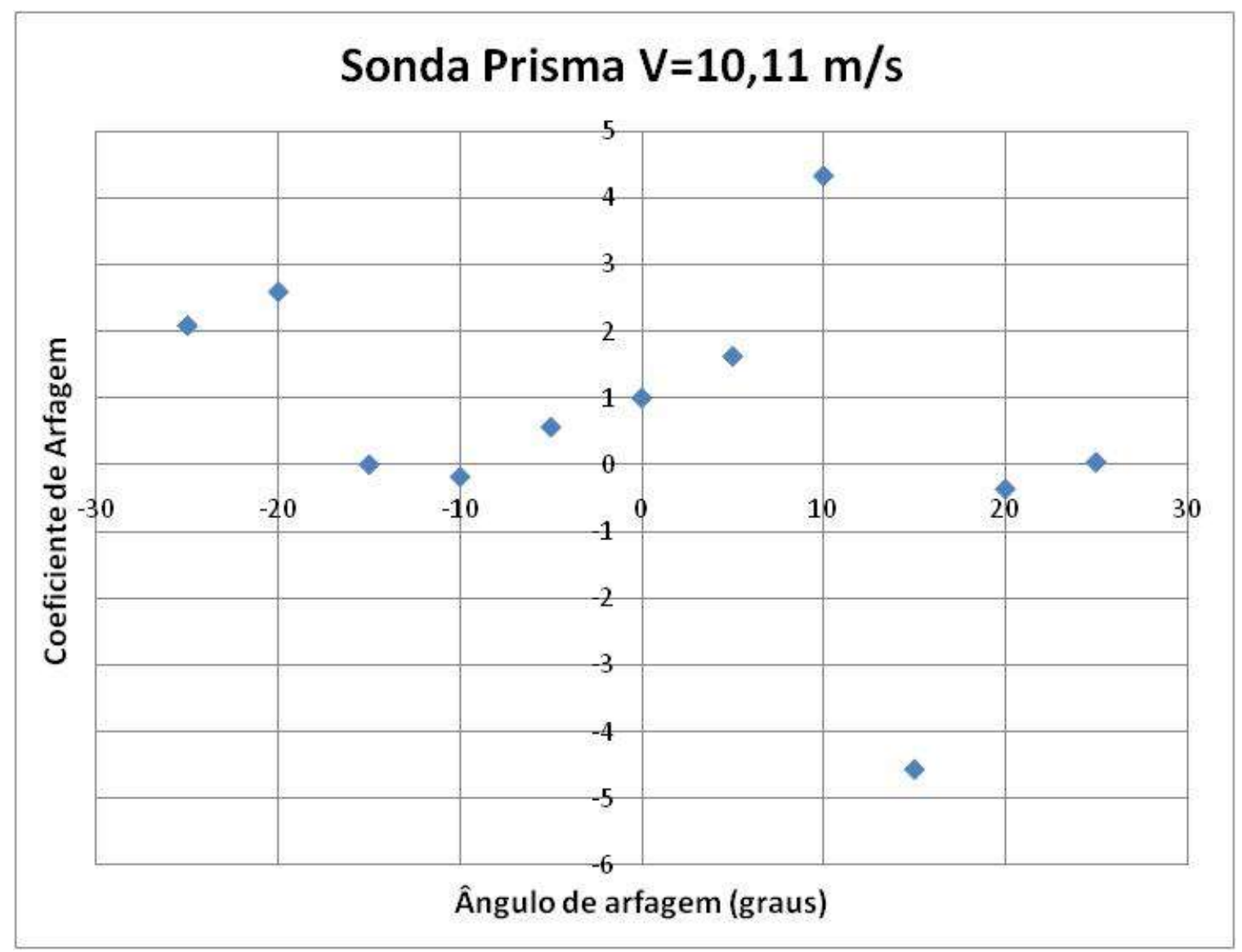

Figura 60 - Ensaio de calibração da sonda tipo prisma. $V=10,11 \mathrm{~m} / \mathrm{s}$. Coeficiente de arfagem definido segundo (NOWACK, 1970), região entre $-25^{\circ}$ e $+25^{\circ}$.

Analisando a região do gráfico entre $-25^{\circ} \mathrm{e}+25^{\circ}$, é possível verificar que para a faixa de ângulos entre $-10^{\circ} \mathrm{a}+10^{\circ}$ existe uma relação única entre coeficiente de arfagem e ângulo de arfagem, ou seja, para esta faixa, um valor de coeficiente de arfagem corresponde a um único valor de ângulo de arfagem.

O terceiro coeficiente de arfagem definido é uma modificação daquele proposto no trabalho de Treaster (TREASTER, et al., 1978), substituindo o denominador $p 1-\bar{p}$ por $\sqrt{\bar{p}^{2}}$, com $\bar{p}=\frac{p 1+p 2+p 3}{3}$. Desta forma, o denominador será sempre maior ou igual a zero e o coeficiente mudará de sinal quando o ângulo de arfagem cruzar o plano horizontal (zero grau). O resultado do ensaio com o uso deste coeficiente está representado nas figuras 61 e 62 a seguir. 


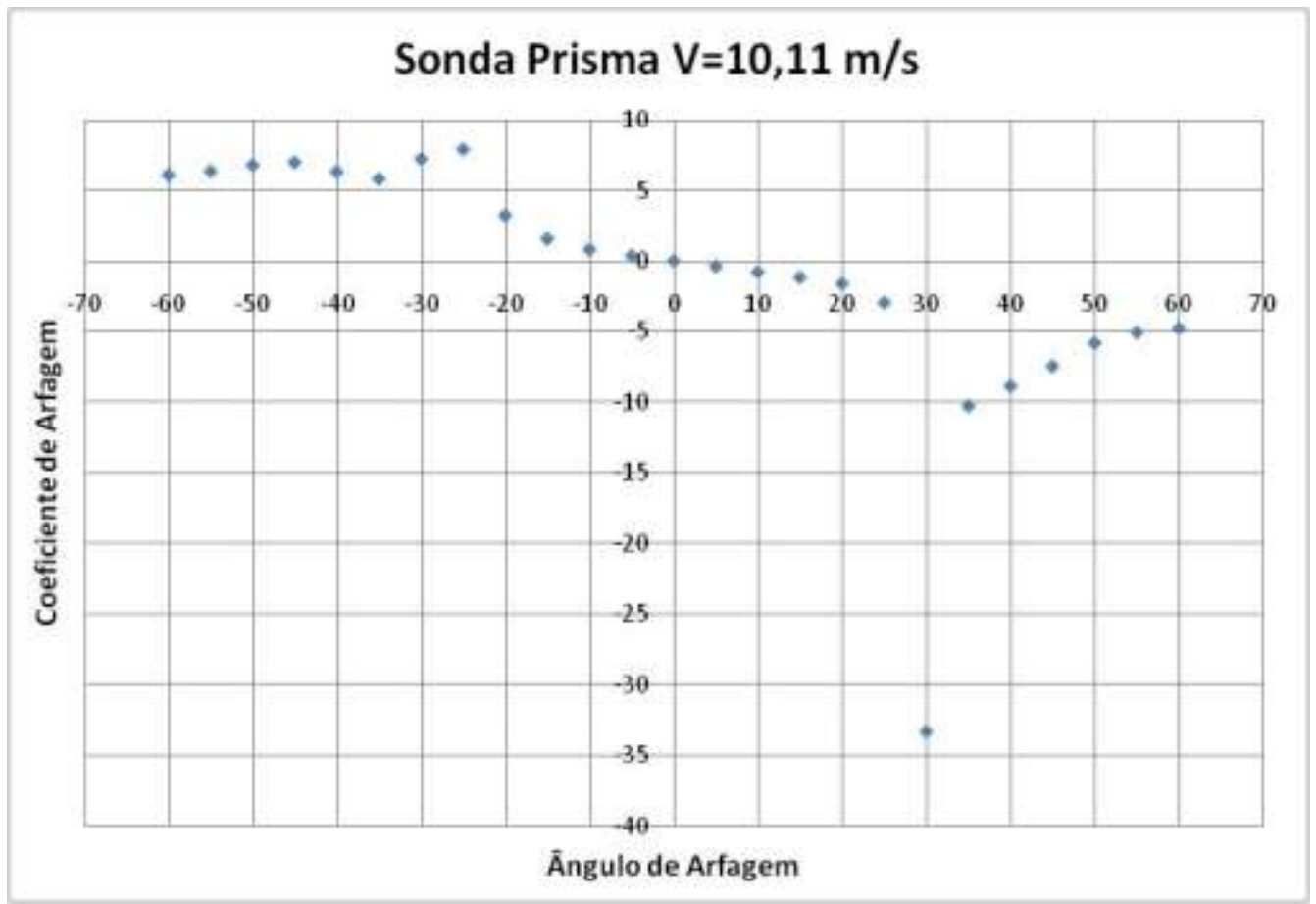

Figura 61 - Ensaio de calibração da sonda tipo prisma. $V=10,11 \mathrm{~m} / \mathrm{s}$. Coeficiente de arfagem definido com o denominador $\sqrt{\bar{p}^{2}}$.

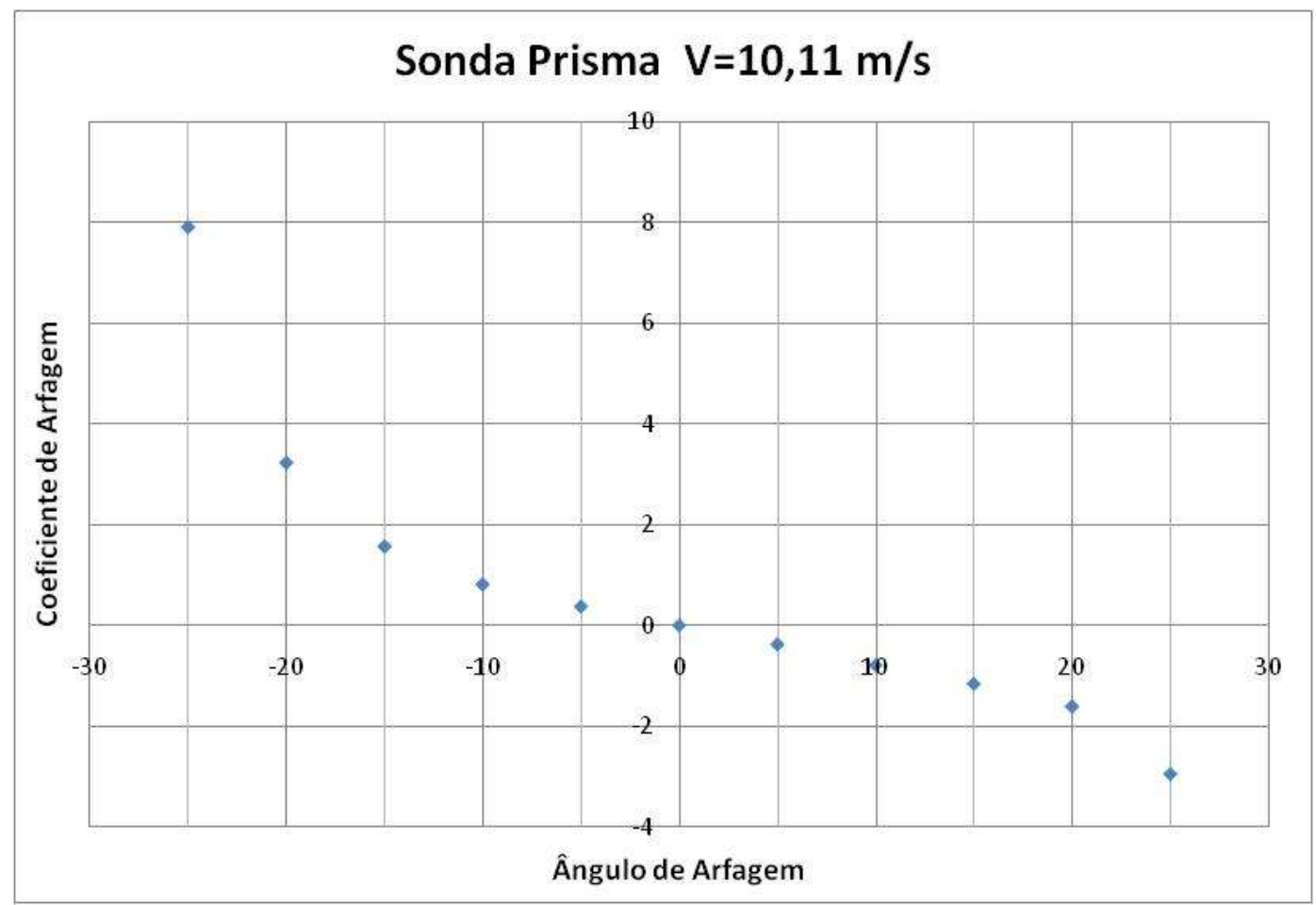

Figura 62 - Ensaio de calibração da sonda tipo prisma. $V=10,11 \mathrm{~m} / \mathrm{s}$. Coeficiente de arfagem definido com o denominador $\sqrt{\bar{p}^{2}}$. Faixa de ângulos entre $-25^{\circ} \mathrm{e}+25^{\circ}$. 
Verifica-se pelo gráfico que esta definição de coeficiente produz uma curva de calibração de maior utilidade, uma vez que é possível relacionar o coeficiente de arfagem com apenas um ângulo de arfagem para a faixa de ângulos entre $-25^{\circ} \mathrm{e}+25^{\circ}$.

Desta forma, este coeficiente é escolhido para a definição das curvas de calibração.

A figura 63 a seguir mostra a comparação dos valores de coeficiente de arfagem para as três velocidades de escoamento ensaiadas.

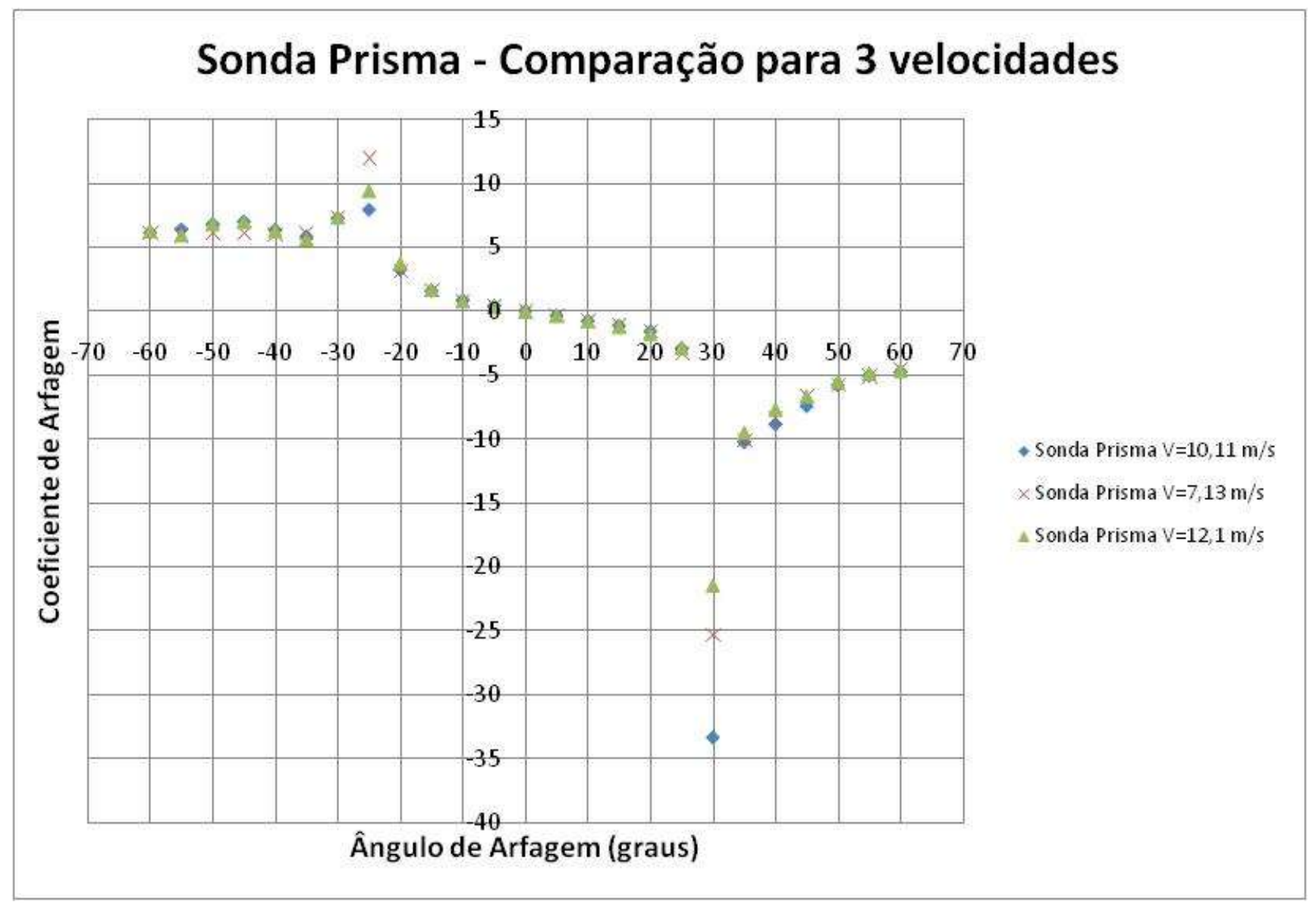

Figura 63 - Ensaio de calibração da sonda tipo prisma. Velocidades de 10,11 m/s, 7,13 m/s e $12,1 \mathrm{~m} / \mathrm{s}$.

Pelos resultados, pode-se confirmar a independência dos valores do coeficiente de arfagem com a velocidade, bem como uma região de instabilidade em torno do ângulo $+30^{\circ}$ e do ângulo $-25^{\circ}$. Para ângulos de arfagem próximos a estes valores, 
verifica-se uma região onde as pressões variam rapidamente, o que pode representar 0 descolamento do escoamento da superfície da sonda.

Adicionalmente, foram verificados os resultados dos coeficientes de pressão estática e pressão total, a fim de que se possa determinar além da direção do escoamento, sua velocidade e a pressão estática do escoamento.

Os gráficos das figuras 64 e 65 representam os coeficientes de pressão estática e pressão total definidos segundo Treaster (TREASTER et al., 1978).

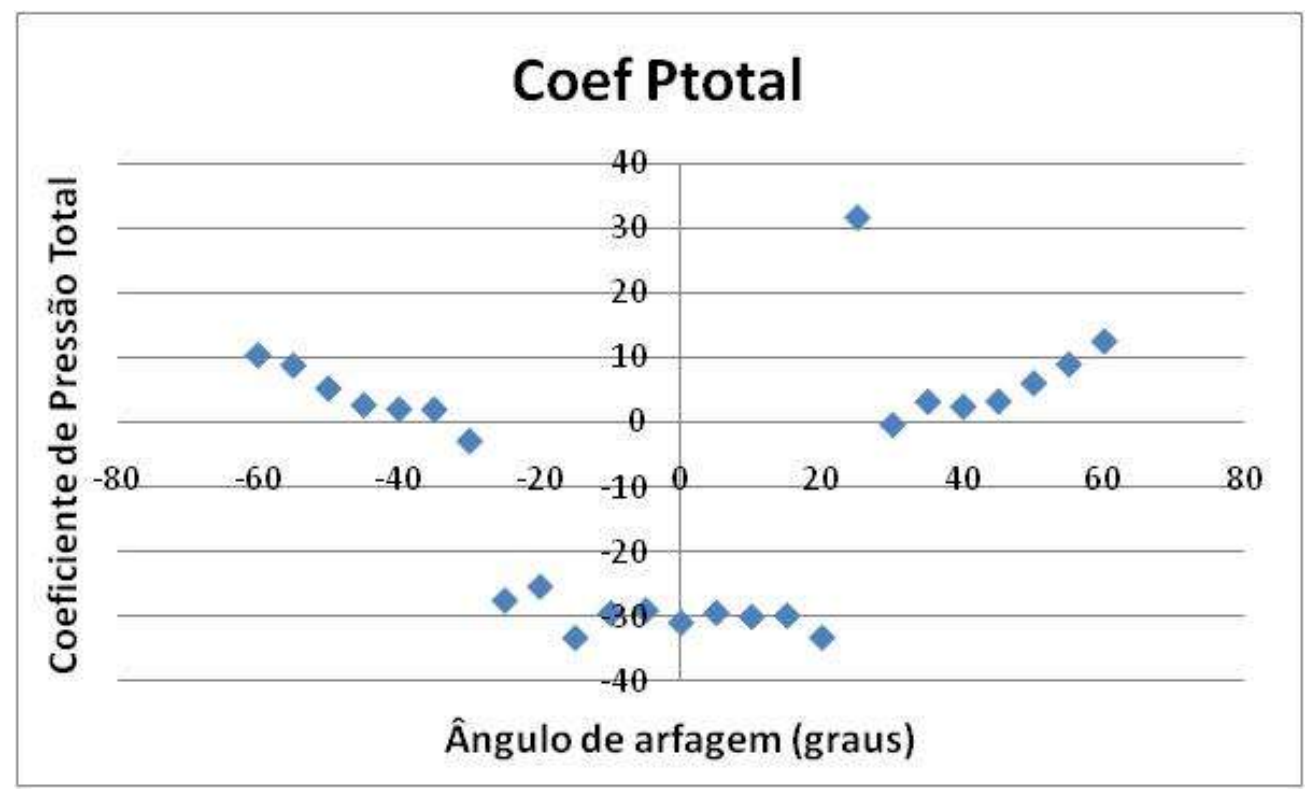

Figura 64 - Ensaio de calibração da sonda tipo prisma. $V=10,11 \mathrm{~m} / \mathrm{s}$. Coeficiente de pressão total definido segundo Treaster (TREASTER, et al., 1978). 


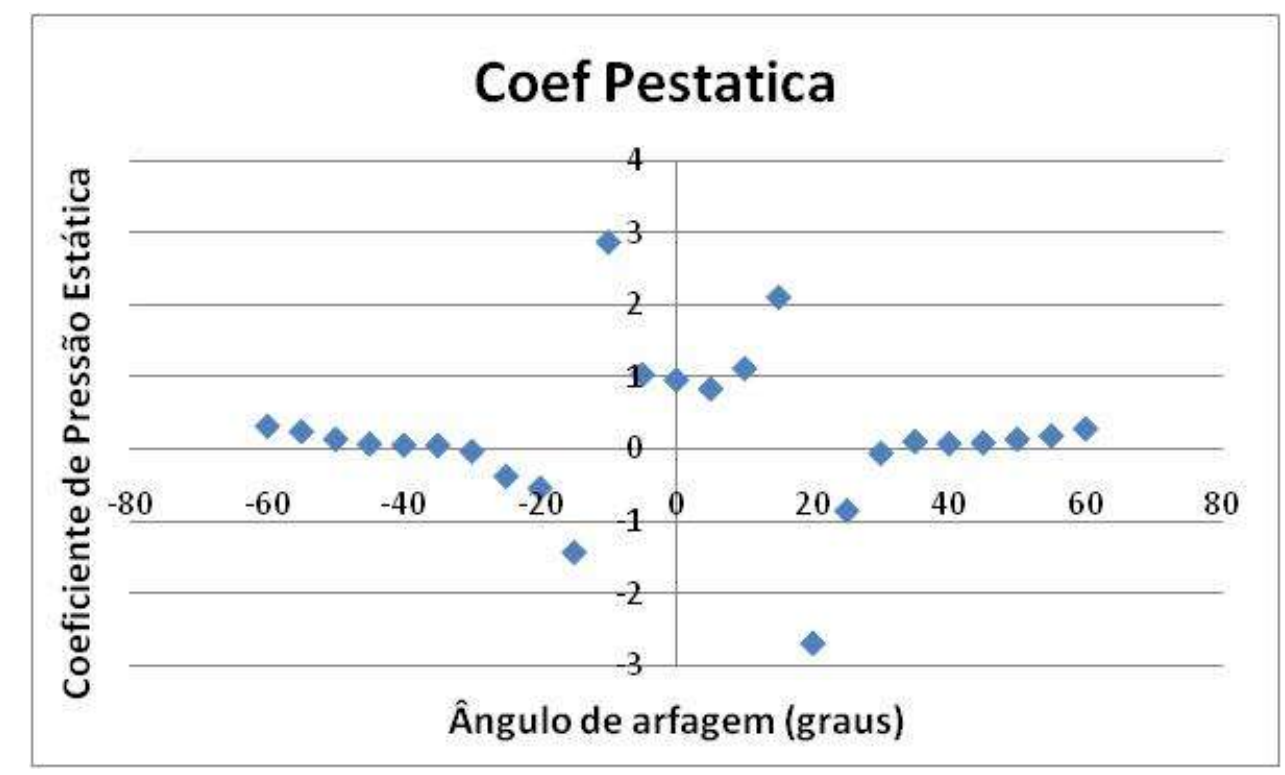

Figura 65 - Ensaio de calibração da sonda tipo prisma. V=10,11 m/s. Coeficiente de pressão estática definido segundo Treaster (TREASTER, et al., 1978).

Como se pode observar, as definições de coeficientes de pressão total e pressão estática sugeridas por Treaster:

$$
K_{\text {total }}=\frac{p 1-p_{\text {total }}}{p 1-\bar{p}} \text { e } K_{\text {estatica }}=\frac{\bar{p}-p_{\text {estatica }}}{p 1-\bar{p}}
$$

não apresentam uma faixa de ângulos para que seja relacionado um valor de coeficiente de pressão para apenas um ângulo. Desta forma, buscaram-se outras definições de coeficientes em que esta relação fosse possível para uma faixa representativa de ângulos em torno do zero grau.

Testando algumas relações entre pressões estática, total e leituras de pressão nas tomadas da sonda, definiram-se os coeficientes:

$$
K_{\text {total }}=\frac{p 2-p 3+p_{\text {total }}}{\sqrt{\bar{p}^{2}}} \text { e } K_{\text {estatica }}=\frac{p 2-p 3+p_{\text {estatica }}}{\sqrt{\bar{p}^{2}}}
$$

Com $\bar{p}=\frac{p 1+p 2+p 3}{3}$.

Que resultaram nos gráficos das figuras 66 e 67 a seguir. 


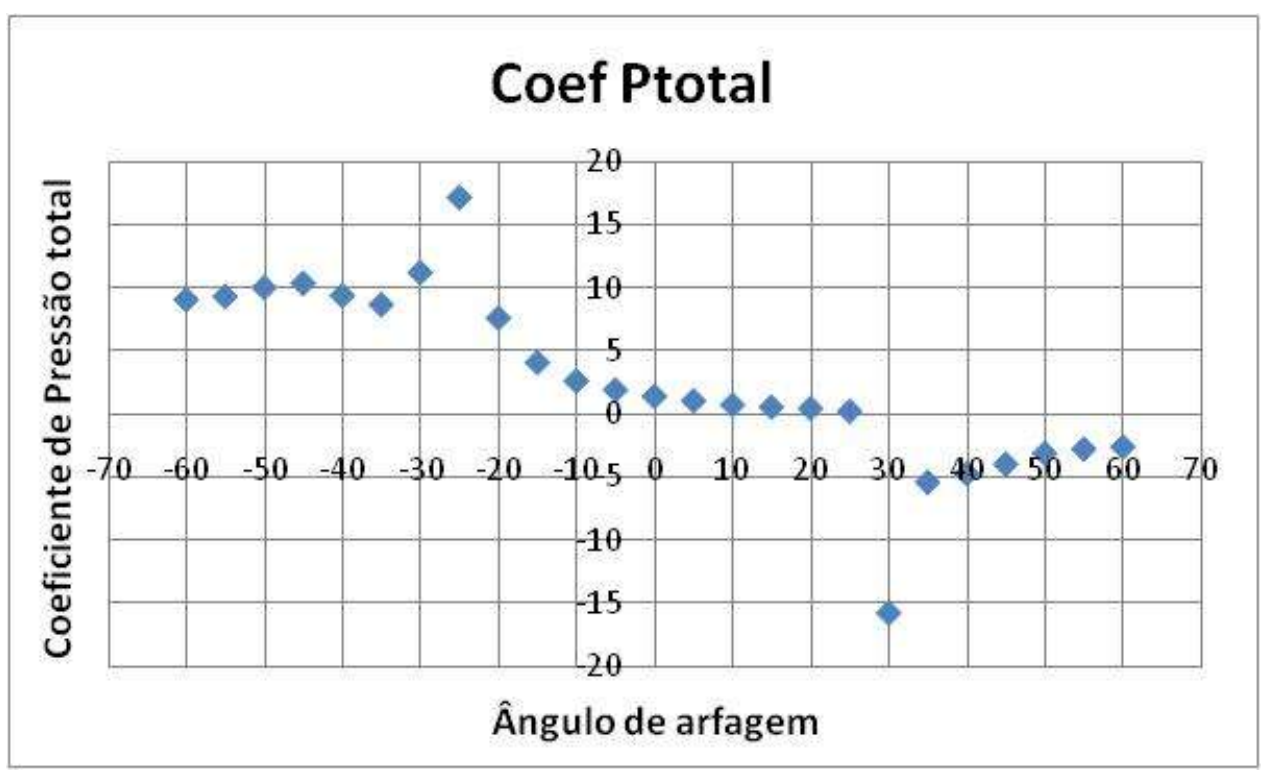

Figura 66 - Ensaio de calibração da sonda tipo prisma. V=10,11 m/s. Coeficiente de pressão total definido com o denominador $\sqrt{\bar{p}^{2}}$.

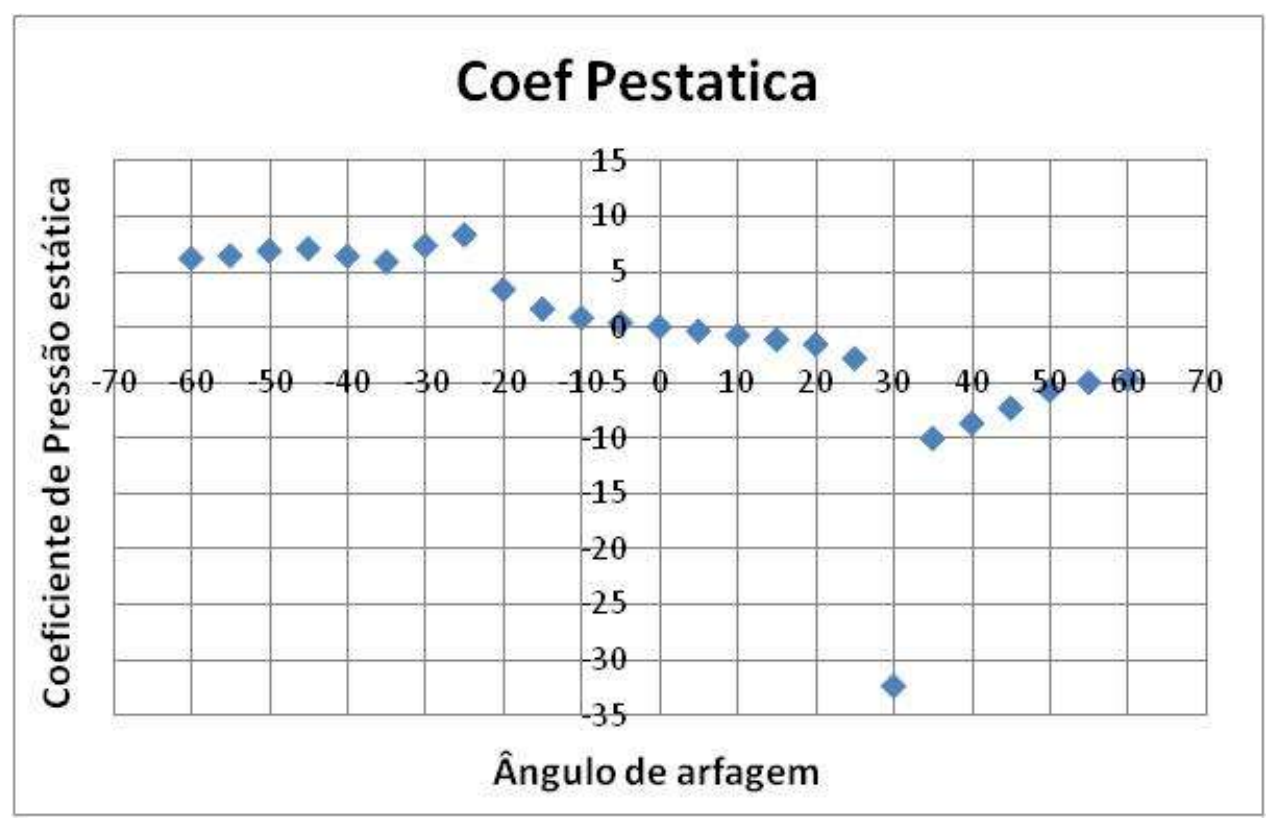

Figura 67 - Ensaio de calibração da sonda tipo prisma. $V=10,11 \mathrm{~m} / \mathrm{s}$. Coeficiente de pressão estática definido com o denominador $\sqrt{\bar{p}^{2}}$.

Verifica-se então que com estas novas definições de coeficiente de pressão total e pressão estática, é possível determinar o valor do coeficiente da pressão em questão pra uma faixa de ângulos entre $-25^{\circ} \mathrm{e}+25^{\circ}$. 
A decisão por este novo coeficiente ocorreu após a análise dos dados com o uso dos demais coeficientes propostos por Treaster et al. (1978) e Nowack (1970), buscando relações entre as pressões que fornecessem uma maior faixa de capacidade de determinação do ângulo de arfagem e das pressões total e estática a partir dos coeficientes. A divisão pelo fator $\sqrt{\bar{p}^{2}}$ apresentou os melhores resultados.

Desta forma, definiram-se para este trabalho os coeficientes de pressão estática e pressão total para a sonda tipo prisma:

$$
K_{\text {total }}=\frac{p 2-p 3+p_{\text {total }}}{\sqrt{\bar{p}^{2}}} \text { e } K_{\text {estatica }}=\frac{p 2-p 3+p_{\text {estatica }}}{\sqrt{\bar{p}^{2}}}
$$

Com $\bar{p}=\frac{p 1+p 2+p 3}{3}$.

\subsubsection{Sonda Pirâmide}

A primeira análise feita foi a escolha do melhor coeficiente para representar os dados medidos, assim como realizado para a sonda tipo prisma. Os gráficos das figuras 68 a 75 a seguir mostram os resultados dos coeficientes de guinada quando a sonda é posicionada em relação ao escoamento variando apenas o ângulo de guinada e os resultados dos coeficientes de arfagem quando a sonda é posicionada em relação ao escoamento variando apenas o ângulo de arfagem, segundo três diferentes definições de coeficientes. Desta forma, assim como o realizado para a sonda tipo prisma, é feita uma comparação entre os coeficientes propostos por Nowack (NOWACK, 1970), Treaster (TREASTER, et al., 1978) e outros coeficientes propostos neste trabalho. 


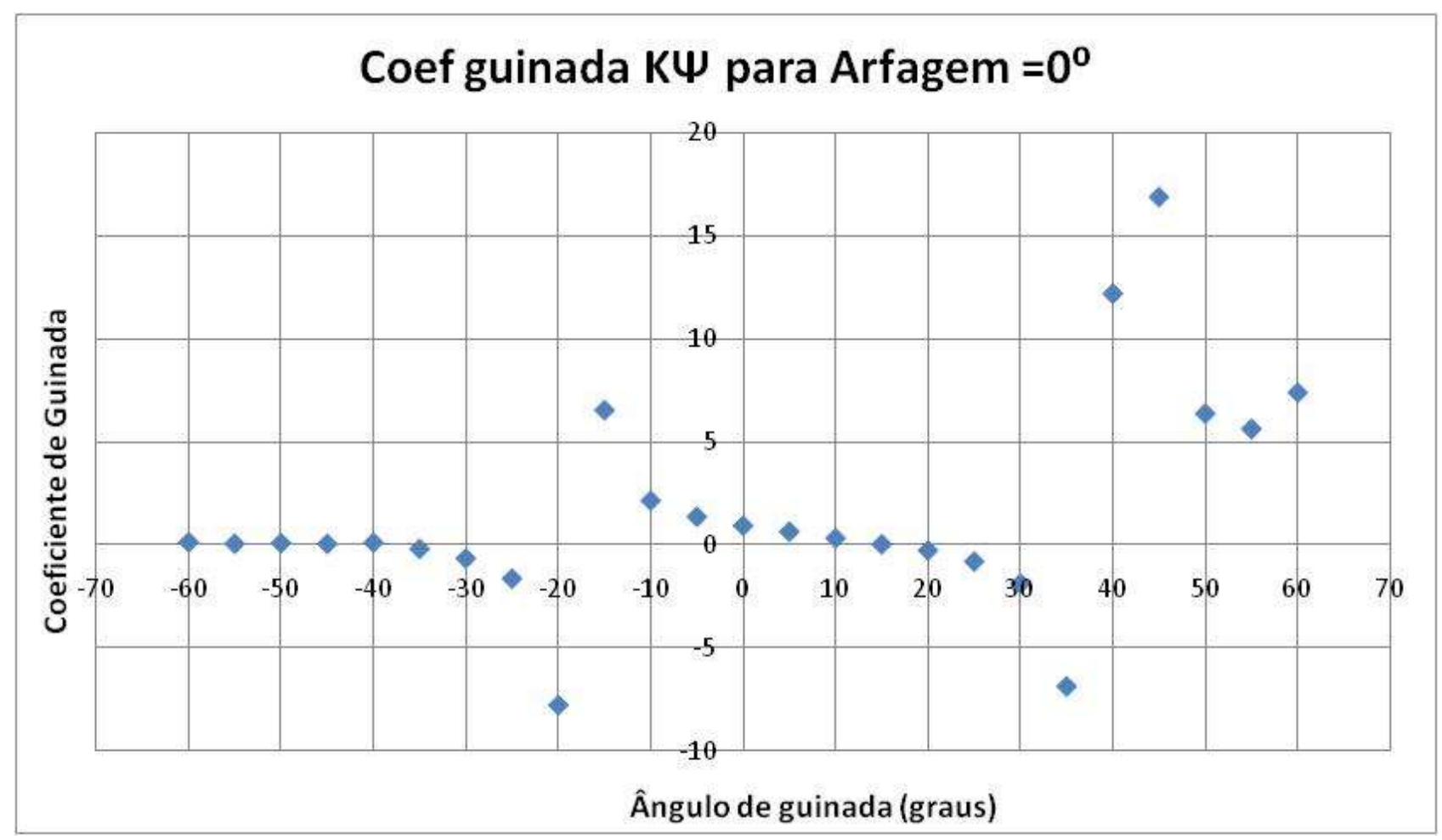

Figura 68- Ensaio de calibração da sonda tipo pirâmide. V=10,03 m/s. Coeficiente de guinada definido segundo (NOWACK, 1970).

Pela definição de coeficientes de guinada segundo Nowack, ou seja,

$$
K_{\psi}=\frac{p 1-p 2}{p 1-p 3}
$$

Verifica-se que a faixa de medição da sonda, ou seja, a faixa de ângulos de guinada para a qual um valor de coeficiente de guinada corresponde a apenas um valor de ângulo de guinada é a região entre $-15^{\circ} \mathrm{e}+35^{\circ}$, o que representa uma amplitude de $50^{\circ}$. O gráfico a seguir representa uma análise similar para o coeficiente de arfagem definido segundo Nowack.

Para esta medição, verificou-se uma assimetria dos coeficientes em torno do zero grau. Isto se deve a mau-posicionamento inicial da sonda, o que fez com que as medições ficassem defasadas. A mesma situação é verificada na figura 69 e na definição dos coeficientes segundo Treaster, figuras 70 e 71. 


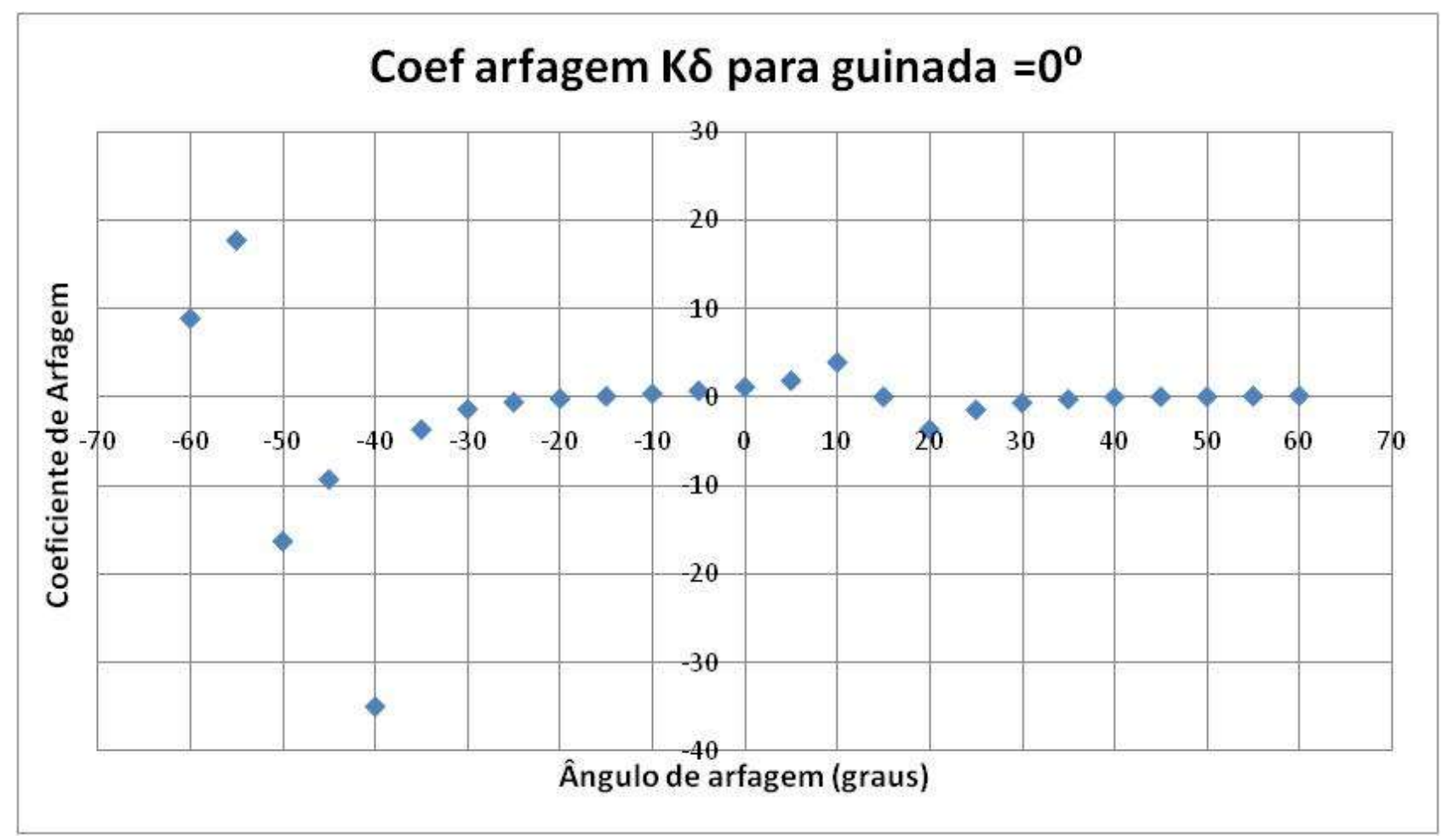

Figura 69 - Ensaio de calibração da sonda tipo pirâmide. V=10,03 m/s. Coeficiente de arfagem definido segundo (NOWACK, 1970).

Para este caso, o coeficiente de arfagem é definido como:

$$
K_{\delta}=\frac{p 1-p 5}{p 1-p 4}
$$

Verifica-se uma faixa de medição de ângulos entre $-40^{\circ}$ e $10^{\circ}$. Assim como verificado para o ângulo de guinada, uma amplitude de $50^{\circ}$ entre o menor e o maior valor de ângulo que pode ser determinado univocamente pelo coeficiente em questão.

Os gráficos a seguir representam a mesma análise, porém feita com os coeficientes definidos segundo Treaster (TREASTER, et al., 1978). 


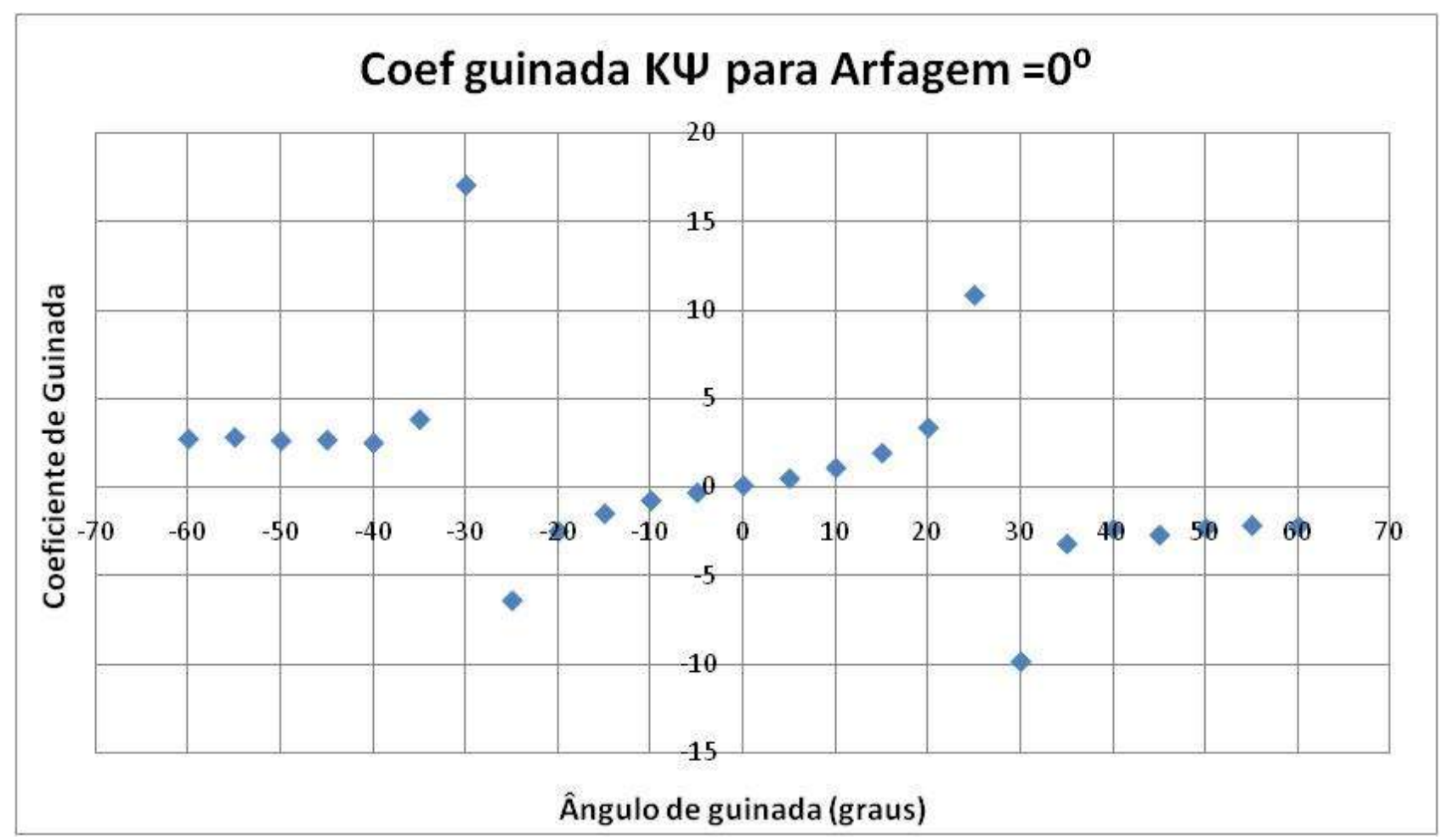

Figura 70 - Ensaio de calibração da sonda tipo pirâmide. $V=10,03 \mathrm{~m} / \mathrm{s}$. Coeficiente de guinada definido segundo (TREASTER et al. , 1978).

Pela definição de coeficientes de guinada segundo Treaster, ou seja,

$$
K_{\psi}=\frac{p 2-p 3}{p 1-\bar{p}} \text { com } \bar{p}=\frac{p 2+p 3+p 4+p 5}{4}
$$

Verifica-se que a faixa de medição da sonda, ou seja, a faixa de ângulos de guinada para a qual um valor de coeficiente de guinada corresponde a apenas um valor de ângulo de guinada é a região entre $-25^{\circ} \mathrm{e}+25^{\circ}$, o que representa uma amplitude de $50^{\circ}$. O gráfico a seguir representa uma análise similar para o coeficiente de arfagem definido segundo Treaster. 


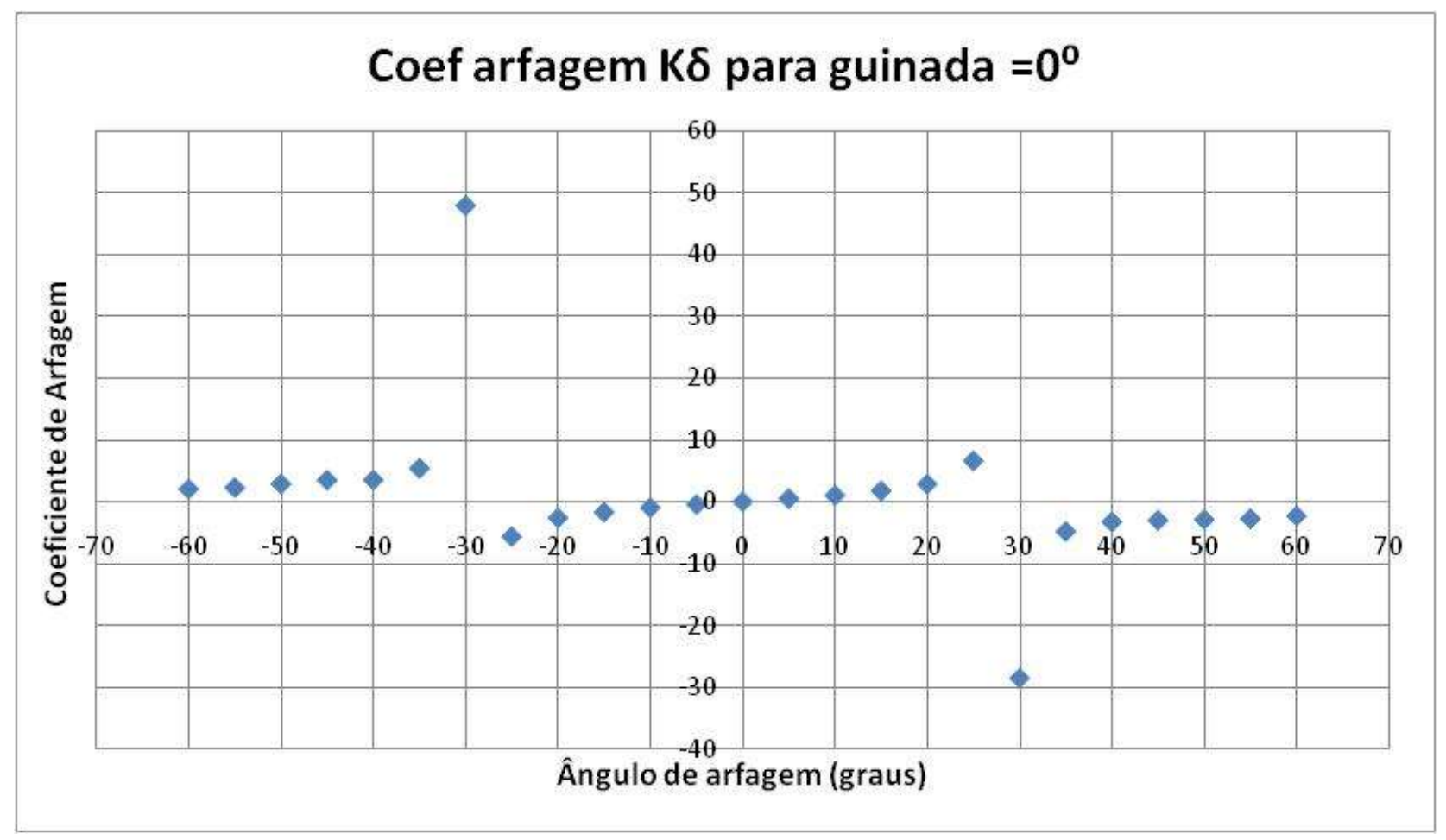

Figura 71 - Ensaio de calibração da sonda tipo pirâmide. V=10,03 m/s. Coeficiente de arfagem definido segundo (TREASTER et al. , 1978).

Para este caso, coeficiente de arfagem é definido como:

$$
K_{\delta}=\frac{p 4-p 5}{p 1-\bar{p}} \operatorname{com} \bar{p}=\frac{p 2+p 3+p 4+p 5}{4}
$$

Verifica-se uma faixa de medição de ângulos entre $-25^{\circ}$ e $25^{\circ}$. Assim como verificado para o ângulo de guinada, uma amplitude de $50^{\circ}$ com centro em $0^{\circ}$.

Em seguida, analisaram-se para os mesmos casos os coeficientes definido como modificações daqueles propostos por Treaster, substituindo o denominador $p 1-\bar{p}$ por $\sqrt{\bar{p}^{2}}$, com $\bar{p}=\frac{p 1+p 2+p 3+p 4+p 5}{5}$. Desta forma, o denominador será sempre maior ou igual a zero e o coeficiente mudará de sinal quando o ângulo de arfagem cruzar o plano horizontal (zero grau). O resultado do ensaio com o uso destes coeficientes estão representados a seguir. 


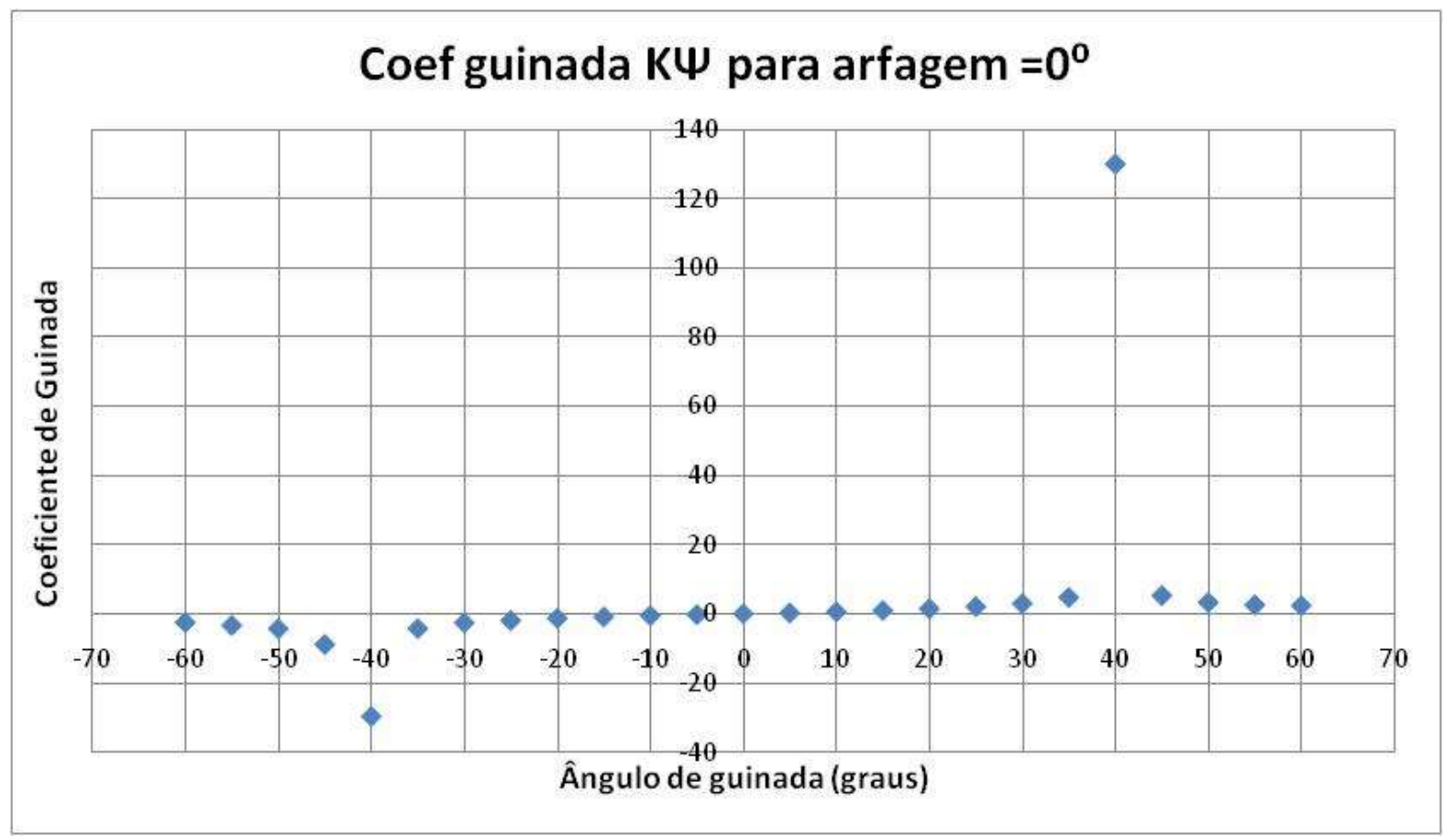

Figura 72 - Ensaio de calibração da sonda tipo pirâmide. $V=10,11 \mathrm{~m} / \mathrm{s}$. Coeficiente de guinada definido com o denominador $\sqrt{\bar{p}^{2}}$.

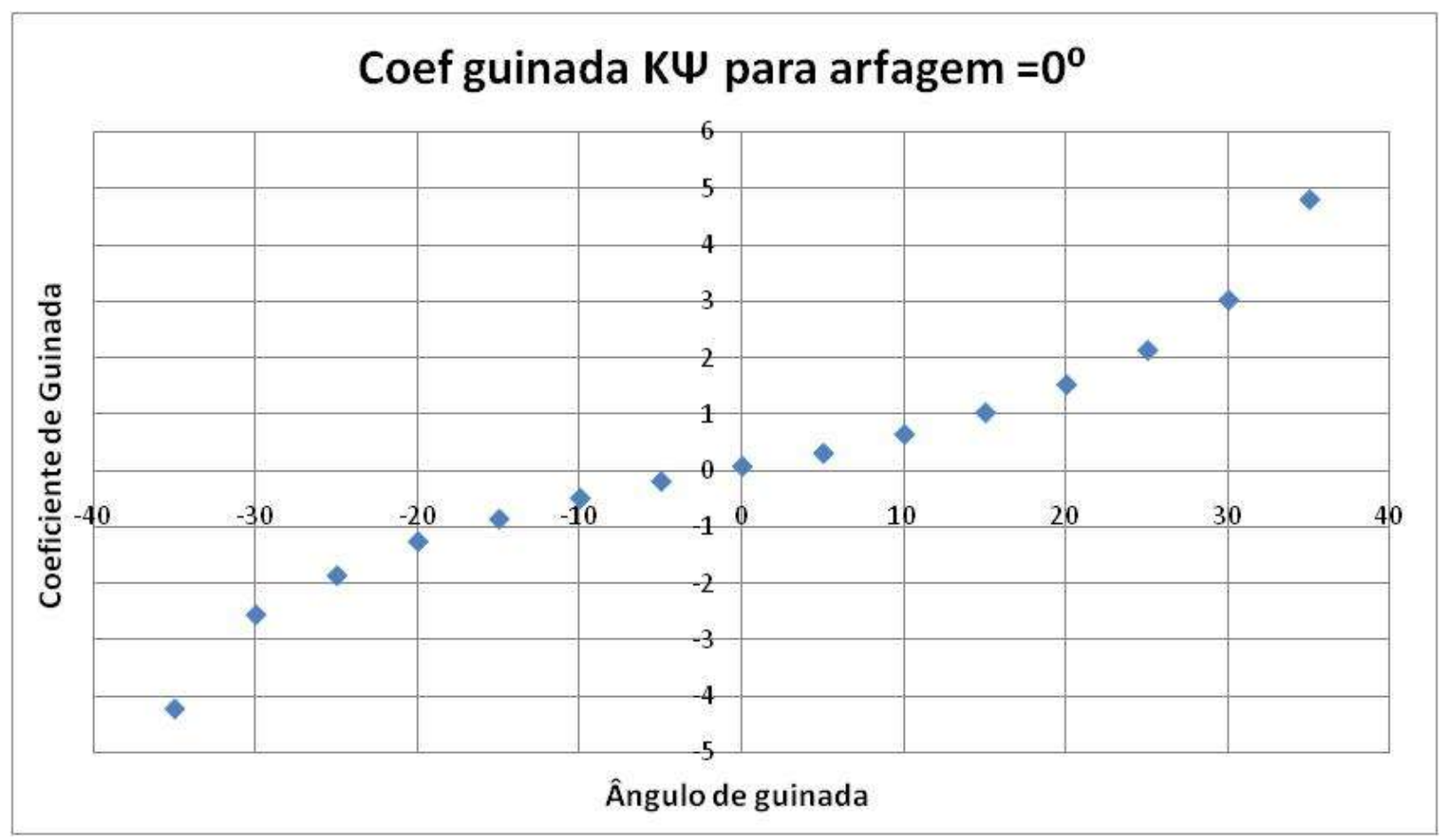

Figura 73 - Ensaio de calibração da sonda tipo pirâmide. $V=10,11 \mathrm{~m} / \mathrm{s}$. Coeficiente de guinada definido com o denominador $\sqrt{\bar{p}^{2}}$ e faixa de ângulos de -35 a +35 graus. 
Verifica-se através destes resultados que o uso desta definição de coeficiente de guinada $K_{\psi}=\frac{p 2-p 3}{\sqrt{\bar{p}^{2}}}$ com $\bar{p}=\frac{p 1+p 2+p 3+p 4+p 5}{5}$ estende a faixa de medição de ângulos para a região entre $-35^{\circ} \mathrm{e}+35^{\circ}$, ou seja, uma amplitude de $70^{\circ}$.

Com esta definição de coeficientes, verifica-se a simetria em torno do zero grau, já que o uso do denominador $\sqrt{\bar{p}^{2}}$ faz com que os coeficientes mudem de sinal apenas quando as relações de pressão no numerador do coeficiente também mudem de sinal, já que o denominador da expressão $\sqrt{\bar{p}^{2}}$ será sempre maior ou igual a zero.

A seguir é representado o resultado da mesma análise para os ângulos de arfagem definidos desta nova forma.

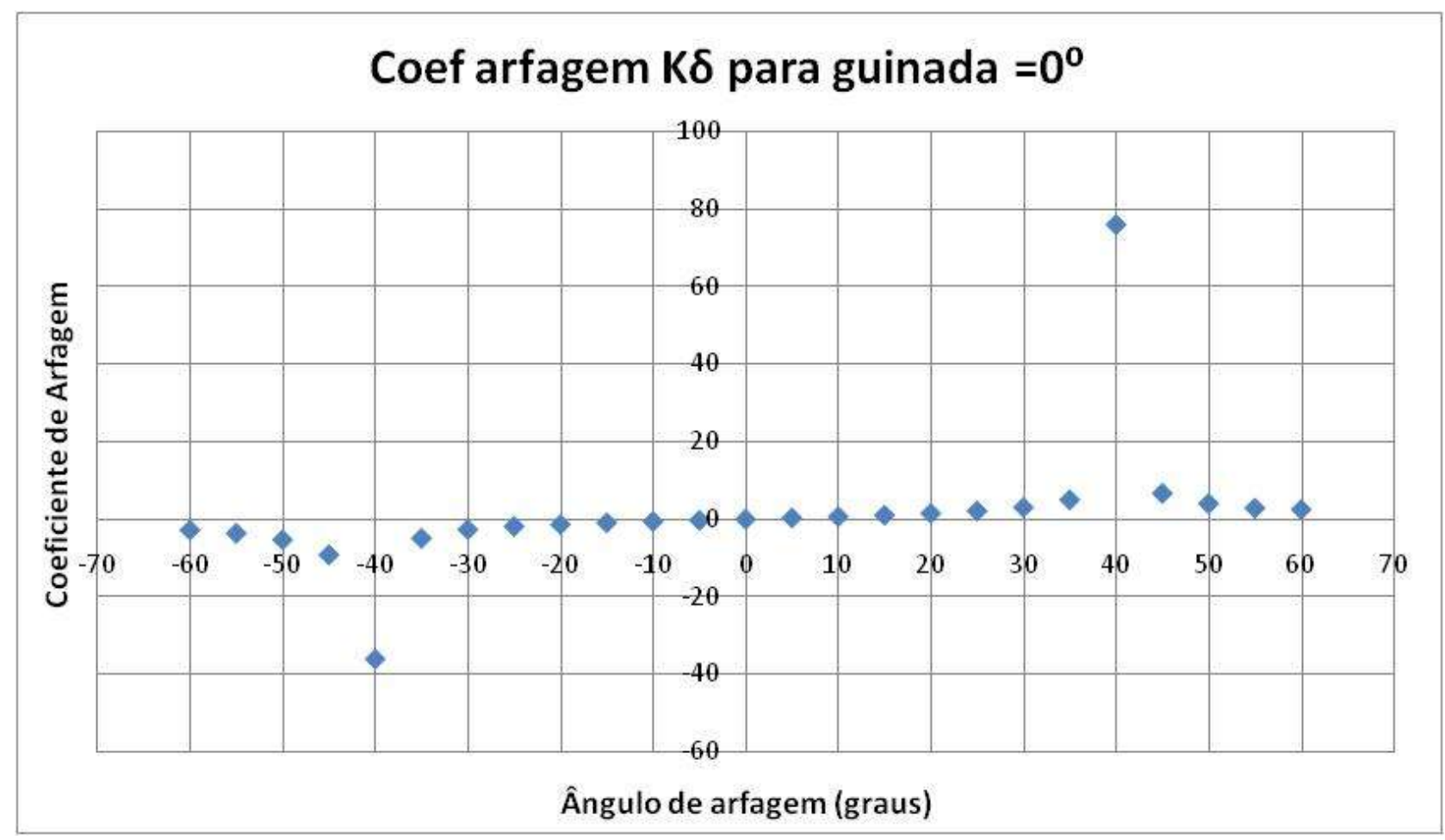

Figura 74 - Ensaio de calibração da sonda tipo pirâmide. V=10,03 m/s. Coeficiente de arfagem definido com o denominador $\sqrt{\bar{p}^{2}}$. 


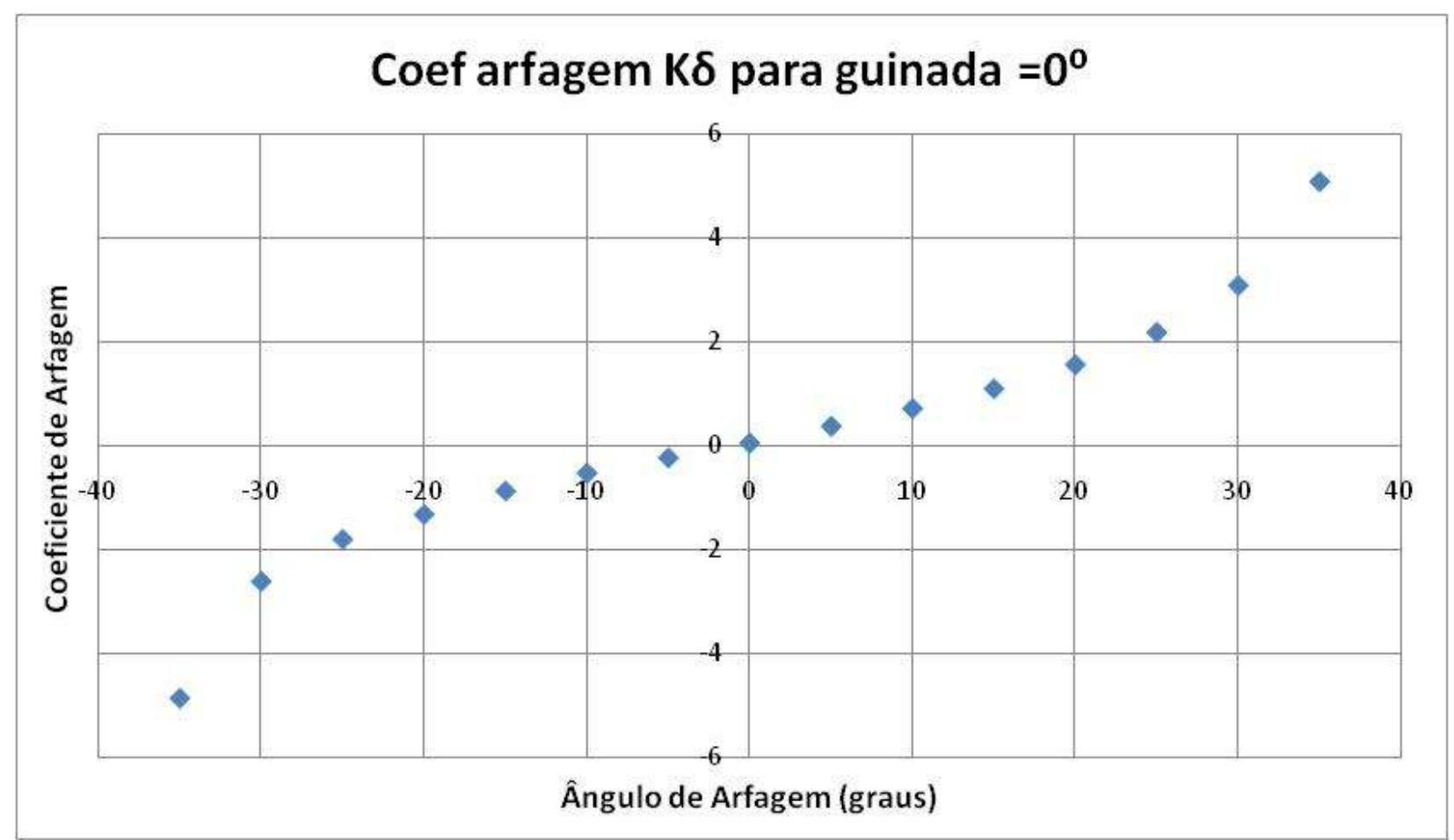

Figura 75 - Ensaio de calibração da sonda tipo pirâmide. $V=10,03 \mathrm{~m} / \mathrm{s}$. Coeficiente de arfagem definido com o denominador $\sqrt{\bar{p}^{2}}$ e faixa de ângulos de -35 a +35 graus.

Por este resultado também se verifica uma faixa de medições entre $-35^{\circ}$ e $+35^{\circ}$ para o ângulo de arfagem, definido o novo coeficiente de arfagem como

$$
K_{\delta}=\frac{p 4-p 5}{\sqrt{\bar{p}^{2}}} \operatorname{com} \bar{p}=\frac{p 1+p 2+p 3+p 4+p 5}{5} .
$$

Desta maneira, definiram-se para este trabalho os coeficientes de guinada e arfagem como:

$K_{\psi}=\frac{p 2-p 3}{\sqrt{\bar{p}^{2}}}$ e $K_{\delta}=\frac{p 4-p 5}{\sqrt{\bar{p}^{2}}} \operatorname{com} \bar{p}=\frac{p 1+p 2+p 3+p 4+p 5}{5}$.

Uma vez definidos os coeficientes a serem utilizados, prossegue-se à análise dos resultados obtidos para a sonda tipo pirâmide.

As figuras abaixo representam as variações dos coeficientes de arfagem e guinada quando a sonda é ensaiada variando os ângulos de guinada e arfagem na mesma proporção. 


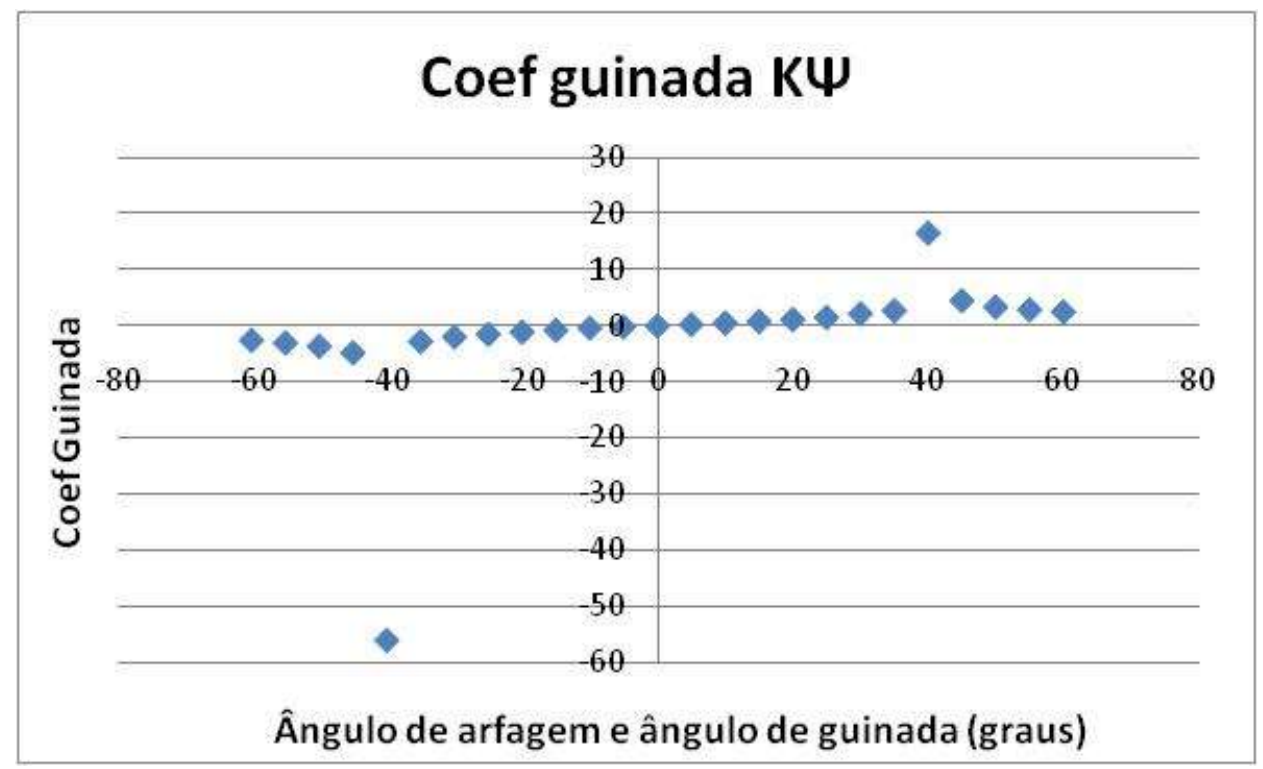

Figura 76 - Ensaio de calibração da sonda tipo pirâmide. $V=10,03 \mathrm{~m} / \mathrm{s}$. Variação dos ângulos de guinada e arfagem na mesma proporção.

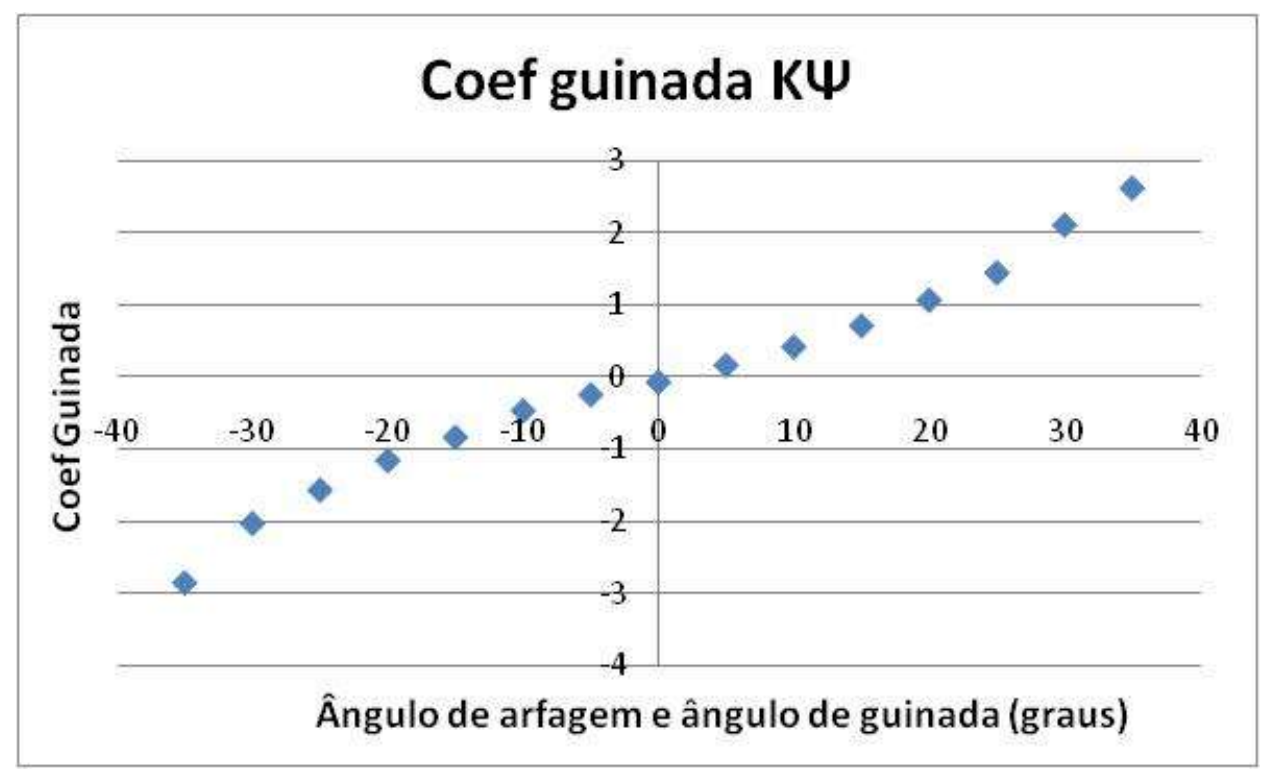

Figura 77 - Ensaio de calibração da sonda tipo pirâmide. V=10,03 m/s. Variação dos ângulos de guinada e arfagem na mesma proporção. Faixa de ângulos entre $-35^{\circ} \mathrm{e}+35^{\circ}$. 


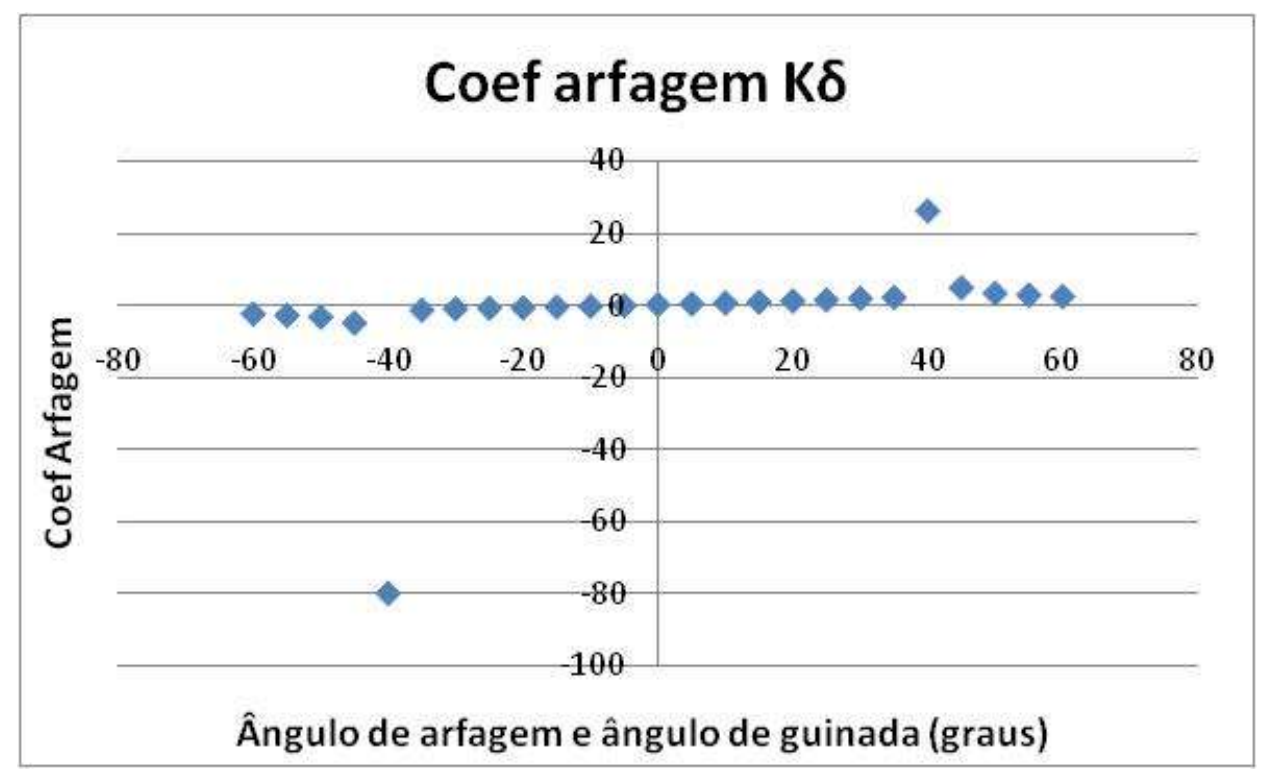

Figura 78 - Ensaio de calibração da sonda tipo pirâmide. V=10,03 m/s. Variação dos ângulos de guinada e arfagem na mesma proporção.

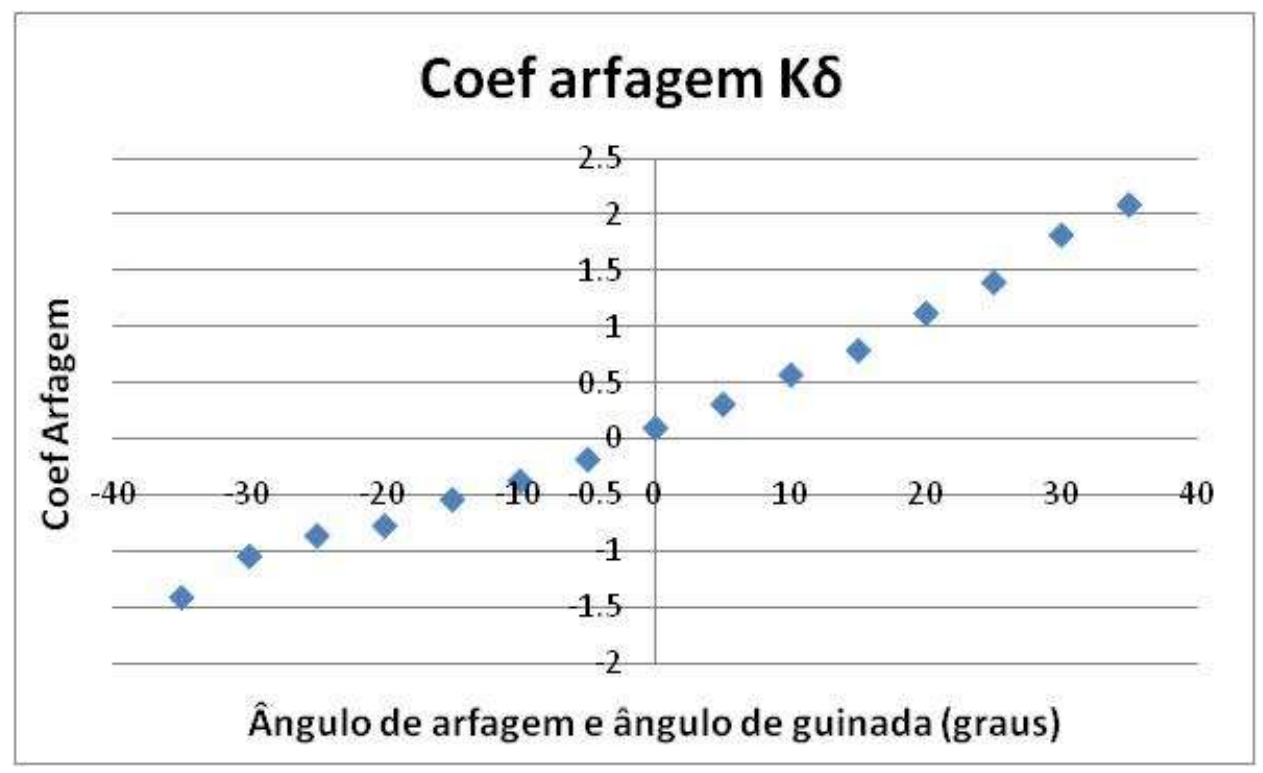

Figura 79 - Ensaio de calibração da sonda tipo pirâmide. $V=10,03 \mathrm{~m} / \mathrm{s}$. Variação dos ângulos de guinada e arfagem na mesma proporção. Faixa de ângulos entre $-35^{\circ} \mathrm{e}+35^{\circ}$.

Como pode ser verificado tanto para o caso do coeficiente de arfagem quanto para o coeficiente de guinada, o comportamento dos coeficientes muda nos ângulos $-40^{\circ}$ e $+40^{\circ}$. Verifica-se que a faixa de ângulos que a sonda é capaz de medir situa-se entre $-35^{\circ}$ e $+35^{\circ}$. No caso anterior, isto também foi evidenciado quando a sonda é 
submetida a um escoamento que forma ângulos de guinada e arfagem variando na mesma proporção, ou seja, na condição $(\psi, \delta)=(\theta, \theta) \operatorname{com} \theta$ variando entre $-60^{\circ} \mathrm{e}+60^{\circ}$.

Desta forma, conclui-se que a faixa de medições para a sonda pirâmide ensaiada é de $-35^{\circ} \mathrm{a}+35^{\circ}$ com o eixo da sonda, tanto para guinada quanto para arfagem.

A definição dos coeficientes de pressão total e pressão estática da sonda pirâmide foi feita de maneira análoga àquela feita para a sonda tipo prisma. Inicialmente, tomou-se como referência a definição de coeficientes adotada pelas referências NASA TM 102200 (ZILLIAC, 1989) e Treaster (TREASTER, et al., 1978). Segundo estas referências, os coeficientes de pressão total e pressão estática são descritos como:

$$
K_{\text {total }}=\frac{p 1-p_{\text {total }}}{p 1-\bar{p}} \text { e } K_{\text {estatica }}=\frac{\bar{p}-p_{\text {estatica }}}{p 1-\bar{p}}
$$

com $\bar{p}=\frac{p 2+p 3+p 4+p 5}{4}$

Esta definição de coeficiente gera as curvas representadas a seguir, tomando-se como exemplo os casos de ângulo de arfagem igual a zero e ângulo de guinada igual a zero. 


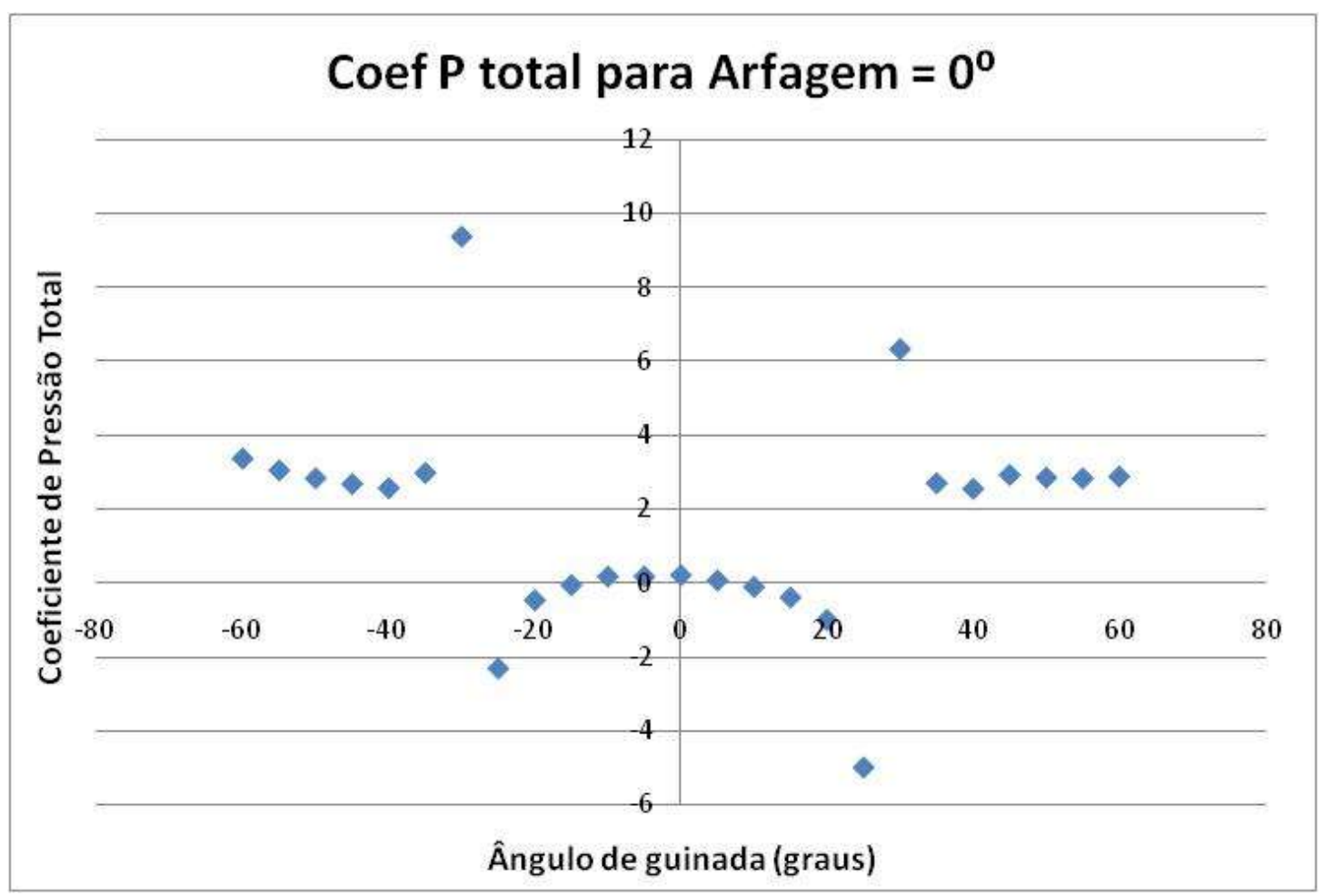

Figura 80 - Ensaio de calibração da sonda tipo pirâmide. $V=10,03 \mathrm{~m} / \mathrm{s}$. Coeficiente de pressão total definido conforme Treaster (TREASTER, et al., 1978) e Zilliac (ZILLIAC, 1989).

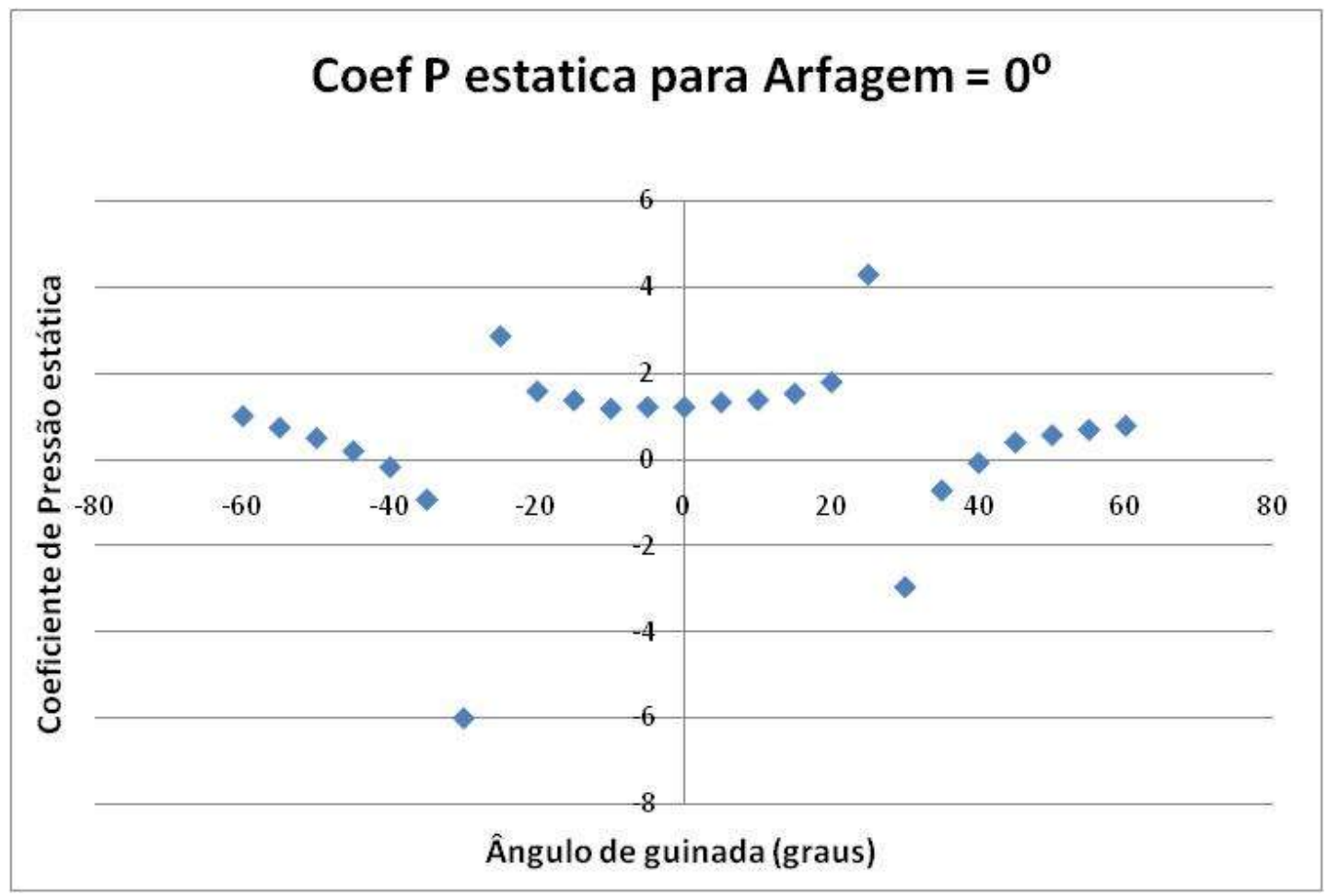

Figura 81 - Ensaio de calibração da sonda tipo pirâmide. V=10,03 m/s. Coeficiente de pressão estática definido conforme Treaster (TREASTER, et al., 1978) e Zilliac (ZILLIAC, 1989). 
Pelas curvas apresentadas segundo os coeficientes definidos por Treaster e Zilliac, percebe-se que o coeficiente muda bruscamente de valor nos ângulos de $-30^{\circ} \mathrm{e}$ $+30^{\circ}$. Outra particularidade é o fato de os coeficientes de pressão apresentarem uma característica de que um valor de coeficiente poder representar dois ângulos de guinada ou arfagem. Isto não é problema, uma vez que é o ângulo detectado pelas sondas que determinará o coeficiente de pressão, e não o contrário. Para a definição de coeficientes segundo Treaster e Zilliac, a faixa de ângulos em que se pode determinar a pressão estática e total através dos coeficientes fica entre $-25^{\circ} \mathrm{e}+25^{\circ}$.

Os gráficos a seguir mostram o comportamento destes coeficientes para o caso de variação do ângulo de guinada e ângulo de arfagem mantido constante e igual a $0^{\circ}$.

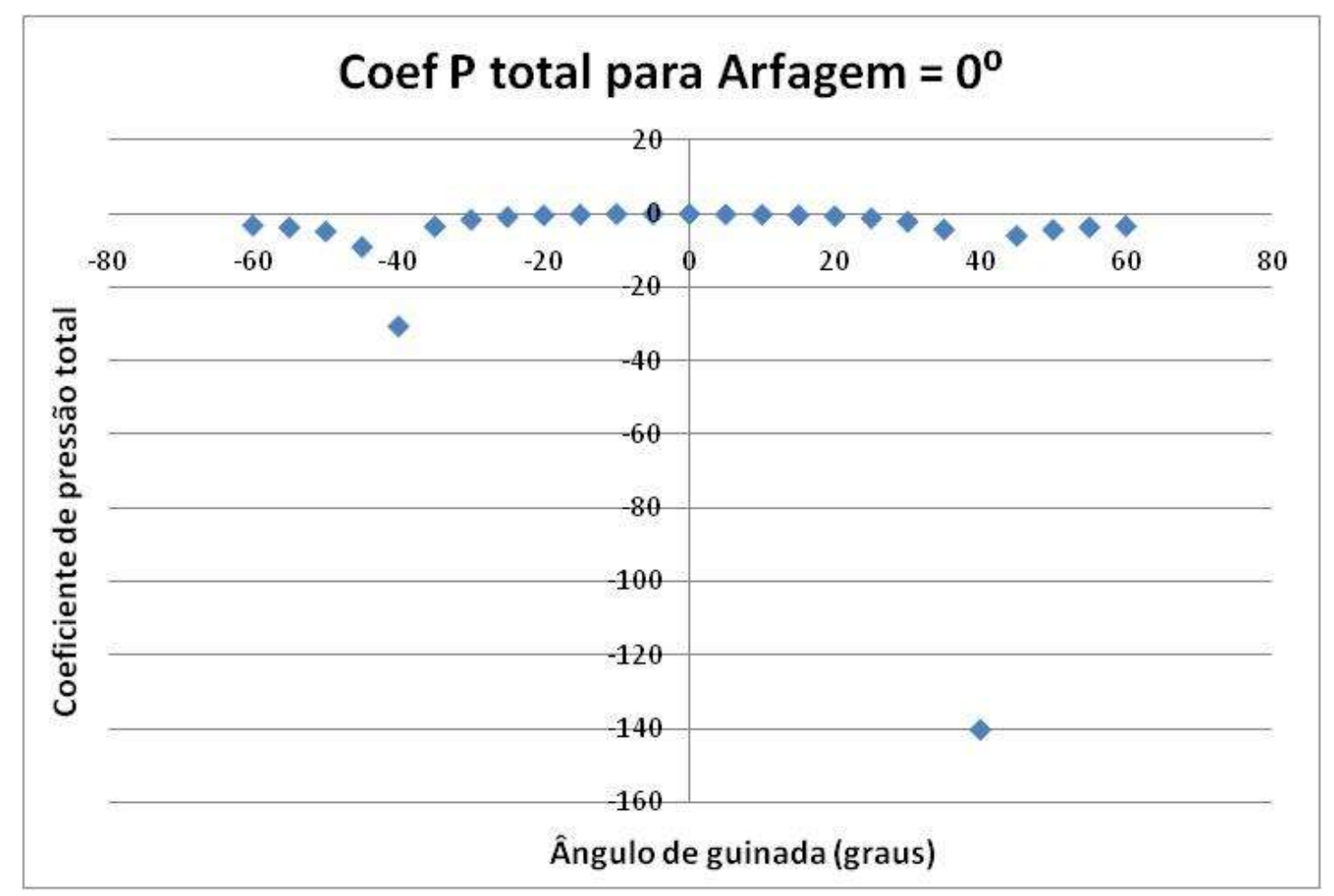

Figura 82 - Ensaio de calibração da sonda tipo pirâmide. $\mathrm{V}=10,03 \mathrm{~m} / \mathrm{s}$. Coeficiente de pressão total definido com o denominador $\sqrt{\bar{p}^{2}}$. 


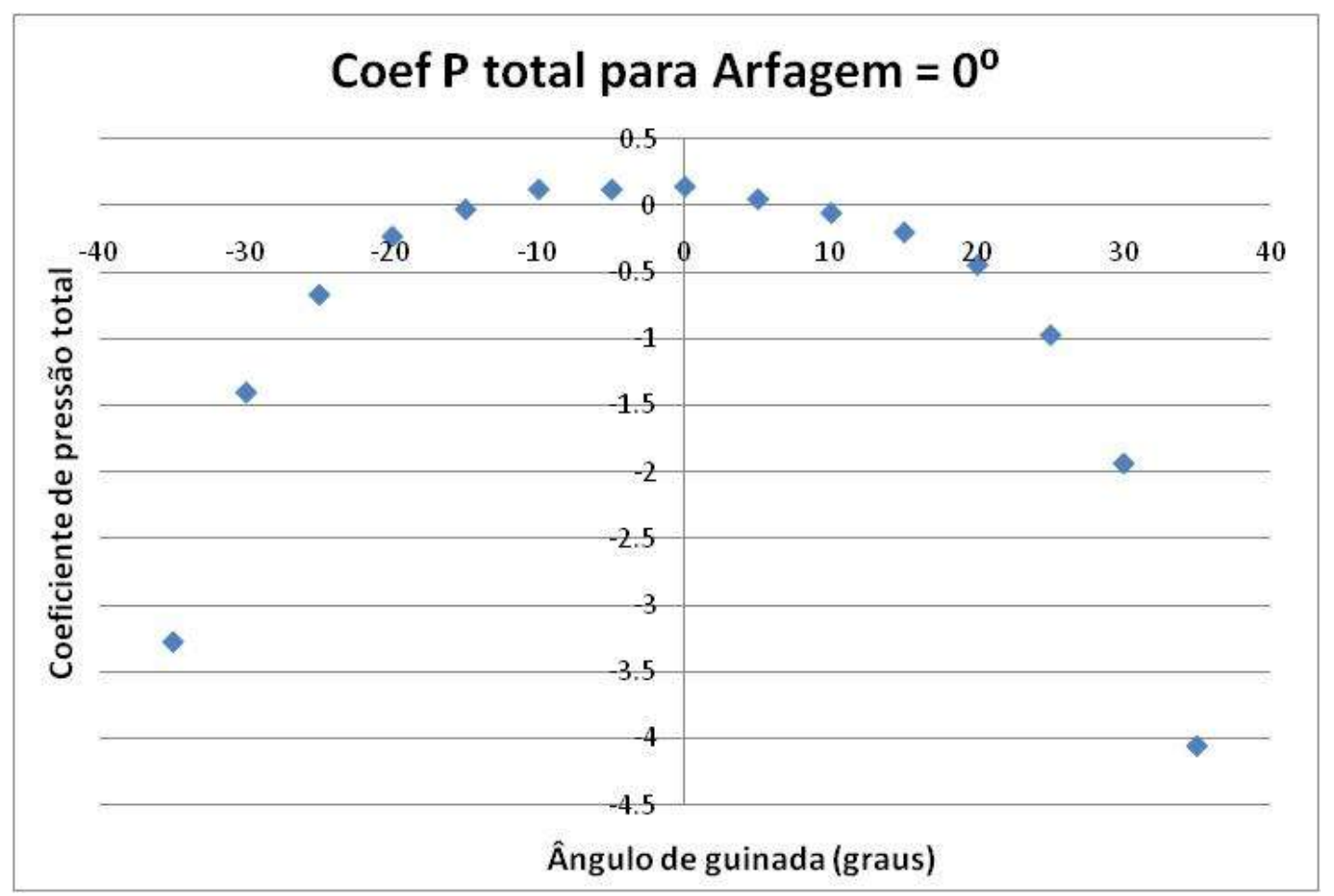

Figura 83 - Ensaio de calibração da sonda tipo pirâmide. V=10,03 m/s. Coeficiente de pressão total definido com o denominador $\sqrt{\bar{p}^{2}}$, faixa de ângulos entre $-35^{\circ} \mathrm{e}+35^{\circ}$.

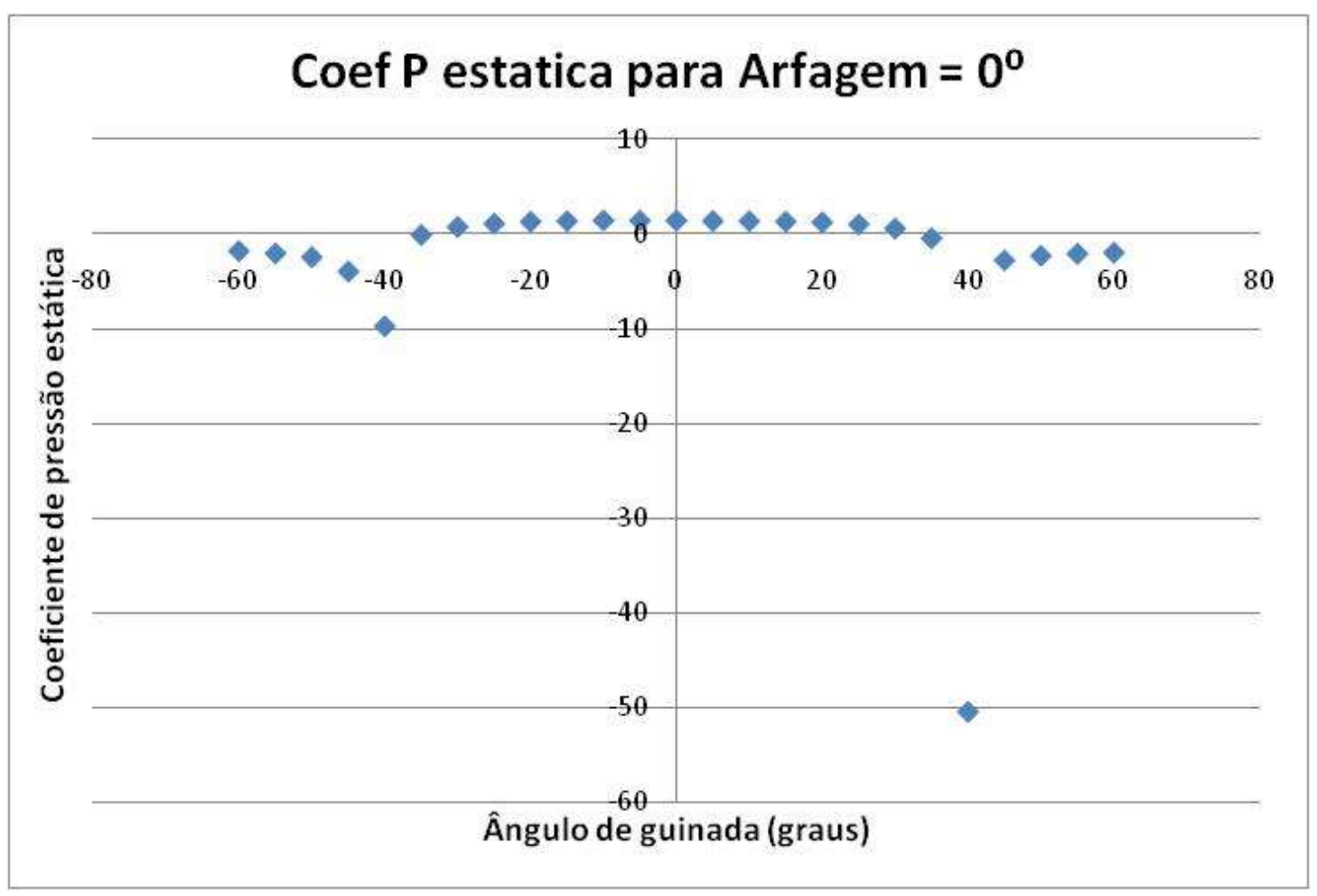

Figura 84 - Ensaio de calibração da sonda tipo pirâmide. $V=10,03 \mathrm{~m} / \mathrm{s}$. Coeficiente de pressão estática definido com o denominador $\sqrt{\bar{p}^{2}}$ 


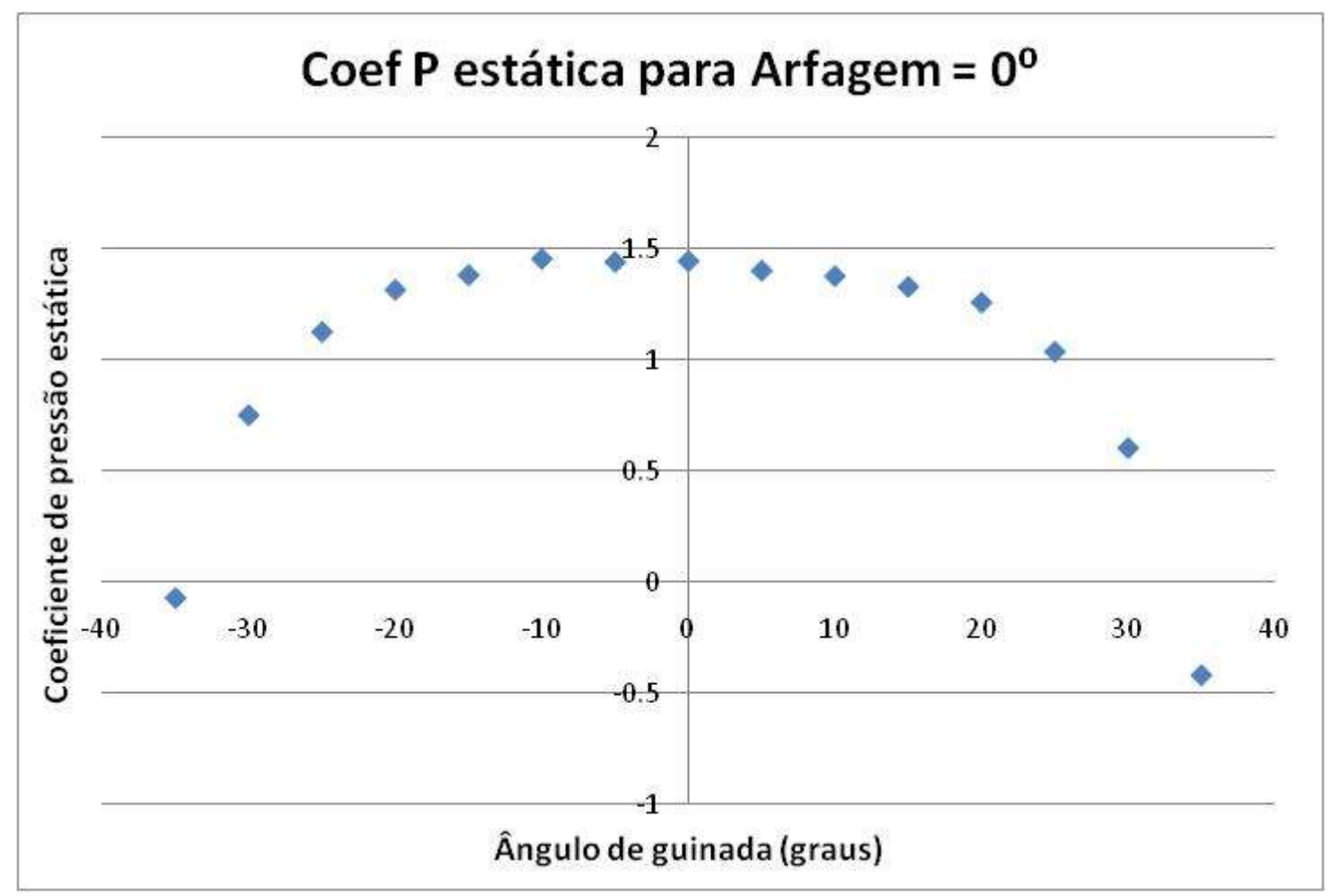

Figura 85 - Ensaio de calibração da sonda tipo pirâmide. $V=10,03 \mathrm{~m} / \mathrm{s}$. Coeficiente de pressão estática definido com o denominador $\sqrt{\bar{p}^{2}}$, faixa de ângulos entre $-35^{\circ} \mathrm{e}+35^{\circ}$.

Observa-se que esta última definição de coeficientes de pressão total e pressão estática estendem a faixa de medições para aquela entre $-35^{\circ} \mathrm{e}+35^{\circ}$. Da mesma forma observada para os coeficientes definidos por Treaster e Zilliac, o coeficiente de pressão pode representar dois ângulos de guinada. No entanto, isso não é problema, uma vez que a determinação da pressão se faz utilizando o gráfico com valores de ângulo de guinada e arfagem previamente determinados pelos coeficientes de guinada e arfagem.

Os gráficos a seguir representam a mesma análise de coeficientes para o caso em que se varia o ângulo de arfagem e o ângulo de guinada é mantido constante e igual a $0^{\circ}$. 


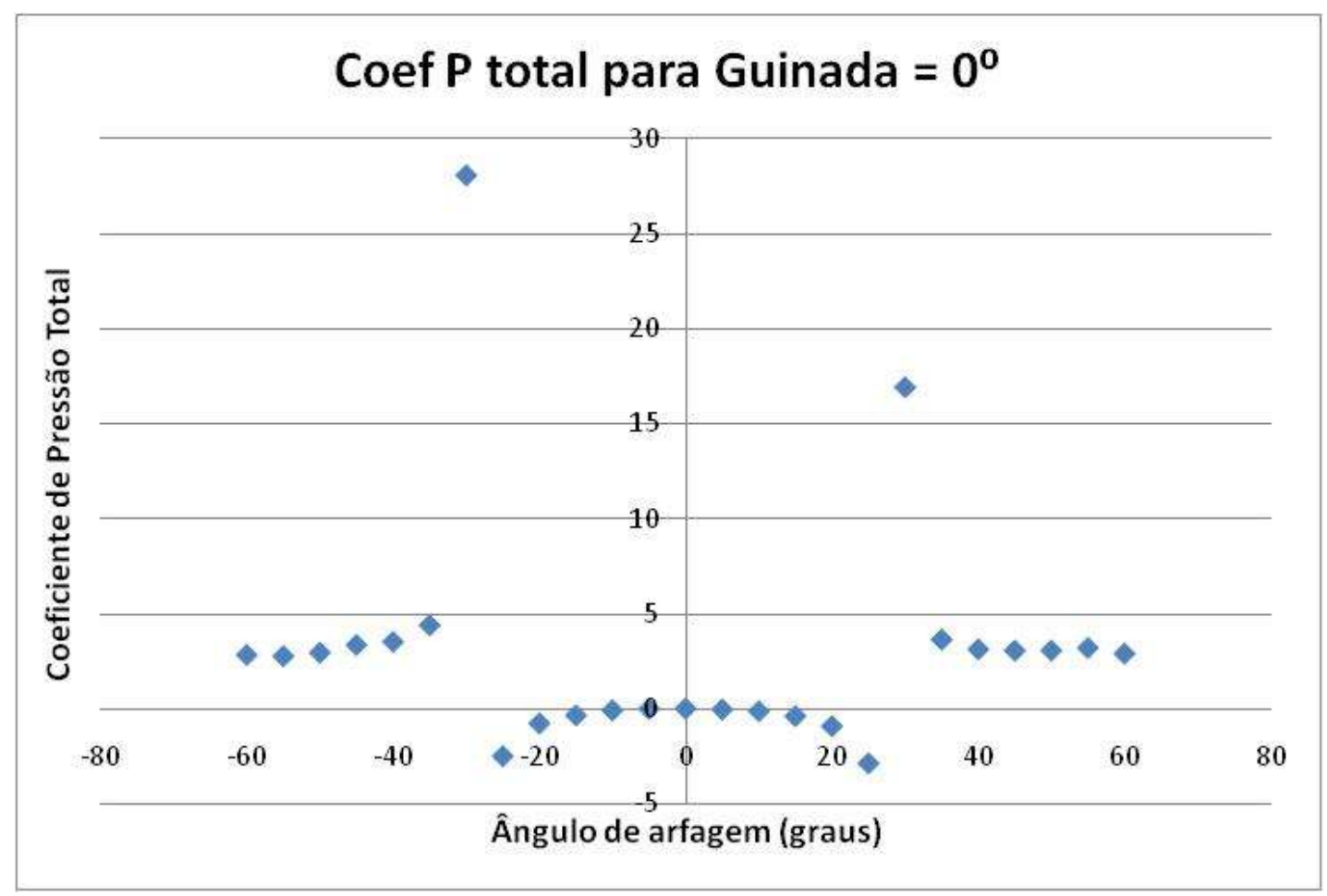

Figura 86 - Ensaio de calibração da sonda tipo pirâmide. $V=10,03 \mathrm{~m} / \mathrm{s}$. Coeficiente de pressão total definido conforme Treaster (TREASTER, et al., 1978) e Zilliac (ZILLIAC, 1989).

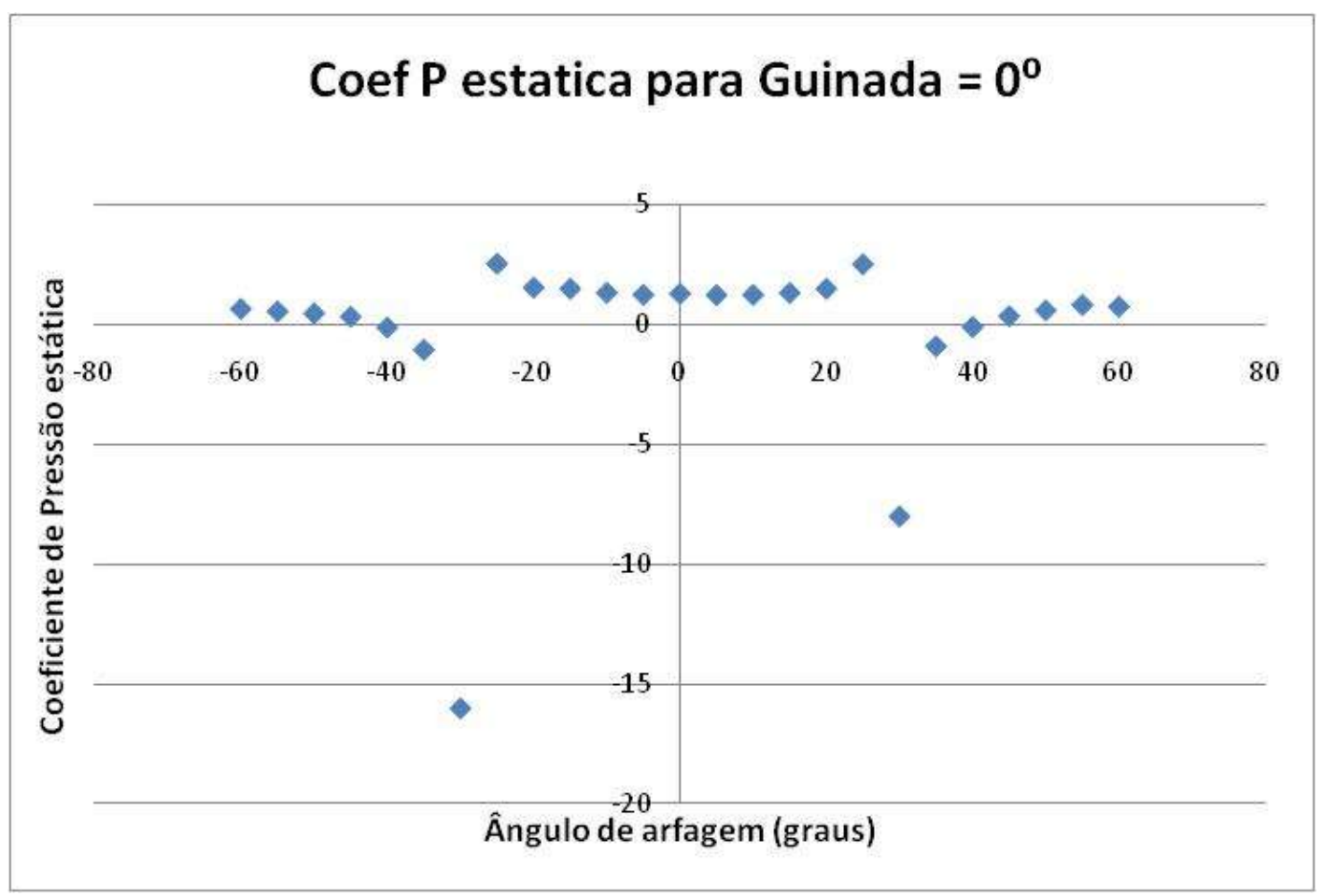

Figura 87 - Ensaio de calibração da sonda tipo pirâmide. $V=10,03 \mathrm{~m} / \mathrm{s}$. Coeficiente de pressão estática definido conforme Treaster (TREASTER, et al., 1978) e Zilliac (ZILLIAC, 1989). 
Conforme observado nos gráficos anteriores, com a definição dos coeficientes de pressão segundo Treaster e Zilliac, a faixa de ângulos que pode ser medida situa-se entre $-25^{\circ}$ e $+25^{\circ}$, uma vez que se observa uma brusca variação no valor dos coeficientes para os ângulos de $-30^{\circ} \mathrm{e}+30^{\circ}$.

Os gráficos a seguir apresentam a mesma análise para o caso dos coeficientes de pressão estática e pressão total definidos como:

$$
K_{\text {total }}=\frac{p 1-p_{\text {total }}}{\sqrt{\bar{p}^{2}}} \text { e } K_{\text {estatica }}=\frac{p 1-p_{\text {estatica }}}{\sqrt{\bar{p}^{2}}}
$$

Com $\bar{p}=\frac{p 1+p 2+p 3+p 4+p 5}{5}$.

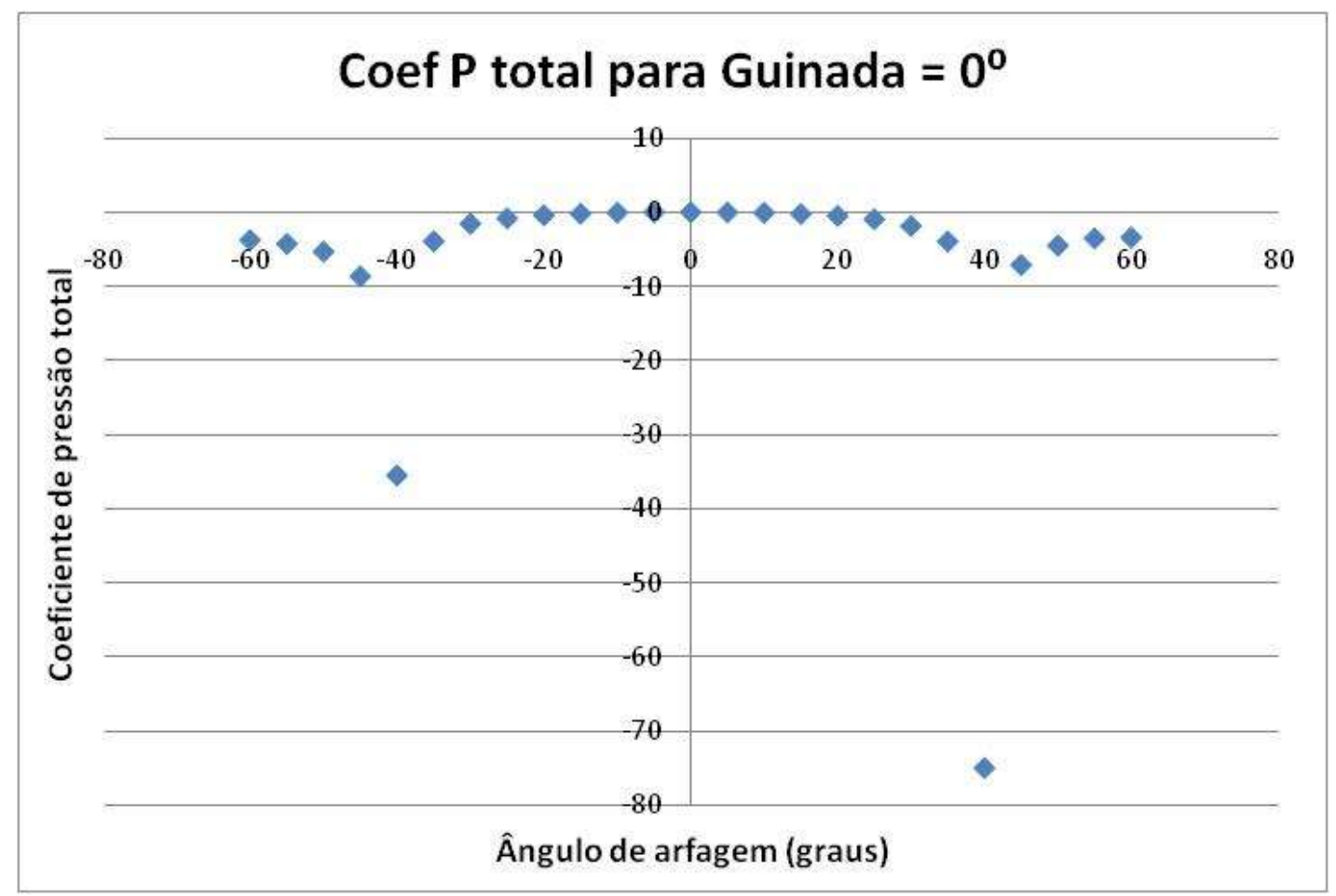

Figura 88 - Ensaio de calibração da sonda tipo pirâmide. $V=10,03 \mathrm{~m} / \mathrm{s}$. Coeficiente de pressão total definido com o denominador $\sqrt{\bar{p}^{2}}$ 


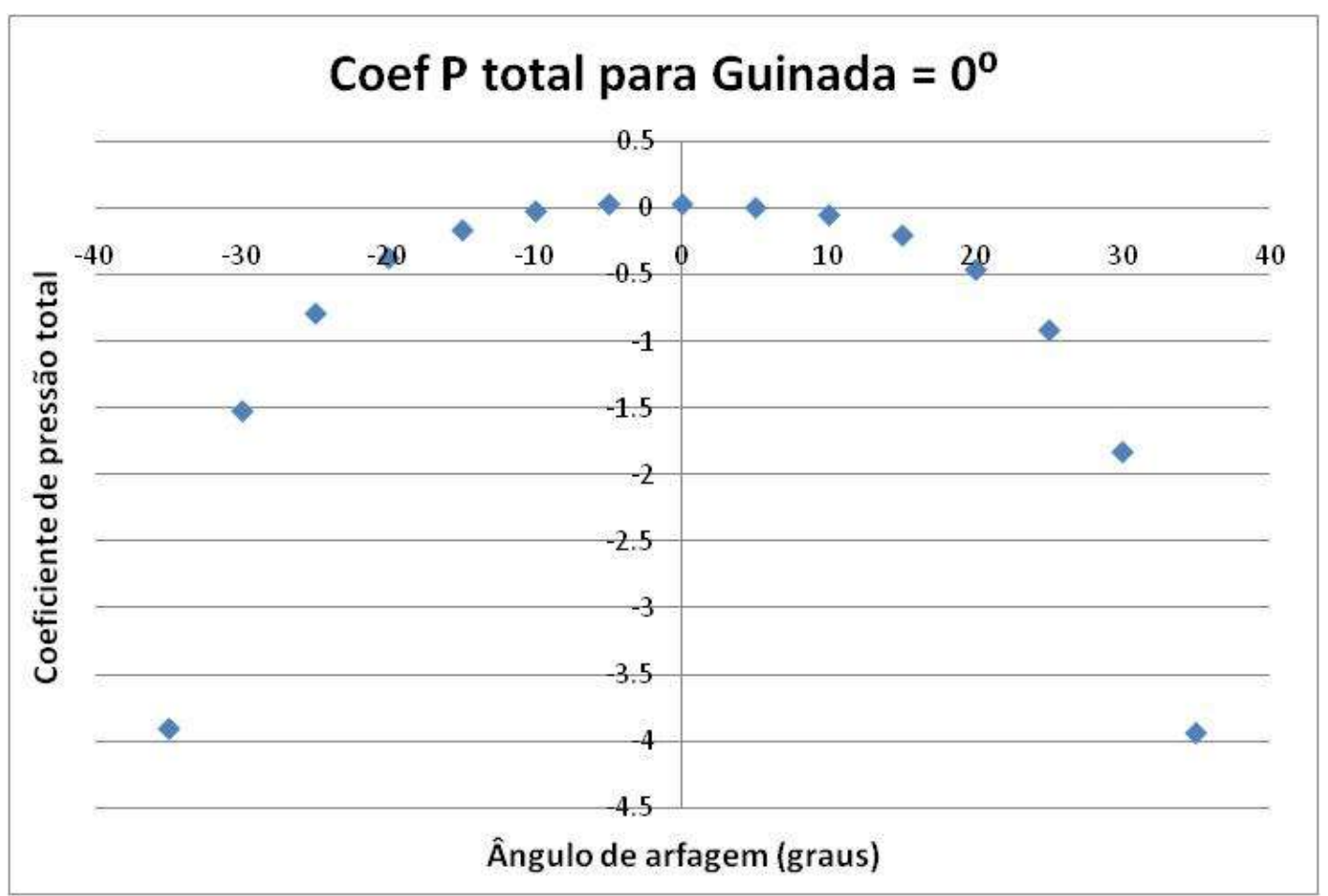

Figura 89 - Ensaio de calibração da sonda tipo pirâmide. $V=10,03 \mathrm{~m} / \mathrm{s}$. Coeficiente de pressão total definido com o denominador $\sqrt{\bar{p}^{2}}$, faixa de ângulos entre $-35^{\circ} \mathrm{e}+35^{\circ}$.

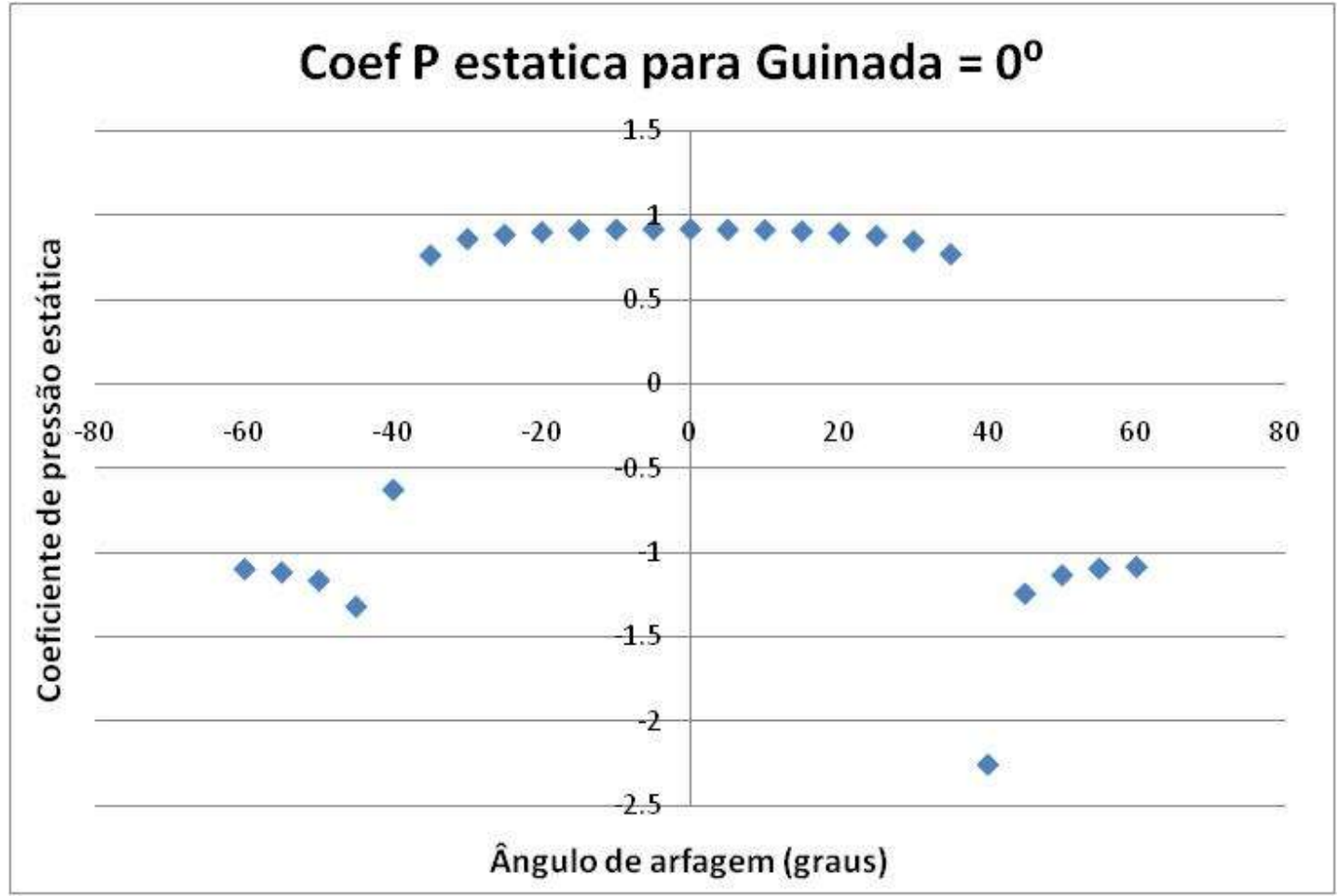

Figura 90 - Ensaio de calibração da sonda tipo pirâmide. V=10,03 m/s. Coeficiente de pressão estática definido com o denominador $\sqrt{\bar{p}^{2}}$ 


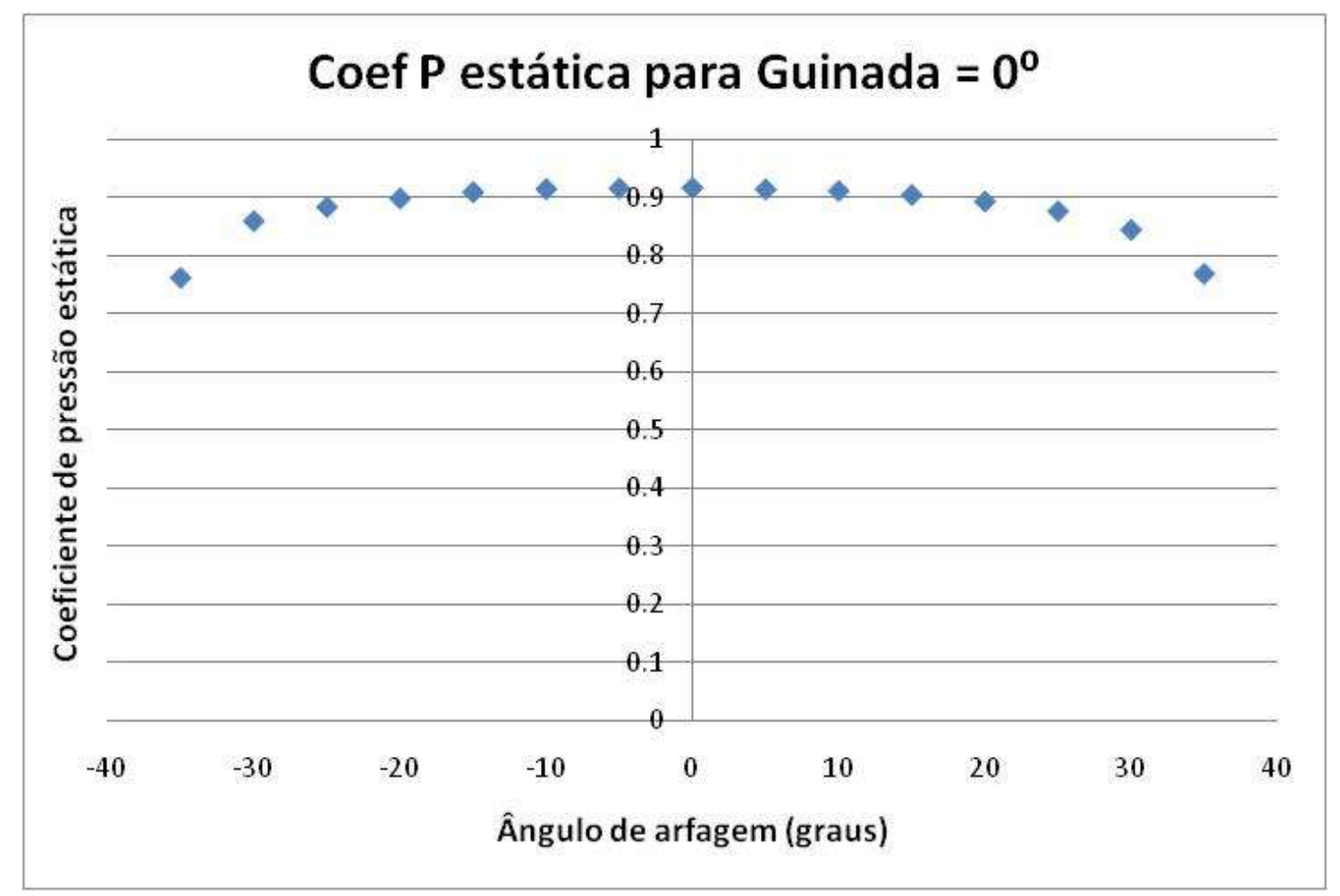

Figura 91 - Ensaio de calibração da sonda tipo pirâmide. $V=10,03 \mathrm{~m} / \mathrm{s}$. Coeficiente de pressão estática definido com o denominador $\sqrt{\bar{p}^{2}}$, faixa de ângulos entre $-35^{\circ} \mathrm{e}+35^{\circ}$.

Conforme observado nos gráficos das figuras 88 a 91, esta nova definição de coeficientes de pressão total e pressão estática, utilizando o denominador $\sqrt{\bar{p}^{2}}$, permitem a determinação dos coeficientes para uma faixa de ângulos entre $-35^{\circ} \mathrm{e}+35^{\circ}$.

Uma vez que todos os coeficientes estão definidos, assim como a faixa de medição de ângulos da sonda, os resultados para os coeficientes de guinada, arfagem, pressão estática e pressão total são representados nos gráficos das figuras 92 a 95, para todas as combinações de guinada e arfagem entre $-35^{\circ} \mathrm{e}+35^{\circ}$. 


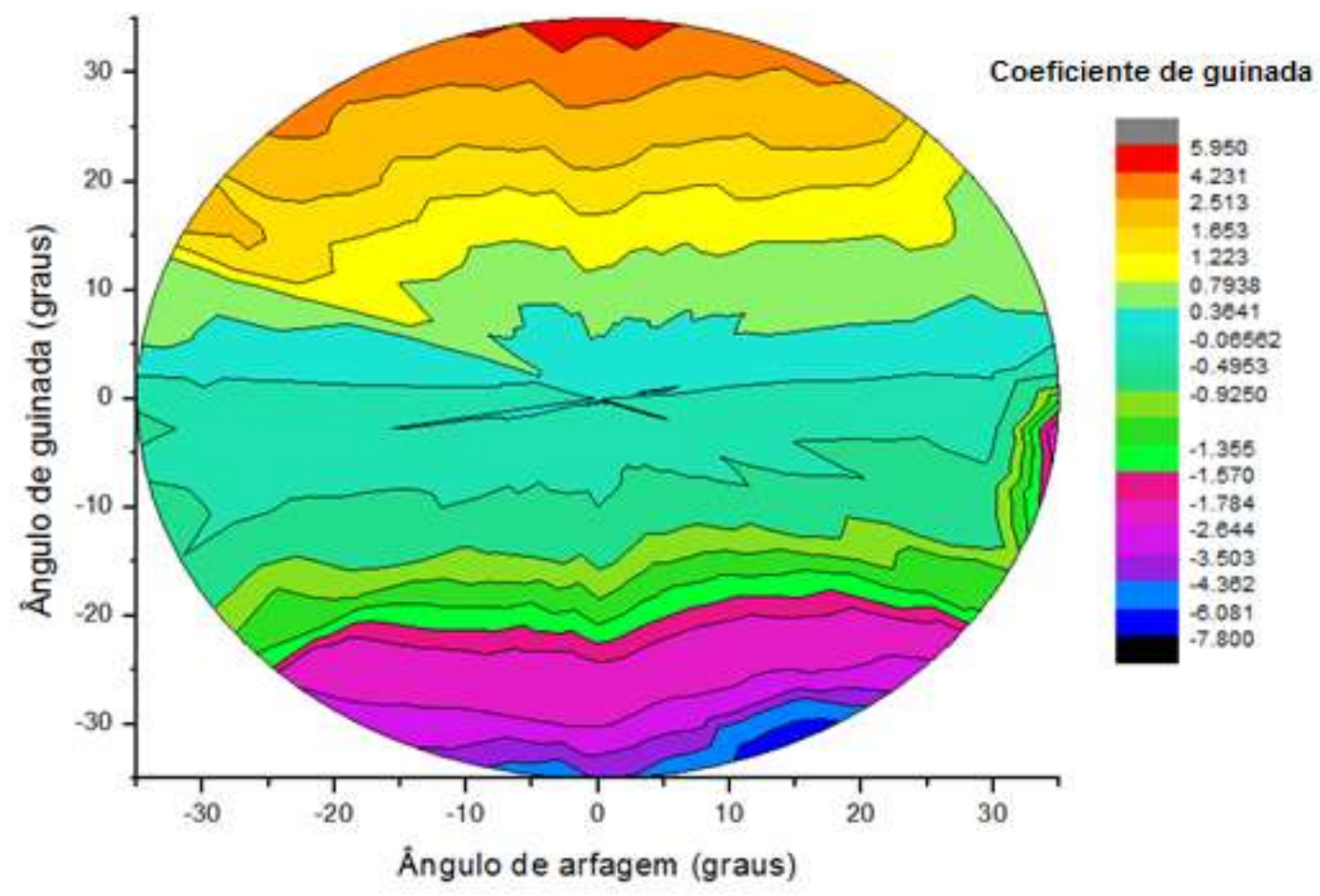

Figura 92 - Ensaio de calibração da sonda tipo pirâmide. Coeficiente de guinada em função dos ângulos de arfagem e guinada. 


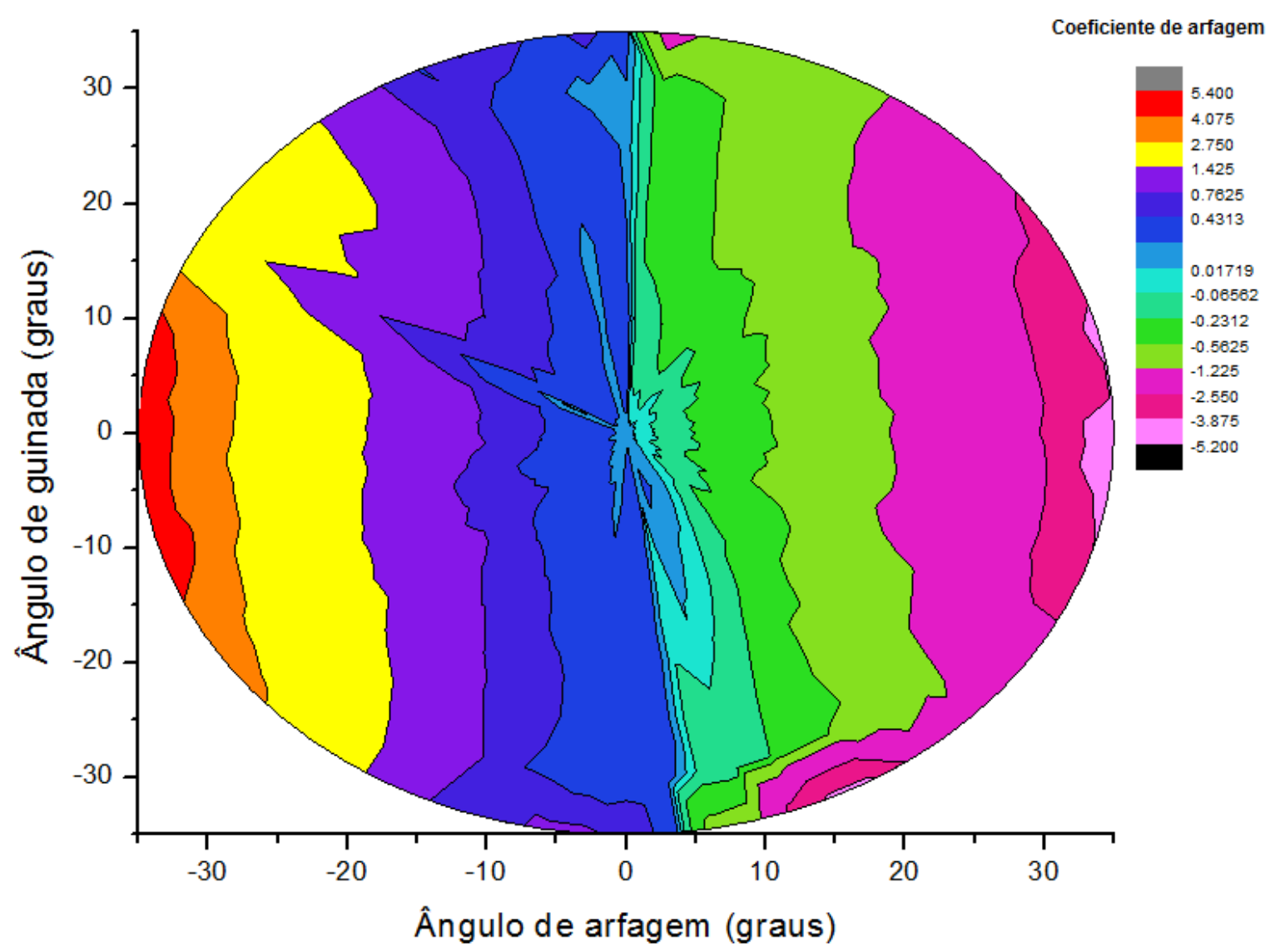

Figura 93 - Ensaio de calibração da sonda tipo pirâmide. Coeficiente de arfagem em função dos ângulos de arfagem e guinada. 


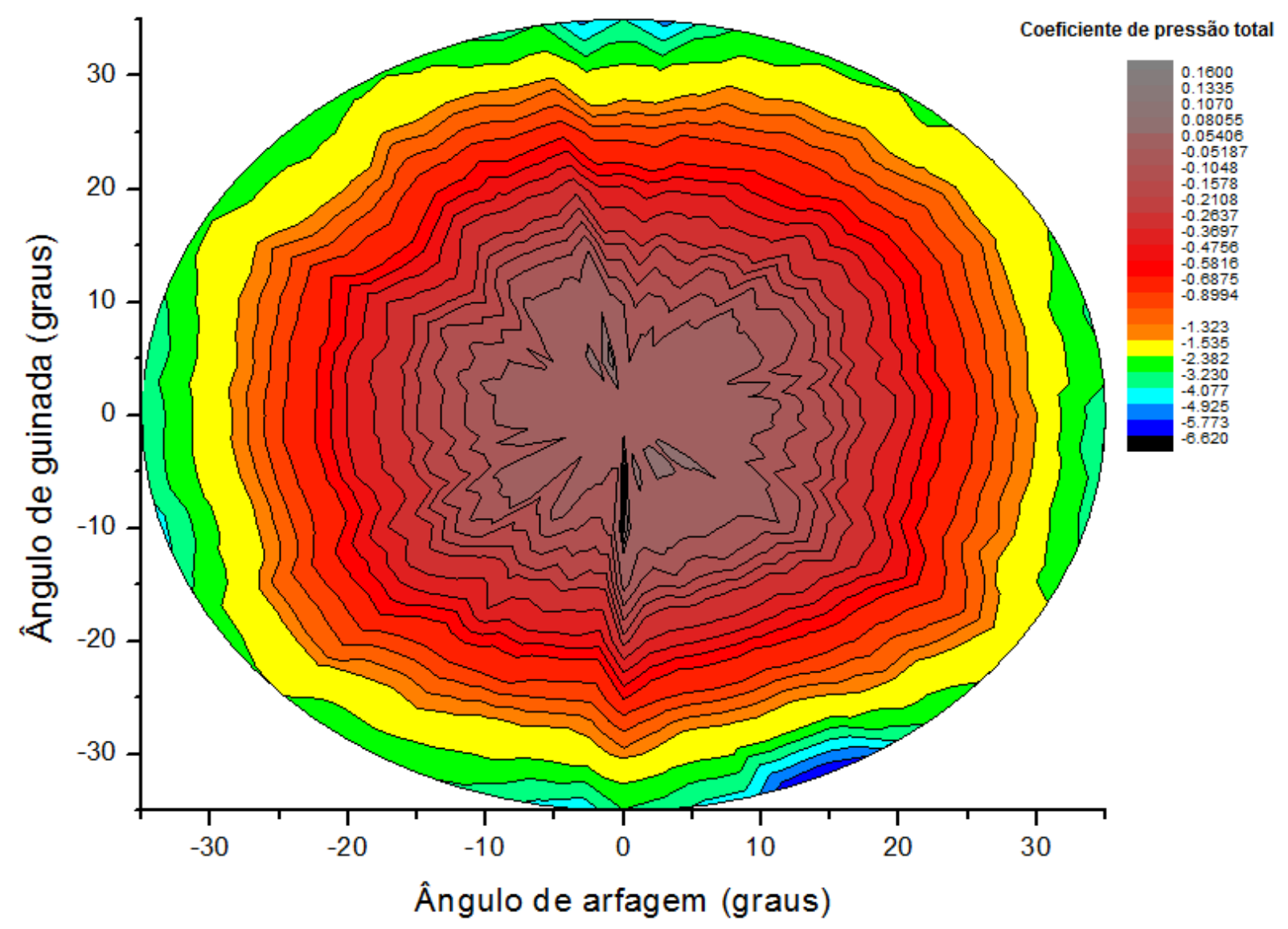

Figura 94 - Ensaio de calibração da sonda tipo pirâmide. Coeficiente de pressão total em função dos ângulos de arfagem e guinada. 


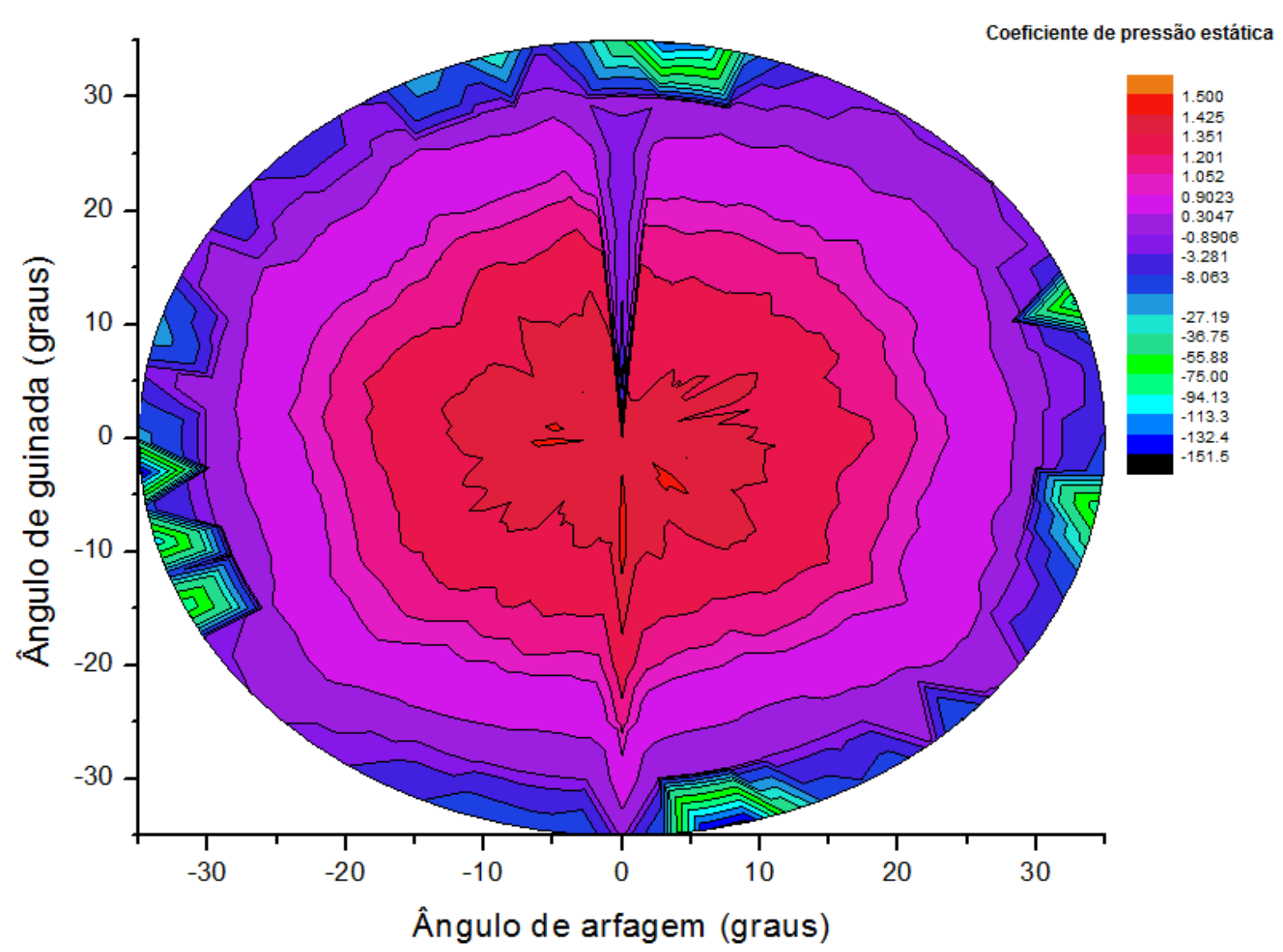

Figura 95 - Ensaio de calibração da sonda tipo pirâmide. Coeficiente de pressão estática em função dos ângulos de arfagem e guinada.

Do resultado destas medições, pode-se observar que o coeficiente de guinada é praticamente invariante com a variação do ângulo de arfagem e possui uma grande sensibilidade à variação do ângulo de guinada. Da mesma forma, observa-se que o coeficiente de arfagem possui uma relativa independência do ângulo de guinada enquanto varia sensivelmente conforme o ângulo de arfagem é variado.

Para os coeficientes de pressão total e pressão estática, observa-se uma simetria do valor do coeficiente em relação à posição de arfagem e guinada nulas. Isto se explica pela simetria da sonda e pelo fato de a determinação das pressões total e estática poder ser feita através de uma relação da pressão em questão com a média das pressões medidas pela sonda. Sendo assim, o coeficiente de pressão total se altera conforme a inclinação da sonda em relação ao escoamento é alterada. No entanto, não importa se esta inclinação possui uma componente maior no plano de 
arfagem ou no plano de guinada. No gráfico da figura 95, em que é representada a pressão estática, observa-se uma grande assimetria para os valores em torno do ângulo de arfagem zero grau. Isto é explicado por falha de posicionamento da sonda para este ângulo e deve-se esperar um comportamento simétrico deste coeficiente, de uma maneira semelhante ao observado para o coeficiente de pressão total, na figura 94.

\subsection{DETERMINAÇÃO DOS PARÂMETROS DE VELOCIDADE E DIREÇÃO DO ESCOAMENTO}

A partir dos resultados das medições e dos gráficos dos coeficientes para as sondas, pode-se determinar características do escoamento a partir de medições de pressão realizadas e com o uso dos gráficos de coeficientes para as sondas.

A seguir é apresentado um roteiro para a determinação de características do escoamento com cada uma das sondas, com exemplo numérico.

\subsubsection{Sonda Prisma}

a) Insere-se a sonda no escoamento que se deseja caracterizar e realizam-se as medições das três pressões nas tomadas p1, p2 e p3. Ex: p1=21 Pa , p2 $=9 \mathrm{~Pa}, \mathrm{p} 3=54 \mathrm{~Pa}$.

b) Com estes valores, calcula-se o coeficiente de arfagem do escoamento, dado

$$
\text { por: } K_{\delta}=\frac{p 2-p 3}{\sqrt{\bar{p}^{2}}} \quad \text { com } \quad \bar{p}=\frac{p 1+p 2+p 3}{3}
$$

Ex: $\mathrm{K} \delta=-1,6$

c) A partir do gráfico da figura 62, determina-se o ângulo de inclinação da sonda em relação vetor velocidade ao escoamento. Ex: $\delta=20^{\circ}$

d) Conhecendo-se o ângulo do vetor velocidade, determina-se o coeficiente de pressão total a partir da figura 66. Ex: $\mathrm{K}_{\text {total }}=0,5$ 
e) De posse do coeficiente de pressão total e das medições de pressão da sonda, calcula-se a pressão total do escoamento pela expressão:

$$
K_{\text {total }}=\frac{p 2-p 3+p_{\text {total }}}{\sqrt{\bar{p}^{2}}} \operatorname{com} \bar{p}=\frac{p 1+p 2+p 3}{3}
$$

Ex: Ptotal $=59 \mathrm{~Pa}$.

f) Analogamente, para a determinação da pressão estática, conhecendo-se o ângulo do vetor velocidade, determina-se o coeficiente de pressão estática a partir da figura 67. Ex: $\mathrm{K}_{\text {estatica }}=-1,5$.

g) De posse do coeficiente de pressão estática e das medições de pressão da sonda, calcula-se a pressão estática do escoamento pela expressão:

$$
K_{\text {estatica }}=\frac{p 2-p 3+p_{\text {estatica }}}{\sqrt{\bar{p}^{2}}} \text { com } \bar{p}=\frac{p 1+p 2+p 3}{3}
$$

Ex: $P_{\text {estatica }}=3 \mathrm{~Pa}$.

h) A magnitude do vetor velocidade do escoamento pode então ser determinada pela expressão: $V=\sqrt{\frac{2\left(P_{\text {total }}-P_{\text {estatica }}\right)}{\rho}}$ em que $\rho$ é a massa específica do ar. Ex: $V=10,1 \mathrm{~m} / \mathrm{s}$

\subsubsection{Sonda Pirâmide}

a) Insere-se a sonda no escoamento que se deseja caracterizar e realizam-se as medições das três pressões nas tomadas p1, p2, p3, p4 e p5. Ex: p1= 53 Pa, p2 $=45 \mathrm{~Pa}, \mathrm{p} 3=19 \mathrm{~Pa}, \mathrm{p} 4=41 \mathrm{~Pa}, \mathrm{p} 5=24 \mathrm{~Pa}$

b) Com estes valores, calculam-se os coeficientes de guinada e arfagem do escoamento. Dados por:

$$
K_{\psi}=\frac{p 2-p 3}{\sqrt{\bar{p}^{2}}} \text { e } K_{\delta}=\frac{p 4-p 5}{\sqrt{\bar{p}^{2}}} \operatorname{com} \bar{p}=\frac{p 1+p 2+p 3+p 4+p 5}{5}
$$

Ex: $\mathrm{K}_{\delta}=0,47$ e $\mathrm{K}_{\psi}=0,71$. 
c) A partir dos gráficos das figuras 92 e 93, determina-se o ângulo de inclinação da sonda em relação vetor velocidade ao escoamento, nas componentes guinada e arfagem. Ex: $\delta=-6,3^{\circ}$ e $\psi=13,6^{\circ}$

d) Conhecendo-se o ângulo do vetor velocidade, nas componentes de guinada e arfagem, determina-se o coeficiente de pressão total a partir da figura 94. Ex: $\mathrm{K}_{\text {total }}=-0,11$

e) De posse do coeficiente de pressão total e das medições de pressão da sonda, calcula-se a pressão total do escoamento pela expressão:

$$
K_{\text {total }}=\frac{p 1-p_{\text {total }}}{\sqrt{\bar{p}^{2}}} \operatorname{com} \bar{p}=\frac{p 1+p 2+p 3+p 4+p 5}{5} . \mathrm{Ex}: \mathrm{P}_{\text {total }}=57 \mathrm{~Pa} \text {. }
$$

f) Analogamente, para a determinação da pressão estática, conhecendo-se o ângulo do vetor velocidade, determina-se o coeficiente de pressão estática a partir da figura 95. Ex: $\mathrm{K}_{\text {estatica }}=1,37$.

g) De posse do coeficiente de pressão estática e das medições de pressão da sonda, calcula-se a pressão estática do escoamento pela expressão:

$$
K_{\text {estatica }}=\frac{p 1-p_{\text {estatica }}}{\sqrt{\bar{p}^{2}}} \operatorname{com} \bar{p}=\frac{p 1+p 2+p 3+p 4+p 5}{5}
$$

Ex: $\mathrm{P}_{\text {estatica }}=3 \mathrm{~Pa}$.

h) A magnitude do vetor velocidade do escoamento pode então ser determinada pela expressão: $V=\sqrt{\frac{2\left(P_{\text {total }}-P_{\text {estatica }}\right)}{\rho}}$ em que $\rho$ é a massa específica do ar. Ex: $V=10,1 \mathrm{~m} / \mathrm{s}$ 


\section{ANÁLISE DE RESULTADOS E CONCLUSÕES}

Para medições de propriedades de escoamentos em máquinas rotativas como ventiladores, compressores e turbinas, é importante utilizar sistemas de medições capazes de fornecer informações de magnitude e direção da velocidade do escoamento em seções de interesse. Este tipo de informação é necessária tanto para a fase de desenvolvimento de máquinas como para a parte de medição de desempenho da máquina e de suas partes integrantes, em particular o elemento rotor.

Este trabalho apresenta um estudo de alternativas de sensores capazes de realizar medições da magnitude da velocidade e direção desse vetor.

A primeira etapa foi estudar a literatura existente sobre sondas direcionais medidoras da velocidade do escoamento de fluidos. Foram encontradas muitas propostas de modelos de sondas. Elas apresentavam diferentes características construtivas, limitações distintas para suas aplicações e faixas de medição próprias.

Foram selecionados dois tipos de sondas, tipo prisma de 3 orifícios e tipo pirâmide de 5 orifícios em função de desejar-se medir escoamentos bidimensionais e tridimensionais.

Foi realizado o projeto detalhado destas sondas, determinando-se parâmetros construtivos como dimensionamento de diâmetro de orifícios e ângulos das faces das pontas de sonda, peças intermediárias, hastes e conexões. Para tanto, foram considerados os esforços na haste devido à força de arrasto.

A fabricação dos protótipos comparou dois processos distintos: a prototipagem rápida em plástico tipo $A B S$ e a usinagem de material metálico, sendo escolhido o latão. Após a realização de ensaios de validação verificando a estanqueidade dos canais transmissores de pressão destes protótipos, verificou-se a inadequação do protótipo fabricado em ABS pela porosidade do material.

A etapa seguinte de ensaios de protótipos em túnel de vento exigiu a busca de alternativas para um dispositivo de posicionamento dos sensores que permitisse a variação angular em dois graus de liberdade. Este dispositivo de posicionamento foi integrado a um cilindro de posicionamento vertical de forma que a sonda pudesse ser localizada na seção de testes do túnel de vento para uma ampla gama de ângulos. 
Foram realizados ensaios para a sonda tipo prisma adotando-se os seguintes parâmetros: velocidades do escoamento de $7,13 \mathrm{~m} / \mathrm{s}, 10,11 \mathrm{~m} / \mathrm{s}$ e $12,10 \mathrm{~m} / \mathrm{s}$; faixa de ângulos de arfagem de $-60^{\circ} \mathrm{a}+60^{\circ} \mathrm{com}$ incrementos de $5^{\circ}$. Dessa forma foram realizadas 75 medições para esta sonda.

Os valores para os coeficientes de arfagem, pressão total e pressão estática obtidos nestes ensaios foram calculados segundo três modelos distintos: aquele proposto por Treaster et al. (1978), Nowack (1970) e o novo modelo proposto neste trabalho.

A análise dos resultados obtidos com o uso dos coeficientes de arfagem, pressão estática e pressão total definidos por Treaster et al. (1978) determinou uma faixa de ângulos de arfagem entre $-10^{\circ} \mathrm{e}+15^{\circ}$ em que é possível estabelecer uma relação entre coeficientes e as respectivas grandezas. Já para o coeficiente determinado conforme Nowack (1970), essa região de correspondência entre coeficientes e ângulo de arfagem situou-se entre $-10^{\circ}$ e $+10^{\circ}$. Um terceiro conjunto de coeficientes foi proposto no trabalho e resultou na determinação de uma faixa de ângulos entre $-25^{\circ} \mathrm{e}+25^{\circ} \mathrm{em}$ que é possível determinar o ângulo de arfagem do vetor velocidade, a pressão estática e a pressão total do escoamento na linha de corrente de referência.

Os ensaios para a sonda tipo pirâmide adotaram como parâmetros a velocidade do escoamento de $10,04 \mathrm{~m} / \mathrm{s}$; faixa de ângulos de arfagem e guinada entre $-60^{\circ} \mathrm{e}+60^{\circ}$ com um total de 900 pontos de medição para esta sonda.

Os resultados dos coeficientes de arfagem, guinada, pressão total e pressão estática também foram calculados segundo três modelos distintos: aquele proposto por Treaster et al. (1978), Nowack (1969) e o novo modelo proposto neste trabalho.

A análise dos resultados obtidos com o uso dos coeficientes definidos por Treaster et al. (1978) resultou em uma faixa de ângulos de arfagem e guinada entre $25^{\circ} \mathrm{e}+25^{\circ} \mathrm{em}$ que os coeficientes de guinada, arfagem, pressão estática e pressão total podem ser relacionados com os ângulos de guinada e arfagem. Pela análise dos dados obtidos com o uso dos coeficientes definidos por Nowack (1969), a faixa de medição ficou situada entre $-40^{\circ} \mathrm{e}+10^{\circ}$ para a determinação do ângulo de arfagem e entre $-15^{\circ}$ e $+35^{\circ}$ para a determinação do ângulo de guinada do vetor velocidade. Estes resultados apresentaram grande dispersão e assimetria. Para o terceiro conjunto de 
coeficientes proposto neste trabalho, determinou-se uma faixa de ângulos de arfagem e guinada entre $-35^{\circ} \mathrm{e}+35^{\circ}$ em que se pode relacionar os coeficientes de arfagem, guinada, pressão total e pressão estática com os ângulos de arfagem e guinada do escoamento.

Dessa maneira, para a sonda tipo prisma é estabelecida a faixa de medições de ângulos entre $-25^{\circ} \mathrm{e}+25^{\circ} \mathrm{em}$ escoamentos bidimensionais e para a sonda tipo pirâmide, a faixa entre $-35^{\circ} \mathrm{e}+35^{\circ}$ em escoamentos tridimensionais.

Foram determinados parâmetros adimensionais usados para avaliação das sondas. Os resultados podem ser extrapolados para outros valores de velocidade do escoamento, uma vez que os coeficientes apresentados independem da velocidade.

Com estes dados, foi possível habilitar os protótipos de medidores fabricados para uso em medições de escoamento, uma vez que sua calibração foi realizada e suas faixas de operação foram determinadas.

Como recomendação para trabalhos futuros, sugere-se o desenvolvimento de outras geometrias de pontas de sondas para tentar ampliar as faixas de medições de ângulos e magnitude da velocidade de escoamento. Também pode ser investigada a aplicação das sondas em ambiente industrial e sua validação adotando-se outras metodologias. 


\section{REFERÊNCIAS BIBLIOGRÁFICAS}

ALLEN, C. M.; HOOPER, L. J. Piezometer Investigation, Transactions of the ASME, vol. 54, 11p., 1932.

AMCA standard 210-07: Laboratory Methods of Testing Fans for Certified Aerodynamic Performance Rating; 2007.

BLEIER, F. P.: Fan Handbook: selection, application and design; pp 4.19-4.21; McGrawHill; 1997.

BRYER, D. W.; PANKHURST, R. C.: Pressure-probe methods for determining Wind speed and flow direction; pp.31-40; National Physics Laboratory, The Campfield Press, St. Albans, UK; 1971.

COLE, E. S. The Pitot Tube in Current Practice, Civil Engr., vol.5, pp.220-222, 1935.

DARCY, H. Mémoires sur le mouvement de l'eau dans les tuyaux, Paris, Comptes Rendus, Académie des Sciences, vol. 38, p.407, 1854.

DARCY, H. Relative a quelques modifications à introduire dans le tube Pitot, Paris, Annales des Pontes et Chaussés, ser.3, 1st part, pp.351-359, 1858.

ENER - DEPARTMENT OF ENERGY AND PROCESS ENGINEERING OF TAMPERE UNIVERSITY OF TECHNOLOGY; Laser Doppler Anemometry; 2009.

Disponível em:

< http://www.tut.fi/units/me/ener/laitteistot/EFD/LDA.html\#The equipment at TUT/ENER>, acessado em 10 set. 2010.

FERREIRA, J.; PEREIRA, N.; JUNIOR, M.; SILVA, J.; BRITTO, R.; PARREIRA, V.; VASCONCELOS, F.; CRIOLLO, C.: Calibração e cálculo da incerteza para um medidor digital de pressões respiratórias, VII SEMETRO, 2009.

FOLSOM, R.G. Review of the Pitot Tube, Chicago, Fluid Meters Research Commitee, 1955.

GJESSING, D.T.; LANES, T.; TANGERUD, A.: A hot wire anemometer for the measurement of the three orthogonal components of wind velocity, and also directly the wind direction, employing no moving parts; J. Physics E: Sci. Instrum. 2 51-54; 1969.

HUBBARD, C. W. Investigation of Errors of Pitot Tubes, Transactions of the ASME, vol. 61, pp. 477-492, 1939.

INMETRO: Guia para expressão da incerteza de medição; ABNT, Rio de Janeiro, 1988. 
LI,Y.; OUYANG, H.; DU, Z. Experimental Research on Aerodynamic Performance and Exit Flow Field of Low Pressure Axial Flow Fan with Circumferential Skewed Blades, Journal of Hydrodynamics Ser. B, 2007, 19(5), pp. 579-586.

MARIANI, A. L. C:_Estudo experimental de escoamentos turbulentos em passagens curtas com sensores multífuros multidirecionais, São Paulo, 212 p. Tese (Doutorado). Escola Politécnica da Universidade de São Paulo. Departamento de Engenharia Mecânica. 2000.

MOODY, L. F. Measurement of the Velocity of Flowing Water, Proc. Engrs. Soc. West. Penn., vol. 30, pp.280-323, 1914.

NOWACK, C.: Improved calibration method for a five-hole spherical Pitot probe; Journal of Physics E : Scientific Instruments; 1970.

PITOT, H. Description d'une machine pour mesurer la vitesse des eaux courantes et le sillage des vaisseaux, Paris, Mémoires, Académie des Sciences, pp. 363-376, 1732.

SCHULZE, W.; ASHBY, G; ERWIN, J.: Several combination probes for surveying static and total pressure and flow direction; NACA TN 2830, Langley Aeronautical Laboratory, Langley Field, Va. Nov. 1952.

SHAW, R.: The influence of hole dimension on static pressure measurements; Journal of Fluid Mechanics; Cambridge; 1960.

TAVOULARIS, S.: Measurement in Fluid Mechanics; Cambridge, New York, 2005.

TREASTER, A; YOCUM, M.: The Calibration and Application of Five-Hole Probes; ISA Transactions; 1979.

WEISSTEIN, E. Cylinder Drag, Wolfram Research; 2006. Disponível em:

< http://scienceworld.wolfram.com/physics/CylinderDrag.html>, acessado em 15 set. 2010.

ZILLIAC, G. Calibration of Seven-Hole Pressure Probes for Use in Fluid Flows with Large Angularity, NASA TM 102200, 1989 


\section{APÊNDICE I}

\section{RESULTADOS DO ENSAIO DE VERIFICAÇÃO DA SONDA PRISMA}


a) Ensaios para $V=10,11 \mathrm{~m} / \mathrm{s}$

\begin{tabular}{|c|c|c|c|c|c|c|c|c|c|}
\hline $\begin{array}{l}\text { Ângulo de } \\
\text { arfagem } \delta \\
\text { (graus) }\end{array}$ & $\mathrm{p} 1(\mathrm{~Pa})$ & p2 (Pa) & p3 (Pa) & $\begin{array}{c}P \\
\text { estática } \\
(\mathrm{Pa})\end{array}$ & Ptotal (Pa) & $\begin{array}{c}\text { Temperatura } \\
\text { de Bulbo Seco } \\
\text { (jato) } \\
{ }^{\circ} \mathrm{C}\end{array}$ & $\begin{array}{c}\text { Temperatura de } \\
\text { Bulbo Úmido } \\
{ }^{\circ} \mathrm{C}\end{array}$ & Patm $(\mathrm{kPa})$ & $\begin{array}{c}\text { Massa } \\
\text { específica do } \\
\text { ar }(\mathrm{kg} / \mathrm{m} 3)\end{array}$ \\
\hline 0 & 60 & 31 & 31 & 3,109 & 58,661 & 24,6 & 20,6 & 93,039 & 1,078 \\
\hline 5 & 61 & 22 & 37 & 3,382 & 58,661 & 24,8 & 20,6 & 93,040 & 1,077 \\
\hline 10 & 54 & 15 & 45 & 3,518 & 58,661 & 25,0 & 20,7 & 93,041 & 1,077 \\
\hline 15 & 42 & 10 & 49 & 3,655 & 58,661 & 25,0 & 20,7 & 93,041 & 1,076 \\
\hline 20 & 21 & 9 & 54 & 3,792 & 58,661 & 25,2 & 20,7 & 93,042 & 1,076 \\
\hline 25 & -1 & 1 & 55 & 3,928 & 58,661 & 25,3 & 20,8 & 93,043 & 1,076 \\
\hline 30 & -19 & -51 & 60 & 4,065 & 58,661 & 25,4 & 20,8 & 93,044 & 1,075 \\
\hline 35 & -35 & -62 & 61 & 4,201 & 58,661 & 25,6 & 20,8 & 93,044 & 1,075 \\
\hline 40 & -42 & -62 & 62 & 4,338 & 58,661 & 25,7 & 20,8 & 93,045 & 1,074 \\
\hline 45 & -48 & -63 & 61 & 4,474 & 58,661 & 25,8 & 20,8 & 93,046 & 1,074 \\
\hline 50 & -56 & -66 & 58 & 4,611 & 58,661 & 25,9 & 20,9 & 93,046 & 1,074 \\
\hline 55 & -62 & -71 & 57 & 4,747 & 58,661 & 26,0 & 20,9 & 93,047 & 1,073 \\
\hline 60 & -59 & -74 & 53 & 4,884 & 58,661 & 26,1 & 20,9 & 93,048 & 1,073 \\
\hline-5 & 54 & 36 & 22 & 5,020 & 58,661 & 26,3 & 21,0 & 93,048 & 1,072 \\
\hline-10 & 38 & 42 & 16 & 5,157 & 58,551 & 26,4 & 21,0 & 93,049 & 1,072 \\
\hline-15 & 11 & 47 & 11 & 5,240 & 58,551 & 26,5 & 21,0 & 93,048 & 1,072 \\
\hline-20 & -19 & 51 & 8 & 5,253 & 58,551 & 26,4 & 20,9 & 93,048 & 1,072 \\
\hline-25 & -41 & 55 & 5 & 5,232 & 58,551 & 26,5 & 21,0 & 93,049 & 1,073 \\
\hline-30 & -54 & 58 & -48 & 5,323 & 58,551 & 26,5 & 20,9 & 93,048 & 1,072 \\
\hline-35 & -61 & 59 & -59 & 5,242 & 58,551 & 26,3 & 21,0 & 93,049 & 1,072 \\
\hline-40 & -57 & 60 & -60 & 5,216 & 58,551 & 26,4 & 20,9 & 93,049 & 1,072 \\
\hline-45 & -51 & 60 & -61 & 5,328 & 58,551 & 26,3 & 21,0 & 93,049 & 1,072 \\
\hline-50 & -48 & 58 & -64 & 5,357 & 58,551 & 26,5 & 20,8 & 93,048 & 1,072 \\
\hline-55 & -46 & 56 & -69 & 5,211 & 58,551 & 26,3 & 20,9 & 93,049 & 1,072 \\
\hline-60 & -43 & 52 & -68 & 5,258 & 58,551 & 26,4 & 20,8 & 93,049 & 1,072 \\
\hline
\end{tabular}




\section{b) Ensaios para $V=7,13 \mathrm{~m} / \mathrm{s}$}

\begin{tabular}{|c|c|c|c|c|c|c|c|c|c|}
\hline $\begin{array}{l}\text { Ângulo de } \\
\text { arfagem } \delta \\
\text { (graus) }\end{array}$ & p1 (Pa) & p2 (Pa) & p3 (Pa) & $\begin{array}{c}\text { P estática } \\
(\mathrm{Pa})\end{array}$ & $\begin{array}{l}\text { Ptotal } \\
(\mathrm{Pa})\end{array}$ & $\begin{array}{c}\text { Temperatura } \\
\text { de Bulbo Seco } \\
\text { (jato) } \\
{ }^{\circ} \mathrm{C}\end{array}$ & $\begin{array}{c}\text { Temperatura } \\
\text { de Bulbo } \\
\text { Úmido } \\
{ }^{\circ} \mathrm{C}\end{array}$ & Patm (kPa) & $\begin{array}{c}\text { Massa } \\
\text { específica do } \\
\text { ar }(\mathrm{kg} / \mathrm{m} 3)\end{array}$ \\
\hline 0 & 33 & 16 & 16 & 0,595 & 31,342 & 26,8 & 21,3 & 93,036 & 1,070 \\
\hline 5 & 32 & 12 & 19 & 0,885 & 31,154 & 26,8 & 21,3 & 93,037 & 1,070 \\
\hline 10 & 28 & 8 & 23 & 1,031 & 31,079 & 26,8 & 21,3 & 93,037 & 1,070 \\
\hline 15 & 21 & 5 & 24 & 1,176 & 31,013 & 26,8 & 21,3 & 93,037 & 1,070 \\
\hline 20 & 10 & 5 & 27 & 1,321 & 30,955 & 26,8 & 21,3 & 93,037 & 1,070 \\
\hline 25 & 1 & -2 & 29 & 1,466 & 30,903 & 26,8 & 21,3 & 93,038 & 1,070 \\
\hline 30 & -10 & -28 & 31 & 1,612 & 30,857 & 26,8 & 21,3 & 93,038 & 1,070 \\
\hline 35 & -19 & -32 & 32 & 1,757 & 30,816 & 26,8 & 21,3 & 93,038 & 1,070 \\
\hline 40 & -23 & -32 & 32 & 1,902 & 30,778 & 26,8 & 21,3 & 93,038 & 1,070 \\
\hline 45 & -27 & -33 & 31 & 2,047 & 30,744 & 26,8 & 21,3 & 93,038 & 1,070 \\
\hline 50 & -30 & -36 & 31 & 2,192 & 30,713 & 26,8 & 21,3 & 93,038 & 1,070 \\
\hline 55 & -32 & -38 & 30 & 2,338 & 30,684 & 26,9 & 21,3 & 93,039 & 1,070 \\
\hline 60 & -33 & -39 & 28 & 2,483 & 30,658 & 26,9 & 21,3 & 93,039 & 1,070 \\
\hline-5 & 29 & 19 & 12 & 2,628 & 30,026 & 26,9 & 21,3 & 93,041 & 1,070 \\
\hline-10 & 21 & 22 & 9 & 2,828 & 30,795 & 26,9 & 21,3 & 93,041 & 1,070 \\
\hline-15 & 5 & 24 & 5 & 2,828 & 30,481 & 27,0 & 21,3 & 93,041 & 1,070 \\
\hline-20 & -9 & 26 & 4 & 2,728 & 30,390 & 26,9 & 21,3 & 93,041 & 1,070 \\
\hline-25 & -21 & 28 & 0 & 2,628 & 30,481 & 26,9 & 21,3 & 93,041 & 1,070 \\
\hline-30 & -28 & 30 & -24 & 2,928 & 30,026 & 26,9 & 21,3 & 93,041 & 1,070 \\
\hline-35 & -32 & 31 & -28 & 2,928 & 30,208 & 26,9 & 21,3 & 93,041 & 1,070 \\
\hline-40 & -31 & 31 & -31 & 2,628 & 30,208 & 26,9 & 21,3 & 93,041 & 1,070 \\
\hline-45 & -31 & 32 & -33 & 3,028 & 30,481 & 27,0 & 21,3 & 93,041 & 1,070 \\
\hline-50 & -29 & 32 & -36 & 2,928 & 30,208 & 26,9 & 21,3 & 93,041 & 1,070 \\
\hline-55 & -28 & 31 & -38 & 2,728 & 30,390 & 26,9 & 21,3 & 93,041 & 1,070 \\
\hline-60 & -24 & 29 & -38 & 2,828 & 30,481 & 26,9 & 21,3 & 93,041 & 1,070 \\
\hline
\end{tabular}




\section{c) Ensaios para $V=12,10 \mathrm{~m} / \mathrm{s}$}

\begin{tabular}{|c|c|c|c|c|c|c|c|c|c|}
\hline $\begin{array}{c}\text { Ângulo de } \\
\text { arfagem } \delta \\
\text { (graus) }\end{array}$ & $\mathrm{p} 1(\mathrm{~Pa})$ & p2 (Pa) & p3 (Pa) & $\begin{array}{c}\text { P estática } \\
(\mathrm{Pa})\end{array}$ & $\begin{array}{c}\text { Ptotal } \\
(\mathrm{Pa})\end{array}$ & $\begin{array}{c}\text { Temperatura } \\
\text { de Bulbo Seco } \\
\text { (jato) } \\
{ }^{\circ} \mathrm{C}\end{array}$ & $\begin{array}{c}\text { Temperatura } \\
\text { de Bulbo } \\
\text { Úmido } \\
{ }^{\circ} \mathrm{C}\end{array}$ & Patm (kPa) & $\begin{array}{c}\text { Massa } \\
\text { específica do } \\
\text { ar }(\mathrm{kg} / \mathrm{m} 3)\end{array}$ \\
\hline 0 & 83 & 41 & 42 & 1,418 & 80,67 & 27,5 & 21,2 & 93,028 & 1,068 \\
\hline 5 & 82 & 31 & 50 & 2,251 & 80,697 & 27,5 & 21,2 & 93,028 & 1,068 \\
\hline 10 & 73 & 21 & 60 & 2,667 & 80,711 & 27,5 & 21,2 & 93,028 & 1,068 \\
\hline 15 & 53 & 13 & 66 & 3,084 & 80,724 & 27,5 & 21,2 & 93,027 & 1,068 \\
\hline 20 & 24 & 10 & 72 & 3,500 & 80,738 & 27,5 & 21,2 & 93,027 & 1,068 \\
\hline 25 & -2 & 3 & 77 & 3,916 & 80,752 & 27,5 & 21,2 & 93,027 & 1,068 \\
\hline 30 & -31 & -70 & 80 & 4,333 & 80,765 & 27,4 & 21,1 & 93,027 & 1,068 \\
\hline 35 & -49 & -88 & 83 & 4,749 & 80,779 & 27,4 & 21,1 & 93,027 & 1,068 \\
\hline 40 & -61 & -87 & 82 & 5,165 & 80,793 & 27,4 & 21,1 & 93,027 & 1,068 \\
\hline 45 & -72 & -88 & 83 & 5,582 & 80,806 & 27,4 & 21,1 & 93,026 & 1,068 \\
\hline 50 & -81 & -94 & 80 & 5,998 & 80,820 & 27,4 & 21,1 & 93,026 & 1,068 \\
\hline 55 & -87 & -102 & 78 & 6,415 & 80,833 & 27,4 & 21,1 & 93,026 & 1,068 \\
\hline 60 & -85 & -104 & 74 & 6,831 & 80,847 & 27,4 & 21,1 & 93,026 & 1,068 \\
\hline-5 & 78 & 51 & 32 & 6,990 & 80,883 & 27,4 & 21,1 & 93,026 & 1,068 \\
\hline-10 & 55 & 59 & 23 & 7,217 & 80,881 & 27,4 & 21,1 & 93,026 & 1,068 \\
\hline-15 & 12 & 66 & 14 & 6,831 & 80,872 & 27,4 & 21,1 & 93,026 & 1,068 \\
\hline-20 & -30 & 71 & 9 & 6,854 & 80,865 & 27,4 & 21,1 & 93,026 & 1,068 \\
\hline-25 & -61 & 76 & 7 & 6,990 & 80,892 & 27,4 & 21,1 & 93,026 & 1,068 \\
\hline-30 & -77 & 79 & -58 & 6,967 & 80,858 & 27,4 & 21,1 & 93,026 & 1,068 \\
\hline-35 & -85 & 82 & -87 & 7,126 & 80,863 & 27,4 & 21,1 & 93,026 & 1,068 \\
\hline-40 & -77 & 83 & -87 & 6,945 & 80,872 & 27,4 & 21,1 & 93,026 & 1,068 \\
\hline-45 & -71 & 83 & -84 & 7,172 & 80,886 & 27,4 & 21,1 & 93,026 & 1,068 \\
\hline-50 & -69 & 82 & -88 & 7,013 & 80,854 & 27,4 & 21,1 & 93,026 & 1,068 \\
\hline-55 & -69 & 78 & -98 & 6,876 & 80,856 & 27,4 & 21,1 & 93,026 & 1,068 \\
\hline-60 & -59 & 74 & -97 & 7,263 & 80,858 & 27,4 & 21,1 & 93,026 & 1,068 \\
\hline
\end{tabular}




\section{APÊNDICE II}




\begin{tabular}{|c|c|c|c|c|c|c|c|c|c|c|c|c|c|c|c|}
\hline $\begin{array}{l}\text { Ângulo } \\
\text { g } \\
\text { (graus) }\end{array}$ & $\begin{array}{l}\text { Ângulo } \\
\text { a } \\
\text { (graus) }\end{array}$ & $\begin{array}{l}\text { Ângulo de } \\
\text { guinada } \psi \\
\text { (graus) }\end{array}$ & $\begin{array}{l}\text { Ângulo de } \\
\text { arfagem } \delta \\
\text { (graus) }\end{array}$ & $\mathrm{p} 1(\mathrm{~Pa})$ & p2 $(\mathrm{Pa})$ & p3 (Pa) & $\mathrm{p} 4(\mathrm{~Pa})$ & p5 $(\mathrm{Pa})$ & $P$ est $(\mathrm{Pa})$ & $P \operatorname{din}(\mathrm{Pa})$ & Ptotal (Pa) & $\begin{array}{c}\text { Temperatura } \\
\text { de Bulbo } \\
\text { Seco (jato) } \\
{ }^{\circ} \mathrm{C}\end{array}$ & $\begin{array}{c}\text { Temperatura } \\
\text { de Bulbo } \\
\text { Úmido } \\
{ }^{\circ} \mathrm{C}\end{array}$ & $\begin{array}{l}\text { Patm } \\
(\mathrm{kPa})\end{array}$ & $\begin{array}{c}\text { massa } \\
\text { específica do } \\
\operatorname{ar}(\mathrm{kg} / \mathrm{m} 3)\end{array}$ \\
\hline 90 & 0 & 0 & 0 & 63 & 36 & 33 & 41 & 34 & 3,254 & 54,193 & 57,113 & 27,7 & 21,2 & 92,825 & 1,064 \\
\hline 90 & -5 & -5 & 0,0 & 62 & 30 & 38 & 41 & 33 & 3,299 & 54,181 & 57,151 & 27,7 & 21,2 & 92,823 & 1,064 \\
\hline 90 & -10 & -10 & 0,0 & 62 & 24 & 44 & 41 & 31 & 3,343 & 54,170 & 57,188 & 27,8 & 21,2 & 92,822 & 1,064 \\
\hline 90 & -15 & -15 & 0,0 & 56 & 17 & 50 & 39 & 29 & 3,387 & 54,159 & 57,225 & 27,8 & 21,2 & 92,820 & 1,064 \\
\hline 90 & -20 & -20 & 0,0 & 49 & 10 & 54 & 36 & 25 & 3,430 & 54,148 & 57,261 & 27,9 & 21,2 & 92,818 & 1,063 \\
\hline 90 & -25 & -25 & 0,0 & 37 & 2 & 58 & 32 & 21 & 3,472 & 54,136 & 57,297 & 27,9 & 21,2 & 92,816 & 1,063 \\
\hline 90 & -30 & $-30,0$ & 0,0 & 22 & -4 & 60 & 27 & 20 & 3,514 & 54,125 & 57,332 & 28,0 & 21,3 & 92,815 & 1,063 \\
\hline 90 & -35 & $-35,0$ & 0,0 & 2 & -11 & 60 & 22 & 11 & 3,555 & 54,115 & 57,367 & 28,0 & 21,3 & 92,813 & 1,063 \\
\hline 90 & -40 & $-40,0$ & 0,0 & -22 & -16 & 61 & 17 & -27 & 3,595 & 54,104 & 57,400 & 28,1 & 21,3 & 92,811 & 1,063 \\
\hline 90 & -45 & $-45,0$ & 0,0 & -40 & -38 & 59 & 7 & -43 & 3,635 & 54,093 & 57,434 & 28,1 & 21,3 & 92,809 & 1,063 \\
\hline 90 & -50 & $-50,0$ & 0,0 & -57 & -51 & 55 & -13 & -58 & 3,674 & 54,083 & 57,466 & 28,2 & 21,3 & 92,808 & 1,062 \\
\hline 90 & -55 & $-55,0$ & 0,0 & -68 & -65 & 51 & -25 & -69 & 3,712 & 54,072 & 57,499 & 28,2 & 21,3 & 92,806 & 1,062 \\
\hline 90 & -60 & $-60,0$ & 0,0 & -76 & -64 & 44 & -36 & -90 & 3,750 & 54,062 & 57,530 & 28,2 & 21,3 & 92,804 & 1,062 \\
\hline 90 & 5 & 5,0 & 0,0 & 59 & 40 & 28 & 40 & 32 & 3,787 & 54,052 & 57,561 & 28,3 & 21,3 & 92,803 & 1,062 \\
\hline 90 & 10 & 10,0 & 0,0 & 55 & 45 & 21 & 37 & 30 & 3,823 & 54,042 & 57,591 & 28,3 & 21,3 & 92,801 & 1,062 \\
\hline 90 & 15 & 15,0 & 0,0 & 50 & 50 & 14 & 33 & 29 & 3,858 & 54,032 & 57,621 & 28,4 & 21,3 & 92,799 & 1,062 \\
\hline 90 & 20 & 20,0 & 0,0 & 43 & 54 & 6 & 29 & 26 & 3,893 & 54,022 & 57,650 & 28,4 & 21,3 & 92,797 & 1,062 \\
\hline 90 & 25 & 25,0 & 0,0 & 31 & 57 & 0 & 24 & 22 & 3,928 & 54,012 & 57,679 & 28,4 & 21,3 & 92,796 & 1,062 \\
\hline 90 & 30 & 30,0 & 0,0 & 16 & 58 & -6 & 20 & 18 & 3,961 & 54,002 & 57,707 & 28,5 & 21,4 & 92,794 & 1,061 \\
\hline 90 & 35 & 35,0 & 0,0 & -3 & 59 & -12 & 16 & 14 & 3,994 & 53,993 & 57,734 & 28,5 & 21,4 & 92,792 & 1,061 \\
\hline 90 & 40 & 40,0 & 0,0 & -27 & 58 & -20 & -8 & -6 & 4,026 & 53,983 & 57,761 & 28,6 & 21,4 & 92,790 & 1,061 \\
\hline 90 & 45 & 45,0 & 0,0 & -46 & 55 & -40 & -33 & -25 & 4,058 & 53,974 & 57,787 & 28,6 & 21,4 & 92,789 & 1,061 \\
\hline 90 & 50 & 50,0 & 0,0 & -62 & 52 & -44 & -49 & -40 & 4,089 & 53,965 & 57,813 & 28,6 & 21,4 & 92,787 & 1,061 \\
\hline 90 & 55 & 55,0 & 0,0 & -76 & 47 & -54 & -63 & -46 & 4,119 & 53,956 & 57,838 & 28,7 & 21,4 & 92,785 & 1,061 \\
\hline 90 & 60 & 60,0 & 0,0 & -84 & 41 & -67 & -68 & -46 & 4,149 & 53,947 & 57,862 & 28,7 & 21,4 & 92,783 & 1,061 \\
\hline 95 & 0 & 0,0 & 0,0 & 58 & 34 & 32 & 38 & 31 & 4,178 & 53,938 & 57,886 & 28,7 & 21,4 & 92,782 & 1,061 \\
\hline 95 & 5 & 5,0 & $-0,4$ & 58 & 40 & 27 & 38 & 31 & 4,206 & 53,929 & 57,909 & 28,8 & 21,4 & 92,780 & 1,060 \\
\hline 95 & 10 & 10,0 & $-0,9$ & 56 & 45 & 20 & 36 & 30 & 4,234 & 53,921 & 57,932 & 28,8 & 21,4 & 92,778 & 1,060 \\
\hline 95 & 15 & 14,9 & $-1,3$ & 50 & 50 & 14 & 34 & 28 & 4,260 & 53,912 & 57,954 & 28,8 & 21,4 & 92,776 & 1,060 \\
\hline 95 & 20 & 19,9 & $-1,7$ & 43 & 53 & 6 & 30 & 24 & 4,287 & 53,904 & 57,975 & 28,9 & 21,4 & 92,774 & 1,060 \\
\hline 95 & 25 & 24,9 & $-2,2$ & 31 & 57 & 0 & 26 & 21 & 4,312 & 53,895 & 57,996 & 28,9 & 21,5 & 92,773 & 1,060 \\
\hline 95 & 30 & 29,9 & $-2,6$ & 14 & 58 & -7 & 19 & 18 & 4,337 & 53,887 & 58,016 & 28,9 & 21,5 & 92,771 & 1,060 \\
\hline 95 & 35 & 34,9 & $-3,1$ & -6 & 58 & -14 & 15 & 8 & 4,361 & 53,879 & 58,036 & 29,0 & 21,5 & 92,769 & 1,060 \\
\hline 95 & 40 & 39,8 & $-3,5$ & -28 & 58 & -20 & 6 & -24 & 4,385 & 53,871 & 58,055 & 29,0 & 21,5 & 92,767 & 1,060 \\
\hline
\end{tabular}




\begin{tabular}{|c|c|c|c|c|c|c|c|c|c|c|c|c|c|c|c|}
\hline $\begin{array}{c}\text { Ângulo } \\
\text { g } \\
\text { (graus) } \\
\end{array}$ & $\begin{array}{c}\begin{array}{c}\text { Ângulo } \\
a \\
\text { (graus) }\end{array} \\
\end{array}$ & $\begin{array}{c}\text { Ângulo de } \\
\text { guinada } \psi \\
\text { (graus) }\end{array}$ & $\begin{array}{c}\begin{array}{c}\text { Ângulo de } \\
\text { arfagem } \delta \\
\text { (graus) }\end{array} \\
\end{array}$ & $\mathrm{p} 1(\mathrm{~Pa})$ & p2 $(\mathrm{Pa})$ & p3 (Pa) & $\mathrm{p} 4(\mathrm{~Pa})$ & p5 (Pa) & $\mathrm{P}$ est $(\mathrm{Pa})$ & $P \operatorname{din}(\mathrm{Pa})$ & Ptotal $(\mathrm{Pa})$ & $\begin{array}{c}\text { Temperatura } \\
\text { de Bulbo } \\
\text { Seco (jato) } \\
{ }^{\circ} \mathrm{C} \\
\end{array}$ & $\begin{array}{c}\text { Temperatura } \\
\text { de Bulbo } \\
\text { Úmido } \\
{ }^{\circ} \mathrm{C} \\
\end{array}$ & $\begin{array}{l}\text { Patm } \\
(\mathrm{kPa})\end{array}$ & $\begin{array}{c}\text { massa } \\
\text { específica do } \\
\operatorname{ar}(\mathrm{kg} / \mathrm{m} 3)\end{array}$ \\
\hline 95 & 45 & 44,8 & $-3,9$ & -47 & 55 & -38 & -14 & -40 & 4,408 & 53,863 & 58,073 & 29,0 & 21,5 & 92,766 & 1,059 \\
\hline 95 & 50 & 49,8 & $-4,4$ & -62 & 52 & -40 & -32 & -52 & 4,430 & 53,856 & 58,091 & 29,0 & 21,5 & 92,764 & 1,059 \\
\hline 95 & 55 & 54,8 & $-4,8$ & -75 & 46 & -51 & -44 & -65 & 4,452 & 53,848 & 58,109 & 29,1 & 21,5 & 92,762 & 1,059 \\
\hline 95 & 60 & 59,8 & $-5,2$ & -87 & 40 & -60 & -47 & -78 & 4,473 & 53,840 & 58,125 & 29,1 & 21,5 & 92,760 & 1,059 \\
\hline 95 & -5 & $-5,0$ & 0,4 & 58 & 29 & 39 & 41 & 31 & 4,493 & 53,833 & 58,142 & 29,1 & 21,5 & 92,759 & 1,059 \\
\hline 95 & -10 & $-10,0$ & 0,9 & 57 & 23 & 44 & 38 & 29 & 4,512 & 53,826 & 58,157 & 29,2 & 21,5 & 92,757 & 1,059 \\
\hline 95 & -15 & $-14,9$ & 1,3 & 53 & 16 & 49 & 36 & 27 & 4,531 & 53,819 & 58,172 & 29,2 & 21,5 & 92,755 & 1,059 \\
\hline 95 & -20 & $-19,9$ & 1,7 & 45 & 9 & 53 & 32 & 24 & 4,549 & 53,812 & 58,186 & 29,2 & 21,5 & 92,753 & 1,059 \\
\hline 95 & -25 & $-24,9$ & 2,2 & 34 & 2 & 56 & 28 & 21 & 4,567 & 53,805 & 58,200 & 29,2 & 21,5 & 92,751 & 1,059 \\
\hline 95 & -30 & $-29,9$ & 2,6 & 19 & -4 & 60 & 23 & 18 & 4,584 & 53,798 & 58,213 & 29,3 & 21,6 & 92,750 & 1,059 \\
\hline 95 & -35 & $-34,9$ & 3,1 & -1 & -11 & 60 & 18 & 13 & 4,600 & 53,791 & 58,226 & 29,3 & 21,6 & 92,748 & 1,059 \\
\hline 95 & -40 & $-39,8$ & 3,5 & -24 & -16 & 59 & 11 & -21 & 4,615 & 53,784 & 58,238 & 29,3 & 21,6 & 92,746 & 1,058 \\
\hline 95 & -45 & $-44,8$ & 3,9 & -42 & -35 & 58 & -8 & -35 & 4,630 & 53,778 & 58,249 & 29,3 & 21,6 & 92,744 & 1,058 \\
\hline 95 & -50 & $-49,8$ & 4,4 & -57 & -43 & 54 & -28 & -49 & 4,644 & 53,772 & 58,260 & 29,3 & 21,6 & 92,742 & 1,058 \\
\hline 95 & -55 & $-54,8$ & 4,8 & -70 & -49 & 50 & -42 & -59 & 4,658 & 53,765 & 58,270 & 29,4 & 21,6 & 92,741 & 1,058 \\
\hline 95 & -60 & $-59,8$ & 5,2 & -76 & -55 & 44 & -58 & -74 & 4,671 & 53,759 & 58,280 & 29,4 & 21,6 & 92,739 & 1,058 \\
\hline 100 & 0 & 0,0 & 0,0 & 60 & 35 & 35 & 37 & 35 & 4,683 & 53,753 & 58,289 & 29,4 & 21,6 & 92,737 & 1,058 \\
\hline 100 & -5 & $-4,9$ & 0,9 & 60 & 29 & 41 & 36 & 35 & 4,695 & 53,747 & 58,297 & 29,4 & 21,6 & 92,735 & 1,058 \\
\hline 100 & -10 & $-9,8$ & 1,7 & 58 & 23 & 46 & 34 & 34 & 4,706 & 53,739 & 58,304 & 29,4 & 21,6 & 92,733 & 1,058 \\
\hline 100 & -15 & $-14,8$ & 2,6 & 52 & 15 & 51 & 30 & 32 & 4,717 & 53,732 & 58,310 & 29,5 & 21,6 & 92,731 & 1,058 \\
\hline 100 & -20 & $-19,7$ & 3,5 & 44 & 8 & 55 & 27 & 29 & 4,727 & 53,723 & 58,314 & 29,5 & 21,6 & 92,730 & 1,058 \\
\hline 100 & -25 & $-24,6$ & 4,3 & 32 & 2 & 58 & 22 & 25 & 4,737 & 53,714 & 58,318 & 29,5 & 21,6 & 92,728 & 1,058 \\
\hline 100 & -30 & $-29,5$ & 5,2 & 16 & -5 & 60 & 18 & 20 & 4,746 & 53,704 & 58,320 & 29,5 & 21,6 & 92,726 & 1,058 \\
\hline 100 & -35 & $-34,5$ & 6,1 & -4 & -11 & 60 & 8 & 18 & 4,755 & 53,694 & 58,321 & 29,5 & 21,6 & 92,724 & 1,057 \\
\hline 100 & -40 & $-39,4$ & 6,9 & -27 & -18 & 60 & -23 & 7 & 4,764 & 53,684 & 58,322 & 29,6 & 21,7 & 92,722 & 1,057 \\
\hline 100 & -45 & $-44,3$ & 7,8 & -46 & -35 & 58 & -38 & -10 & 4,771 & 53,673 & 58,321 & 29,6 & 21,7 & 92,720 & 1,057 \\
\hline 100 & -50 & $-49,2$ & 8,7 & -60 & -41 & 53 & -51 & -18 & 4,779 & 53,662 & 58,319 & 29,6 & 21,7 & 92,718 & 1,057 \\
\hline 100 & -55 & $-54,2$ & 9,6 & -73 & -52 & 48 & -73 & -21 & 4,786 & 53,650 & 58,317 & 29,6 & 21,7 & 92,716 & 1,057 \\
\hline 100 & -60 & $-59,1$ & 10,4 & -82 & -62 & 42 & -94 & -16 & 4,792 & 53,638 & 58,314 & 29,6 & 21,7 & 92,713 & 1,057 \\
\hline 100 & 5 & 4,9 & $-0,9$ & 61 & 38 & 31 & 37 & 35 & 4,797 & 53,626 & 58,309 & 29,7 & 21,7 & 92,711 & 1,057 \\
\hline 100 & 10 & 9,8 & $-1,7$ & 59 & 44 & 25 & 36 & 33 & 4,802 & 53,614 & 58,305 & 29,7 & 21,7 & 92,709 & 1,057 \\
\hline 100 & 15 & 14,8 & $-2,6$ & 55 & 49 & 17 & 33 & 31 & 4,807 & 53,602 & 58,299 & 29,7 & 21,7 & 92,707 & 1,057 \\
\hline 100 & 20 & 19,7 & $-3,5$ & 48 & 53 & 10 & 31 & 27 & 4,811 & 53,590 & 58,293 & 29,7 & 21,7 & 92,705 & 1,057 \\
\hline 100 & 25 & 24,6 & $-4,3$ & 37 & 56 & 3 & 27 & 23 & 4,814 & 53,578 & 58,286 & 29,7 & 21,7 & 92,703 & 1,057 \\
\hline 100 & 30 & 29,5 & $-5,2$ & 23 & 58 & -3 & 22 & 19 & 4,816 & 53,566 & 58,278 & 29,8 & 21,7 & 92,701 & 1,057 \\
\hline 100 & 35 & 34,5 & $-6,1$ & 5 & 58 & -11 & 17 & 13 & 4,818 & 53,554 & 58,270 & 29,8 & 21,7 & 92,699 & 1,057 \\
\hline 100 & 40 & 39,4 & $-6,9$ & -16 & 58 & -17 & 13 & -13 & 4,819 & 53,542 & 58,261 & 29,8 & 21,7 & 92,697 & 1,057 \\
\hline 100 & 45 & 44,3 & $-7,8$ & -38 & 56 & -34 & 1 & -36 & 4,820 & 53,530 & 58,252 & 29,8 & 21,7 & 92,695 & 1,057 \\
\hline 100 & 50 & 49,2 & $-8,7$ & -56 & 53 & -36 & -14 & -54 & 4,819 & 53,519 & 58,242 & 29,8 & 21,7 & 92,692 & 1,057 \\
\hline 100 & 55 & 54,2 & $-9,6$ & -70 & 48 & -56 & -27 & -66 & 4,818 & 53,508 & 58,232 & 29,8 & 21,8 & 92,690 & 1,057 \\
\hline
\end{tabular}




\begin{tabular}{|c|c|c|c|c|c|c|c|c|c|c|c|c|c|c|c|}
\hline $\begin{array}{c}\text { Ângulo } \\
\text { g } \\
\text { (graus) }\end{array}$ & $\begin{array}{c}\text { Ângulo } \\
\text { a } \\
\text { (graus) }\end{array}$ & $\begin{array}{c}\text { Ângulo de } \\
\text { guinada } \Psi \\
\text { (graus) }\end{array}$ & $\begin{array}{c}\text { Ângulo de } \\
\text { arfagem } \delta \\
\text { (graus) }\end{array}$ & $\mathrm{p} 1(\mathrm{~Pa})$ & p2 (Pa) & p3 $(\mathrm{Pa})$ & $\mathrm{p} 4(\mathrm{~Pa})$ & p5 $(\mathrm{Pa})$ & $\mathrm{P}$ est $(\mathrm{Pa})$ & $P \operatorname{din}(\mathrm{Pa})$ & Ptotal $(\mathrm{Pa})$ & $\begin{array}{c}\text { Temperatura } \\
\text { de Bulbo } \\
\text { Seco (jato) } \\
{ }^{\circ} \mathrm{C}\end{array}$ & $\begin{array}{c}\text { Temperatura } \\
\text { de Bulbo } \\
\text { Úmido } \\
{ }^{\circ} \mathrm{C}\end{array}$ & $\begin{array}{l}\text { Patm } \\
(\mathrm{kPa})\end{array}$ & $\begin{array}{l}\text { massa } \\
\text { específica do } \\
\text { ar }(\mathrm{kg} / \mathrm{m} 3)\end{array}$ \\
\hline 100 & 60 & 59,1 & $-10,4$ & -81 & 42 & -64 & -34 & -82 & 4,816 & 53,498 & 58,222 & 29,9 & 21,8 & 92,688 & 1,057 \\
\hline 105 & 0 & 0,0 & 0,0 & 60 & 32 & 36 & 36 & 35 & 4,814 & 53,488 & 58,211 & 29,9 & 21,8 & 92,686 & 1,057 \\
\hline 105 & 5 & 4,8 & $-1,3$ & 60 & 38 & 31 & 37 & 34 & 4,810 & 53,478 & 58,200 & 29,9 & 21,8 & 92,684 & 1,057 \\
\hline 105 & 10 & 9,7 & $-2,6$ & 57 & 43 & 24 & 37 & 31 & 4,806 & 53,469 & 58,188 & 29,9 & 21,8 & 92,682 & 1,057 \\
\hline 105 & 15 & 14,5 & $-3,9$ & 53 & 48 & 17 & 35 & 29 & 4,801 & 53,461 & 58,177 & 29,9 & 21,8 & 92,680 & 1,057 \\
\hline 105 & 20 & 19,3 & $-5,2$ & 46 & 52 & 10 & 32 & 25 & 4,796 & 53,453 & 58,165 & 29,9 & 21,8 & 92,678 & 1,056 \\
\hline 105 & 25 & 24,1 & $-6,5$ & 36 & 55 & 3 & 29 & 21 & 4,789 & 53,446 & 58,153 & 29,9 & 21,8 & 92,676 & 1,056 \\
\hline 105 & 30 & 29,0 & $-7,8$ & 21 & 57 & -4 & 24 & 19 & 4,781 & 53,439 & 58,141 & 29,9 & 21,8 & 92,674 & 1,056 \\
\hline 105 & 35 & 33,8 & $-9,1$ & 3 & 57 & -11 & 19 & 9 & 4,773 & 53,434 & 58,129 & 29,9 & 21,8 & 92,672 & 1,056 \\
\hline 105 & 40 & 38,6 & $-10,4$ & -19 & 57 & -19 & 14 & -30 & 4,764 & 53,429 & 58,116 & 29,9 & 21,8 & 92,670 & 1,056 \\
\hline 105 & 45 & 43,5 & $-11,6$ & -38 & 54 & -40 & 10 & -46 & 4,754 & 53,425 & 58,104 & 29,9 & 21,8 & 92,668 & 1,056 \\
\hline 105 & 50 & 48,3 & $-12,9$ & -56 & 51 & -66 & 4 & -62 & 4,743 & 53,422 & 58,092 & 29,9 & 21,8 & 92,666 & 1,056 \\
\hline 105 & 55 & 53,1 & $-14,2$ & -72 & 46 & -60 & -5 & -73 & 4,731 & 53,420 & 58,080 & 29,9 & 21,8 & 92,664 & 1,056 \\
\hline 105 & 60 & 58,0 & $-15,5$ & -83 & 41 & -66 & -8 & -84 & 4,718 & 53,419 & 58,068 & 29,9 & 21,8 & 92,663 & 1,056 \\
\hline 105 & -5 & $-4,8$ & 1,3 & 59 & 27 & 43 & 37 & 32 & 4,704 & 53,420 & 58,056 & 29,9 & 21,8 & 92,661 & 1,056 \\
\hline 105 & -10 & $-9,7$ & 2,6 & 57 & 22 & 47 & 34 & 32 & 4,689 & 53,421 & 58,044 & 29,9 & 21,8 & 92,659 & 1,056 \\
\hline 105 & -15 & $-14,5$ & 3,9 & 53 & 14 & 53 & 31 & 30 & 4,673 & 53,424 & 58,033 & 29,9 & 21,8 & 92,657 & 1,056 \\
\hline 105 & -20 & $-19,3$ & 5,2 & 44 & 8 & 56 & 27 & 27 & 4,656 & 53,428 & 58,022 & 29,9 & 21,9 & 92,656 & 1,056 \\
\hline 105 & -25 & $-24,1$ & 6,5 & 32 & 1 & 60 & 23 & 26 & 4,638 & 53,433 & 58,011 & 29,9 & 21,9 & 92,654 & 1,056 \\
\hline 105 & -30 & $-29,0$ & 7,8 & 16 & -5 & 60 & 19 & 21 & 4,620 & 53,440 & 58,000 & 29,9 & 21,9 & 92,652 & 1,056 \\
\hline 105 & -35 & $-33,8$ & 9,1 & -4 & -11 & 61 & 6 & 17 & 4,600 & 53,448 & 57,990 & 29,9 & 21,9 & 92,651 & 1,056 \\
\hline 105 & -40 & $-38,6$ & 10,4 & -27 & -18 & 60 & -26 & 11 & 4,579 & 53,457 & 57,980 & 29,8 & 21,9 & 92,649 & 1,056 \\
\hline 105 & -45 & $-43,5$ & 11,6 & -45 & -35 & 58 & -41 & -4 & 4,556 & 53,468 & 57,971 & 29,8 & 21,9 & 92,648 & 1,056 \\
\hline 105 & -50 & $-48,3$ & 12,9 & -59 & -46 & 53 & -53 & -11 & 4,533 & 53,481 & 57,962 & 29,8 & 21,9 & 92,646 & 1,056 \\
\hline 105 & -55 & $-53,1$ & 14,2 & -70 & -57 & 48 & -70 & -12 & 4,509 & 53,495 & 57,954 & 29,8 & 21,9 & 92,645 & 1,056 \\
\hline 105 & -60 & $-58,0$ & 15,5 & -79 & -67 & 42 & -83 & -5 & 4,483 & 53,511 & 57,946 & 29,7 & 21,9 & 92,644 & 1,056 \\
\hline 110 & 0 & 0,0 & 0,0 & 60 & 32 & 37 & 40 & 32 & 4,457 & 53,528 & 57,939 & 29,7 & 21,9 & 92,642 & 1,056 \\
\hline 110 & -5 & $-4,7$ & 1,7 & 58 & 27 & 43 & 37 & 33 & 4,429 & 53,548 & 57,933 & 29,7 & 21,9 & 92,641 & 1,056 \\
\hline 110 & -10 & $-9,4$ & 3,4 & 57 & 21 & 48 & 34 & 33 & 4,400 & 53,569 & 57,927 & 29,6 & 21,9 & 92,640 & 1,056 \\
\hline 110 & -15 & $-14,1$ & 5,1 & 52 & 15 & 53 & 31 & 31 & 4,370 & 53,592 & 57,922 & 29,6 & 21,9 & 92,639 & 1,056 \\
\hline 110 & -20 & $-18,8$ & 6,8 & 44 & 7 & 56 & 26 & 29 & 4,338 & 53,618 & 57,918 & 29,6 & 21,9 & 92,638 & 1,056 \\
\hline 110 & -25 & $-23,5$ & 8,6 & 32 & 1 & 60 & 22 & 26 & 4,303 & 53,647 & 57,913 & 29,5 & 21,9 & 92,637 & 1,056 \\
\hline 110 & -30 & $-28,2$ & 10,3 & 16 & -5 & 60 & 18 & 23 & 4,264 & 53,679 & 57,910 & 29,5 & 21,9 & 92,636 & 1,056 \\
\hline 110 & -35 & $-32,9$ & 12,0 & -6 & -13 & 60 & -10 & 19 & 4,224 & 53,714 & 57,906 & 29,4 & 21,9 & 92,635 & 1,056 \\
\hline 110 & -40 & $-37,6$ & 13,7 & -27 & -17 & 60 & -35 & 16 & 4,180 & 53,752 & 57,903 & 29,3 & 21,9 & 92,634 & 1,056 \\
\hline 110 & -45 & $-42,3$ & 15,4 & -43 & -54 & 57 & -47 & 12 & 4,134 & 53,793 & 57,901 & 29,3 & 21,9 & 92,633 & 1,056 \\
\hline 110 & -50 & $-47,0$ & 17,1 & -60 & -68 & 53 & -64 & 8 & 4,085 & 53,837 & 57,898 & 29,2 & 21,9 & 92,632 & 1,056 \\
\hline 110 & -55 & $-51,7$ & 18,8 & -74 & -70 & 48 & -76 & 7 & 4,035 & 53,883 & 57,896 & 29,1 & 21,9 & 92,631 & 1,056 \\
\hline 110 & -60 & $-56,4$ & 20,5 & -83 & -85 & 42 & -87 & 1 & 3,982 & 53,931 & 57,894 & 29,1 & 21,9 & 92,631 & 1,056 \\
\hline 110 & 5 & 4,7 & $-1,7$ & 59 & 36 & 32 & 40 & 31 & 3,926 & 53,982 & 57,892 & 29,0 & 21,9 & 92,630 & 1,056 \\
\hline
\end{tabular}




\begin{tabular}{|c|c|c|c|c|c|c|c|c|c|c|c|c|c|c|c|}
\hline $\begin{array}{c}\text { Ângulo } \\
\text { g } \\
\text { (graus) }\end{array}$ & $\begin{array}{c}\text { Ângulo } \\
\text { a } \\
\text { (graus) }\end{array}$ & $\begin{array}{c}\text { Ângulo de } \\
\text { guinada } \Psi \\
\text { (graus) }\end{array}$ & $\begin{array}{c}\text { Ângulo de } \\
\text { arfagem } \delta \\
\text { (graus) }\end{array}$ & $\mathrm{p} 1(\mathrm{~Pa})$ & p2 (Pa) & p3 (Pa) & $\mathrm{p} 4(\mathrm{~Pa})$ & p5 $(\mathrm{Pa})$ & $\mathrm{P}$ est $(\mathrm{Pa})$ & $P \operatorname{din}(\mathrm{Pa})$ & Ptotal $(\mathrm{Pa})$ & $\begin{array}{c}\text { Temperatura } \\
\text { de Bulbo } \\
\text { Seco (jato) } \\
{ }^{\circ} \mathrm{C}\end{array}$ & $\begin{array}{c}\text { Temperatura } \\
\text { de Bulbo } \\
\text { Úmido } \\
{ }^{\circ} \mathrm{C}\end{array}$ & $\begin{array}{l}\text { Patm } \\
(\mathrm{kPa})\end{array}$ & $\begin{array}{l}\text { massa } \\
\text { específica do } \\
\text { ar }(\mathrm{kg} / \mathrm{m} 3)\end{array}$ \\
\hline 110 & 10 & 9,4 & $-3,4$ & 58 & 42 & 26 & 41 & 28 & 3,869 & 54,035 & 57,891 & 28,9 & 21,9 & 92,629 & 1,056 \\
\hline 110 & 15 & 14,1 & $-5,1$ & 53 & 46 & 18 & 40 & 24 & 3,810 & 54,091 & 57,890 & 28,8 & 21,9 & 92,628 & 1,056 \\
\hline 110 & 20 & 18,8 & $-6,8$ & 46 & 50 & 12 & 37 & 21 & 3,749 & 54,148 & 57,889 & 28,7 & 21,9 & 92,628 & 1,056 \\
\hline 110 & 25 & 23,5 & $-8,6$ & 35 & 53 & 4 & 34 & 18 & 3,687 & 54,207 & 57,888 & 28,7 & 21,9 & 92,627 & 1,056 \\
\hline 110 & 30 & 28,2 & $-10,3$ & 22 & 54 & -3 & 31 & 19 & 3,622 & 54,267 & 57,888 & 28,6 & 22,0 & 92,626 & 1,056 \\
\hline 110 & 35 & 32,9 & $-12,0$ & 4 & 54 & -11 & 25 & 12 & 3,557 & 54,330 & 57,887 & 28,5 & 22,0 & 92,626 & 1,056 \\
\hline 110 & 40 & 37,6 & $-13,7$ & -16 & 54 & -18 & 20 & -33 & 3,490 & 54,394 & 57,887 & 28,4 & 22,0 & 92,625 & 1,056 \\
\hline 110 & 45 & 42,3 & $-15,4$ & -35 & 51 & -40 & 14 & -63 & 3,421 & 54,459 & 57,887 & 28,3 & 22,0 & 92,625 & 1,056 \\
\hline 110 & 50 & 47,0 & $-17,1$ & -50 & 47 & -73 & 8 & -70 & 3,352 & 54,525 & 57,887 & 28,2 & 22,0 & 92,624 & 1,056 \\
\hline 110 & 55 & 51,7 & $-18,8$ & -68 & 43 & -82 & 2 & -79 & 3,282 & 54,593 & 57,887 & 28,1 & 22,0 & 92,624 & 1,056 \\
\hline 110 & 60 & 56,4 & $-20,5$ & -83 & 37 & -90 & -3 & -93 & 3,210 & 54,662 & 57,887 & 28,0 & 22,0 & 92,623 & 1,056 \\
\hline 115 & 0 & 0,0 & 0,0 & 60 & 31 & 37 & 39 & 33 & 3,138 & 54,731 & 57,887 & 27,9 & 22,0 & 92,623 & 1,056 \\
\hline 115 & 5 & 4,5 & $-2,1$ & 60 & 37 & 32 & 40 & 31 & 3,065 & 54,802 & 57,887 & 27,8 & 22,0 & 92,623 & 1,056 \\
\hline 115 & 10 & 9,1 & $-4,2$ & 57 & 41 & 26 & 41 & 28 & 2,991 & 54,873 & 57,888 & 27,7 & 22,0 & 92,622 & 1,056 \\
\hline 115 & 15 & 13,6 & $-6,3$ & 53 & 45 & 19 & 41 & 24 & 2,917 & 54,944 & 57,888 & 27,6 & 22,0 & 92,622 & 1,056 \\
\hline 115 & 20 & 18,1 & $-8,5$ & 45 & 49 & 11 & 40 & 19 & 2,843 & 55,016 & 57,888 & 27,4 & 22,0 & 92,622 & 1,056 \\
\hline 115 & 25 & 22,7 & $-10,6$ & 36 & 52 & 5 & 39 & 18 & 2,768 & 55,089 & 57,889 & 27,3 & 22,0 & 92,621 & 1,056 \\
\hline 115 & 30 & 27,2 & $-12,7$ & 22 & 53 & -3 & 34 & 18 & 2,693 & 55,161 & 57,889 & 27,2 & 22,0 & 92,621 & 1,056 \\
\hline 115 & 35 & 31,7 & $-14,8$ & 5 & 53 & -10 & 29 & 21 & 2,618 & 55,234 & 57,889 & 27,1 & 22,0 & 92,621 & 1,056 \\
\hline 115 & 40 & 36,3 & $-16,9$ & -17 & 51 & -17 & 23 & -36 & 2,543 & 55,306 & 57,889 & 27,0 & 22,0 & 92,621 & 1,056 \\
\hline 115 & 45 & 40,8 & $-19,0$ & -34 & 48 & -33 & 18 & -67 & 2,468 & 55,379 & 57,890 & 26,9 & 22,0 & 92,620 & 1,056 \\
\hline 115 & 50 & 45,3 & $-21,1$ & -49 & 44 & -78 & 12 & -80 & 2,394 & 55,451 & 57,890 & 26,8 & 22,0 & 92,620 & 1,056 \\
\hline 115 & 55 & 49,8 & $-23,2$ & -65 & 40 & -84 & 7 & -90 & 2,319 & 55,522 & 57,890 & 26,7 & 22,0 & 92,620 & 1,056 \\
\hline 115 & 60 & 54,4 & $-25,4$ & -83 & 34 & -91 & -2 & -92 & 2,245 & 55,593 & 57,890 & 26,6 & 22,0 & 92,620 & 1,056 \\
\hline 115 & -5 & $-4,5$ & 2,1 & 60 & 28 & 43 & 38 & 34 & 2,172 & 55,664 & 57,889 & 26,4 & 22,0 & 92,620 & 1,056 \\
\hline 115 & -10 & $-9,1$ & 4,2 & 57 & 22 & 48 & 34 & 34 & 2,100 & 55,734 & 57,889 & 26,3 & 22,0 & 92,620 & 1,056 \\
\hline 115 & -15 & $-13,6$ & 6,3 & 52 & 15 & 53 & 30 & 33 & 2,028 & 55,803 & 57,888 & 26,2 & 22,0 & 92,620 & 1,056 \\
\hline 115 & -20 & $-18,1$ & 8,5 & 44 & 8 & 57 & 25 & 32 & 1,957 & 55,871 & 57,888 & 26,1 & 22,0 & 92,620 & 1,056 \\
\hline 115 & -25 & $-22,7$ & 10,6 & 31 & 1 & 59 & 20 & 30 & 1,887 & 55,937 & 57,887 & 26,0 & 22,0 & 92,620 & 1,056 \\
\hline 115 & -30 & $-27,2$ & 12,7 & 15 & -6 & 60 & 15 & 26 & 1,818 & 56,003 & 57,886 & 25,9 & 22,0 & 92,620 & 1,056 \\
\hline 115 & -35 & $-31,7$ & 14,8 & -5 & -13 & 60 & -17 & 22 & 1,751 & 56,067 & 57,885 & 25,8 & 22,0 & 92,620 & 1,056 \\
\hline 115 & -40 & $-36,3$ & 16,9 & -26 & -18 & 59 & -45 & 18 & 1,685 & 56,130 & 57,883 & 25,7 & 22,0 & 92,621 & 1,056 \\
\hline 115 & -45 & $-40,8$ & 19,0 & -43 & -64 & 56 & -56 & 13 & 1,620 & 56,191 & 57,881 & 25,6 & 22,0 & 92,621 & 1,056 \\
\hline 115 & -50 & $-45,3$ & 21,1 & -57 & -68 & 52 & -66 & 9 & 1,557 & 56,250 & 57,879 & 25,5 & 22,0 & 92,621 & 1,056 \\
\hline 115 & -55 & $-49,8$ & 23,2 & -75 & -81 & 46 & -80 & 4 & 1,495 & 56,308 & 57,877 & 25,4 & 22,0 & 92,621 & 1,056 \\
\hline 115 & -60 & $-54,4$ & 25,4 & -86 & -85 & 39 & 94 & -3 & 1,435 & 56,364 & 57,874 & 25,3 & 22,0 & 92,622 & 1,056 \\
\hline 120 & 0 & 0,0 & 0,0 & 60 & 32 & 38 & 38 & 33 & 1,377 & 56,417 & 57,872 & 25,2 & 22,0 & 92,622 & 1,056 \\
\hline 120 & -5 & $-4,3$ & 2,5 & 60 & 28 & 43 & 36 & 34 & 1,321 & 56,469 & 57,868 & 25,1 & 22,0 & 92,622 & 1,056 \\
\hline 120 & -10 & $-8,7$ & 5,0 & 57 & 22 & 48 & 32 & 35 & 1,267 & 56,518 & 57,865 & 25,0 & 22,0 & 92,622 & 1,056 \\
\hline 120 & -15 & $-13,0$ & 7,5 & 53 & 15 & 53 & 28 & 35 & 1,215 & 56,565 & 57,861 & 24,9 & 22,0 & 92,623 & 1,056 \\
\hline
\end{tabular}




\begin{tabular}{|c|c|c|c|c|c|c|c|c|c|c|c|c|c|c|c|}
\hline $\begin{array}{c}\text { Ângulo } \\
\text { g } \\
\text { (graus) }\end{array}$ & $\begin{array}{c}\text { Ângulo } \\
a \\
\text { (graus) }\end{array}$ & $\begin{array}{c}\text { Ângulo de } \\
\text { guinada } \psi \\
\text { (graus) }\end{array}$ & $\begin{array}{c}\text { Ângulo de } \\
\text { arfagem } \delta \\
\text { (graus) }\end{array}$ & $\mathrm{p} 1(\mathrm{~Pa})$ & p2 $(\mathrm{Pa})$ & p3 $(\mathrm{Pa})$ & $\mathrm{p} 4(\mathrm{~Pa})$ & p5 (Pa) & $\mathrm{P}$ est $(\mathrm{Pa})$ & $P \operatorname{din}(\mathrm{Pa})$ & Ptotal $(\mathrm{Pa})$ & $\begin{array}{c}\text { Temperatura } \\
\text { de Bulbo } \\
\text { Seco (jato) } \\
{ }^{\circ} \mathrm{C}\end{array}$ & $\begin{array}{c}\text { Temperatura } \\
\text { de Bulbo } \\
\text { Úmido } \\
{ }^{\circ} \mathrm{C}\end{array}$ & $\begin{array}{l}\text { Patm } \\
(\mathrm{kPa})\end{array}$ & $\begin{array}{c}\text { massa } \\
\text { específica do } \\
\text { ar }(\mathrm{kg} / \mathrm{m} 3)\end{array}$ \\
\hline 120 & -20 & $-17,3$ & 10,0 & 44 & 8 & 56 & 22 & 34 & 1,166 & 56,609 & 57,857 & 24,8 & 22,0 & 92,623 & 1,056 \\
\hline 120 & -25 & $-21,7$ & 12,5 & 33 & 1 & 57 & 18 & 31 & 1,119 & 56,650 & 57,852 & 24,7 & 22,0 & 92,624 & 1,056 \\
\hline 120 & -30 & $-26,0$ & 15,0 & 17 & -6 & 58 & 15 & 28 & 1,074 & 56,689 & 57,847 & 24,7 & 22,0 & 92,624 & 1,056 \\
\hline 120 & -35 & $-30,3$ & 17,5 & -3 & -12 & 58 & -17 & 25 & 1,032 & 56,725 & 57,842 & 24,6 & 21,9 & 92,625 & 1,056 \\
\hline 120 & -40 & $-34,6$ & 20,0 & -24 & -18 & 57 & -51 & 20 & 0,993 & 56,758 & 57,836 & 24,5 & 21,9 & 92,625 & 1,057 \\
\hline 120 & -45 & $-39,0$ & 22,5 & -41 & -63 & 53 & -65 & 16 & 0,956 & 56,788 & 57,830 & 24,4 & 21,9 & 92,626 & 1,057 \\
\hline 120 & -50 & $-43,3$ & 25,0 & -56 & -74 & 49 & -73 & 13 & 0,923 & 56,814 & 57,823 & 24,4 & 21,9 & 92,626 & 1,057 \\
\hline 120 & -55 & $-47,6$ & 27,5 & -72 & -80 & 43 & -83 & 6 & 0,892 & 56,837 & 57,816 & 24,3 & 21,9 & 92,627 & 1,057 \\
\hline 120 & -60 & $-52,0$ & 30,0 & -85 & -86 & 36 & -85 & 0 & 0,865 & 56,857 & 57,808 & 24,3 & 21,9 & 92,627 & 1,057 \\
\hline 120 & 5 & 4,3 & $-2,5$ & 59 & 36 & 31 & 40 & 31 & 0,841 & 56,873 & 57,800 & 24,2 & 21,9 & 92,628 & 1,057 \\
\hline 120 & 10 & 8,7 & $-5,0$ & 57 & 40 & 26 & 43 & 27 & 0,820 & 56,885 & 57,791 & 24,1 & 21,9 & 92,629 & 1,057 \\
\hline 120 & 15 & 13,0 & $-7,5$ & 53 & 44 & 19 & 43 & 22 & 0,803 & 56,894 & 57,782 & 24,1 & 21,9 & 92,629 & 1,057 \\
\hline 120 & 20 & 17,3 & $-10,0$ & 46 & 47 & 12 & 41 & 17 & 0,788 & 56,900 & 57,772 & 24,0 & 21,9 & 92,630 & 1,057 \\
\hline 120 & 25 & 21,7 & $-12,5$ & 35 & 49 & 4 & 39 & 15 & 0,776 & 56,902 & 57,761 & 24,0 & 21,9 & 92,631 & 1,057 \\
\hline 120 & 30 & 26,0 & $-15,0$ & 21 & 50 & -2 & 36 & 14 & 0,768 & 56,900 & 57,750 & 24,0 & 21,8 & 92,632 & 1,058 \\
\hline 120 & 35 & 30,3 & $-17,5$ & 8 & 51 & -8 & 32 & 17 & 0,762 & 56,896 & 57,739 & 23,9 & 21,8 & 92,633 & 1,058 \\
\hline 120 & 40 & 34,6 & $-20,0$ & -14 & 48 & -14 & 27 & -26 & 0,759 & 56,888 & 57,726 & 23,9 & 21,8 & 92,634 & 1,058 \\
\hline 120 & 45 & 39,0 & $-22,5$ & -33 & 46 & -38 & 21 & -71 & 0,759 & 56,877 & 57,714 & 23,8 & 21,8 & 92,635 & 1,058 \\
\hline 120 & 50 & 43,3 & $-25,0$ & -48 & 41 & -85 & 15 & -87 & 0,761 & 56,863 & 57,700 & 23,8 & 21,8 & 92,636 & 1,058 \\
\hline 120 & 55 & 47,6 & $-27,5$ & -63 & 36 & -89 & 9 & -97 & 0,766 & 56,847 & 57,686 & 23,8 & 21,8 & 92,638 & 1,058 \\
\hline 120 & 60 & 52,0 & $-30,0$ & -80 & 31 & -96 & 2 & -100 & 0,774 & 56,827 & 57,672 & 23,7 & 21,7 & 92,639 & 1,059 \\
\hline 125 & 0 & 0,0 & 0,0 & 60 & 31 & 37 & 38 & 32 & 0,784 & 56,805 & 57,657 & 23,7 & 21,7 & 92,640 & 1,059 \\
\hline 125 & 5 & 4,1 & $-2,9$ & 58 & 35 & 31 & 40 & 31 & 0,796 & 56,780 & 57,642 & 23,7 & 21,7 & 92,642 & 1,059 \\
\hline 125 & 10 & 8,2 & $-5,7$ & 58 & 39 & 26 & 43 & 26 & 0,811 & 56,752 & 57,626 & 23,7 & 21,7 & 92,643 & 1,059 \\
\hline 125 & 15 & 12,3 & $-8,6$ & 53 & 42 & 19 & 44 & 20 & 0,828 & 56,722 & 57,610 & 23,6 & 21,7 & 92,645 & 1,059 \\
\hline 125 & 20 & 16,4 & $-11,5$ & 46 & 45 & 12 & 43 & 16 & 0,847 & 56,689 & 57,594 & 23,6 & 21,6 & 92,646 & 1,060 \\
\hline 125 & 25 & 20,5 & $-14,3$ & 35 & 47 & 6 & 40 & 13 & 0,868 & 56,654 & 57,577 & 23,6 & 21,6 & 92,648 & 1,060 \\
\hline 125 & 30 & 24,6 & $-17,2$ & 23 & 47 & 0 & 39 & 11 & 0,891 & 56,617 & 57,559 & 23,6 & 21,6 & 92,650 & 1,060 \\
\hline 125 & 35 & 28,7 & $-20,1$ & 7 & 47 & -7 & 35 & 14 & 0,917 & 56,578 & 57,542 & 23,5 & 21,6 & 92,651 & 1,060 \\
\hline 125 & 40 & 32,8 & $-22,9$ & -12 & 45 & -12 & 30 & -23 & 0,944 & 56,536 & 57,524 & 23,5 & 21,6 & 92,653 & 1,061 \\
\hline 125 & 45 & 36,9 & $-25,8$ & -32 & 42 & -49 & 25 & -75 & 0,973 & 56,492 & 57,505 & 23,5 & 21,5 & 92,655 & 1,061 \\
\hline 125 & 50 & 41,0 & $-28,7$ & -47 & 37 & -90 & 19 & -92 & 1,003 & 56,447 & 57,486 & 23,5 & 21,5 & 92,657 & 1,061 \\
\hline 125 & 55 & 45,1 & $-31,5$ & -61 & 33 & -92 & 13 & -99 & 1,036 & 56,399 & 57,467 & 23,5 & 21,5 & 92,659 & 1,061 \\
\hline 125 & 60 & 49,1 & $-34,4$ & -74 & 26 & -96 & 7 & -103 & 1,070 & 56,350 & 57,448 & 23,5 & 21,5 & 92,660 & 1,062 \\
\hline 125 & -5 & $-4,1$ & 2,9 & 60 & 27 & 40 & 34 & 35 & 1,106 & 56,298 & 57,428 & 23,5 & 21,4 & 92,662 & 1,062 \\
\hline 125 & -10 & $-8,2$ & 5,7 & 57 & 22 & 44 & 30 & 35 & 1,143 & 56,246 & 57,408 & 23,5 & 21,4 & 92,664 & 1,062 \\
\hline 125 & -15 & $-12,3$ & 8,6 & 53 & 15 & 50 & 24 & 36 & 1,181 & 56,191 & 57,388 & 23,4 & 21,4 & 92,666 & 1,063 \\
\hline 125 & -20 & $-16,4$ & 11,5 & 44 & 9 & 53 & 19 & 37 & 1,221 & 56,135 & 57,368 & 23,4 & 21,3 & 92,668 & 1,063 \\
\hline 125 & -25 & $-20,5$ & 14,3 & 34 & 2 & 54 & 17 & 36 & 1,262 & 56,078 & 57,347 & 23,4 & 21,3 & 92,670 & 1,063 \\
\hline 125 & -30 & $-24,6$ & 17,2 & 20 & -4 & 55 & 17 & 32 & 1,305 & 56,019 & 57,326 & 23,4 & 21,3 & 92,672 & 1,063 \\
\hline
\end{tabular}




\begin{tabular}{|c|c|c|c|c|c|c|c|c|c|c|c|c|c|c|c|}
\hline $\begin{array}{c}\text { Ângulo } \\
\text { g } \\
\text { (graus) }\end{array}$ & $\begin{array}{c}\text { Ângulo } \\
\text { a } \\
\text { (graus) }\end{array}$ & $\begin{array}{l}\text { Ângulo de } \\
\text { guinada } \Psi \\
\text { (graus) }\end{array}$ & $\begin{array}{l}\text { Ângulo de } \\
\text { arfagem } \delta \\
\text { (graus) }\end{array}$ & $\mathrm{p} 1(\mathrm{~Pa})$ & p2 $(\mathrm{Pa})$ & p3 $(\mathrm{Pa})$ & p4 (Pa) & p5 (Pa) & $\mathrm{P}$ est $(\mathrm{Pa})$ & $\mathrm{P} \operatorname{din}(\mathrm{Pa})$ & Ptotal $(\mathrm{Pa})$ & $\begin{array}{c}\text { Temperatura } \\
\text { de Bulbo } \\
\text { Seco (jato) } \\
{ }^{\circ} \mathrm{C}\end{array}$ & $\begin{array}{c}\text { Temperatura } \\
\text { de Bulbo } \\
\text { Úmido } \\
{ }^{\circ} \mathrm{C}\end{array}$ & $\begin{array}{l}\text { Patm } \\
(\mathrm{kPa})\end{array}$ & $\begin{array}{c}\text { massa } \\
\text { específica do } \\
\text { ar }(\mathrm{kg} / \mathrm{m} 3)\end{array}$ \\
\hline 125 & -35 & $-28,7$ & 20,1 & 2 & -10 & 55 & -6 & 30 & 1,348 & 55,959 & 57,305 & 23,4 & 21,3 & 92,675 & 1,064 \\
\hline 125 & -40 & $-32,8$ & 22,9 & -19 & -17 & 52 & -51 & 25 & 1,393 & 55,898 & 57,284 & 23,4 & 21,2 & 92,677 & 1,064 \\
\hline 125 & -45 & $-36,9$ & 25,8 & -37 & -54 & 49 & -73 & 21 & 1,438 & 55,836 & 57,263 & 23,4 & 21,2 & 92,679 & 1,064 \\
\hline 125 & -50 & $-41,0$ & 28,7 & -51 & -80 & 45 & -83 & 17 & 1,485 & 55,773 & 57,241 & 23,4 & 21,2 & 92,681 & 1,065 \\
\hline 125 & -55 & $-45,1$ & 31,5 & -66 & -80 & 39 & -90 & 12 & 1,532 & 55,709 & 57,219 & 23,4 & 21,1 & 92,683 & 1,065 \\
\hline 125 & -60 & $-49,1$ & 34,4 & -78 & -85 & 32 & -89 & 5 & 1,581 & 55,643 & 57,198 & 23,4 & 21,1 & 92,685 & 1,065 \\
\hline 130 & 0 & 0,0 & 0,0 & 59 & 31 & 35 & 37 & 32 & 1,630 & 55,578 & 57,176 & 23,4 & 21,1 & 92,688 & 1,065 \\
\hline 130 & -5 & $-3,8$ & 3,2 & 59 & 27 & 40 & 33 & 35 & 1,679 & 55,511 & 57,154 & 23,4 & 21,1 & 92,690 & 1,066 \\
\hline 130 & -10 & $-7,7$ & 6,4 & 57 & 22 & 43 & 28 & 38 & 1,729 & 55,444 & 57,132 & 23,5 & 21,0 & 92,692 & 1,066 \\
\hline 130 & -15 & $-11,5$ & 9,6 & 53 & 16 & 47 & 24 & 39 & 1,780 & 55,376 & 57,109 & 23,5 & 21,0 & 92,695 & 1,066 \\
\hline 130 & -20 & $-15,3$ & 12,9 & 46 & 10 & 51 & 19 & 38 & 1,831 & 55,307 & 57,087 & 23,5 & 21,0 & 92,697 & 1,067 \\
\hline 130 & -25 & $-19,2$ & 16,1 & 35 & 4 & 52 & 16 & 38 & 1,883 & 55,239 & 57,065 & 23,5 & 20,9 & 92,699 & 1,067 \\
\hline 130 & -30 & $-23,0$ & 19,3 & 22 & -2 & 54 & 16 & 37 & 1,935 & 55,170 & 57,043 & 23,5 & 20,9 & 92,701 & 1,067 \\
\hline 130 & -35 & $-26,8$ & 22,5 & 5 & -8 & 52 & 5 & 34 & 1,987 & 55,100 & 57,020 & 23,5 & 20,9 & 92,704 & 1,068 \\
\hline 130 & -40 & $-30,6$ & 25,7 & -15 & -15 & 50 & 47 & 30 & 2,039 & 55,031 & 56,998 & 23,5 & 20,9 & 92,706 & 1,068 \\
\hline 130 & -45 & $-34,5$ & 28,9 & -36 & -53 & 45 & -79 & 25 & 2,092 & 54,961 & 56,976 & 23,5 & 20,8 & 92,708 & 1,068 \\
\hline 130 & -50 & $-38,3$ & 32,1 & -49 & -86 & 40 & -88 & 21 & 2,144 & 54,892 & 56,954 & 23,5 & 20,8 & 92,711 & 1,068 \\
\hline 130 & -55 & $-42,1$ & 35,4 & -62 & -86 & 34 & -94 & 16 & 2,197 & 54,822 & 56,931 & 23,5 & 20,8 & 92,713 & 1,069 \\
\hline 130 & -60 & $-46,0$ & 38,6 & -74 & -87 & 28 & -92 & 10 & 2,249 & 54,753 & 56,909 & 23,6 & 20,7 & 92,715 & 1,069 \\
\hline 130 & 5 & 3,8 & $-3,2$ & 57 & 35 & 29 & 41 & 30 & 2,301 & 54,684 & 56,887 & 23,6 & 20,7 & 92,718 & 1,069 \\
\hline 130 & 10 & 7,7 & $-6,4$ & 55 & 39 & 23 & 43 & 25 & 2,353 & 54,615 & 56,865 & 23,6 & 20,7 & 92,720 & 1,070 \\
\hline 130 & 15 & 11,5 & $-9,6$ & 51 & 42 & 17 & 44 & 20 & 2,405 & 54,547 & 56,843 & 23,6 & 20,6 & 92,722 & 1,070 \\
\hline 130 & 20 & 15,3 & $-12,9$ & 43 & 44 & 10 & 44 & 14 & 2,456 & 54,479 & 56,822 & 23,6 & 20,6 & 92,725 & 1,070 \\
\hline 130 & 25 & 19,2 & $-16,1$ & 33 & 46 & 4 & 43 & 10 & 2,507 & 54,411 & 56,800 & 23,6 & 20,6 & 92,727 & 1,070 \\
\hline 130 & 30 & 23,0 & $-19,3$ & 18 & 46 & -3 & 40 & 9 & 2,557 & 54,344 & 56,779 & 23,6 & 20,6 & 92,729 & 1,071 \\
\hline 130 & 35 & 26,8 & $-22,5$ & 4 & 45 & -8 & 38 & 11 & 2,607 & 54,278 & 56,758 & 23,7 & 20,5 & 92,732 & 1,071 \\
\hline 130 & 40 & 30,6 & $-25,7$ & -16 & 42 & -11 & 33 & -33 & 2,656 & 54,213 & 56,736 & 23,7 & 20,5 & 92,734 & 1,071 \\
\hline 130 & 45 & 34,5 & $-28,9$ & -34 & 38 & -60 & 29 & -79 & 2,705 & 54,148 & 56,716 & 23,7 & 20,5 & 92,736 & 1,072 \\
\hline 130 & 50 & 38,3 & $-32,1$ & -50 & 33 & -96 & 22 & -98 & 2,752 & 54,085 & 56,695 & 23,7 & 20,4 & 92,738 & 1,072 \\
\hline 130 & 55 & 42,1 & $-35,4$ & -63 & 28 & -102 & 16 & -103 & 2,799 & 54,022 & 56,675 & 23,7 & 20,4 & 92,741 & 1,072 \\
\hline 130 & 60 & 46,0 & $-38,6$ & -75 & 23 & -102 & 8 & -106 & 2,845 & 53,961 & 56,654 & 23,8 & 20,4 & 92,743 & 1,072 \\
\hline 135 & 0 & 0,0 & 0,0 & 58 & 31 & 34 & 37 & 33 & 2,890 & 53,900 & 56,634 & 23,8 & 20,4 & 92,745 & 1,073 \\
\hline 135 & 5 & 3,5 & $-3,5$ & 57 & 35 & 29 & 41 & 29 & 2,934 & 53,841 & 56,615 & 23,8 & 20,3 & 92,747 & 1,073 \\
\hline 135 & 10 & 7,1 & $-7,1$ & 54 & 38 & 23 & 44 & 23 & 2,976 & 53,784 & 56,595 & 23,8 & 20,3 & 92,749 & 1,073 \\
\hline 135 & 15 & 10,6 & $-10,6$ & 49 & 41 & 17 & 45 & 18 & 3,018 & 53,727 & 56,576 & 23,8 & 20,3 & 92,751 & 1,073 \\
\hline 135 & 20 & 14,1 & $-14,1$ & 41 & 42 & 10 & 46 & 12 & 3,058 & 53,673 & 56,558 & 23,8 & 20,3 & 92,753 & 1,074 \\
\hline 135 & 25 & 17,7 & $-17,7$ & 31 & 43 & 5 & 45 & 8 & 3,097 & 53,619 & 56,539 & 23,9 & 20,2 & 92,756 & 1,074 \\
\hline 135 & 30 & 21,2 & $-21,2$ & 19 & 43 & -2 & 43 & 4 & 3,134 & 53,568 & 56,521 & 23,9 & 20,2 & 92,758 & 1,074 \\
\hline 135 & 35 & 24,7 & $-24,7$ & 3 & 42 & -3 & 40 & 4 & 3,170 & 53,518 & 56,504 & 23,9 & 20,2 & 92,760 & 1,074 \\
\hline 135 & 40 & 28,3 & $-28,3$ & -15 & 38 & -8 & 36 & -37 & 3,205 & 53,470 & 56,486 & 23,9 & 20,2 & 92,762 & 1,075 \\
\hline
\end{tabular}




\begin{tabular}{|c|c|c|c|c|c|c|c|c|c|c|c|c|c|c|c|}
\hline $\begin{array}{c}\text { Ângulo } \\
\text { g } \\
\text { (graus) }\end{array}$ & $\begin{array}{c}\text { Ângulo } \\
\text { a } \\
\text { (graus) }\end{array}$ & $\begin{array}{c}\text { Ângulo de } \\
\text { guinada } \Psi \\
\text { (graus) }\end{array}$ & $\begin{array}{l}\text { Ângulo de } \\
\text { arfagem } \delta \\
\text { (graus) }\end{array}$ & $\mathrm{p} 1(\mathrm{~Pa})$ & p2 (Pa) & p3 (Pa) & $\mathrm{p} 4(\mathrm{~Pa})$ & p5 $(\mathrm{Pa})$ & $\mathrm{P}$ est $(\mathrm{Pa})$ & $P \operatorname{din}(\mathrm{Pa})$ & Ptotal $(\mathrm{Pa})$ & $\begin{array}{c}\text { Temperatura } \\
\text { de Bulbo } \\
\text { Seco (jato) } \\
{ }^{\circ} \mathrm{C}\end{array}$ & $\begin{array}{c}\text { Temperatura } \\
\text { de Bulbo } \\
\text { Úmido } \\
{ }^{\circ} \mathrm{C}\end{array}$ & $\begin{array}{l}\text { Patm } \\
(\mathrm{kPa})\end{array}$ & $\begin{array}{c}\text { massa } \\
\text { específica do } \\
\text { ar }(\mathrm{kg} / \mathrm{m} 3)\end{array}$ \\
\hline 135 & 45 & 31,8 & $-31,8$ & -34 & 34 & -65 & 30 & -77 & 3,238 & 53,423 & 56,469 & 23,9 & 20,2 & 92,764 & 1,075 \\
\hline 135 & 50 & 35,4 & $-35,4$ & -49 & 29 & -98 & 25 & -101 & 3,269 & 53,379 & 56,453 & 24,0 & 20,1 & 92,765 & 1,075 \\
\hline 135 & 55 & 38,9 & $-38,9$ & -61 & 24 & -105 & 19 & -107 & 3,298 & 53,337 & 56,437 & 24,0 & 20,1 & 92,767 & 1,075 \\
\hline 135 & 60 & 42,4 & $-42,4$ & -72 & 18 & -105 & 13 & -108 & 3,326 & 53,297 & 56,421 & 24,0 & 20,1 & 92,769 & 1,075 \\
\hline 135 & -5 & $-3,5$ & 3,5 & 60 & 29 & 39 & 32 & 39 & 3,352 & 53,259 & 56,406 & 24,0 & 20,1 & 92,771 & 1,075 \\
\hline 135 & -10 & $-7,1$ & 7,1 & 58 & 23 & 41 & 27 & 41 & 3,375 & 53,223 & 56,391 & 24,0 & 20,1 & 92,773 & 1,076 \\
\hline 135 & -15 & $-10,6$ & 10,6 & 53 & 16 & 46 & 22 & 41 & 3,397 & 53,190 & 56,377 & 24,1 & 20,0 & 92,774 & 1,076 \\
\hline 135 & -20 & $-14,1$ & 14,1 & 46 & 10 & 48 & 17 & 42 & 3,417 & 53,159 & 56,363 & 24,1 & 20,0 & 92,776 & 1,076 \\
\hline 135 & -25 & $-17,7$ & 17,7 & 35 & 4 & 50 & 16 & 41 & 3,434 & 53,130 & 56,349 & 24,1 & 20,0 & 92,778 & 1,076 \\
\hline 135 & -30 & $-21,2$ & 21,2 & 22 & -1 & 50 & 14 & 40 & 3,449 & 53,105 & 56,337 & 24,1 & 20,0 & 92,779 & 1,076 \\
\hline 135 & -35 & $-24,7$ & 24,7 & 6 & -6 & 49 & 10 & 37 & 3,462 & 53,082 & 56,324 & 24,1 & 20,0 & 92,781 & 1,076 \\
\hline 135 & -40 & $-28,3$ & 28,3 & -15 & -11 & 45 & -47 & 33 & 3,473 & 53,061 & 56,313 & 24,1 & 20,0 & 92,782 & 1,077 \\
\hline 135 & -45 & $-31,8$ & 31,8 & -33 & -66 & 42 & -83 & 29 & 3,481 & 53,044 & 56,302 & 24,1 & 19,9 & 92,784 & 1,077 \\
\hline 135 & -50 & $-35,4$ & 35,4 & -49 & -92 & 36 & -93 & 24 & 3,487 & 53,029 & 56,291 & 24,2 & 19,9 & 92,785 & 1,077 \\
\hline 135 & -55 & $-38,9$ & 38,9 & -60 & -95 & 31 & -98 & 19 & 3,490 & 53,017 & 56,281 & 24,2 & 19,9 & 92,786 & 1,077 \\
\hline 135 & -60 & $-42,4$ & 42,4 & -71 & -92 & 24 & -95 & 14 & 3,490 & 53,009 & 56,272 & 24,2 & 19,9 & 92,788 & 1,077 \\
\hline 140 & 0 & 0,0 & 0,0 & 60 & 34 & 36 & 37 & 35 & 3,488 & 53,003 & 56,263 & 24,2 & 19,9 & 92,789 & 1,077 \\
\hline 140 & -5 & $-3,2$ & 3,8 & 60 & 31 & 38 & 33 & 38 & 3,483 & 53,000 & 56,255 & 24,2 & 19,9 & 92,790 & 1,077 \\
\hline 140 & -10 & $-6,4$ & 7,7 & 59 & 26 & 42 & 29 & 41 & 3,477 & 53,000 & 56,247 & 24,2 & 19,9 & 92,791 & 1,077 \\
\hline 140 & -15 & $-9,6$ & 11,5 & 55 & 20 & 44 & 23 & 44 & 3,469 & 53,001 & 56,240 & 24,2 & 19,9 & 92,792 & 1,077 \\
\hline 140 & -20 & $-12,9$ & 15,3 & 48 & 14 & 46 & 17 & 45 & 3,458 & 53,005 & 56,233 & 24,3 & 19,9 & 92,794 & 1,077 \\
\hline 140 & -25 & $-16,1$ & 19,2 & 36 & 6 & 46 & 13 & 47 & 3,447 & 53,010 & 56,226 & 24,3 & 19,9 & 92,795 & 1,077 \\
\hline 140 & -30 & $-19,3$ & 23,0 & 25 & 5 & 46 & 9 & 46 & 3,433 & 53,018 & 56,220 & 24,3 & 19,9 & 92,796 & 1,077 \\
\hline 140 & -35 & $-22,5$ & 26,8 & 12 & 0 & 45 & 7 & 43 & 3,418 & 53,027 & 56,214 & 24,3 & 19,9 & 92,797 & 1,077 \\
\hline 140 & -40 & $-25,7$ & 30,6 & -6 & -3 & 42 & -28 & 41 & 3,401 & 53,038 & 56,208 & 24,3 & 19,8 & 92,798 & 1,077 \\
\hline 140 & -45 & $-28,9$ & 34,5 & -25 & -58 & 38 & -70 & 37 & 3,382 & 53,052 & 56,203 & 24,3 & 19,8 & 92,799 & 1,077 \\
\hline 140 & -50 & $-32,1$ & 38,3 & -42 & -72 & 33 & -89 & 32 & 3,363 & 53,067 & 56,199 & 24,4 & 19,8 & 92,800 & 1,077 \\
\hline 140 & -55 & $-35,4$ & 42,1 & -53 & -84 & 26 & -94 & 27 & 3,341 & 53,083 & 56,194 & 24,4 & 19,8 & 92,801 & 1,077 \\
\hline 140 & -60 & $-38,6$ & 46,0 & -63 & -83 & 22 & -91 & 22 & 3,318 & 53,101 & 56,190 & 24,4 & 19,8 & 92,802 & 1,077 \\
\hline 140 & 5 & 3,2 & $-3,8$ & 56 & 37 & 29 & 40 & 30 & 3,294 & 53,121 & 56,186 & 24,4 & 19,8 & 92,802 & 1,077 \\
\hline 140 & 10 & 6,4 & $-7,7$ & 55 & 40 & 24 & 43 & 25 & 3,269 & 53,143 & 56,183 & 24,4 & 19,8 & 92,803 & 1,077 \\
\hline 140 & 15 & 9,6 & $-11,5$ & 50 & 42 & 18 & 46 & 19 & 3,242 & 53,166 & 56,180 & 24,4 & 19,8 & 92,804 & 1,077 \\
\hline 140 & 20 & 12,9 & $-15,3$ & 41 & 43 & 13 & 46 & 12 & 3,214 & 53,190 & 56,177 & 24,5 & 19,8 & 92,805 & 1,077 \\
\hline 140 & 25 & 16,1 & $-19,2$ & 32 & 43 & 7 & 41 & 9 & 3,184 & 53,216 & 56,174 & 24,5 & 19,8 & 92,806 & 1,077 \\
\hline 140 & 30 & 19,3 & $-23,0$ & 18 & 42 & 2 & 45 & 5 & 3,154 & 53,243 & 56,172 & 24,5 & 19,8 & 92,807 & 1,077 \\
\hline 140 & 35 & 22,5 & $-26,8$ & 5 & 40 & 2 & 42 & 3 & 3,122 & 53,271 & 56,170 & 24,5 & 19,8 & 92,807 & 1,077 \\
\hline 140 & 40 & 25,7 & $-30,6$ & -14 & 37 & -4 & 39 & -28 & 3,090 & 53,301 & 56,168 & 24,6 & 19,8 & 92,808 & 1,077 \\
\hline 140 & 45 & 28,9 & $-34,5$ & -32 & 33 & -62 & 34 & -70 & 3,056 & 53,332 & 56,166 & 24,6 & 19,8 & 92,809 & 1,077 \\
\hline 140 & 50 & 32,1 & $-38,3$ & -48 & 28 & -96 & 28 & -96 & 3,022 & 53,364 & 56,165 & 24,6 & 19,8 & 92,810 & 1,077 \\
\hline 140 & 55 & 35,4 & $-42,1$ & -60 & 22 & -101 & 23 & -102 & 2,986 & 53,397 & 56,164 & 24,6 & 19,8 & 92,810 & 1,077 \\
\hline
\end{tabular}




\begin{tabular}{|c|c|c|c|c|c|c|c|c|c|c|c|c|c|c|c|}
\hline $\begin{array}{c}\text { Ângulo } \\
\text { g } \\
\text { (graus) }\end{array}$ & $\begin{array}{c}\text { Ângulo } \\
a \\
\text { (graus) }\end{array}$ & $\begin{array}{c}\text { Ângulo de } \\
\text { guinada } \psi \\
\text { (graus) }\end{array}$ & $\begin{array}{c}\text { Ângulo de } \\
\text { arfagem } \delta \\
\text { (graus) }\end{array}$ & $\mathrm{p} 1(\mathrm{~Pa})$ & p2 (Pa) & p3 $(\mathrm{Pa})$ & $\mathrm{p} 4(\mathrm{~Pa})$ & p5 $(\mathrm{Pa})$ & $\mathrm{P}$ est $(\mathrm{Pa})$ & $P \operatorname{din}(\mathrm{Pa})$ & Ptotal $(\mathrm{Pa})$ & $\begin{array}{c}\text { Temperatura } \\
\text { de Bulbo } \\
\text { Seco (jato) } \\
{ }^{\circ} \mathrm{C}\end{array}$ & $\begin{array}{c}\text { Temperatura } \\
\text { de Bulbo } \\
\text { Úmido } \\
{ }^{\circ} \mathrm{C}\end{array}$ & $\begin{array}{l}\text { Patm } \\
(\mathrm{kPa})\end{array}$ & $\begin{array}{c}\text { massa } \\
\text { específica do } \\
\text { ar }(\mathrm{kg} / \mathrm{m} 3)\end{array}$ \\
\hline 140 & 60 & 38,6 & $-46,0$ & -70 & 16 & -104 & 17 & -103 & 2,950 & 53,431 & 56,163 & 24,6 & 19,8 & 92,811 & 1,077 \\
\hline 145 & 0 & 0,0 & 0,0 & 59 & 33 & 34 & 35 & 33 & 2,913 & 53,466 & 56,163 & 24,7 & 19,8 & 92,812 & 1,077 \\
\hline 145 & 5 & 2,9 & $-4,1$ & 56 & 37 & 30 & 40 & 29 & 2,875 & 53,502 & 56,162 & 24,7 & 19,8 & 92,812 & 1,077 \\
\hline 145 & 10 & 5,7 & $-8,2$ & 54 & 38 & 25 & 43 & 23 & 2,836 & 53,539 & 56,162 & 24,7 & 19,8 & 92,813 & 1,077 \\
\hline 145 & 15 & 8,6 & $-12,3$ & 51 & 41 & 19 & 45 & 17 & 2,797 & 53,577 & 56,162 & 24,7 & 19,8 & 92,814 & 1,077 \\
\hline 145 & 20 & 11,5 & $-16,4$ & 43 & 41 & 14 & 47 & 11 & 2,757 & 53,615 & 56,162 & 24,8 & 19,8 & 92,814 & 1,076 \\
\hline 145 & 25 & 14,3 & $-20,5$ & 32 & 41 & 8 & 47 & 6 & 2,716 & 53,654 & 56,163 & 24,8 & 19,9 & 92,815 & 1,076 \\
\hline 145 & 30 & 17,2 & $-24,6$ & 20 & 39 & 5 & 47 & 1 & 2,675 & 53,694 & 56,163 & 24,8 & 19,9 & 92,816 & 1,076 \\
\hline 145 & 35 & 20,1 & $-28,7$ & 4 & 37 & 8 & 45 & -1 & 2,633 & 53,735 & 56,164 & 24,8 & 19,9 & 92,816 & 1,076 \\
\hline 145 & 40 & 22,9 & $-32,8$ & -15 & 33 & -22 & 41 & -25 & 2,591 & 53,776 & 56,165 & 24,9 & 19,9 & 92,817 & 1,076 \\
\hline 145 & 45 & 25,8 & $-36,9$ & -33 & 29 & -70 & 35 & -72 & 2,548 & 53,818 & 56,166 & 24,9 & 19,9 & 92,817 & 1,076 \\
\hline 145 & 50 & 28,7 & $-41,0$ & -46 & 24 & -94 & 30 & -95 & 2,505 & 53,860 & 56,167 & 24,9 & 19,9 & 92,818 & 1,076 \\
\hline 145 & 55 & 31,5 & $-45,1$ & -58 & 19 & -100 & 24 & -101 & 2,462 & 53,902 & 56,168 & 25,0 & 19,9 & 92,818 & 1,076 \\
\hline 145 & 60 & 34,4 & $-49,1$ & -69 & 13 & -100 & 19 & -98 & 2,419 & 53,945 & 56,170 & 25,0 & 19,9 & 92,819 & 1,076 \\
\hline 145 & -5 & $-2,9$ & 4,1 & 58 & 31 & 37 & 32 & 39 & 2,375 & 53,988 & 56,171 & 25,0 & 19,9 & 92,819 & 1,076 \\
\hline 145 & -10 & $-5,7$ & 8,2 & 57 & 27 & 40 & 28 & 42 & 2,331 & 54,032 & 56,173 & 25,0 & 19,9 & 92,820 & 1,076 \\
\hline 145 & -15 & $-8,6$ & 12,3 & 54 & 22 & 42 & 23 & 45 & 2,287 & 54,075 & 56,174 & 25,1 & 19,9 & 92,821 & 1,075 \\
\hline 145 & -20 & $-11,5$ & 16,4 & 47 & 16 & 44 & 16 & 47 & 2,242 & 54,119 & 56,176 & 25,1 & 19,9 & 92,821 & 1,075 \\
\hline 145 & -25 & $-14,3$ & 20,5 & 39 & 12 & 44 & 11 & 49 & 2,198 & 54,163 & 56,178 & 25,1 & 19,9 & 92,822 & 1,075 \\
\hline 145 & -30 & $-17,2$ & 24,6 & 28 & 9 & 43 & 6 & 49 & 2,154 & 54,207 & 56,180 & 25,1 & 19,9 & 92,822 & 1,075 \\
\hline 145 & -35 & $-20,1$ & 28,7 & 13 & 10 & 42 & 4 & 47 & 2,110 & 54,251 & 56,182 & 25,2 & 19,9 & 92,822 & 1,075 \\
\hline 145 & -40 & $-22,9$ & 32,8 & -4 & -12 & 39 & -7 & 46 & 2,066 & 54,295 & 56,184 & 25,2 & 19,9 & 92,823 & 1,075 \\
\hline 145 & -45 & $-25,8$ & 36,9 & -22 & -65 & 34 & -62 & 41 & 2,022 & 54,339 & 56,186 & 25,2 & 19,9 & 92,823 & 1,075 \\
\hline 145 & -50 & $-28,7$ & 41,0 & -38 & -87 & 31 & -86 & 36 & 1,978 & 54,382 & 56,189 & 25,2 & 19,9 & 92,824 & 1,075 \\
\hline 145 & -55 & $-31,5$ & 45,1 & -50 & -91 & 25 & -90 & 30 & 1,934 & 54,426 & 56,191 & 25,3 & 20,0 & 92,824 & 1,075 \\
\hline 145 & -60 & $-34,4$ & 49,1 & -60 & -92 & 17 & -84 & 25 & 1,891 & 54,469 & 56,193 & 25,3 & 20,0 & 92,825 & 1,074 \\
\hline 150 & 0 & 0,0 & 0,0 & 60 & 32 & 37 & 37 & 35 & 1,848 & 54,512 & 56,195 & 25,3 & 20,0 & 92,825 & 1,074 \\
\hline 150 & -5 & $-2,5$ & 4,3 & 59 & 29 & 41 & 33 & 39 & 1,805 & 54,554 & 56,197 & 25,3 & 20,0 & 92,826 & 1,074 \\
\hline 150 & -10 & $-5,0$ & 8,7 & 57 & 25 & 43 & 27 & 43 & 1,763 & 54,597 & 56,200 & 25,4 & 20,0 & 92,826 & 1,074 \\
\hline 150 & -15 & $-7,5$ & 13,0 & 53 & 20 & 45 & 21 & 46 & 1,721 & 54,638 & 56,202 & 25,4 & 20,0 & 92,826 & 1,074 \\
\hline 150 & -20 & $-10,0$ & 17,3 & 47 & 16 & 45 & 15 & 49 & 1,680 & 54,679 & 56,204 & 25,4 & 20,0 & 92,827 & 1,074 \\
\hline 150 & -25 & $-12,5$ & 21,7 & 37 & 12 & 45 & 10 & 50 & 1,639 & 54,720 & 56,206 & 25,4 & 20,0 & 92,827 & 1,074 \\
\hline 150 & -30 & $-15,0$ & 26,0 & 24 & 10 & 42 & 5 & 50 & 1,599 & 54,760 & 56,208 & 25,5 & 20,0 & 92,828 & 1,074 \\
\hline 150 & -35 & $-17,5$ & 30,3 & 10 & 11 & 39 & 2 & 48 & 1,559 & 54,799 & 56,210 & 25,5 & 20,0 & 92,828 & 1,074 \\
\hline 150 & -40 & $-20,0$ & 34,6 & -8 & -36 & 36 & -30 & 46 & 1,520 & 54,838 & 56,212 & 25,5 & 20,0 & 92,829 & 1,073 \\
\hline 150 & -45 & $-22,5$ & 39,0 & -25 & -75 & 31 & -70 & 41 & 1,482 & 54,875 & 56,214 & 25,5 & 20,0 & 92,829 & 1,073 \\
\hline 150 & -50 & $-25,0$ & 43,3 & -40 & -87 & 26 & -86 & 37 & 1,445 & 54,912 & 56,216 & 25,6 & 20,0 & 92,829 & 1,073 \\
\hline 150 & -55 & $-27,5$ & 47,6 & -52 & -92 & 20 & -87 & 31 & 1,408 & 54,948 & 56,218 & 25,6 & 20,0 & 92,830 & 1,073 \\
\hline 150 & -60 & $-30,0$ & 52,0 & -61 & -90 & 14 & -85 & 27 & 1,373 & 54,984 & 56,220 & 25,6 & 20,0 & 92,830 & 1,073 \\
\hline 150 & 5 & 2,5 & $-4,3$ & 58 & 41 & 27 & 33 & 33 & 1,338 & 55,018 & 56,222 & 25,6 & 20,0 & 92,831 & 1,073 \\
\hline
\end{tabular}




\begin{tabular}{|c|c|c|c|c|c|c|c|c|c|c|c|c|c|c|c|}
\hline $\begin{array}{c}\text { Ângulo } \\
\text { g } \\
\text { (graus) }\end{array}$ & $\begin{array}{c}\text { Ângulo } \\
\text { a } \\
\text { (graus) }\end{array}$ & $\begin{array}{l}\text { Ângulo de } \\
\text { guinada } \Psi \\
\text { (graus) }\end{array}$ & $\begin{array}{c}\text { Ângulo de } \\
\text { arfagem } \delta \\
\text { (graus) }\end{array}$ & $\mathrm{p} 1(\mathrm{~Pa})$ & p2 (Pa) & p3 (Pa) & p4 (Pa) & p5 $(\mathrm{Pa})$ & P est $(\mathrm{Pa})$ & $P \operatorname{din}(\mathrm{Pa})$ & Ptotal $(\mathrm{Pa})$ & $\begin{array}{c}\text { Temperatura } \\
\text { de Bulbo } \\
\text { Seco (jato) } \\
{ }^{\circ} \mathrm{C}\end{array}$ & $\begin{array}{c}\text { Temperatura } \\
\text { de Bulbo } \\
\text { Úmido } \\
{ }^{\circ} \mathrm{C}\end{array}$ & $\begin{array}{l}\text { Patm } \\
(\mathrm{kPa})\end{array}$ & $\begin{array}{c}\text { massa } \\
\text { específica do } \\
\operatorname{ar}(\mathrm{kg} / \mathrm{m} 3)\end{array}$ \\
\hline 150 & 10 & 5,0 & $-8,7$ & 55 & 44 & 22 & 37 & 29 & 1,304 & 55,051 & 56,223 & 25,7 & 20,1 & 92,831 & 1,073 \\
\hline 150 & 15 & 7,5 & $-13,0$ & 52 & 46 & 17 & 40 & 22 & 1,271 & 55,083 & 56,225 & 25,7 & 20,1 & 92,832 & 1,073 \\
\hline 150 & 20 & 10,0 & $-17,3$ & 45 & 47 & 12 & 41 & 17 & 1,240 & 55,114 & 56,226 & 25,7 & 20,1 & 92,832 & 1,073 \\
\hline 150 & 25 & 12,5 & $-21,7$ & 36 & 46 & 8 & 43 & 13 & 1,209 & 55,143 & 56,227 & 25,7 & 20,1 & 92,832 & 1,073 \\
\hline 150 & 30 & 15,0 & $-26,0$ & 23 & 45 & 3 & 43 & 8 & 1,180 & 55,172 & 56,228 & 25,8 & 20,1 & 92,833 & 1,072 \\
\hline 150 & 35 & 17,5 & $-30,3$ & 9 & 42 & -1 & 40 & 6 & 1,151 & 55,199 & 56,229 & 25,8 & 20,1 & 92,833 & 1,072 \\
\hline 150 & 40 & 20,0 & $-34,6$ & -8 & 38 & 0 & 38 & -14 & 1,124 & 55,225 & 56,230 & 25,8 & 20,1 & 92,834 & 1,072 \\
\hline 150 & 45 & 22,5 & $-39,0$ & 27 & 33 & -50 & 34 & -57 & 1,098 & 55,249 & 56,230 & 25,8 & 20,1 & 92,834 & 1,072 \\
\hline 150 & 50 & 25,0 & $-43,3$ & -42 & 28 & -90 & 29 & -93 & 1,074 & 55,272 & 56,231 & 25,8 & 20,1 & 92,835 & 1,072 \\
\hline 150 & 55 & 27,5 & $-47,6$ & -55 & 22 & -99 & 23 & -102 & 1,051 & 55,294 & 56,231 & 25,9 & 20,1 & 92,835 & 1,072 \\
\hline 150 & 60 & 30,0 & $-52,0$ & -66 & 16 & -102 & 19 & -104 & 1,029 & 55,314 & 56,231 & 25,9 & 20,1 & 92,836 & 1,072 \\
\hline 155 & 0 & 0,0 & 0,0 & 57 & 37 & 28 & 29 & 38 & 1,009 & 55,332 & 56,231 & 25,9 & 20,1 & 92,836 & 1,072 \\
\hline 155 & 5 & 2,1 & $-4,5$ & 57 & 40 & 26 & 34 & 31 & 0,990 & 55,349 & 56,231 & 25,9 & 20,1 & 92,836 & 1,072 \\
\hline 155 & 10 & 4,2 & $-9,1$ & 55 & 42 & 21 & 39 & 27 & 0,974 & 55,363 & 56,231 & 25,9 & 20,1 & 92,837 & 1,072 \\
\hline 155 & 15 & 6,3 & $-13,6$ & 51 & 43 & 17 & 42 & 19 & 0,959 & 55,376 & 56,231 & 26,0 & 20,1 & 92,837 & 1,072 \\
\hline 155 & 20 & 8,5 & $-18,1$ & 44 & 43 & 12 & 45 & 13 & 0,945 & 55,388 & 56,232 & 26,0 & 20,1 & 92,838 & 1,072 \\
\hline 155 & 25 & 10,6 & $-22,7$ & 35 & 42 & 8 & 46 & 8 & 0,934 & 55,397 & 56,232 & 26,0 & 20,1 & 92,838 & 1,072 \\
\hline 155 & 30 & 12,7 & $-27,2$ & 22 & 40 & 4 & 45 & 2 & 0,924 & 55,405 & 56,233 & 26,0 & 20,1 & 92,839 & 1,072 \\
\hline 155 & 35 & 14,8 & $-31,7$ & 8 & 37 & 8 & 45 & -2 & 0,915 & 55,411 & 56,234 & 26,0 & 20,1 & 92,839 & 1,072 \\
\hline 155 & 40 & 16,9 & $-36,3$ & -10 & 32 & -5 & 42 & -9 & 0,908 & 55,415 & 56,235 & 26,0 & 20,1 & 92,840 & 1,072 \\
\hline 155 & 45 & 19,0 & $-40,8$ & -27 & 28 & -55 & 38 & -54 & 0,903 & 55,418 & 56,236 & 26,1 & 20,1 & 92,840 & 1,071 \\
\hline 155 & 50 & 21,1 & $-45,3$ & -42 & 23 & -91 & 33 & -92 & 0,900 & 55,419 & 56,237 & 26,1 & 20,1 & 92,841 & 1,071 \\
\hline 155 & 55 & 23,2 & $-49,8$ & -54 & 17 & -97 & 28 & -99 & 0,898 & 55,419 & 56,239 & 26,1 & 20,1 & 92,841 & 1,071 \\
\hline 155 & 60 & 25,4 & $-54,4$ & -65 & 11 & -101 & 22 & -98 & 0,897 & 55,417 & 56,241 & 26,1 & 20,1 & 92,842 & 1,071 \\
\hline 155 & -5 & $-2,1$ & 4,5 & 58 & 31 & 36 & 30 & 40 & 0,898 & 55,413 & 56,243 & 26,1 & 20,1 & 92,842 & 1,071 \\
\hline 155 & -10 & $-4,2$ & 9,1 & 55 & 27 & 36 & 23 & 44 & 0,901 & 55,408 & 56,245 & 26,2 & 20,1 & 92,843 & 1,071 \\
\hline 155 & -15 & $-6,3$ & 13,6 & 51 & 23 & 38 & 18 & 47 & 0,905 & 55,402 & 56,247 & 26,2 & 20,2 & 92,843 & 1,071 \\
\hline 155 & -20 & $-8,5$ & 18,1 & 44 & 18 & 39 & 11 & 50 & 0,910 & 55,394 & 56,249 & 26,2 & 20,2 & 92,843 & 1,071 \\
\hline 155 & -25 & $-10,6$ & 22,7 & 34 & 15 & 37 & 5 & 51 & 0,917 & 55,384 & 56,251 & 26,2 & 20,2 & 92,844 & 1,071 \\
\hline 155 & -30 & $-12,7$ & 27,2 & 21 & 15 & 33 & -1 & 50 & 0,925 & 55,373 & 56,254 & 26,2 & 20,2 & 92,844 & 1,071 \\
\hline 155 & -35 & $-14,8$ & 31,7 & 6 & 11 & 30 & -7 & 50 & 0,934 & 55,361 & 56,257 & 26,2 & 20,2 & 92,845 & 1,071 \\
\hline 155 & -40 & $-16,9$ & 36,3 & -11 & -39 & 26 & -13 & 49 & 0,945 & 55,348 & 56,259 & 26,3 & 20,2 & 92,845 & 1,071 \\
\hline 155 & -45 & $-19,0$ & 40,8 & -28 & -69 & 22 & -69 & 45 & 0,957 & 55,333 & 56,262 & 26,3 & 20,2 & 92,846 & 1,071 \\
\hline 155 & -50 & $-21,1$ & 45,3 & -39 & -79 & 17 & -77 & 40 & 0,971 & 55,316 & 56,265 & 26,3 & 20,2 & 92,846 & 1,071 \\
\hline 155 & -55 & $-23,2$ & 49,8 & -54 & -89 & 10 & -80 & 35 & 0,985 & 55,299 & 56,268 & 26,3 & 20,2 & 92,847 & 1,071 \\
\hline 155 & -60 & $-25,4$ & 54,4 & -65 & -87 & 5 & -82 & 30 & 1,001 & 55,280 & 56,272 & 26,3 & 20,2 & 92,847 & 1,071 \\
\hline 160 & 0 & 0,0 & 0,0 & 58 & 34 & 32 & 33 & 35 & 1,018 & 55,260 & 56,275 & 26,3 & 20,2 & 92,847 & 1,071 \\
\hline 160 & -5 & $-1,7$ & 4,7 & 58 & 32 & 34 & 29 & 39 & 1,036 & 55,239 & 56,279 & 26,4 & 20,2 & 92,848 & 1,070 \\
\hline 160 & -10 & $-3,4$ & 9,4 & 56 & 28 & 34 & 23 & 44 & 1,056 & 55,217 & 56,282 & 26,4 & 20,2 & 92,848 & 1,070 \\
\hline 160 & -15 & $-5,1$ & 14,1 & 52 & 24 & 36 & 17 & 48 & 1,076 & 55,193 & 56,286 & 26,4 & 20,2 & 92,849 & 1,070 \\
\hline
\end{tabular}




\begin{tabular}{|c|c|c|c|c|c|c|c|c|c|c|c|c|c|c|c|}
\hline $\begin{array}{c}\text { Ângulo } \\
\text { g } \\
\text { (graus) }\end{array}$ & $\begin{array}{c}\text { Ângulo } \\
\text { a } \\
\text { (graus) }\end{array}$ & $\begin{array}{l}\text { Ângulo de } \\
\text { guinada } \psi \\
\text { (graus) }\end{array}$ & $\begin{array}{c}\text { Ângulo de } \\
\text { arfagem } \delta \\
\text { (graus) }\end{array}$ & $\mathrm{p} 1(\mathrm{~Pa})$ & p2 $(\mathrm{Pa})$ & p3 $(\mathrm{Pa})$ & p4 (Pa) & p5 (Pa) & $\mathrm{P}$ est $(\mathrm{Pa})$ & $\mathrm{P} \operatorname{din}(\mathrm{Pa})$ & Ptotal $(\mathrm{Pa})$ & $\begin{array}{c}\text { Temperatura } \\
\text { de Bulbo } \\
\text { Seco (jato) } \\
{ }^{\circ} \mathrm{C} \\
\end{array}$ & $\begin{array}{c}\text { Temperatura } \\
\text { de Bulbo } \\
\text { Úmido } \\
{ }^{\circ} \mathrm{C}\end{array}$ & $\begin{array}{l}\text { Patm } \\
(\mathrm{kPa})\end{array}$ & $\begin{array}{c}\text { massa } \\
\text { específica do } \\
\text { ar }(\mathrm{kg} / \mathrm{m} 3)\end{array}$ \\
\hline 160 & -20 & $-6,8$ & 18,8 & 44 & 20 & 35 & 10 & 52 & 1,098 & 55,168 & 56,290 & 26,4 & 20,2 & 92,849 & 1,070 \\
\hline 160 & -25 & $-8,6$ & 23,5 & 34 & 17 & 33 & 5 & 53 & 1,121 & 55,142 & 56,294 & 26,4 & 20,2 & 92,850 & 1,070 \\
\hline 160 & -30 & $-10,3$ & 28,2 & 22 & 17 & 30 & -2 & 54 & 1,145 & 55,116 & 56,298 & 26,4 & 20,2 & 92,850 & 1,070 \\
\hline 160 & -35 & $-12,0$ & 32,9 & 6 & 4 & 27 & -8 & 52 & 1,169 & 55,088 & 56,302 & 26,5 & 20,2 & 92,850 & 1,070 \\
\hline 160 & -40 & $-13,7$ & 37,6 & -12 & -41 & 22 & -14 & 50 & 1,195 & 55,059 & 56,306 & 26,5 & 20,2 & 92,851 & 1,070 \\
\hline 160 & -45 & $-15,4$ & 42,3 & -28 & -64 & 19 & -57 & 47 & 1,222 & 55,029 & 56,310 & 26,5 & 20,3 & 92,851 & 1,070 \\
\hline 160 & -50 & $-17,1$ & 47,0 & -42 & -72 & 14 & -70 & 43 & 1,250 & 54,998 & 56,314 & 26,5 & 20,3 & 92,852 & 1,070 \\
\hline 160 & -55 & $-18,8$ & 51,7 & -55 & -81 & 8 & -74 & 38 & 1,278 & 54,966 & 56,319 & 26,5 & 20,3 & 92,852 & 1,070 \\
\hline 160 & -60 & $-20,5$ & 56,4 & -70 & -80 & 1 & -80 & 33 & 1,308 & 54,933 & 56,323 & 26,5 & 20,3 & 92,852 & 1,070 \\
\hline 160 & 5 & 1,7 & $-4,7$ & 57 & 31 & 33 & 40 & 27 & 1,338 & 54,899 & 56,328 & 26,5 & 20,3 & 92,853 & 1,070 \\
\hline 160 & 10 & 3,4 & $-9,4$ & 55 & 32 & 30 & 45 & 22 & 1,370 & 54,865 & 56,333 & 26,6 & 20,3 & 92,853 & 1,070 \\
\hline 160 & 15 & 5,1 & $-14,1$ & 51 & 32 & 25 & 49 & 15 & 1,402 & 54,829 & 56,337 & 26,6 & 20,3 & 92,854 & 1,070 \\
\hline 160 & 20 & 6,8 & $-18,8$ & 43 & 31 & 20 & 51 & 8 & 1,435 & 54,793 & 56,342 & 26,6 & 20,3 & 92,854 & 1,070 \\
\hline 160 & 25 & 8,6 & $-23,5$ & 34 & 29 & 16 & 53 & 1 & 1,469 & 54,756 & 56,347 & 26,6 & 20,3 & 92,854 & 1,069 \\
\hline 160 & 30 & 10,3 & $-28,2$ & 22 & 26 & 15 & 54 & -5 & 1,503 & 54,718 & 56,352 & 26,6 & 20,3 & 92,855 & 1,069 \\
\hline 160 & 35 & 12,0 & $-32,9$ & 6 & 23 & 16 & 52 & -11 & 1,539 & 54,680 & 56,357 & 26,6 & 20,3 & 92,855 & 1,069 \\
\hline 160 & 40 & 13,7 & $-37,6$ & -14 & 18 & -30 & 51 & -19 & 1,575 & 54,640 & 56,362 & 26,6 & 20,3 & 92,856 & 1,069 \\
\hline 160 & 45 & 15,4 & $-42,3$ & -30 & 15 & -60 & 47 & -35 & 1,611 & 54,600 & 56,367 & 26,7 & 20,3 & 92,856 & 1,069 \\
\hline 160 & 50 & 17,1 & $-47,0$ & -44 & 10 & -74 & 43 & -80 & 1,649 & 54,560 & 56,372 & 26,7 & 20,3 & 92,856 & 1,069 \\
\hline 160 & 55 & 18,8 & $-51,7$ & -57 & 5 & -83 & 38 & -82 & 1,687 & 54,518 & 56,377 & 26,7 & 20,3 & 92,857 & 1,069 \\
\hline 160 & 60 & 20,5 & $-56,4$ & -74 & -1 & -89 & 31 & -91 & 1,725 & 54,476 & 56,382 & 26,7 & 20,3 & 92,857 & 1,069 \\
\hline 165 & 0 & 0,0 & 0,0 & 57 & 29 & 35 & 35 & 32 & 1,764 & 54,434 & 56,387 & 26,7 & 20,4 & 92,857 & 1,069 \\
\hline 165 & 5 & 1,3 & $-4,8$ & 57 & 31 & 34 & 40 & 27 & 1,804 & 54,391 & 56,392 & 26,7 & 20,4 & 92,858 & 1,069 \\
\hline 165 & 10 & 2,6 & $-9,7$ & 56 & 32 & 30 & 46 & 21 & 1,844 & 54,347 & 56,397 & 26,7 & 20,4 & 92,858 & 1,069 \\
\hline 165 & 15 & 3,9 & $-14,5$ & 51 & 30 & 26 & 49 & 14 & 1,885 & 54,303 & 56,403 & 26,8 & 20,4 & 92,858 & 1,069 \\
\hline 165 & 20 & 5,2 & $-19,3$ & 44 & 29 & 22 & 53 & 7 & 1,927 & 54,258 & 56,408 & 26,8 & 20,4 & 92,859 & 1,069 \\
\hline 165 & 25 & 6,5 & $-24,1$ & 34 & 26 & 16 & 54 & 0 & 1,968 & 54,213 & 56,413 & 26,8 & 20,4 & 92,859 & 1,069 \\
\hline 165 & 30 & 7,8 & $-29,0$ & 21 & 23 & 15 & 55 & -6 & 2,011 & 54,167 & 56,418 & 26,8 & 20,4 & 92,859 & 1,069 \\
\hline 165 & 35 & 9,1 & $-33,8$ & 4 & 19 & 10 & 55 & -13 & 2,053 & 54,121 & 56,424 & 26,8 & 20,4 & 92,860 & 1,069 \\
\hline 165 & 40 & 10,4 & $-38,6$ & -16 & 14 & -35 & 53 & -20 & 2,096 & 54,075 & 56,429 & 26,8 & 20,4 & 92,860 & 1,069 \\
\hline 165 & 45 & 11,6 & $-43,5$ & -34 & 10 & -56 & 50 & -43 & 2,140 & 54,028 & 56,434 & 26,8 & 20,4 & 92,860 & 1,069 \\
\hline 165 & 50 & 12,9 & $-48,3$ & -46 & 6 & -66 & 47 & -71 & 2,183 & 53,981 & 56,440 & 26,9 & 20,4 & 92,861 & 1,068 \\
\hline 165 & 55 & 14,2 & $-53,1$ & -65 & 1 & -79 & 41 & -83 & 2,227 & 53,933 & 56,445 & 26,9 & 20,4 & 92,861 & 1,068 \\
\hline 165 & 60 & 15,5 & $-58,0$ & -78 & -3 & -87 & 34 & -93 & 2,272 & 53,885 & 56,450 & 26,9 & 20,4 & 92,861 & 1,068 \\
\hline 165 & -5 & $-1,3$ & 4,8 & 57 & 28 & 38 & 31 & 39 & 2,316 & 53,837 & 56,456 & 26,9 & 20,4 & 92,862 & 1,068 \\
\hline 165 & -10 & $-2,6$ & 9,7 & 55 & 25 & 39 & 24 & 44 & 2,361 & 53,789 & 56,461 & 26,9 & 20,4 & 92,862 & 1,068 \\
\hline 165 & -15 & $-3,9$ & 14,5 & 51 & 21 & 38 & 17 & 48 & 2,406 & 53,741 & 56,466 & 26,9 & 20,5 & 92,862 & 1,068 \\
\hline 165 & -20 & $-5,2$ & 19,3 & 43 & 17 & 38 & 11 & 51 & 2,452 & 53,692 & 56,472 & 26,9 & 20,5 & 92,863 & 1,068 \\
\hline 165 & -25 & $-6,5$ & 24,1 & 33 & 16 & 35 & 5 & 52 & 2,497 & 53,643 & 56,477 & 26,9 & 20,5 & 92,863 & 1,068 \\
\hline 165 & -30 & $-7,8$ & 29,0 & 20 & 16 & 32 & -2 & 53 & 2,543 & 53,594 & 56,482 & 27,0 & 20,5 & 92,863 & 1,068 \\
\hline
\end{tabular}




\begin{tabular}{|c|c|c|c|c|c|c|c|c|c|c|c|c|c|c|c|}
\hline $\begin{array}{c}\text { Ângulo } \\
\text { g } \\
\text { (graus) }\end{array}$ & $\begin{array}{c}\text { Ângulo } \\
\text { a } \\
\text { (graus) }\end{array}$ & $\begin{array}{l}\text { Ângulo de } \\
\text { guinada } \psi \\
\text { (graus) }\end{array}$ & $\begin{array}{c}\text { Ângulo de } \\
\text { arfagem } \delta \\
\text { (graus) }\end{array}$ & $\mathrm{p} 1(\mathrm{~Pa})$ & p2 $(\mathrm{Pa})$ & p3 $(\mathrm{Pa})$ & p4 (Pa) & p5 (Pa) & $\mathrm{P}$ est $(\mathrm{Pa})$ & $\mathrm{P} \operatorname{din}(\mathrm{Pa})$ & Ptotal $(\mathrm{Pa})$ & $\begin{array}{c}\text { Temperatura } \\
\text { de Bulbo } \\
\text { Seco (jato) } \\
{ }^{\circ} \mathrm{C}\end{array}$ & $\begin{array}{c}\text { Temperatura } \\
\text { de Bulbo } \\
\text { Úmido } \\
{ }^{\circ} \mathrm{C}\end{array}$ & $\begin{array}{l}\text { Patm } \\
(\mathrm{kPa})\end{array}$ & $\begin{array}{c}\text { massa } \\
\text { específica do } \\
\text { ar }(\mathrm{kg} / \mathrm{m} 3)\end{array}$ \\
\hline 165 & -35 & $-9,1$ & 33,8 & 3 & 2 & 27 & -8 & 52 & 2,589 & 53,545 & 56,487 & 27,0 & 20,5 & 92,863 & 1,068 \\
\hline 165 & -40 & $-10,4$ & 38,6 & -14 & -47 & 23 & -14 & 50 & 2,634 & 53,496 & 56,493 & 27,0 & 20,5 & 92,864 & 1,068 \\
\hline 165 & -45 & $-11,6$ & 43,5 & -29 & -65 & 17 & -65 & 47 & 2,680 & 53,446 & 56,498 & 27,0 & 20,5 & 92,864 & 1,068 \\
\hline 165 & -50 & $-12,9$ & 48,3 & -42 & -74 & 13 & -72 & 43 & 2,726 & 53,397 & 56,503 & 27,0 & 20,5 & 92,864 & 1,068 \\
\hline 165 & -55 & $-14,2$ & 53,1 & -58 & -82 & 6 & -74 & 37 & 2,772 & 53,348 & 56,508 & 27,0 & 20,5 & 92,865 & 1,068 \\
\hline 165 & -60 & $-15,5$ & 58,0 & -73 & -82 & 0 & -79 & 33 & 2,818 & 53,298 & 56,513 & 27,0 & 20,5 & 92,865 & 1,068 \\
\hline 170 & 0 & 0,0 & 0,0 & 58 & 31 & 37 & 36 & 33 & 2,864 & 53,249 & 56,518 & 27,0 & 20,5 & 92,865 & 1,068 \\
\hline 170 & -5 & $-0,9$ & 4,9 & 58 & 29 & 38 & 32 & 40 & 2,910 & 53,200 & 56,523 & 27,0 & 20,5 & 92,865 & 1,068 \\
\hline 170 & -10 & $-1,7$ & 9,8 & 55 & 26 & 38 & 24 & 45 & 2,956 & 53,151 & 56,528 & 27,1 & 20,5 & 92,866 & 1,068 \\
\hline 170 & -15 & $-2,6$ & 14,8 & 51 & 23 & 35 & 18 & 48 & 3,002 & 53,102 & 56,533 & 27,1 & 20,5 & 92,866 & 1,067 \\
\hline 170 & -20 & $-3,5$ & 19,7 & 43 & 19 & 34 & 12 & 52 & 3,048 & 53,053 & 56,538 & 27,1 & 20,5 & 92,866 & 1,067 \\
\hline 170 & -25 & $-4,3$ & 24,6 & 34 & 17 & 32 & 5 & 54 & 3,093 & 53,004 & 56,542 & 27,1 & 20,5 & 92,866 & 1,067 \\
\hline 170 & -30 & $-5,2$ & 29,5 & 21 & 18 & 28 & -2 & 54 & 3,139 & 52,956 & 56,547 & 27,1 & 20,6 & 92,866 & 1,067 \\
\hline 170 & -35 & $-6,1$ & 34,5 & 5 & -2 & 24 & -8 & 54 & 3,184 & 52,907 & 56,552 & 27,1 & 20,6 & 92,867 & 1,067 \\
\hline 170 & -40 & $-6,9$ & 39,4 & -14 & -43 & 19 & -15 & 52 & 3,229 & 52,859 & 56,556 & 27,1 & 20,6 & 92,867 & 1,067 \\
\hline 170 & -45 & $-7,8$ & 44,3 & -30 & -56 & 15 & -53 & 49 & 3,273 & 52,812 & 56,561 & 27,1 & 20,6 & 92,867 & 1,067 \\
\hline 170 & -50 & $-8,7$ & 49,2 & -45 & -65 & 9 & -68 & 46 & 3,318 & 52,764 & 56,565 & 27,1 & 20,6 & 92,867 & 1,067 \\
\hline 170 & -55 & $-9,6$ & 54,2 & -62 & -76 & 3 & -77 & 40 & 3,362 & 52,717 & 56,570 & 27,1 & 20,6 & 92,868 & 1,067 \\
\hline 170 & -60 & $-10,4$ & 59,1 & -77 & -88 & -3 & -82 & 35 & 3,406 & 52,670 & 56,574 & 27,2 & 20,6 & 92,868 & 1,067 \\
\hline 170 & 5 & 0,9 & $-4,9$ & 57 & 30 & 35 & 41 & 27 & 3,449 & 52,623 & 56,578 & 27,2 & 20,6 & 92,868 & 1,067 \\
\hline 170 & 10 & 1,7 & $-9,8$ & 55 & 30 & 30 & 46 & 20 & 3,492 & 52,577 & 56,582 & 27,2 & 20,6 & 92,868 & 1,067 \\
\hline 170 & 15 & 2,6 & $-14,8$ & 50 & 28 & 26 & 50 & 13 & 3,535 & 52,532 & 56,586 & 27,2 & 20,6 & 92,868 & 1,067 \\
\hline 170 & 20 & 3,5 & $-19,7$ & 44 & 27 & 23 & 54 & 6 & 3,577 & 52,486 & 56,590 & 27,2 & 20,6 & 92,868 & 1,067 \\
\hline 170 & 25 & 4,3 & $-24,6$ & 33 & 23 & 18 & 56 & 0 & 3,619 & 52,442 & 56,594 & 27,2 & 20,6 & 92,869 & 1,067 \\
\hline 170 & 30 & 5,2 & $-29,5$ & 20 & 20 & 14 & 56 & -7 & 3,661 & 52,397 & 56,597 & 27,2 & 20,6 & 92,869 & 1,067 \\
\hline 170 & 35 & 6,1 & $-34,5$ & 3 & 16 & 8 & 56 & -13 & 3,702 & 52,354 & 56,601 & 27,2 & 20,6 & 92,869 & 1,067 \\
\hline 170 & 40 & 6,9 & $-39,4$ & -16 & 12 & 30 & 55 & -22 & 3,742 & 52,310 & 56,605 & 27,2 & 20,6 & 92,869 & 1,067 \\
\hline 170 & 45 & 7,8 & $-44,3$ & -32 & 9 & -44 & 52 & -43 & 3,782 & 52,268 & 56,608 & 27,2 & 20,6 & 92,869 & 1,067 \\
\hline 170 & 50 & 8,7 & $-49,2$ & -51 & 5 & -61 & 48 & -67 & 3,821 & 52,226 & 56,611 & 27,2 & 20,6 & 92,869 & 1,067 \\
\hline 170 & 55 & 9,6 & $-54,2$ & -64 & 3 & -73 & 43 & -72 & 3,860 & 52,184 & 56,614 & 27,3 & 20,6 & 92,869 & 1,067 \\
\hline 170 & 60 & 10,4 & $-59,1$ & -78 & -2 & -83 & 36 & -69 & 3,898 & 52,143 & 56,617 & 27,3 & 20,6 & 92,870 & 1,067 \\
\hline 175 & 0 & 0,0 & 0,0 & 48 & 29 & 36 & 36 & 32 & 3,936 & 52,103 & 56,620 & 27,3 & 20,7 & 92,870 & 1,067 \\
\hline 175 & 5 & 0,4 & $-5,0$ & 57 & 30 & 35 & 41 & 27 & 3,972 & 52,064 & 56,623 & 27,3 & 20,7 & 92,870 & 1,066 \\
\hline 175 & 10 & 0,9 & $-10,0$ & 55 & 29 & 32 & 46 & 20 & 4,009 & 52,025 & 56,626 & 27,3 & 20,7 & 92,870 & 1,066 \\
\hline 175 & 15 & 1,3 & $-14,9$ & 50 & 27 & 28 & 49 & 14 & 4,044 & 51,987 & 56,628 & 27,3 & 20,7 & 92,870 & 1,066 \\
\hline 175 & 20 & 1,7 & $-19,9$ & 43 & 25 & 24 & 54 & 6 & 4,079 & 51,950 & 56,631 & 27,3 & 20,7 & 92,870 & 1,066 \\
\hline 175 & 25 & 2,2 & $-24,9$ & 33 & 21 & 20 & 55 & -1 & 4,113 & 51,914 & 56,633 & 27,3 & 20,7 & 92,870 & 1,066 \\
\hline 175 & 30 & 2,6 & $-29,9$ & 21 & 17 & 16 & 57 & -7 & 4,146 & 51,878 & 56,635 & 27,3 & 20,7 & 92,870 & 1,066 \\
\hline 175 & 35 & 3,1 & $-34,9$ & 3 & 14 & 13 & 57 & -13 & 4,178 & 51,843 & 56,637 & 27,3 & 20,7 & 92,870 & 1,066 \\
\hline 175 & 40 & 3,5 & $-39,8$ & -17 & 10 & -17 & 55 & -20 & 4,210 & 51,809 & 56,639 & 27,3 & 20,7 & 92,870 & 1,066 \\
\hline
\end{tabular}




\begin{tabular}{|c|c|c|c|c|c|c|c|c|c|c|c|c|c|c|c|}
\hline $\begin{array}{c}\text { Ângulo } \\
\text { g } \\
\text { (graus) }\end{array}$ & $\begin{array}{c}\text { Ângulo } \\
\text { a } \\
\text { (graus) }\end{array}$ & $\begin{array}{c}\text { Ângulo de } \\
\text { guinada } \Psi \\
\text { (graus) }\end{array}$ & $\begin{array}{c}\text { Ângulo de } \\
\text { arfagem } \delta \\
\text { (graus) }\end{array}$ & $\mathrm{p} 1(\mathrm{~Pa})$ & p2 (Pa) & p3 (Pa) & p4 (Pa) & p5 $(\mathrm{Pa})$ & $\mathrm{P}$ est $(\mathrm{Pa})$ & $P \operatorname{din}(\mathrm{Pa})$ & Ptotal $(\mathrm{Pa})$ & $\begin{array}{c}\text { Temperatura } \\
\text { de Bulbo } \\
\text { Seco (jato) } \\
{ }^{\circ} \mathrm{C}\end{array}$ & $\begin{array}{c}\text { Temperatura } \\
\text { de Bulbo } \\
\text { Úmido } \\
{ }^{\circ} \mathrm{C}\end{array}$ & $\begin{array}{l}\text { Patm } \\
(\mathrm{kPa})\end{array}$ & $\begin{array}{l}\text { massa } \\
\text { específica do } \\
\text { ar }(\mathrm{kg} / \mathrm{m} 3)\end{array}$ \\
\hline 175 & 45 & 3,9 & $-44,8$ & -36 & -3 & -36 & 54 & -37 & 4,240 & 51,776 & 56,641 & 27,3 & 20,7 & 92,870 & 1,066 \\
\hline 175 & 50 & 4,4 & $-49,8$ & -51 & -11 & -49 & 49 & -46 & 4,270 & 51,744 & 56,642 & 27,3 & 20,7 & 92,870 & 1,066 \\
\hline 175 & 55 & 4,8 & $-54,8$ & -63 & -18 & -65 & 44 & -59 & 4,299 & 51,713 & 56,644 & 27,4 & 20,7 & 92,871 & 1,066 \\
\hline 175 & 60 & 5,2 & $-59,8$ & -73 & -15 & -85 & 38 & -66 & 4,327 & 51,683 & 56,645 & 27,4 & 20,7 & 92,871 & 1,066 \\
\hline 175 & -5 & $-0,4$ & 5,0 & 58 & 29 & 38 & 30 & 40 & 4,354 & 51,654 & 56,646 & 27,4 & 20,7 & 92,871 & 1,066 \\
\hline 175 & -10 & $-0,9$ & 10,0 & 56 & 27 & 37 & 25 & 44 & 4,380 & 51,626 & 56,647 & 27,4 & 20,7 & 92,871 & 1,066 \\
\hline 175 & -15 & $-1,3$ & 14,9 & 52 & 24 & 36 & 18 & 49 & 4,405 & 51,599 & 56,648 & 27,4 & 20,7 & 92,871 & 1,066 \\
\hline 175 & -20 & $-1,7$ & 19,9 & 44 & 20 & 33 & 11 & 52 & 4,429 & 51,573 & 56,648 & 27,4 & 20,7 & 92,871 & 1,066 \\
\hline 175 & -25 & $-2,2$ & 24,9 & 34 & 17 & 29 & 4 & 54 & 4,452 & 51,548 & 56,649 & 27,4 & 20,7 & 92,871 & 1,066 \\
\hline 175 & -30 & $-2,6$ & 29,9 & 21 & 17 & 26 & -2 & 55 & 4,474 & 51,525 & 56,649 & 27,4 & 20,7 & 92,871 & 1,066 \\
\hline 175 & -35 & $-3,1$ & 34,9 & 4 & -6 & 20 & -10 & 56 & 4,495 & 51,502 & 56,649 & 27,4 & 20,7 & 92,871 & 1,066 \\
\hline 175 & -40 & $-3,5$ & 39,8 & -12 & -36 & 15 & -15 & 55 & 4,514 & 51,481 & 56,649 & 27,4 & 20,7 & 92,871 & 1,066 \\
\hline 175 & -45 & $-3,9$ & 44,8 & -29 & -46 & 11 & -55 & 51 & 4,533 & 51,460 & 56,648 & 27,4 & 20,7 & 92,871 & 1,066 \\
\hline 175 & -50 & $-4,4$ & 49,8 & -47 & -61 & 8 & -64 & 48 & 4,550 & 51,441 & 56,648 & 27,4 & 20,7 & 92,871 & 1,066 \\
\hline 175 & -55 & $-4,8$ & 54,8 & -62 & -72 & 4 & -73 & 43 & 4,566 & 51,424 & 56,647 & 27,4 & 20,7 & 92,871 & 1,066 \\
\hline 175 & -60 & $-5,2$ & 59,8 & -76 & -81 & -2 & -83 & 37 & 4,581 & 51,407 & 56,646 & 27,4 & 20,7 & 92,870 & 1,066 \\
\hline 180 & 0 & 0,0 & 0,0 & 58 & 30 & 36 & 36 & 34 & 4,595 & 51,392 & 56,645 & 27,4 & 20,7 & 92,870 & 1,066 \\
\hline 180 & -5 & 0,0 & 5,0 & 58 & 29 & 36 & 30 & 39 & 4,607 & 51,378 & 56,644 & 27,4 & 20,7 & 92,870 & 1,066 \\
\hline 180 & -10 & 0,0 & 10,0 & 56 & 28 & 35 & 25 & 45 & 4,618 & 51,366 & 56,642 & 27,4 & 20,7 & 92,870 & 1,066 \\
\hline 180 & -15 & 0,0 & 15,0 & 51 & 26 & 34 & 18 & 49 & 4,628 & 51,355 & 56,641 & 27,5 & 20,7 & 92,870 & 1,066 \\
\hline 180 & -20 & 0,0 & 20,0 & 45 & 22 & 30 & 10 & 52 & 4,636 & 51,345 & 56,639 & 27,5 & 20,7 & 92,870 & 1,066 \\
\hline 180 & -25 & 0,0 & 25,0 & 35 & 19 & 27 & 4 & 54 & 4,644 & 51,337 & 56,637 & 27,5 & 20,7 & 92,870 & 1,066 \\
\hline 180 & -30 & 0,0 & 30,0 & 22 & 17 & 22 & -3 & 57 & 4,649 & 51,330 & 56,634 & 27,5 & 20,7 & 92,870 & 1,066 \\
\hline 180 & -35 & 0,0 & 35,0 & 4 & 0 & 18 & -10 & 56 & 4,653 & 51,325 & 56,632 & 27,5 & 20,7 & 92,870 & 1,066 \\
\hline 180 & -40 & 0,0 & 40,0 & -14 & -29 & 13 & -16 & 56 & 4,656 & 51,321 & 56,629 & 27,5 & 20,7 & 92,870 & 1,066 \\
\hline 180 & -45 & 0,0 & 45,0 & -31 & -41 & 8 & -40 & 53 & 4,658 & 51,319 & 56,626 & 27,5 & 20,7 & 92,870 & 1,066 \\
\hline 180 & -50 & 0,0 & 50,0 & -48 & -53 & 6 & -54 & 50 & 4,657 & 51,318 & 56,623 & 27,5 & 20,7 & 92,869 & 1,066 \\
\hline 180 & -55 & 0,0 & 55,0 & -62 & -67 & 1 & -56 & 44 & 4,656 & 51,319 & 56,619 & 27,5 & 20,7 & 92,869 & 1,066 \\
\hline 180 & -60 & 0,0 & 60,0 & -69 & -82 & 2 & -57 & 37 & 4,653 & 51,322 & 56,616 & 27,5 & 20,7 & 92,869 & 1,066 \\
\hline 180 & 5 & 0,0 & $-5,0$ & 57 & 25 & 40 & 40 & 26 & 4,648 & 51,326 & 56,612 & 27,5 & 20,7 & 92,869 & 1,066 \\
\hline 180 & 10 & 0,0 & $-10,0$ & 55 & 23 & 38 & 46 & 20 & 4,641 & 51,332 & 56,607 & 27,5 & 20,7 & 92,869 & 1,066 \\
\hline 180 & 15 & 0,0 & $-15,0$ & 50 & 22 & 34 & 50 & 13 & 4,633 & 51,339 & 56,603 & 27,5 & 20,7 & 92,869 & 1,066 \\
\hline 180 & 20 & 0,0 & $-20,0$ & 43 & 19 & 30 & 53 & 6 & 4,624 & 51,348 & 56,598 & 27,5 & 20,7 & 92,868 & 1,066 \\
\hline 180 & 25 & 0,0 & $-25,0$ & 33 & 17 & 26 & 56 & -1 & 4,612 & 51,359 & 56,593 & 27,5 & 20,7 & 92,868 & 1,066 \\
\hline 180 & 30 & 0,0 & $-30,0$ & 19 & 16 & 19 & 57 & -7 & 4,599 & 51,372 & 56,588 & 27,5 & 20,7 & 92,868 & 1,066 \\
\hline 180 & 35 & 0,0 & $-35,0$ & 2 & 10 & 15 & 57 & -14 & 4,585 & 51,387 & 56,583 & 27,5 & 20,7 & 92,868 & 1,066 \\
\hline 180 & 40 & 0,0 & $-40,0$ & -18 & -22 & 11 & 55 & -21 & 4,568 & 51,403 & 56,577 & 27,5 & 20,7 & 92,868 & 1,066 \\
\hline 180 & 45 & 0,0 & $-45,0$ & -38 & -37 & -6 & 52 & -38 & 4,550 & 51,421 & 56,571 & 27,5 & 20,7 & 92,867 & 1,066 \\
\hline 180 & 50 & 0,0 & $-50,0$ & -53 & -50 & -18 & 49 & -51 & 4,530 & 51,441 & 56,565 & 27,5 & 20,7 & 92,867 & 1,066 \\
\hline 180 & 55 & 0,0 & $-55,0$ & -65 & -65 & -31 & 44 & -57 & 4,508 & 51,463 & 56,558 & 27,5 & 20,7 & 92,867 & 1,066 \\
\hline
\end{tabular}




\begin{tabular}{|c|c|c|c|c|c|c|c|c|c|c|c|c|c|c|c|}
\hline $\begin{array}{c}\text { Ângulo } \\
\text { g } \\
\text { (graus) }\end{array}$ & $\begin{array}{c}\text { Ângulo } \\
\text { a } \\
\text { (graus) }\end{array}$ & $\begin{array}{c}\text { Ângulo de } \\
\text { guinada } \Psi \\
\text { (graus) }\end{array}$ & $\begin{array}{c}\text { Ângulo de } \\
\text { arfagem } \delta \\
\text { (graus) }\end{array}$ & $\mathrm{p} 1(\mathrm{~Pa})$ & p2 (Pa) & p3 (Pa) & $\mathrm{p} 4(\mathrm{~Pa})$ & p5 $(\mathrm{Pa})$ & $\mathrm{P}$ est $(\mathrm{Pa})$ & $P \operatorname{din}(\mathrm{Pa})$ & Ptotal $(\mathrm{Pa})$ & $\begin{array}{c}\text { Temperatura } \\
\text { de Bulbo } \\
\text { Seco (jato) } \\
{ }^{\circ} \mathrm{C}\end{array}$ & $\begin{array}{c}\text { Temperatura } \\
\text { de Bulbo } \\
\text { Úmido } \\
{ }^{\circ} \mathrm{C}\end{array}$ & $\begin{array}{l}\text { Patm } \\
(\mathrm{kPa})\end{array}$ & $\begin{array}{l}\text { massa } \\
\text { específica do } \\
\text { ar }(\mathrm{kg} / \mathrm{m} 3)\end{array}$ \\
\hline 180 & 60 & 0,0 & $-60,0$ & -75 & -70 & -26 & 38 & -62 & 4,485 & 51,487 & 56,552 & 27,5 & 20,7 & 92,867 & 1,066 \\
\hline 185 & 0 & 0,0 & 0,0 & 57 & 25 & 41 & 35 & 31 & 4,459 & 51,513 & 56,545 & 27,5 & 20,7 & 92,866 & 1,066 \\
\hline 185 & 5 & $-0,4$ & $-5,0$ & 57 & 24 & 40 & 40 & 27 & 4,432 & 51,540 & 56,537 & 27,5 & 20,7 & 92,866 & 1,066 \\
\hline 185 & 10 & $-0,9$ & $-10,0$ & 55 & 22 & 39 & 45 & 18 & 4,403 & 51,570 & 56,530 & 27,5 & 20,7 & 92,866 & 1,066 \\
\hline 185 & 15 & $-1,3$ & $-14,9$ & 50 & 21 & 36 & 50 & 13 & 4,371 & 51,602 & 56,522 & 27,5 & 20,7 & 92,866 & 1,066 \\
\hline 185 & 20 & $-1,7$ & $-19,9$ & 43 & 18 & 33 & 52 & 6 & 4,338 & 51,636 & 56,514 & 27,5 & 20,7 & 92,865 & 1,066 \\
\hline 185 & 25 & $-2,2$ & $-24,9$ & 33 & 16 & 29 & 55 & -1 & 4,303 & 51,671 & 56,505 & 27,5 & 20,7 & 92,865 & 1,066 \\
\hline 185 & 30 & $-2,6$ & $-29,9$ & 19 & 16 & 23 & 56 & -7 & 4,266 & 51,709 & 56,496 & 27,5 & 20,7 & 92,865 & 1,066 \\
\hline 185 & 35 & $-3,1$ & $-34,9$ & 3 & 8 & 18 & 56 & -14 & 4,227 & 51,749 & 56,487 & 27,5 & 20,6 & 92,864 & 1,066 \\
\hline 185 & 40 & $-3,5$ & $-39,8$ & -16 & -31 & 13 & 55 & -21 & 4,185 & 51,792 & 56,478 & 27,5 & 20,6 & 92,864 & 1,066 \\
\hline 185 & 45 & $-3,9$ & $-44,8$ & -34 & -45 & 9 & 52 & -39 & 4,142 & 51,836 & 56,468 & 27,5 & 20,6 & 92,864 & 1,066 \\
\hline 185 & 50 & $-4,4$ & $-49,8$ & -52 & -58 & 2 & 49 & -58 & 4,097 & 51,882 & 56,458 & 27,5 & 20,6 & 92,863 & 1,066 \\
\hline 185 & 55 & $-4,8$ & $-54,8$ & -65 & -69 & -1 & 44 & -68 & 4,049 & 51,931 & 56,448 & 27,5 & 20,6 & 92,863 & 1,066 \\
\hline 185 & 60 & $-5,2$ & $-59,8$ & -77 & -84 & 0 & 37 & -64 & 3,999 & 51,982 & 56,437 & 27,5 & 20,6 & 92,863 & 1,066 \\
\hline 185 & -5 & 0,4 & 5,0 & 58 & 32 & 34 & 30 & 40 & 3,948 & 52,035 & 56,427 & 27,5 & 20,6 & 92,862 & 1,066 \\
\hline 185 & -10 & 0,9 & 10,0 & 57 & 31 & 34 & 24 & 44 & 3,893 & 52,091 & 56,415 & 27,5 & 20,6 & 92,862 & 1,066 \\
\hline 185 & -15 & 1,3 & 14,9 & 51 & 28 & 31 & 18 & 49 & 3,837 & 52,149 & 56,404 & 27,5 & 20,6 & 92,861 & 1,066 \\
\hline 185 & -20 & 1,7 & 19,9 & 45 & 25 & 27 & 11 & 52 & 3,779 & 52,209 & 56,392 & 27,5 & 20,6 & 92,861 & 1,066 \\
\hline 185 & -25 & 2,2 & 24,9 & 35 & 22 & 24 & 4 & 55 & 3,718 & 52,272 & 56,380 & 27,5 & 20,6 & 92,861 & 1,066 \\
\hline 185 & -30 & 2,6 & 29,9 & 21 & 18 & 18 & -1 & 55 & 3,655 & 52,337 & 56,367 & 27,5 & 20,6 & 92,860 & 1,066 \\
\hline 185 & -35 & 3,1 & 34,9 & 5 & 13 & 16 & -8 & 57 & 3,589 & 52,404 & 56,354 & 27,5 & 20,6 & 92,860 & 1,066 \\
\hline 185 & -40 & 3,5 & 39,8 & -14 & -11 & 3 & -15 & 56 & 3,521 & 52,474 & 56,341 & 27,5 & 20,5 & 92,859 & 1,066 \\
\hline 185 & -45 & 3,9 & 44,8 & -31 & -28 & -15 & -32 & 54 & 3,451 & 52,546 & 56,328 & 27,5 & 20,5 & 92,859 & 1,066 \\
\hline 185 & -50 & 4,4 & 49,8 & -46 & -40 & -24 & -34 & 50 & 3,378 & 52,621 & 56,314 & 27,5 & 20,5 & 92,858 & 1,066 \\
\hline 185 & -55 & 4,8 & 54,8 & -61 & -49 & -35 & -46 & 46 & 3,303 & 52,699 & 56,300 & 27,5 & 20,5 & 92,858 & 1,066 \\
\hline 185 & -60 & 5,2 & 59,8 & -68 & -56 & -23 & -58 & 40 & 3,226 & 52,779 & 56,285 & 27,5 & 20,5 & 92,857 & 1,066 \\
\hline 190 & 0 & 0,0 & 0,0 & 57 & 32 & 36 & 35 & 33 & 3,146 & 52,861 & 56,270 & 27,5 & 20,5 & 92,857 & 1,066 \\
\hline 190 & -5 & 0,9 & 4,9 & 56 & 32 & 35 & 31 & 40 & 3,063 & 52,946 & 56,255 & 27,5 & 20,5 & 92,856 & 1,066 \\
\hline 190 & -10 & 1,7 & 9,8 & 55 & 32 & 33 & 24 & 44 & 2,978 & 53,034 & 56,239 & 27,5 & 20,5 & 92,856 & 1,066 \\
\hline 190 & -15 & 2,6 & 14,8 & 50 & 30 & 30 & 18 & 50 & 2,890 & 53,125 & 56,223 & 27,5 & 20,5 & 92,855 & 1,066 \\
\hline 190 & -20 & 3,5 & 19,7 & 43 & 27 & 27 & 10 & 54 & 2,800 & 53,218 & 56,206 & 27,5 & 20,5 & 92,855 & 1,066 \\
\hline 190 & -25 & 4,3 & 24,6 & 33 & 24 & 23 & 4 & 56 & 2,708 & 53,314 & 56,189 & 27,5 & 20,4 & 92,854 & 1,066 \\
\hline 190 & -30 & 5,2 & 29,5 & 21 & 20 & 19 & -2 & 57 & 2,614 & 53,411 & 56,172 & 27,5 & 20,4 & 92,854 & 1,066 \\
\hline 190 & -35 & 6,1 & 34,5 & 4 & 16 & 16 & -9 & 57 & 2,518 & 53,510 & 56,154 & 27,5 & 20,4 & 92,853 & 1,066 \\
\hline 190 & -40 & 6,9 & 39,4 & -16 & 8 & -10 & -16 & 57 & 2,421 & 53,610 & 56,137 & 27,5 & 20,4 & 92,853 & 1,066 \\
\hline 190 & -45 & 7,8 & 44,3 & -35 & -11 & -33 & -34 & 54 & 2,323 & 53,711 & 56,119 & 27,5 & 20,4 & 92,852 & 1,066 \\
\hline 190 & -50 & 8,7 & 49,2 & -49 & -25 & -43 & -43 & 51 & 2,225 & 53,813 & 56,101 & 27,5 & 20,4 & 92,851 & 1,066 \\
\hline 190 & -55 & 9,6 & 54,2 & -60 & -31 & -53 & -50 & 46 & 2,125 & 53,916 & 56,083 & 27,5 & 20,4 & 92,851 & 1,066 \\
\hline 190 & -60 & 10,4 & 59,1 & -71 & -29 & -69 & -59 & 40 & 2,026 & 54,019 & 56,065 & 27,5 & 20,4 & 92,850 & 1,066 \\
\hline 190 & 5 & $-0,9$ & $-4,9$ & 56 & 32 & 33 & 41 & 28 & 1,926 & 54,122 & 56,046 & 27,4 & 20,3 & 92,850 & 1,067 \\
\hline
\end{tabular}




\begin{tabular}{|c|c|c|c|c|c|c|c|c|c|c|c|c|c|c|c|}
\hline $\begin{array}{c}\text { Ângulo } \\
\text { g } \\
\text { (graus) }\end{array}$ & $\begin{array}{c}\text { Ângulo } \\
\text { a } \\
\text { (graus) }\end{array}$ & $\begin{array}{c}\text { Ângulo de } \\
\text { guinada } \Psi \\
\text { (graus) }\end{array}$ & $\begin{array}{c}\text { Ângulo de } \\
\text { arfagem } \delta \\
\text { (graus) }\end{array}$ & $\mathrm{p} 1(\mathrm{~Pa})$ & p2 (Pa) & p3 (Pa) & $\mathrm{p} 4(\mathrm{~Pa})$ & p5 $(\mathrm{Pa})$ & $\mathrm{P}$ est $(\mathrm{Pa})$ & $P \operatorname{din}(\mathrm{Pa})$ & Ptotal $(\mathrm{Pa})$ & $\begin{array}{c}\text { Temperatura } \\
\text { de Bulbo } \\
\text { Seco (jato) } \\
{ }^{\circ} \mathrm{C}\end{array}$ & $\begin{array}{c}\text { Temperatura } \\
\text { de Bulbo } \\
\text { Úmido } \\
{ }^{\circ} \mathrm{C}\end{array}$ & $\begin{array}{l}\text { Patm } \\
(\mathrm{kPa})\end{array}$ & $\begin{array}{l}\text { massa } \\
\text { específica do } \\
\text { ar }(\mathrm{kg} / \mathrm{m} 3)\end{array}$ \\
\hline 190 & 10 & $-1,7$ & $-9,8$ & 54 & 30 & 32 & 46 & 22 & 1,826 & 54,226 & 56,028 & 27,4 & 20,3 & 92,849 & 1,067 \\
\hline 190 & 15 & $-2,6$ & $-14,8$ & 49 & 27 & 29 & 50 & 14 & 1,727 & 54,328 & 56,010 & 27,4 & 20,3 & 92,848 & 1,067 \\
\hline 190 & 20 & $-3,5$ & $-19,7$ & 43 & 24 & 27 & 53 & 6 & 1,628 & 54,430 & 55,992 & 27,4 & 20,3 & 92,848 & 1,067 \\
\hline 190 & 25 & $-4,3$ & $-24,6$ & 32 & 20 & 23 & 56 & 1 & 1,531 & 54,532 & 55,974 & 27,4 & 20,3 & 92,847 & 1,067 \\
\hline 190 & 30 & $-5,2$ & $-29,5$ & 19 & 16 & 19 & 57 & -6 & 1,434 & 54,632 & 55,957 & 27,4 & 20,3 & 92,846 & 1,067 \\
\hline 190 & 35 & $-6,1$ & $-34,5$ & 2 & 12 & 15 & 57 & -13 & 1,338 & 54,730 & 55,939 & 27,4 & 20,3 & 92,846 & 1,067 \\
\hline 190 & 40 & $-6,9$ & $-39,4$ & -19 & -14 & 9 & 56 & -20 & 1,245 & 54,827 & 55,922 & 27,4 & 20,2 & 92,845 & 1,067 \\
\hline 190 & 45 & $-7,8$ & $-44,3$ & -38 & -36 & -8 & 54 & -39 & 1,153 & 54,922 & 55,905 & 27,4 & 20,2 & 92,845 & 1,067 \\
\hline 190 & 50 & $-8,7$ & $-49,2$ & -53 & -47 & -19 & 49 & -49 & 1,063 & 55,015 & 55,889 & 27,4 & 20,2 & 92,844 & 1,067 \\
\hline 190 & 55 & $-9,6$ & $-54,2$ & -67 & -65 & -27 & 43 & -57 & 0,975 & 55,106 & 55,873 & 27,4 & 20,2 & 92,844 & 1,067 \\
\hline 190 & 60 & $-10,4$ & $-59,1$ & -76 & -72 & -18 & 38 & -64 & 0,890 & 55,194 & 55,857 & 27,4 & 20,2 & 92,843 & 1,067 \\
\hline 195 & 0 & 0,0 & 0,0 & 57 & 33 & 32 & 34 & 35 & 0,807 & 55,280 & 55,842 & 27,4 & 20,2 & 92,842 & 1,067 \\
\hline 195 & 5 & $-1,3$ & $-4,8$ & 57 & 32 & 33 & 40 & 29 & 0,726 & 55,364 & 55,827 & 27,4 & 20,2 & 92,842 & 1,067 \\
\hline 195 & 10 & $-2,6$ & $-9,7$ & 55 & 29 & 33 & 45 & 22 & 0,646 & 55,446 & 55,812 & 27,4 & 20,2 & 92,841 & 1,067 \\
\hline 195 & 15 & $-3,9$ & $-14,5$ & 50 & 26 & 30 & 49 & 15 & 0,569 & 55,526 & 55,797 & 27,4 & 20,2 & 92,841 & 1,067 \\
\hline 195 & 20 & $-5,2$ & $-19,3$ & 43 & 22 & 28 & 53 & 8 & 0,492 & 55,605 & 55,783 & 27,4 & 20,1 & 92,840 & 1,067 \\
\hline 195 & 25 & $-6,5$ & $-24,1$ & 32 & 18 & 25 & 55 & 1 & 0,418 & 55,682 & 55,769 & 27,4 & 20,1 & 92,840 & 1,067 \\
\hline 195 & 30 & $-7,8$ & $-29,0$ & 18 & 15 & 21 & 56 & -6 & 0,345 & 55,757 & 55,755 & 27,4 & 20,1 & 92,839 & 1,067 \\
\hline 195 & 35 & $-9,1$ & $-33,8$ & 1 & 6 & 16 & 56 & -14 & 0,274 & 55,831 & 55,742 & 27,4 & 20,1 & 92,839 & 1,067 \\
\hline 195 & 40 & $-10,4$ & $-38,6$ & -18 & -28 & 12 & 54 & -19 & 0,204 & 55,903 & 55,729 & 27,4 & 20,1 & 92,838 & 1,067 \\
\hline 195 & 45 & $-11,6$ & $-43,5$ & -35 & -43 & 9 & 52 & -39 & 0,136 & 55,973 & 55,716 & 27,4 & 20,1 & 92,838 & 1,067 \\
\hline 195 & 50 & $-12,9$ & $-48,3$ & -52 & -59 & 2 & 48 & -56 & 0,069 & 56,042 & 55,703 & 27,4 & 20,1 & 92,837 & 1,067 \\
\hline 195 & 55 & $-14,2$ & $-53,1$ & -68 & -72 & 1 & 43 & -68 & 0,004 & 56,109 & 55,691 & 27,4 & 20,1 & 92,837 & 1,067 \\
\hline 195 & 60 & $-15,5$ & $-58,0$ & -78 & -84 & -2 & 36 & -69 & $-0,059$ & 56,174 & 55,679 & 27,4 & 20,1 & 92,836 & 1,067 \\
\hline 195 & -5 & 1,3 & 4,8 & 59 & 36 & 30 & 30 & 40 & $-0,121$ & 56,238 & 55,667 & 27,4 & 20,1 & 92,836 & 1,067 \\
\hline 195 & -10 & 2,6 & 9,7 & 56 & 36 & 29 & 24 & 45 & $-0,181$ & 56,301 & 55,656 & 27,4 & 20,1 & 92,835 & 1,067 \\
\hline 195 & -15 & 3,9 & 14,5 & 52 & 35 & 27 & 18 & 49 & $-0,240$ & 56,361 & 55,644 & 27,4 & 20,1 & 92,835 & 1,067 \\
\hline 195 & -20 & 5,2 & 19,3 & 44 & 32 & 24 & 10 & 54 & $-0,297$ & 56,420 & 55,633 & 27,4 & 20,1 & 92,834 & 1,067 \\
\hline 195 & -25 & 6,5 & 24,1 & 34 & 29 & 20 & 2 & 56 & $-0,353$ & 56,478 & 55,622 & 27,4 & 20,0 & 92,834 & 1,067 \\
\hline 195 & -30 & 7,8 & 29,0 & 21 & 25 & 19 & -3 & 58 & $-0,407$ & 56,534 & 55,612 & 27,4 & 20,0 & 92,833 & 1,067 \\
\hline 195 & -35 & 9,1 & 33,8 & 3 & 20 & 10 & -10 & 57 & $-0,460$ & 56,589 & 55,602 & 27,4 & 20,0 & 92,833 & 1,067 \\
\hline 195 & -40 & 10,4 & 38,6 & -16 & 16 & -29 & -18 & 57 & $-0,512$ & 56,642 & 55,592 & 27,4 & 20,0 & 92,832 & 1,068 \\
\hline 195 & -45 & 11,6 & 43,5 & -32 & 12 & -45 & -46 & 54 & $-0,562$ & 56,693 & 55,582 & 27,4 & 20,0 & 92,832 & 1,068 \\
\hline 195 & -50 & 12,9 & 48,3 & -49 & 6 & -57 & -64 & 51 & $-0,610$ & 56,743 & 55,572 & 27,4 & 20,0 & 92,832 & 1,068 \\
\hline 195 & -55 & 14,2 & 53,1 & -66 & 4 & -71 & -73 & 45 & $-0,657$ & 56,792 & 55,563 & 27,4 & 20,0 & 92,831 & 1,068 \\
\hline 195 & -60 & 15,5 & 58,0 & -80 & 2 & -80 & -80 & 39 & $-0,703$ & 56,839 & 55,554 & 27,4 & 20,0 & 92,831 & 1,068 \\
\hline 200 & 0 & 0,0 & 0,0 & 57 & 36 & 33 & 35 & 34 & $-0,747$ & 56,884 & 55,545 & 27,4 & 20,0 & 92,830 & 1,068 \\
\hline 200 & -5 & 1,7 & 4,7 & 57 & 37 & 31 & 30 & 40 & $-0,790$ & 56,929 & 55,536 & 27,4 & 20,0 & 92,830 & 1,068 \\
\hline 200 & -10 & 3,4 & 9,4 & 54 & 37 & 29 & 25 & 44 & $-0,832$ & 56,972 & 55,528 & 27,4 & 20,0 & 92,829 & 1,068 \\
\hline 200 & -15 & 5,1 & 14,1 & 51 & 36 & 25 & 18 & 49 & $-0,872$ & 57,013 & 55,520 & 27,4 & 20,0 & 92,829 & 1,068 \\
\hline
\end{tabular}




\begin{tabular}{|c|c|c|c|c|c|c|c|c|c|c|c|c|c|c|c|}
\hline $\begin{array}{c}\text { Ângulo } \\
\text { g } \\
\text { (graus) }\end{array}$ & $\begin{array}{c}\text { Ângulo } \\
\text { a } \\
\text { (graus) }\end{array}$ & $\begin{array}{l}\text { Ângulo de } \\
\text { guinada } \psi \\
\text { (graus) }\end{array}$ & $\begin{array}{c}\text { Ângulo de } \\
\text { arfagem } \delta \\
\text { (graus) }\end{array}$ & $\mathrm{p} 1(\mathrm{~Pa})$ & p2 $(\mathrm{Pa})$ & p3 $(\mathrm{Pa})$ & p4 (Pa) & p5 (Pa) & $\mathrm{P}$ est $(\mathrm{Pa})$ & $\mathrm{P} \operatorname{din}(\mathrm{Pa})$ & Ptotal $(\mathrm{Pa})$ & $\begin{array}{c}\text { Temperatura } \\
\text { de Bulbo } \\
\text { Seco (jato) } \\
{ }^{\circ} \mathrm{C} \\
\end{array}$ & $\begin{array}{c}\text { Temperatura } \\
\text { de Bulbo } \\
\text { Úmido } \\
{ }^{\circ} \mathrm{C}\end{array}$ & $\begin{array}{l}\text { Patm } \\
(\mathrm{kPa})\end{array}$ & $\begin{array}{c}\text { massa } \\
\text { específica do } \\
\text { ar }(\mathrm{kg} / \mathrm{m} 3)\end{array}$ \\
\hline 200 & -20 & 6,8 & 18,8 & 43 & 34 & 22 & 11 & 53 & $-0,911$ & 57,053 & 55,512 & 27,4 & 20,0 & 92,829 & 1,068 \\
\hline 200 & -25 & 8,6 & 23,5 & 34 & 32 & 19 & 4 & 55 & $-0,949$ & 57,092 & 55,504 & 27,4 & 20,0 & 92,828 & 1,068 \\
\hline 200 & -30 & 10,3 & 28,2 & 21 & 28 & 18 & -3 & 57 & $-0,985$ & 57,129 & 55,496 & 27,4 & 20,0 & 92,828 & 1,068 \\
\hline 200 & -35 & 12,0 & 32,9 & 5 & 24 & 15 & -11 & 56 & $-1,020$ & 57,165 & 55,489 & 27,4 & 20,0 & 92,827 & 1,068 \\
\hline 200 & -40 & 13,7 & 37,6 & -17 & 18 & -37 & -18 & 55 & $-1,054$ & 57,200 & 55,482 & 27,4 & 20,0 & 92,827 & 1,068 \\
\hline 200 & -45 & 15,4 & 42,3 & -31 & 15 & -53 & -34 & 53 & $-1,086$ & 57,233 & 55,475 & 27,4 & 20,0 & 92,826 & 1,068 \\
\hline 200 & -50 & 17,1 & 47,0 & -45 & 10 & -63 & -66 & 48 & $-1,117$ & 57,265 & 55,468 & 27,4 & 20,0 & 92,826 & 1,068 \\
\hline 200 & -55 & 18,8 & 51,7 & -61 & 5 & -74 & -76 & 44 & $-1,147$ & 57,296 & 55,462 & 27,4 & 20,0 & 92,826 & 1,068 \\
\hline 200 & -60 & 20,5 & 56,4 & -79 & 0 & -88 & -85 & 37 & $-1,176$ & 57,325 & 55,456 & 27,4 & 20,0 & 92,825 & 1,068 \\
\hline 200 & 5 & $-1,7$ & $-4,7$ & 57 & 30 & 34 & 38 & 29 & $-1,203$ & 57,353 & 55,450 & 27,4 & 20,0 & 92,825 & 1,068 \\
\hline 200 & 10 & $-3,4$ & $-9,4$ & 54 & 27 & 33 & 42 & 23 & $-1,229$ & 57,380 & 55,444 & 27,4 & 20,0 & 92,825 & 1,068 \\
\hline 200 & 15 & $-5,1$ & $-14,1$ & 50 & 24 & 32 & 46 & 16 & $-1,254$ & 57,406 & 55,438 & 27,4 & 20,0 & 92,824 & 1,068 \\
\hline 200 & 20 & $-6,8$ & $-18,8$ & 42 & 19 & 30 & 50 & 8 & $-1,278$ & 57,430 & 55,433 & 27,4 & 20,0 & 92,824 & 1,068 \\
\hline 200 & 25 & $-8,6$ & $-23,5$ & 32 & 16 & 28 & 53 & 1 & $-1,301$ & 57,453 & 55,427 & 27,4 & 19,9 & 92,823 & 1,068 \\
\hline 200 & 30 & $-10,3$ & $-28,2$ & 19 & 15 & 23 & 53 & -5 & $-1,322$ & 57,475 & 55,422 & 27,4 & 19,9 & 92,823 & 1,068 \\
\hline 200 & 35 & $-12,0$ & $-32,9$ & 1 & 8 & 19 & 54 & -14 & $-1,343$ & 57,496 & 55,417 & 27,4 & 19,9 & 92,823 & 1,068 \\
\hline 200 & 40 & $-13,7$ & $-37,6$ & -18 & -37 & 14 & 52 & -21 & $-1,362$ & 57,516 & 55,413 & 27,4 & 19,9 & 92,822 & 1,068 \\
\hline 200 & 45 & $-15,4$ & $-42,3$ & -35 & -55 & 10 & 48 & -51 & $-1,380$ & 57,534 & 55,408 & 27,4 & 19,9 & 92,822 & 1,068 \\
\hline 200 & 50 & $-17,1$ & $-47,0$ & -49 & -66 & 5 & 44 & -70 & $-1,397$ & 57,551 & 55,404 & 27,4 & 19,9 & 92,822 & 1,068 \\
\hline 200 & 55 & $-18,8$ & $-51,7$ & -66 & -77 & 1 & 39 & -84 & $-1,413$ & 57,568 & 55,400 & 27,4 & 19,9 & 92,821 & 1,068 \\
\hline 200 & 60 & $-20,5$ & $-56,4$ & -81 & -86 & -4 & 33 & -92 & $-1,428$ & 57,583 & 55,396 & 27,4 & 19,9 & 92,821 & 1,068 \\
\hline 205 & 0 & 0,0 & 0,0 & 56 & 32 & 32 & 33 & 35 & $-1,442$ & 57,597 & 55,392 & 27,4 & 19,9 & 92,821 & 1,068 \\
\hline 205 & 5 & $-2,1$ & $-4,5$ & 55 & 30 & 34 & 38 & 29 & $-1,454$ & 57,609 & 55,389 & 27,4 & 19,9 & 92,820 & 1,068 \\
\hline 205 & 10 & $-4,2$ & $-9,1$ & 54 & 27 & 34 & 42 & 23 & $-1,466$ & 57,621 & 55,385 & 27,4 & 19,9 & 92,820 & 1,068 \\
\hline 205 & 15 & $-6,3$ & $-13,6$ & 49 & 23 & 34 & 46 & 16 & $-1,477$ & 57,632 & 55,382 & 27,4 & 19,9 & 92,820 & 1,068 \\
\hline 205 & 20 & $-8,5$ & $-18,1$ & 42 & 18 & 32 & 49 & 9 & $-1,486$ & 57,641 & 55,379 & 27,4 & 19,9 & 92,819 & 1,068 \\
\hline 205 & 25 & $-10,6$ & $-22,7$ & 33 & 15 & 30 & 51 & 2 & $-1,495$ & 57,650 & 55,376 & 27,4 & 19,9 & 92,819 & 1,068 \\
\hline 205 & 30 & $-12,7$ & $-27,2$ & 20 & 14 & 27 & 51 & -5 & $-1,502$ & 57,657 & 55,373 & 27,4 & 19,9 & 92,819 & 1,067 \\
\hline 205 & 35 & $-14,8$ & $-31,7$ & 3 & 15 & 23 & 51 & -13 & $-1,509$ & 57,664 & 55,371 & 27,4 & 19,9 & 92,818 & 1,067 \\
\hline 205 & 40 & $-16,9$ & $-36,3$ & -15 & -32 & 18 & 50 & -20 & $-1,514$ & 57,670 & 55,368 & 27,4 & 19,9 & 92,818 & 1,067 \\
\hline 205 & 45 & $-19,0$ & $-40,8$ & -31 & -63 & 14 & 47 & -34 & $-1,519$ & 57,674 & 55,366 & 27,4 & 20,0 & 92,818 & 1,067 \\
\hline 205 & 50 & $-21,1$ & $-45,3$ & -45 & -71 & 8 & 43 & -77 & $-1,523$ & 57,678 & 55,364 & 27,4 & 20,0 & 92,817 & 1,067 \\
\hline 205 & 55 & $-23,2$ & $-49,8$ & -62 & -80 & 2 & 37 & -85 & $-1,526$ & 57,680 & 55,362 & 27,4 & 20,0 & 92,817 & 1,067 \\
\hline 205 & 60 & $-25,4$ & $-54,4$ & -76 & -87 & -4 & 30 & -89 & $-1,528$ & 57,682 & 55,360 & 27,4 & 20,0 & 92,817 & 1,067 \\
\hline 205 & -5 & 2,1 & 4,5 & 57 & 36 & 30 & 29 & 39 & $-1,529$ & 57,682 & 55,359 & 27,4 & 20,0 & 92,816 & 1,067 \\
\hline 205 & -10 & 4,2 & 9,1 & 56 & 37 & 27 & 24 & 45 & $-1,529$ & 57,682 & 55,357 & 27,4 & 20,0 & 92,816 & 1,067 \\
\hline 205 & -15 & 6,3 & 13,6 & 52 & 37 & 23 & 18 & 49 & $-1,528$ & 57,681 & 55,356 & 27,4 & 20,0 & 92,816 & 1,067 \\
\hline 205 & -20 & 8,5 & 18,1 & 45 & 36 & 20 & 10 & 52 & $-1,526$ & 57,679 & 55,355 & 27,4 & 20,0 & 92,815 & 1,067 \\
\hline 205 & -25 & 10,6 & 22,7 & 35 & 34 & 16 & 4 & 54 & $-1,524$ & 57,676 & 55,354 & 27,4 & 20,0 & 92,815 & 1,067 \\
\hline 205 & -30 & 12,7 & 27,2 & 23 & 30 & 15 & -3 & 55 & $-1,520$ & 57,672 & 55,353 & 27,4 & 20,0 & 92,815 & 1,067 \\
\hline
\end{tabular}




\begin{tabular}{|c|c|c|c|c|c|c|c|c|c|c|c|c|c|c|c|}
\hline $\begin{array}{c}\text { Ângulo } \\
\text { g } \\
\text { (graus) }\end{array}$ & $\begin{array}{c}\text { Ângulo } \\
\text { a } \\
\text { (graus) }\end{array}$ & $\begin{array}{l}\text { Ângulo de } \\
\text { guinada } \psi \\
\text { (graus) }\end{array}$ & $\begin{array}{c}\text { Ângulo de } \\
\text { arfagem } \delta \\
\text { (graus) }\end{array}$ & $\mathrm{p} 1(\mathrm{~Pa})$ & p2 $(\mathrm{Pa})$ & p3 $(\mathrm{Pa})$ & p4 (Pa) & p5 (Pa) & $\mathrm{P}$ est $(\mathrm{Pa})$ & $\mathrm{P} \operatorname{din}(\mathrm{Pa})$ & Ptotal $(\mathrm{Pa})$ & $\begin{array}{c}\text { Temperatura } \\
\text { de Bulbo } \\
\text { Seco (jato) } \\
{ }^{\circ} \mathrm{C}\end{array}$ & $\begin{array}{c}\text { Temperatura } \\
\text { de Bulbo } \\
\text { Úmido } \\
{ }^{\circ} \mathrm{C}\end{array}$ & $\begin{array}{l}\text { Patm } \\
(\mathrm{kPa})\end{array}$ & $\begin{array}{c}\text { massa } \\
\text { específica do } \\
\text { ar }(\mathrm{kg} / \mathrm{m} 3)\end{array}$ \\
\hline 205 & -35 & 14,8 & 31,7 & 7 & 27 & 19 & -11 & 56 & $-1,516$ & 57,668 & 55,352 & 27,4 & 20,0 & 92,815 & 1,067 \\
\hline 205 & -40 & 16,9 & 36,3 & -13 & 22 & -30 & -18 & 54 & $-1,511$ & 57,662 & 55,352 & 27,4 & 20,0 & 92,814 & 1,067 \\
\hline 205 & -45 & 19,0 & 40,8 & -30 & 18 & -59 & -27 & 51 & $-1,505$ & 57,656 & 55,351 & 27,4 & 20,0 & 92,814 & 1,067 \\
\hline 205 & -50 & 21,1 & 45,3 & -42 & 13 & -71 & -73 & 47 & $-1,499$ & 57,648 & 55,351 & 27,4 & 20,0 & 92,814 & 1,067 \\
\hline 205 & -55 & 23,2 & 49,8 & -57 & 8 & -79 & -76 & 42 & $-1,491$ & 57,640 & 55,350 & 27,5 & 20,0 & 92,813 & 1,067 \\
\hline 205 & -60 & 25,4 & 54,4 & -73 & 1 & -82 & -82 & 36 & $-1,483$ & 57,632 & 55,350 & 27,5 & 20,0 & 92,813 & 1,067 \\
\hline 210 & 0 & 0,0 & 0,0 & 58 & 35 & 33 & 37 & 34 & $-1,474$ & 57,622 & 55,350 & 27,5 & 20,0 & 92,813 & 1,067 \\
\hline 210 & -5 & 2,5 & 4,3 & 58 & 38 & 31 & 32 & 39 & $-1,465$ & 57,612 & 55,351 & 27,5 & 20,0 & 92,813 & 1,067 \\
\hline 210 & -10 & 5,0 & 8,7 & 56 & 39 & 27 & 26 & 44 & $-1,454$ & 57,601 & 55,351 & 27,5 & 20,0 & 92,812 & 1,067 \\
\hline 210 & -15 & 7,5 & 13,0 & 53 & 39 & 23 & 20 & 46 & $-1,443$ & 57,589 & 55,351 & 27,5 & 20,0 & 92,812 & 1,067 \\
\hline 210 & -20 & 10,0 & 17,3 & 46 & 39 & 17 & 14 & 50 & $-1,431$ & 57,576 & 55,352 & 27,5 & 20,0 & 92,812 & 1,067 \\
\hline 210 & -25 & 12,5 & 21,7 & 36 & 38 & 16 & 8 & 53 & $-1,419$ & 57,563 & 55,352 & 27,5 & 20,0 & 92,811 & 1,067 \\
\hline 210 & -30 & 15,0 & 26,0 & 24 & 35 & 13 & 1 & 53 & $-1,406$ & 57,549 & 55,353 & 27,5 & 20,0 & 92,811 & 1,067 \\
\hline 210 & -35 & 17,5 & 30,3 & 9 & 31 & 19 & -6 & 53 & $-1,392$ & 57,534 & 55,354 & 27,5 & 20,0 & 92,811 & 1,067 \\
\hline 210 & -40 & 20,0 & 34,6 & -8 & 28 & -13 & -12 & 52 & $-1,377$ & 57,519 & 55,355 & 27,5 & 20,0 & 92,811 & 1,067 \\
\hline 210 & -45 & 22,5 & 39,0 & -26 & 23 & -54 & -27 & 48 & $-1,362$ & 57,503 & 55,356 & 27,5 & 20,0 & 92,810 & 1,067 \\
\hline 210 & -50 & 25,0 & 43,3 & -40 & 18 & -75 & -74 & 43 & $-1,347$ & 57,486 & 55,357 & 27,5 & 20,0 & 92,810 & 1,067 \\
\hline 210 & -55 & 27,5 & 47,6 & -54 & 13 & -85 & -77 & 39 & $-1,330$ & 57,469 & 55,358 & 27,5 & 20,0 & 92,810 & 1,067 \\
\hline 210 & -60 & 30,0 & 52,0 & -68 & 7 & -86 & -80 & 32 & $-1,313$ & 57,451 & 55,360 & 27,5 & 20,0 & 92,810 & 1,067 \\
\hline 210 & 5 & $-2,5$ & $-4,3$ & 58 & 31 & 36 & 39 & 30 & $-1,296$ & 57,433 & 55,361 & 27,5 & 20,0 & 92,809 & 1,067 \\
\hline 210 & 10 & $-5,0$ & $-8,7$ & 56 & 26 & 38 & 44 & 23 & $-1,278$ & 57,414 & 55,363 & 27,5 & 20,1 & 92,809 & 1,067 \\
\hline 210 & 15 & $-7,5$ & $-13,0$ & 52 & 22 & 37 & 47 & 16 & $-1,259$ & 57,394 & 55,365 & 27,5 & 20,1 & 92,809 & 1,067 \\
\hline 210 & 20 & $-10,0$ & $-17,3$ & 45 & 17 & 37 & 51 & 9 & $-1,240$ & 57,374 & 55,366 & 27,5 & 20,1 & 92,809 & 1,067 \\
\hline 210 & 25 & $-12,5$ & $-21,7$ & 36 & 14 & 36 & 53 & 3 & $-1,220$ & 57,353 & 55,368 & 27,5 & 20,1 & 92,808 & 1,067 \\
\hline 210 & 30 & $-15,0$ & $-26,0$ & 24 & 12 & 33 & 54 & -3 & $-1,200$ & 57,331 & 55,370 & 27,5 & 20,1 & 92,808 & 1,067 \\
\hline 210 & 35 & $-17,5$ & $-30,3$ & 7 & 15 & 28 & 53 & -11 & $-1,179$ & 57,309 & 55,372 & 27,5 & 20,1 & 92,808 & 1,067 \\
\hline 210 & 40 & $-20,0$ & $-34,6$ & -12 & -23 & 24 & 50 & -17 & $-1,158$ & 57,287 & 55,374 & 27,5 & 20,1 & 92,808 & 1,067 \\
\hline 210 & 45 & $-22,5$ & $-39,0$ & -28 & -61 & 20 & 48 & -32 & $-1,136$ & 57,264 & 55,376 & 27,6 & 20,1 & 92,807 & 1,067 \\
\hline 210 & 50 & $-25,0$ & $-43,3$ & -40 & -79 & 14 & 42 & -83 & $-1,114$ & 57,241 & 55,379 & 27,6 & 20,1 & 92,807 & 1,067 \\
\hline 210 & 55 & $-27,5$ & $-47,6$ & -56 & -88 & 9 & 38 & -84 & $-1,091$ & 57,217 & 55,381 & 27,6 & 20,1 & 92,807 & 1,066 \\
\hline 210 & 60 & $-30,0$ & $-52,0$ & -70 & -90 & 3 & 31 & -91 & $-1,068$ & 57,192 & 55,383 & 27,6 & 20,1 & 92,807 & 1,066 \\
\hline 215 & 0 & 0,0 & 0,0 & 58 & 33 & 34 & 36 & 35 & $-1,044$ & 57,168 & 55,386 & 27,6 & 20,1 & 92,806 & 1,066 \\
\hline 215 & 5 & $-2,9$ & $-4,1$ & 58 & 30 & 37 & 41 & 30 & $-1,020$ & 57,142 & 55,388 & 27,6 & 20,1 & 92,806 & 1,066 \\
\hline 215 & 10 & $-5,7$ & $-8,2$ & 56 & 26 & 38 & 44 & 24 & $-0,996$ & 57,117 & 55,391 & 27,6 & 20,1 & 92,806 & 1,066 \\
\hline 215 & 15 & $-8,6$ & $-12,3$ & 51 & 22 & 39 & 47 & 18 & $-0,971$ & 57,091 & 55,394 & 27,6 & 20,1 & 92,806 & 1,066 \\
\hline 215 & 20 & $-11,5$ & $-16,4$ & 44 & 16 & 39 & 50 & 11 & $-0,946$ & 57,064 & 55,396 & 27,6 & 20,1 & 92,805 & 1,066 \\
\hline 215 & 25 & $-14,3$ & $-20,5$ & 36 & 13 & 38 & 53 & 4 & $-0,920$ & 57,037 & 55,399 & 27,6 & 20,1 & 92,805 & 1,066 \\
\hline 215 & 30 & $-17,2$ & $-24,6$ & 24 & 9 & 36 & 53 & -2 & $-0,894$ & 57,010 & 55,402 & 27,6 & 20,1 & 92,805 & 1,066 \\
\hline 215 & 35 & $-20,1$ & $-28,7$ & 7 & 13 & 32 & 51 & -9 & $-0,868$ & 56,982 & 55,405 & 27,6 & 20,2 & 92,805 & 1,066 \\
\hline 215 & 40 & $-22,9$ & $-32,8$ & -9 & 0 & 29 & 49 & -14 & $-0,842$ & 56,954 & 55,408 & 27,6 & 20,2 & 92,804 & 1,066 \\
\hline
\end{tabular}




\begin{tabular}{|c|c|c|c|c|c|c|c|c|c|c|c|c|c|c|c|}
\hline $\begin{array}{c}\text { Ângulo } \\
\text { g } \\
\text { (graus) }\end{array}$ & $\begin{array}{c}\text { Ângulo } \\
\text { a } \\
\text { (graus) }\end{array}$ & $\begin{array}{l}\text { Ângulo de } \\
\text { guinada } \Psi \\
\text { (graus) }\end{array}$ & $\begin{array}{c}\text { Ângulo de } \\
\text { arfagem } \delta \\
\text { (graus) }\end{array}$ & $\mathrm{p} 1(\mathrm{~Pa})$ & p2 $(\mathrm{Pa})$ & p3 $(\mathrm{Pa})$ & p4 (Pa) & p5 (Pa) & $\mathrm{P}$ est $(\mathrm{Pa})$ & $\mathrm{P} \operatorname{din}(\mathrm{Pa})$ & Ptotal $(\mathrm{Pa})$ & $\begin{array}{c}\text { Temperatura } \\
\text { de Bulbo } \\
\text { Seco (jato) } \\
{ }^{\circ} \mathrm{C} \\
\end{array}$ & $\begin{array}{c}\text { Temperatura } \\
\text { de Bulbo } \\
\text { Úmido } \\
{ }^{\circ} \mathrm{C}\end{array}$ & $\begin{array}{l}\text { Patm } \\
(\mathrm{kPa})\end{array}$ & $\begin{array}{c}\text { massa } \\
\text { específica do } \\
\text { ar }(\mathrm{kg} / \mathrm{m} 3)\end{array}$ \\
\hline 215 & 45 & $-25,8$ & $-36,9$ & -27 & -64 & 24 & 46 & -40 & $-0,815$ & 56,926 & 55,411 & 27,6 & 20,2 & 92,804 & 1,066 \\
\hline 215 & 50 & $-28,7$ & $-41,0$ & -40 & -83 & 18 & 41 & -87 & $-0,787$ & 56,898 & 55,414 & 27,6 & 20,2 & 92,804 & 1,066 \\
\hline 215 & 55 & $-31,5$ & $-45,1$ & -53 & -94 & 13 & 35 & 89 & $-0,760$ & 56,869 & 55,417 & 27,6 & 20,2 & 92,804 & 1,066 \\
\hline 215 & 60 & $-34,4$ & $-49,1$ & -66 & -97 & 8 & 29 & -95 & $-0,732$ & 56,840 & 55,420 & 27,6 & 20,2 & 92,804 & 1,066 \\
\hline 215 & -5 & 2,9 & 4,1 & 58 & 37 & 32 & 32 & 39 & $-0,704$ & 56,810 & 55,424 & 27,6 & 20,2 & 92,803 & 1,066 \\
\hline 215 & -10 & 5,7 & 8,2 & 56 & 39 & 29 & 27 & 44 & $-0,676$ & 56,780 & 55,427 & 27,6 & 20,2 & 92,803 & 1,066 \\
\hline 215 & -15 & 8,6 & 12,3 & 53 & 39 & 24 & 21 & 48 & $-0,647$ & 56,750 & 55,430 & 27,7 & 20,2 & 92,803 & 1,066 \\
\hline 215 & -20 & 11,5 & 16,4 & 45 & 39 & 20 & 14 & 50 & $-0,618$ & 56,720 & 55,434 & 27,7 & 20,2 & 92,803 & 1,066 \\
\hline 215 & -25 & 14,3 & 20,5 & 36 & 39 & 16 & 8 & 52 & $-0,589$ & 56,690 & 55,437 & 27,7 & 20,2 & 92,802 & 1,066 \\
\hline 215 & -30 & 17,2 & 24,6 & 23 & 37 & 14 & 1 & 53 & $-0,560$ & 56,659 & 55,440 & 27,7 & 20,2 & 92,802 & 1,066 \\
\hline 215 & -35 & 20,1 & 28,7 & 8 & 33 & 19 & -5 & 52 & $-0,531$ & 56,628 & 55,444 & 27,7 & 20,2 & 92,802 & 1,066 \\
\hline 215 & -40 & 22,9 & 32,8 & -9 & 30 & -15 & -10 & 51 & $-0,501$ & 56,597 & 55,447 & 27,7 & 20,2 & 92,802 & 1,066 \\
\hline 215 & -45 & 25,8 & 36,9 & -27 & 26 & -61 & -41 & 46 & $-0,471$ & 56,566 & 55,451 & 27,7 & 20,2 & 92,801 & 1,066 \\
\hline 215 & -50 & 28,7 & 41,0 & -39 & 21 & -78 & -76 & 42 & $-0,441$ & 56,534 & 55,454 & 27,7 & 20,3 & 92,801 & 1,066 \\
\hline 215 & -55 & 31,5 & 45,1 & -52 & 16 & -87 & -76 & 37 & $-0,411$ & 56,503 & 55,458 & 27,7 & 20,3 & 92,801 & 1,066 \\
\hline 215 & -60 & 34,4 & 49,1 & -65 & 10 & -88 & -80 & 30 & $-0,381$ & 56,471 & 55,461 & 27,7 & 20,3 & 92,801 & 1,066 \\
\hline 220 & 0 & 0,0 & 0,0 & 59 & 34 & 35 & 38 & 35 & $-0,351$ & 56,439 & 55,465 & 27,7 & 20,3 & 92,801 & 1,066 \\
\hline 220 & -5 & 3,2 & 3,8 & 59 & 37 & 31 & 33 & 39 & $-0,320$ & 56,407 & 55,469 & 27,7 & 20,3 & 92,800 & 1,065 \\
\hline 220 & -10 & 6,4 & 7,7 & 56 & 39 & 28 & 29 & 43 & $-0,290$ & 56,376 & 55,472 & 27,7 & 20,3 & 92,800 & 1,065 \\
\hline 220 & -15 & 9,6 & 11,5 & 53 & 41 & 23 & 22 & 47 & $-0,259$ & 56,343 & 55,476 & 27,7 & 20,3 & 92,800 & 1,065 \\
\hline 220 & -20 & 12,9 & 15,3 & 46 & 42 & 18 & 17 & 49 & $-0,229$ & 56,311 & 55,479 & 27,7 & 20,3 & 92,800 & 1,065 \\
\hline 220 & -25 & 16,1 & 19,2 & 36 & 41 & 14 & 10 & 51 & $-0,198$ & 56,279 & 55,483 & 27,7 & 20,3 & 92,799 & 1,065 \\
\hline 220 & -30 & 19,3 & 23,0 & 24 & 40 & 12 & 4 & 51 & $-0,167$ & 56,247 & 55,487 & 27,7 & 20,3 & 92,799 & 1,065 \\
\hline 220 & -35 & 22,5 & 26,8 & 9 & 37 & 15 & -2 & 50 & $-0,136$ & 56,215 & 55,490 & 27,8 & 20,3 & 92,799 & 1,065 \\
\hline 220 & -40 & 25,7 & 30,6 & -8 & 33 & -6 & -6 & 48 & $-0,106$ & 56,182 & 55,494 & 27,8 & 20,3 & 92,799 & 1,065 \\
\hline 220 & -45 & 28,9 & 34,5 & -25 & 30 & -60 & -35 & 44 & $-0,075$ & 56,150 & 55,498 & 27,8 & 20,3 & 92,799 & 1,065 \\
\hline 220 & -50 & 32,1 & 38,3 & -39 & 25 & -82 & -80 & 39 & $-0,044$ & 56,118 & 55,501 & 27,8 & 20,3 & 92,798 & 1,065 \\
\hline 220 & -55 & 35,4 & 42,1 & -52 & 20 & -89 & -83 & 34 & $-0,013$ & 56,085 & 55,505 & 27,8 & 20,3 & 92,798 & 1,065 \\
\hline 220 & -60 & 38,6 & 46,0 & -62 & 14 & -90 & -83 & 28 & 0,017 & 56,053 & 55,509 & 27,8 & 20,4 & 92,798 & 1,065 \\
\hline 220 & 5 & $-3,2$ & $-3,8$ & 59 & 31 & 36 & 41 & 29 & 0,048 & 56,021 & 55,512 & 27,8 & 20,4 & 92,798 & 1,065 \\
\hline 220 & 10 & $-6,4$ & $-7,7$ & 56 & 27 & 37 & 46 & 24 & 0,079 & 55,989 & 55,516 & 27,8 & 20,4 & 92,797 & 1,065 \\
\hline 220 & 15 & $-9,6$ & $-11,5$ & 53 & 22 & 39 & 49 & 18 & 0,109 & 55,957 & 55,519 & 27,8 & 20,4 & 92,797 & 1,065 \\
\hline 220 & 20 & $-12,9$ & $-15,3$ & 46 & 17 & 40 & 51 & 11 & 0,140 & 55,925 & 55,523 & 27,8 & 20,4 & 92,797 & 1,065 \\
\hline 220 & 25 & $-16,1$ & $-19,2$ & 36 & 12 & 39 & 52 & 4 & 0,170 & 55,893 & 55,527 & 27,8 & 20,4 & 92,797 & 1,065 \\
\hline 220 & 30 & $-19,3$ & $-23,0$ & 25 & 8 & 38 & 52 & -1 & 0,200 & 55,861 & 55,530 & 27,8 & 20,4 & 92,796 & 1,065 \\
\hline 220 & 35 & $-22,5$ & $-26,8$ & 9 & 11 & 35 & 51 & -7 & 0,230 & 55,830 & 55,534 & 27,8 & 20,4 & 92,796 & 1,065 \\
\hline 220 & 40 & $-25,7$ & $-30,6$ & -8 & 5 & 31 & 48 & -12 & 0,260 & 55,798 & 55,537 & 27,8 & 20,4 & 92,796 & 1,065 \\
\hline 220 & 45 & $-28,9$ & $-34,5$ & -24 & -59 & 28 & 44 & -34 & 0,290 & 55,767 & 55,541 & 27,8 & 20,4 & 92,796 & 1,065 \\
\hline 220 & 50 & $-32,1$ & $-38,3$ & -40 & -87 & 22 & -39 & -90 & 0,320 & 55,736 & 55,544 & 27,8 & 20,4 & 92,796 & 1,065 \\
\hline 220 & 55 & $-35,4$ & $-42,1$ & -52 & -95 & 17 & 33 & -94 & 0,349 & 55,705 & 55,547 & 27,8 & 20,4 & 92,795 & 1,065 \\
\hline
\end{tabular}




\begin{tabular}{|c|c|c|c|c|c|c|c|c|c|c|c|c|c|c|c|}
\hline $\begin{array}{c}\text { Ângulo } \\
\text { g } \\
\text { (graus) }\end{array}$ & $\begin{array}{c}\text { Ângulo } \\
\text { a } \\
\text { (graus) }\end{array}$ & $\begin{array}{l}\text { Ângulo de } \\
\text { guinada } \psi \\
\text { (graus) }\end{array}$ & $\begin{array}{c}\text { Ângulo de } \\
\text { arfagem } \delta \\
\text { (graus) }\end{array}$ & $\mathrm{p} 1(\mathrm{~Pa})$ & p2 $(\mathrm{Pa})$ & p3 $(\mathrm{Pa})$ & p4 (Pa) & p5 (Pa) & $\mathrm{P}$ est $(\mathrm{Pa})$ & $\mathrm{P} \operatorname{din}(\mathrm{Pa})$ & Ptotal $(\mathrm{Pa})$ & $\begin{array}{c}\text { Temperatura } \\
\text { de Bulbo } \\
\text { Seco (jato) } \\
{ }^{\circ} \mathrm{C}\end{array}$ & $\begin{array}{c}\text { Temperatura } \\
\text { de Bulbo } \\
\text { Úmido } \\
{ }^{\circ} \mathrm{C}\end{array}$ & $\begin{array}{l}\text { Patm } \\
(\mathrm{kPa})\end{array}$ & $\begin{array}{c}\text { massa } \\
\text { específica do } \\
\text { ar }(\mathrm{kg} / \mathrm{m} 3)\end{array}$ \\
\hline 220 & 60 & $-38,6$ & $-46,0$ & -63 & -97 & 11 & 28 & -93 & 0,379 & 55,674 & 55,551 & 27,8 & 20,4 & 92,795 & 1,065 \\
\hline 225 & 0 & 0,0 & 0,0 & 59 & 34 & 34 & 37 & 34 & 0,408 & 55,644 & 55,554 & 27,9 & 20,4 & 92,795 & 1,065 \\
\hline 225 & 5 & $-3,5$ & $-3,5$ & 58 & 30 & 36 & 40 & 29 & 0,436 & 55,614 & 55,558 & 27,9 & 20,5 & 92,795 & 1,065 \\
\hline 225 & 10 & $-7,1$ & $-7,1$ & 57 & 26 & 39 & 43 & 25 & 0,465 & 55,583 & 55,561 & 27,9 & 20,5 & 92,794 & 1,064 \\
\hline 225 & 15 & $-10,6$ & $-10,6$ & 52 & 19 & 40 & 47 & 18 & 0,494 & 55,554 & 55,564 & 27,9 & 20,5 & 92,794 & 1,064 \\
\hline 225 & 20 & $-14,1$ & $-14,1$ & 45 & 15 & 42 & 48 & 13 & 0,522 & 55,524 & 55,567 & 27,9 & 20,5 & 92,794 & 1,064 \\
\hline 225 & 25 & $-17,7$ & $-17,7$ & 37 & 10 & 42 & 50 & 7 & 0,550 & 55,495 & 55,570 & 27,9 & 20,5 & 92,794 & 1,064 \\
\hline 225 & 30 & $-21,2$ & $-21,2$ & 26 & 7 & 41 & 50 & 1 & 0,577 & 55,466 & 55,573 & 27,9 & 20,5 & 92,793 & 1,064 \\
\hline 225 & 35 & $-24,7$ & $-24,7$ & 10 & 7 & 38 & 48 & -3 & 0,604 & 55,437 & 55,576 & 27,9 & 20,5 & 92,793 & 1,064 \\
\hline 225 & 40 & $-28,3$ & $-28,3$ & -8 & 3 & 35 & 45 & -5 & 0,631 & 55,409 & 55,579 & 27,9 & 20,5 & 92,793 & 1,064 \\
\hline 225 & 45 & $-31,8$ & $-31,8$ & -25 & -50 & 31 & 40 & -54 & 0,658 & 55,381 & 55,582 & 27,9 & 20,5 & 92,793 & 1,064 \\
\hline 225 & 50 & $-35,4$ & $-35,4$ & -41 & -89 & 26 & 35 & -92 & 0,685 & 55,353 & 55,585 & 27,9 & 20,5 & 92,792 & 1,064 \\
\hline 225 & 55 & $-38,9$ & $-38,9$ & -55 & -98 & 21 & 29 & -100 & 0,711 & 55,326 & 55,588 & 27,9 & 20,5 & 92,792 & 1,064 \\
\hline 225 & 60 & $-42,4$ & $-42,4$ & -54 & -98 & 20 & 29 & -101 & 0,736 & 55,299 & 55,591 & 27,9 & 20,5 & 92,792 & 1,064 \\
\hline 225 & -5 & 3,5 & 3,5 & 59 & 38 & 31 & 32 & 40 & 0,762 & 55,272 & 55,593 & 27,9 & 20,5 & 92,792 & 1,064 \\
\hline 225 & -10 & 7,1 & 7,1 & 57 & 40 & 26 & 27 & 45 & 0,786 & 55,246 & 55,596 & 27,9 & 20,5 & 92,791 & 1,064 \\
\hline 225 & -15 & 10,6 & 10,6 & 52 & 42 & 21 & 21 & 48 & 0,811 & 55,220 & 55,599 & 27,9 & 20,5 & 92,791 & 1,064 \\
\hline 225 & -20 & 14,1 & 14,1 & 44 & 43 & 17 & 15 & 49 & 0,835 & 55,195 & 55,601 & 27,9 & 20,5 & 92,791 & 1,064 \\
\hline 225 & -25 & 17,7 & 17,7 & 35 & 43 & 13 & 9 & 50 & 0,859 & 55,170 & 55,604 & 27,9 & 20,6 & 92,791 & 1,064 \\
\hline 225 & -30 & 21,2 & 21,2 & 24 & 42 & 9 & 4 & 40 & 0,882 & 55,145 & 55,606 & 28,0 & 20,6 & 92,790 & 1,064 \\
\hline 225 & -35 & 24,7 & 24,7 & 9 & 40 & 13 & -1 & 48 & 0,905 & 55,121 & 55,608 & 28,0 & 20,6 & 92,790 & 1,064 \\
\hline 225 & -40 & 28,3 & 28,3 & -10 & 37 & -4 & -3 & 45 & 0,927 & 55,098 & 55,610 & 28,0 & 20,6 & 92,790 & 1,064 \\
\hline 225 & -45 & 31,8 & 31,8 & -28 & 33 & -61 & -55 & 41 & 0,949 & 55,074 & 55,612 & 28,0 & 20,6 & 92,790 & 1,064 \\
\hline 225 & -50 & 35,4 & 35,4 & -41 & 28 & -88 & -86 & 36 & 0,971 & 55,052 & 55,615 & 28,0 & 20,6 & 92,789 & 1,064 \\
\hline 225 & -55 & 38,9 & 38,9 & -53 & 23 & -94 & -91 & 30 & 0,992 & 55,030 & 55,616 & 28,0 & 20,6 & 92,789 & 1,064 \\
\hline 225 & -60 & 42,4 & 42,4 & -63 & 17 & -91 & -87 & 23 & 1,012 & 55,008 & 55,618 & 28,0 & 20,6 & 92,789 & 1,064 \\
\hline 230 & 0 & 0,0 & 0,0 & 60 & 34 & 35 & 36 & 35 & 1,032 & 54,987 & 55,620 & 28,0 & 20,6 & 92,789 & 1,064 \\
\hline 230 & -5 & 3,8 & 3,2 & 59 & 38 & 32 & 33 & 40 & 1,051 & 54,967 & 55,622 & 28,0 & 20,6 & 92,788 & 1,064 \\
\hline 230 & -10 & 7,7 & 6,4 & 57 & 41 & 28 & 28 & 44 & 1,070 & 54,947 & 55,623 & 28,0 & 20,6 & 92,788 & 1,064 \\
\hline 230 & -15 & 11,5 & 9,6 & 53 & 44 & 21 & 22 & 46 & 1,088 & 54,928 & 55,625 & 28,0 & 20,6 & 92,788 & 1,064 \\
\hline 230 & -20 & 15,3 & 12,9 & 46 & 45 & 16 & 17 & 47 & 1,106 & 54,909 & 55,626 & 28,0 & 20,6 & 92,787 & 1,064 \\
\hline 230 & -25 & 19,2 & 16,1 & 36 & 45 & 10 & 10 & 47 & 1,123 & 54,891 & 55,627 & 28,0 & 20,6 & 92,787 & 1,064 \\
\hline 230 & -30 & 23,0 & 19,3 & 21 & 44 & 4 & 6 & 47 & 1,140 & 54,873 & 55,629 & 28,0 & 20,6 & 92,787 & 1,063 \\
\hline 230 & -35 & 26,8 & 22,5 & 5 & 41 & 3 & 3 & 45 & 1,155 & 54,856 & 55,630 & 28,0 & 20,6 & 92,787 & 1,063 \\
\hline 230 & -40 & 30,6 & 25,7 & -12 & 39 & 2 & -5 & 43 & 1,171 & 54,840 & 55,631 & 28,0 & 20,6 & 92,786 & 1,063 \\
\hline 230 & -45 & 34,5 & 28,9 & -31 & 36 & -61 & -57 & 38 & 1,185 & 54,825 & 55,632 & 28,0 & 20,6 & 92,786 & 1,063 \\
\hline 230 & -50 & 38,3 & 32,1 & -45 & 31 & -92 & -89 & 32 & 1,199 & 54,810 & 55,632 & 28,0 & 20,6 & 92,786 & 1,063 \\
\hline 230 & -55 & 42,1 & 35,4 & -59 & 25 & -97 & -96 & 26 & 1,213 & 54,796 & 55,633 & 28,0 & 20,7 & 92,785 & 1,063 \\
\hline 230 & -60 & 46,0 & 38,6 & -68 & 20 & -96 & -93 & 21 & 1,225 & 54,782 & 55,634 & 28,0 & 20,7 & 92,785 & 1,063 \\
\hline 230 & 5 & $-3,8$ & $-3,2$ & 55 & 28 & 37 & 39 & 31 & 1,237 & 54,769 & 55,634 & 28,1 & 20,7 & 92,785 & 1,063 \\
\hline
\end{tabular}




\begin{tabular}{|c|c|c|c|c|c|c|c|c|c|c|c|c|c|c|c|}
\hline $\begin{array}{l}\text { Ângulo } \\
\text { g } \\
\text { (graus) }\end{array}$ & $\begin{array}{l}\text { Ângulo } \\
\text { a } \\
\text { (graus) }\end{array}$ & $\begin{array}{l}\text { Ângulo de } \\
\text { guinada } \psi \\
\quad \text { (graus) }\end{array}$ & $\begin{array}{l}\text { Ângulo de } \\
\text { arfagem } \delta \\
\text { (graus) }\end{array}$ & $\mathrm{p} 1(\mathrm{~Pa})$ & p2 $(\mathrm{Pa})$ & p3 (Pa) & $\mathrm{p} 4(\mathrm{~Pa})$ & p5 $(\mathrm{Pa})$ & P est $(\mathrm{Pa})$ & $P \operatorname{din}(\mathrm{Pa})$ & Ptotal $(\mathrm{Pa})$ & $\begin{array}{c}\text { Temperatura } \\
\text { de Bulbo } \\
\text { Seco (jato) } \\
{ }^{\circ} \mathrm{C} \\
\end{array}$ & $\begin{array}{c}\text { Temperatura } \\
\text { de Bulbo } \\
\text { Úmido } \\
{ }^{\circ} \mathrm{C}\end{array}$ & $\begin{array}{l}\text { Patm } \\
(\mathrm{kPa})\end{array}$ & $\begin{array}{c}\text { massa } \\
\text { específica do } \\
\operatorname{ar}(\mathrm{kg} / \mathrm{m} 3)\end{array}$ \\
\hline 230 & 10 & $-7,7$ & $-6,4$ & 53 & 23 & 40 & 41 & 26 & 1,249 & 54,757 & 55,634 & 28,1 & 20,7 & 92,785 & 1,063 \\
\hline 230 & 15 & $-11,5$ & $-9,6$ & 50 & 17 & 43 & 43 & 19 & 1,259 & 54,746 & 55,634 & 28,1 & 20,7 & 92,784 & 1,063 \\
\hline 230 & 20 & $-15,3$ & $-12,9$ & 44 & 12 & 43 & 45 & 14 & 1,269 & 54,735 & 55,634 & 28,1 & 20,7 & 92,784 & 1,063 \\
\hline 230 & 25 & $-19,2$ & $-16,1$ & 34 & 6 & 44 & 45 & 9 & 1,278 & 54,725 & 55,634 & 28,1 & 20,7 & 92,784 & 1,063 \\
\hline 230 & 30 & $-23,0$ & $-19,3$ & 22 & 0 & 44 & 44 & 4 & 1,287 & 54,716 & 55,634 & 28,1 & 20,7 & 92,783 & 1,063 \\
\hline 230 & 35 & $-26,8$ & $-22,5$ & 6 & -5 & 42 & 42 & 3 & 1,294 & 54,708 & 55,634 & 28,1 & 20,7 & 92,783 & 1,063 \\
\hline 230 & 40 & $-30,6$ & $-25,7$ & -11 & -5 & 39 & 39 & -12 & 1,301 & 54,701 & 55,633 & 28,1 & 20,7 & 92,783 & 1,063 \\
\hline 230 & 45 & $-34,5$ & $-28,9$ & -31 & -49 & 35 & 34 & -65 & 1,307 & 54,694 & 55,633 & 28,1 & 20,7 & 92,782 & 1,063 \\
\hline 230 & 50 & $-38,3$ & $-32,1$ & -46 & -91 & 31 & 30 & -96 & 1,312 & 54,688 & 55,632 & 28,1 & 20,7 & 92,782 & 1,063 \\
\hline 230 & 55 & $-42,1$ & $-35,4$ & -60 & -101 & 24 & 24 & -103 & 1,317 & 54,683 & 55,631 & 28,1 & 20,7 & 92,782 & 1,063 \\
\hline 230 & 60 & $-46,0$ & $-38,6$ & -70 & -102 & 19 & 18 & -104 & 1,320 & 54,679 & 55,630 & 28,1 & 20,7 & 92,781 & 1,063 \\
\hline 235 & 0 & 0,0 & 0,0 & 56 & 32 & 32 & 35 & 35 & 1,323 & 54,676 & 55,629 & 28,1 & 20,7 & 92,781 & 1,063 \\
\hline 235 & 5 & $-4,1$ & $-2,9$ & 56 & 28 & 36 & 38 & 31 & 1,325 & 54,673 & 55,628 & 28,1 & 20,7 & 92,781 & 1,063 \\
\hline 235 & 10 & $-8,2$ & $-5,7$ & 54 & 23 & 40 & 41 & 27 & 1,328 & 54,670 & 55,627 & 28,1 & 20,7 & 92,780 & 1,063 \\
\hline 235 & 15 & $-12,3$ & $-8,6$ & 49 & 16 & 44 & 41 & 21 & 1,330 & 54,668 & 55,625 & 28,1 & 20,7 & 92,780 & 1,063 \\
\hline 235 & 20 & $-16,4$ & $-11,5$ & 42 & 10 & 45 & 43 & 16 & 1,332 & 54,665 & 55,624 & 28,1 & 20,7 & 92,780 & 1,063 \\
\hline 235 & 25 & $-20,5$ & $-14,3$ & 32 & 5 & 47 & 43 & 12 & 1,335 & 54,662 & 55,623 & 28,1 & 20,7 & 92,779 & 1,063 \\
\hline 235 & 30 & $-24,6$ & $-17,2$ & 20 & -1 & 46 & 41 & 8 & 1,337 & 54,659 & 55,622 & 28,1 & 20,7 & 92,779 & 1,063 \\
\hline 235 & 35 & $-28,7$ & $-20,1$ & 4 & -7 & 45 & 40 & 10 & 1,339 & 54,656 & 55,620 & 28,1 & 20,7 & 92,779 & 1,063 \\
\hline 235 & 40 & $-32,8$ & $-22,9$ & -15 & -9 & 42 & 36 & -23 & 1,342 & 54,654 & 55,619 & 28,1 & 20,7 & 92,778 & 1,063 \\
\hline 235 & 45 & $-36,9$ & $-25,8$ & -32 & -45 & 39 & 31 & -69 & 1,344 & 54,651 & 55,618 & 28,1 & 20,7 & 92,778 & 1,063 \\
\hline 235 & 50 & $-41,0$ & $-28,7$ & -48 & -90 & 34 & 26 & -93 & 1,346 & 54,648 & 55,617 & 28,1 & 20,7 & 92,778 & 1,063 \\
\hline 235 & 55 & $-45,1$ & $-31,5$ & -61 & -98 & 29 & 21 & -99 & 1,349 & 54,645 & 55,615 & 28,1 & 20,7 & 92,777 & 1,063 \\
\hline 235 & 60 & $-49,1$ & $-34,4$ & -72 & -97 & 23 & 15 & -100 & 1,351 & 54,642 & 55,614 & 28,1 & 20,7 & 92,777 & 1,063 \\
\hline 235 & -5 & 4,1 & 2,9 & 56 & 38 & 29 & 34 & 37 & 1,353 & 54,640 & 55,613 & 28,1 & 20,7 & 92,777 & 1,063 \\
\hline 235 & -10 & 8,2 & 5,7 & 55 & 41 & 24 & 29 & 40 & 1,356 & 54,637 & 55,612 & 28,2 & 20,7 & 92,776 & 1,063 \\
\hline 235 & -15 & 12,3 & 8,6 & 50 & 44 & 18 & 24 & 42 & 1,358 & 54,634 & 55,610 & 28,2 & 20,7 & 92,776 & 1,063 \\
\hline 235 & -20 & 16,4 & 11,5 & 43 & 46 & 12 & 18 & 44 & 1,361 & 54,631 & 55,609 & 28,2 & 20,7 & 92,776 & 1,063 \\
\hline 235 & -25 & 20,5 & 14,3 & 34 & 48 & 7 & 14 & 44 & 1,363 & 54,628 & 55,608 & 28,2 & 20,7 & 92,775 & 1,063 \\
\hline 235 & -30 & 24,6 & 17,2 & 23 & 48 & 2 & 10 & 43 & 1,365 & 54,625 & 55,607 & 28,2 & 20,7 & 92,775 & 1,063 \\
\hline 235 & -35 & 28,7 & 20,1 & 7 & 47 & -3 & 12 & 41 & 1,368 & 54,623 & 55,605 & 28,2 & 20,8 & 92,775 & 1,063 \\
\hline 235 & -40 & 32,8 & 22,9 & -10 & 44 & -7 & 5 & 37 & 1,370 & 54,620 & 55,604 & 28,2 & 20,8 & 92,774 & 1,063 \\
\hline 235 & -45 & 36,9 & 25,8 & -28 & 41 & -46 & -54 & 34 & 1,372 & 54,617 & 55,603 & 28,2 & 20,8 & 92,774 & 1,063 \\
\hline 235 & -50 & 41,0 & 28,7 & -44 & 36 & -86 & -85 & 28 & 1,375 & 54,614 & 55,602 & 28,2 & 20,8 & 92,774 & 1,063 \\
\hline 235 & -55 & 45,1 & 31,5 & -56 & 31 & -93 & -91 & 24 & 1,377 & 54,611 & 55,600 & 28,2 & 20,8 & 92,773 & 1,062 \\
\hline 235 & -60 & 49,1 & 34,4 & -66 & 26 & -90 & -90 & 17 & 1,380 & 54,608 & 55,599 & 28,2 & 20,8 & 92,773 & 1,062 \\
\hline 240 & 0 & 0,0 & 0,0 & 56 & 33 & 33 & 37 & 35 & 1,382 & 54,606 & 55,598 & 28,2 & 20,8 & 92,773 & 1,062 \\
\hline 240 & -5 & 4,3 & 2,5 & 56 & 38 & 29 & 34 & 38 & 1,384 & 54,603 & 55,597 & 28,2 & 20,8 & 92,772 & 1,062 \\
\hline 240 & -10 & 8,7 & 5,0 & 55 & 42 & 24 & 29 & 40 & 1,387 & 54,600 & 55,595 & 28,2 & 20,8 & 92,772 & 1,062 \\
\hline 240 & -15 & 13,0 & 7,5 & 51 & 45 & 18 & 24 & 42 & 1,389 & 54,597 & 55,594 & 28,2 & 20,8 & 92,772 & 1,062 \\
\hline
\end{tabular}




\begin{tabular}{|c|c|c|c|c|c|c|c|c|c|c|c|c|c|c|c|}
\hline $\begin{array}{c}\text { Ângulo } \\
\text { g } \\
\text { (graus) } \\
\end{array}$ & $\begin{array}{c}\begin{array}{c}\text { Ângulo } \\
a \\
\text { (graus) }\end{array} \\
\end{array}$ & $\begin{array}{c}\text { Ângulo de } \\
\text { guinada } \psi \\
\text { (graus) }\end{array}$ & $\begin{array}{c}\begin{array}{c}\text { Ângulo de } \\
\text { arfagem } \delta \\
\text { (graus) }\end{array} \\
\end{array}$ & $\mathrm{p} 1(\mathrm{~Pa})$ & p2 $(\mathrm{Pa})$ & p3 (Pa) & $\mathrm{p} 4(\mathrm{~Pa})$ & p5 (Pa) & $\mathrm{P}$ est $(\mathrm{Pa})$ & $P \operatorname{din}(\mathrm{Pa})$ & Ptotal $(\mathrm{Pa})$ & $\begin{array}{c}\text { Temperatura } \\
\text { de Bulbo } \\
\text { Seco (jato) } \\
{ }^{\circ} \mathrm{C} \\
\end{array}$ & $\begin{array}{c}\text { Temperatura } \\
\text { de Bulbo } \\
\text { Úmido } \\
{ }^{\circ} \mathrm{C} \\
\end{array}$ & $\begin{array}{l}\text { Patm } \\
(\mathrm{kPa})\end{array}$ & $\begin{array}{c}\text { massa } \\
\text { específica do } \\
\operatorname{ar}(\mathrm{kg} / \mathrm{m} 3)\end{array}$ \\
\hline 240 & -20 & 17,3 & 10,0 & 42 & 48 & 11 & 19 & 42 & 1,391 & 54,594 & 55,593 & 28,2 & 20,8 & 92,771 & 1,062 \\
\hline 240 & -25 & 21,7 & 12,5 & 34 & 50 & 6 & 16 & 41 & 1,394 & 54,591 & 55,592 & 28,2 & 20,8 & 92,771 & 1,062 \\
\hline 240 & -30 & 26,0 & 15,0 & 21 & 50 & 0 & 13 & 40 & 1,396 & 54,588 & 55,590 & 28,2 & 20,8 & 92,771 & 1,062 \\
\hline 240 & -35 & 30,3 & 17,5 & 5 & 49 & -6 & 16 & 36 & 1,399 & 54,586 & 55,589 & 28,2 & 20,8 & 92,770 & 1,062 \\
\hline 240 & -40 & 34,6 & 20,0 & -11 & 48 & -10 & -4 & 34 & 1,401 & 54,583 & 55,588 & 28,2 & 20,8 & 92,770 & 1,062 \\
\hline 240 & -45 & 39,0 & 22,5 & -29 & 44 & -45 & -61 & 29 & 1,403 & 54,580 & 55,587 & 28,2 & 20,8 & 92,769 & 1,062 \\
\hline 240 & -50 & 43,3 & 25,0 & -44 & 40 & -84 & -82 & 24 & 1,406 & 54,577 & 55,585 & 28,2 & 20,8 & 92,769 & 1,062 \\
\hline 240 & -55 & 47,6 & 27,5 & -57 & 35 & -86 & -88 & 19 & 1,408 & 54,574 & 55,584 & 28,2 & 20,8 & 92,769 & 1,062 \\
\hline 240 & -60 & 52,0 & 30,0 & -68 & 30 & -86 & -86 & 13 & 1,411 & 54,571 & 55,583 & 28,2 & 20,8 & 92,768 & 1,062 \\
\hline 240 & 5 & $-4,3$ & $-2,5$ & 56 & 27 & 37 & 38 & 31 & 1,413 & 54,568 & 55,582 & 28,2 & 20,8 & 92,768 & 1,062 \\
\hline 240 & 10 & $-8,7$ & $-5,0$ & 56 & 22 & 43 & 40 & 27 & 1,415 & 54,566 & 55,580 & 28,2 & 20,8 & 92,768 & 1,062 \\
\hline 240 & 15 & $-13,0$ & $-7,5$ & 50 & 16 & 45 & 42 & 22 & 1,418 & 54,563 & 55,579 & 28,3 & 20,8 & 92,767 & 1,062 \\
\hline 240 & 20 & $-17,3$ & $-10,0$ & 45 & 10 & 47 & 41 & 17 & 1,420 & 54,560 & 55,578 & 28,3 & 20,8 & 92,767 & 1,062 \\
\hline 240 & 25 & $-21,7$ & $-12,5$ & 33 & 4 & 49 & 41 & 13 & 1,423 & 54,557 & 55,577 & 28,3 & 20,8 & 92,767 & 1,062 \\
\hline 240 & 30 & $-26,0$ & $-15,0$ & 21 & -2 & 49 & 39 & 10 & 1,425 & 54,554 & 55,575 & 28,3 & 20,8 & 92,766 & 1,062 \\
\hline 240 & 35 & $-30,3$ & $-17,5$ & 2 & -9 & 48 & 37 & 14 & 1,427 & 54,551 & 55,574 & 28,3 & 20,8 & 92,766 & 1,062 \\
\hline 240 & 40 & $-34,6$ & $-20,0$ & -17 & -12 & 45 & 32 & -31 & 1,430 & 54,548 & 55,573 & 28,3 & 20,8 & 92,766 & 1,062 \\
\hline 240 & 45 & $-39,0$ & $-22,5$ & -34 & -47 & 41 & 28 & -76 & 1,432 & 54,545 & 55,571 & 28,3 & 20,8 & 92,765 & 1,062 \\
\hline 240 & 50 & $-43,3$ & $-25,0$ & -50 & -88 & 37 & 23 & -90 & 1,435 & 54,542 & 55,570 & 28,3 & 20,8 & 92,765 & 1,062 \\
\hline 240 & 55 & $-47,6$ & $-27,5$ & -65 & -94 & 32 & 16 & -97 & 1,437 & 54,540 & 55,569 & 28,3 & 20,8 & 92,765 & 1,062 \\
\hline 240 & 60 & $-52,0$ & $-30,0$ & -75 & -94 & 26 & 11 & -98 & 1,439 & 54,537 & 55,568 & 28,3 & 20,8 & 92,764 & 1,062 \\
\hline 245 & 0 & 0,0 & 0,0 & 56 & 32 & 32 & 35 & 34 & 1,442 & 54,534 & 55,566 & 28,3 & 20,8 & 92,764 & 1,062 \\
\hline 245 & 5 & $-4,5$ & $-2,1$ & 56 & 27 & 37 & 37 & 32 & 1,444 & 54,531 & 55,565 & 28,3 & 20,8 & 92,764 & 1,062 \\
\hline 245 & 10 & $-9,1$ & $-4,2$ & 55 & 22 & 42 & 39 & 29 & 1,447 & 54,528 & 55,564 & 28,3 & 20,8 & 92,763 & 1,062 \\
\hline 245 & 15 & $-13,6$ & $-6,3$ & 50 & 16 & 46 & 40 & 23 & 1,449 & 54,525 & 55,563 & 28,3 & 20,8 & 92,763 & 1,062 \\
\hline 245 & 20 & $-18,1$ & $-8,5$ & 42 & 9 & 48 & 40 & 18 & 1,452 & 54,522 & 55,561 & 28,3 & 20,8 & 92,763 & 1,062 \\
\hline 245 & 25 & $-22,7$ & $-10,6$ & 32 & 3 & 51 & 38 & 16 & 1,454 & 54,519 & 55,560 & 28,3 & 20,9 & 92,762 & 1,062 \\
\hline 245 & 30 & $-27,2$ & $-12,7$ & 19 & -4 & 50 & 35 & 15 & 1,456 & 54,516 & 55,559 & 28,3 & 20,9 & 92,762 & 1,062 \\
\hline 245 & 35 & $-31,7$ & $-14,8$ & 1 & -11 & 50 & 32 & 17 & 1,459 & 54,513 & 55,557 & 28,3 & 20,9 & 92,762 & 1,062 \\
\hline 245 & 40 & $-36,3$ & $-16,9$ & -19 & -17 & 48 & 28 & -25 & 1,461 & 54,511 & 55,556 & 28,3 & 20,9 & 92,761 & 1,062 \\
\hline 245 & 45 & $-40,8$ & $-19,0$ & -38 & -35 & 45 & 24 & -73 & 1,464 & 54,508 & 55,555 & 28,3 & 20,9 & 92,761 & 1,062 \\
\hline 245 & 50 & $-45,3$ & $-21,1$ & -51 & -82 & 40 & 19 & -85 & 1,466 & 54,505 & 55,554 & 28,3 & 20,9 & 92,760 & 1,062 \\
\hline 245 & 55 & $-49,8$ & $-23,2$ & -67 & -87 & 36 & 14 & -94 & 1,469 & 54,502 & 55,552 & 28,3 & 20,9 & 92,760 & 1,062 \\
\hline 245 & 60 & $-54,4$ & $-25,4$ & -81 & -92 & 29 & 7 & -95 & 1,471 & 54,499 & 55,551 & 28,3 & 20,9 & 92,760 & 1,062 \\
\hline 245 & -5 & 4,5 & 2,1 & 57 & 36 & 29 & 31 & 39 & 1,474 & 54,496 & 55,550 & 28,3 & 20,9 & 92,759 & 1,062 \\
\hline 245 & -10 & 9,1 & 4,2 & 54 & 41 & 23 & 28 & 42 & 1,476 & 54,493 & 55,548 & 28,3 & 20,9 & 92,759 & 1,062 \\
\hline 245 & -15 & 13,6 & 6,3 & 51 & 44 & 18 & 23 & 42 & 1,478 & 54,490 & 55,547 & 28,4 & 20,9 & 92,759 & 1,062 \\
\hline 245 & -20 & 18,1 & 8,5 & 42 & 47 & 11 & 19 & 43 & 1,481 & 54,487 & 55,546 & 28,4 & 20,9 & 92,758 & 1,062 \\
\hline 245 & -25 & 22,7 & 10,6 & 34 & 49 & 6 & 15 & 43 & 1,483 & 54,484 & 55,545 & 28,4 & 20,9 & 92,758 & 1,062 \\
\hline 245 & -30 & 27,2 & 12,7 & 22 & 49 & 0 & 13 & 40 & 1,486 & 54,481 & 55,543 & 28,4 & 20,9 & 92,758 & 1,061 \\
\hline
\end{tabular}




\begin{tabular}{|c|c|c|c|c|c|c|c|c|c|c|c|c|c|c|c|}
\hline $\begin{array}{c}\text { Ângulo } \\
\text { g } \\
\text { (graus) } \\
\end{array}$ & $\begin{array}{c}\begin{array}{c}\text { Ângulo } \\
a \\
\text { (graus) }\end{array} \\
\end{array}$ & $\begin{array}{c}\text { Ângulo de } \\
\text { guinada } \psi \\
\text { (graus) }\end{array}$ & $\begin{array}{c}\begin{array}{c}\text { Ângulo de } \\
\text { arfagem } \delta \\
\text { (graus) }\end{array} \\
\end{array}$ & $\mathrm{p} 1(\mathrm{~Pa})$ & p2 $(\mathrm{Pa})$ & p3 (Pa) & $\mathrm{p} 4(\mathrm{~Pa})$ & p5 $(\mathrm{Pa})$ & $\mathrm{P}$ est $(\mathrm{Pa})$ & $P \operatorname{din}(\mathrm{Pa})$ & Ptotal $(\mathrm{Pa})$ & $\begin{array}{c}\text { Temperatura } \\
\text { de Bulbo } \\
\text { Seco (jato) } \\
{ }^{\circ} \mathrm{C} \\
\end{array}$ & $\begin{array}{c}\text { Temperatura } \\
\text { de Bulbo } \\
\text { Úmido } \\
{ }^{\circ} \mathrm{C} \\
\end{array}$ & $\begin{array}{l}\text { Patm } \\
(\mathrm{kPa})\end{array}$ & $\begin{array}{c}\text { massa } \\
\text { específica do } \\
\operatorname{ar}(\mathrm{kg} / \mathrm{m} 3)\end{array}$ \\
\hline 245 & -35 & 31,7 & 14,8 & 5 & 49 & -6 & 16 & 37 & 1,488 & 54,478 & 55,542 & 28,4 & 20,9 & 92,757 & 1,061 \\
\hline 245 & -40 & 36,3 & 16,9 & -15 & 47 & -12 & -18 & 33 & 1,491 & 54,475 & 55,541 & 28,4 & 20,9 & 92,757 & 1,061 \\
\hline 245 & -45 & 40,8 & 19,0 & -31 & 44 & -41 & -66 & 28 & 1,493 & 54,472 & 55,539 & 28,4 & 20,9 & 92,757 & 1,061 \\
\hline 245 & -50 & 45,3 & 21,1 & -44 & 40 & -81 & -79 & 23 & 1,496 & 54,469 & 55,538 & 28,4 & 20,9 & 92,756 & 1,061 \\
\hline 245 & -55 & 49,8 & 23,2 & -56 & 35 & -83 & -85 & 18 & 1,498 & 54,467 & 55,537 & 28,4 & 20,9 & 92,756 & 1,061 \\
\hline 245 & -60 & 54,4 & 25,4 & -69 & 30 & -83 & -84 & 12 & 1,501 & 54,464 & 55,536 & 28,4 & 20,9 & 92,756 & 1,061 \\
\hline 250 & 0 & 0,0 & 0,0 & 56 & 32 & 34 & 34 & 37 & 1,503 & 54,461 & 55,534 & 28,4 & 20,9 & 92,755 & 1,061 \\
\hline 250 & -5 & 4,7 & 1,7 & 56 & 37 & 30 & 32 & 39 & 1,505 & 54,458 & 55,533 & 28,4 & 20,9 & 92,755 & 1,061 \\
\hline 250 & -10 & 9,4 & 3,4 & 53 & 42 & 23 & 28 & 41 & 1,508 & 54,455 & 55,532 & 28,4 & 20,9 & 92,755 & 1,061 \\
\hline 250 & -15 & 14,1 & 5,1 & 49 & 46 & 16 & 24 & 41 & 1,510 & 54,452 & 55,530 & 28,4 & 20,9 & 92,754 & 1,061 \\
\hline 250 & -20 & 18,8 & 6,8 & 43 & 49 & 11 & 21 & 41 & 1,513 & 54,449 & 55,529 & 28,4 & 20,9 & 92,754 & 1,061 \\
\hline 250 & -25 & 23,5 & 8,6 & 33 & 51 & 5 & 16 & 39 & 1,515 & 54,446 & 55,528 & 28,4 & 20,9 & 92,753 & 1,061 \\
\hline 250 & -30 & 28,2 & 10,3 & 19 & 52 & -2 & 16 & 37 & 1,518 & 54,443 & 55,526 & 28,4 & 20,9 & 92,753 & 1,061 \\
\hline 250 & -35 & 32,9 & 12,0 & 1 & 52 & -10 & 17 & 33 & 1,520 & 54,440 & 55,525 & 28,4 & 20,9 & 92,753 & 1,061 \\
\hline 250 & -40 & 37,6 & 13,7 & -17 & 50 & -15 & -29 & 28 & 1,523 & 54,437 & 55,524 & 28,4 & 20,9 & 92,752 & 1,061 \\
\hline 250 & -45 & 42,3 & 15,4 & -33 & 47 & -47 & -65 & 25 & 1,525 & 54,434 & 55,522 & 28,4 & 20,9 & 92,752 & 1,061 \\
\hline 250 & -50 & 47,0 & 17,1 & -47 & 43 & -75 & -76 & 19 & 1,528 & 54,431 & 55,521 & 28,4 & 20,9 & 92,752 & 1,061 \\
\hline 250 & -55 & 51,7 & 18,8 & -62 & 38 & -79 & -83 & 13 & 1,530 & 54,428 & 55,520 & 28,4 & 20,9 & 92,751 & 1,061 \\
\hline 250 & -60 & 56,4 & 20,5 & -75 & 33 & -83 & -81 & 6 & 1,533 & 54,425 & 55,519 & 28,4 & 20,9 & 92,751 & 1,061 \\
\hline 250 & 5 & $-4,7$ & $-1,7$ & 56 & 27 & 37 & 37 & 32 & 1,535 & 54,422 & 55,517 & 28,4 & 20,9 & 92,751 & 1,061 \\
\hline 250 & 10 & $-9,4$ & $-3,4$ & 54 & 22 & 42 & 38 & 28 & 1,538 & 54,419 & 55,516 & 28,4 & 20,9 & 92,750 & 1,061 \\
\hline 250 & 15 & $-14,1$ & $-5,1$ & 49 & 15 & 45 & 37 & 23 & 1,540 & 54,416 & 55,515 & 28,5 & 21,0 & 92,750 & 1,061 \\
\hline 250 & 20 & $-18,8$ & $-6,8$ & 43 & 8 & 49 & 37 & 20 & 1,543 & 54,413 & 55,513 & 28,5 & 21,0 & 92,750 & 1,061 \\
\hline 250 & 25 & $-23,5$ & $-8,6$ & 33 & 2 & 51 & 35 & 17 & 1,545 & 54,410 & 55,512 & 28,5 & 21,0 & 92,749 & 1,061 \\
\hline 250 & 30 & $-28,2$ & $-10,3$ & 17 & -5 & 52 & 32 & 15 & 1,548 & 54,407 & 55,511 & 28,5 & 21,0 & 92,749 & 1,061 \\
\hline 250 & 35 & $-32,9$ & $-12,0$ & 0 & -12 & 51 & 28 & 19 & 1,550 & 54,404 & 55,509 & 28,5 & 21,0 & 92,748 & 1,061 \\
\hline 250 & 40 & $-37,6$ & $-13,7$ & -20 & -18 & 50 & 24 & -27 & 1,553 & 54,401 & 55,508 & 28,5 & 21,0 & 92,748 & 1,061 \\
\hline 250 & 45 & $-42,3$ & $-15,4$ & -39 & -37 & 47 & 20 & -67 & 1,555 & 54,398 & 55,507 & 28,5 & 21,0 & 92,748 & 1,061 \\
\hline 250 & 50 & $-47,0$ & $-17,1$ & -55 & -80 & 42 & 13 & -81 & 1,558 & 54,395 & 55,505 & 28,5 & 21,0 & 92,747 & 1,061 \\
\hline 250 & 55 & $-51,7$ & $-18,8$ & -72 & -84 & 37 & 9 & -90 & 1,560 & 54,392 & 55,504 & 28,5 & 21,0 & 92,747 & 1,061 \\
\hline 250 & 60 & $-56,4$ & $-20,5$ & -85 & -92 & 33 & 1 & -91 & 1,563 & 54,389 & 55,503 & 28,5 & 21,0 & 92,747 & 1,061 \\
\hline 255 & 0 & 0,0 & 0,0 & 56 & 32 & 31 & 35 & 35 & 1,565 & 54,386 & 55,501 & 28,5 & 21,0 & 92,746 & 1,061 \\
\hline 255 & 5 & $-4,8$ & $-1,3$ & 56 & 28 & 37 & 37 & 33 & 1,568 & 54,383 & 55,500 & 28,5 & 21,0 & 92,746 & 1,061 \\
\hline 255 & 10 & $-9,7$ & $-2,6$ & 53 & 21 & 41 & 37 & 30 & 1,570 & 54,380 & 55,499 & 28,5 & 21,0 & 92,746 & 1,061 \\
\hline 255 & 15 & $-14,5$ & $-3,9$ & 50 & 15 & 46 & 36 & 26 & 1,573 & 54,377 & 55,497 & 28,5 & 21,0 & 92,745 & 1,061 \\
\hline 255 & 20 & $-19,3$ & $-5,2$ & 42 & 7 & 51 & 35 & 21 & 1,575 & 54,374 & 55,496 & 28,5 & 21,0 & 92,745 & 1,061 \\
\hline 255 & 25 & $-24,1$ & $-6,5$ & 31 & 1 & 52 & 32 & 18 & 1,578 & 54,371 & 55,495 & 28,5 & 21,0 & 92,745 & 1,061 \\
\hline 255 & 30 & $-29,0$ & $-7,8$ & 17 & -6 & 53 & 29 & 19 & 1,580 & 54,368 & 55,493 & 28,5 & 21,0 & 92,744 & 1,061 \\
\hline 255 & 35 & $-33,8$ & $-9,1$ & -2 & -13 & 54 & 25 & 15 & 1,583 & 54,365 & 55,492 & 28,5 & 21,0 & 92,744 & 1,061 \\
\hline 255 & 40 & $-38,6$ & $-10,4$ & -24 & -20 & 53 & 20 & -40 & 1,585 & 54,362 & 55,491 & 28,5 & 21,0 & 92,743 & 1,061 \\
\hline
\end{tabular}




\begin{tabular}{|c|c|c|c|c|c|c|c|c|c|c|c|c|c|c|c|}
\hline $\begin{array}{c}\text { Ângulo } \\
\text { g } \\
\text { (graus) }\end{array}$ & $\begin{array}{c}\text { Ângulo } \\
\text { a } \\
\text { (graus) }\end{array}$ & $\begin{array}{l}\text { Ângulo de } \\
\text { guinada } \Psi \\
\text { (graus) }\end{array}$ & $\begin{array}{c}\text { Ângulo de } \\
\text { arfagem } \delta \\
\text { (graus) }\end{array}$ & $\mathrm{p} 1(\mathrm{~Pa})$ & $\mathrm{p} 2(\mathrm{~Pa})$ & p3 (Pa) & $\mathrm{p} 4(\mathrm{~Pa})$ & p5 (Pa) & P est $(\mathrm{Pa})$ & $P \operatorname{din}(\mathrm{Pa})$ & Ptotal $(\mathrm{Pa})$ & $\begin{array}{c}\text { Temperatura } \\
\text { de Bulbo } \\
\text { Seco (jato) } \\
{ }^{\circ} \mathrm{C}\end{array}$ & $\begin{array}{c}\text { Temperatura } \\
\text { de Bulbo } \\
\text { Úmido } \\
{ }^{\circ} \mathrm{C}\end{array}$ & $\begin{array}{l}\text { Patm } \\
(\mathrm{kPa})\end{array}$ & $\begin{array}{c}\text { massa } \\
\text { específica do } \\
\operatorname{ar}(\mathrm{kg} / \mathrm{m} 3)\end{array}$ \\
\hline 255 & 45 & $-43,5$ & $-11,6$ & -42 & -41 & 50 & 16 & -64 & 1,588 & 54,359 & 55,489 & 28,5 & 21,0 & 92,743 & 1,061 \\
\hline 255 & 50 & $-48,3$ & $-12,9$ & -57 & -75 & 46 & 10 & -73 & 1,590 & 54,356 & 55,488 & 28,5 & 21,0 & 92,743 & 1,061 \\
\hline 255 & 55 & $-53,1$ & $-14,2$ & -74 & -84 & 42 & 4 & -81 & 1,593 & 54,353 & 55,487 & 28,5 & 21,0 & 92,742 & 1,061 \\
\hline 255 & 60 & $-58,0$ & $-15,5$ & -87 & -87 & 36 & -1 & -86 & 1,596 & 54,350 & 55,486 & 28,5 & 21,0 & 92,742 & 1,060 \\
\hline 255 & -5 & 4,8 & 1,3 & 57 & 38 & 31 & 34 & 38 & 1,598 & 54,347 & 55,484 & 28,5 & 21,0 & 92,742 & 1,060 \\
\hline 255 & -10 & 9,7 & 2,6 & 54 & 43 & 23 & 31 & 40 & 1,601 & 54,344 & 55,483 & 28,5 & 21,0 & 92,741 & 1,060 \\
\hline 255 & -15 & 14,5 & 3,9 & 49 & 47 & 17 & 27 & 39 & 1,603 & 54,341 & 55,481 & 28,6 & 21,0 & 92,741 & 1,060 \\
\hline 255 & -20 & 19,3 & 5,2 & 42 & 51 & 10 & 23 & 38 & 1,606 & 54,338 & 55,480 & 28,6 & 21,0 & 92,741 & 1,060 \\
\hline 255 & -25 & 24,1 & 6,5 & 32 & 54 & 4 & 19 & 35 & 1,608 & 54,335 & 55,479 & 28,6 & 21,0 & 92,740 & 1,060 \\
\hline 255 & -30 & 29,0 & 7,8 & 20 & 54 & -2 & 18 & 33 & 1,611 & 54,332 & 55,477 & 28,6 & 21,0 & 92,740 & 1,060 \\
\hline 255 & -35 & 33,8 & 9,1 & 3 & 54 & -10 & 15 & 28 & 1,613 & 54,329 & 55,476 & 28,6 & 21,0 & 92,739 & 1,060 \\
\hline 255 & -40 & 38,6 & 10,4 & -19 & 53 & -17 & -35 & 23 & 1,616 & 54,326 & 55,475 & 28,6 & 21,0 & 92,739 & 1,060 \\
\hline 255 & -45 & 43,5 & 11,6 & -35 & 50 & -43 & -60 & 19 & 1,618 & 54,323 & 55,473 & 28,6 & 21,0 & 92,739 & 1,060 \\
\hline 255 & -50 & 48,3 & 12,9 & -48 & 46 & -69 & -65 & 14 & 1,621 & 54,320 & 55,472 & 28,6 & 21,0 & 92,738 & 1,060 \\
\hline 255 & -55 & 53,1 & 14,2 & -67 & 42 & -79 & -75 & 8 & 1,623 & 54,317 & 55,471 & 28,6 & 21,0 & 92,738 & 1,060 \\
\hline 255 & -60 & 58,0 & 15,5 & -80 & 36 & -80 & -80 & 2 & 1,626 & 54,313 & 55,469 & 28,6 & 21,0 & 92,738 & 1,060 \\
\hline 260 & 0 & 0,0 & 0,0 & 57 & 33 & 33 & 35 & 37 & 1,629 & 54,310 & 55,468 & 28,6 & 21,1 & 92,737 & 1,060 \\
\hline 260 & -5 & 4,9 & 0,9 & 56 & 39 & 29 & 34 & 39 & 1,631 & 54,307 & 55,467 & 28,6 & 21,1 & 92,737 & 1,060 \\
\hline 260 & -10 & 9,8 & 1,7 & 54 & 43 & 23 & 32 & 39 & 1,634 & 54,304 & 55,465 & 28,6 & 21,1 & 92,737 & 1,060 \\
\hline 260 & -15 & 14,8 & 2,6 & 50 & 48 & 16 & 28 & 38 & 1,636 & 54,301 & 55,464 & 28,6 & 21,1 & 92,736 & 1,060 \\
\hline 260 & -20 & 19,7 & 3,5 & 42 & 52 & 10 & 24 & 35 & 1,639 & 54,298 & 55,463 & 28,6 & 21,1 & 92,736 & 1,060 \\
\hline 260 & -25 & 24,6 & 4,3 & 32 & 54 & 3 & 20 & 33 & 1,641 & 54,295 & 55,461 & 28,6 & 21,1 & 92,735 & 1,060 \\
\hline 260 & -30 & 29,5 & 5,2 & 17 & 56 & -4 & 18 & 28 & 1,644 & 54,292 & 55,460 & 28,6 & 21,1 & 92,735 & 1,060 \\
\hline 260 & -35 & 34,5 & 6,1 & 0 & 56 & -11 & 8 & 25 & 1,647 & 54,289 & 55,459 & 28,6 & 21,1 & 92,735 & 1,060 \\
\hline 260 & -40 & 39,4 & 6,9 & -21 & 54 & -18 & -35 & 19 & 1,649 & 54,286 & 55,457 & 28,6 & 21,1 & 92,734 & 1,060 \\
\hline 260 & -45 & 44,3 & 7,8 & -36 & 52 & -51 & -52 & 16 & 1,652 & 54,283 & 55,456 & 28,6 & 21,1 & 92,734 & 1,060 \\
\hline 260 & -50 & 49,2 & 8,7 & -53 & 48 & -64 & -61 & 10 & 1,654 & 54,280 & 55,455 & 28,6 & 21,1 & 92,734 & 1,060 \\
\hline 260 & -55 & 54,2 & 9,6 & -69 & 44 & -79 & -73 & 5 & 1,657 & 54,277 & 55,453 & 28,6 & 21,1 & 92,733 & 1,060 \\
\hline 260 & -60 & 59,1 & 10,4 & -81 & 38 & -87 & -84 & 3 & 1,659 & 54,274 & 55,452 & 28,6 & 21,1 & 92,733 & 1,060 \\
\hline 260 & 5 & $-4,9$ & $-0,9$ & 55 & 27 & 37 & 36 & 32 & 1,662 & 54,270 & 55,451 & 28,6 & 21,1 & 92,732 & 1,060 \\
\hline 260 & 10 & $-9,8$ & $-1,7$ & 53 & 21 & 42 & 36 & 30 & 1,665 & 54,267 & 55,449 & 28,7 & 21,1 & 92,732 & 1,060 \\
\hline 260 & 15 & $-14,8$ & $-2,6$ & 49 & 15 & 45 & 35 & 26 & 1,667 & 54,264 & 55,448 & 28,7 & 21,1 & 92,732 & 1,060 \\
\hline 260 & 20 & $-19,7$ & $-3,5$ & 42 & 8 & 50 & 34 & 22 & 1,670 & 54,261 & 55,446 & 28,7 & 21,1 & 92,731 & 1,060 \\
\hline 260 & 25 & $-24,6$ & $-4,3$ & 30 & 1 & 53 & 30 & 19 & 1,672 & 54,258 & 55,445 & 28,7 & 21,1 & 92,731 & 1,060 \\
\hline 260 & 30 & $-29,5$ & $-5,2$ & 16 & -5 & 53 & 27 & 19 & 1,675 & 54,255 & 55,444 & 28,7 & 21,1 & 92,731 & 1,060 \\
\hline 260 & 35 & $-34,5$ & $-6,1$ & -3 & -13 & 54 & 22 & 10 & 1,677 & 54,252 & 55,442 & 28,7 & 21,1 & 92,730 & 1,060 \\
\hline 260 & 40 & $-39,4$ & $-6,9$ & -24 & -20 & 53 & 17 & -38 & 1,680 & 54,249 & 55,441 & 28,7 & 21,1 & 92,730 & 1,060 \\
\hline 260 & 45 & $-44,3$ & $-7,8$ & -43 & -42 & 51 & 12 & -58 & 1,683 & 54,246 & 55,440 & 28,7 & 21,1 & 92,729 & 1,060 \\
\hline 260 & 50 & $-49,2$ & $-8,7$ & -59 & -70 & 47 & 6 & -67 & 1,685 & 54,243 & 55,438 & 28,7 & 21,1 & 92,729 & 1,060 \\
\hline 260 & 55 & $-54,2$ & $-9,6$ & -77 & -82 & 42 & 0 & -78 & 1,688 & 54,240 & 55,437 & 28,7 & 21,1 & 92,729 & 1,060 \\
\hline
\end{tabular}




\begin{tabular}{|c|c|c|c|c|c|c|c|c|c|c|c|c|c|c|c|}
\hline $\begin{array}{c}\text { Ângulo } \\
\text { g } \\
\text { (graus) }\end{array}$ & $\begin{array}{c}\text { Ângulo } \\
\text { a } \\
\text { (graus) }\end{array}$ & $\begin{array}{l}\text { Ângulo de } \\
\text { guinada } \psi \\
\text { (graus) }\end{array}$ & $\begin{array}{c}\text { Ângulo de } \\
\text { arfagem } \delta \\
\text { (graus) }\end{array}$ & p1 $(\mathrm{Pa})$ & $\mathrm{p} 2(\mathrm{~Pa})$ & p3 (Pa) & p4 (Pa) & p5 $(\mathrm{Pa})$ & $\mathrm{P}$ est $(\mathrm{Pa})$ & $\mathrm{P} \operatorname{din}(\mathrm{Pa})$ & Ptotal $(\mathrm{Pa})$ & $\begin{array}{c}\text { Temperatura } \\
\text { de Bulbo } \\
\text { Seco (jato) } \\
{ }^{\circ} \mathrm{C} \\
\end{array}$ & $\begin{array}{c}\text { Temperatura } \\
\text { de Bulbo } \\
\text { Úmido } \\
{ }^{\circ} \mathrm{C} \\
\end{array}$ & $\begin{array}{l}\text { Patm } \\
(\mathrm{kPa})\end{array}$ & $\begin{array}{l}\text { massa } \\
\text { específica do } \\
\text { ar }(\mathrm{kg} / \mathrm{m} 3)\end{array}$ \\
\hline 260 & 60 & $-59,1$ & $-10,4$ & -87 & -90 & 37 & -3 & -88 & 1,690 & 54,236 & 55,436 & 28,7 & 21,1 & 92,728 & 1,060 \\
\hline 265 & 0 & 0,0 & 0,0 & 55 & 32 & 31 & 35 & 34 & 1,693 & 54,233 & 55,434 & 28,7 & 21,1 & 92,728 & 1,060 \\
\hline 265 & 5 & $-5,0$ & $-0,4$ & 55 & 28 & 37 & 35 & 33 & 1,696 & 54,230 & 55,433 & 28,7 & 21,1 & 92,728 & 1,060 \\
\hline 265 & 10 & $-10,0$ & $-0,9$ & 54 & 21 & 43 & 35 & 31 & 1,698 & 54,227 & 55,431 & 28,7 & 21,1 & 92,727 & 1,060 \\
\hline 265 & 15 & $-14,9$ & $-1,3$ & 49 & 14 & 47 & 34 & 26 & 1,701 & 54,224 & 55,430 & 28,7 & 21,1 & 92,727 & 1,060 \\
\hline 265 & 20 & $-19,9$ & $-1,7$ & 41 & 8 & 51 & 31 & 23 & 1,703 & 54,221 & 55,429 & 28,7 & 21,1 & 92,727 & 1,059 \\
\hline 265 & 25 & $-24,9$ & $-2,2$ & 30 & 1 & 53 & 28 & 20 & 1,706 & 54,218 & 55,427 & 28,7 & 21,1 & 92,726 & 1,059 \\
\hline 265 & 30 & $-29,9$ & $-2,6$ & 18 & -3 & 55 & 24 & 19 & 1,709 & 54,215 & 55,426 & 28,7 & 21,1 & 92,726 & 1,059 \\
\hline 265 & 35 & $-34,9$ & $-3,1$ & -4 & -13 & 55 & 19 & 8 & 1,711 & 54,211 & 55,425 & 28,7 & 21,1 & 92,725 & 1,059 \\
\hline 265 & 40 & $-39,8$ & $-3,5$ & -27 & -19 & 55 & 14 & -34 & 1,714 & 54,208 & 55,423 & 28,7 & 21,2 & 92,725 & 1,059 \\
\hline 265 & 45 & $-44,8$ & $-3,9$ & -43 & -47 & 52 & 9 & -48 & 1,717 & 54,205 & 55,422 & 28,7 & 21,2 & 92,725 & 1,059 \\
\hline 265 & 50 & $-49,8$ & $-4,4$ & -61 & -66 & 49 & 2 & -64 & 1,719 & 54,202 & 55,420 & 28,7 & 21,2 & 92,724 & 1,059 \\
\hline 265 & 55 & $-54,8$ & $-4,8$ & -77 & -68 & 44 & -6 & -76 & 1,722 & 54,199 & 55,419 & 28,7 & 21,2 & 92,724 & 1,059 \\
\hline 265 & 60 & $-59,8$ & $-5,2$ & -88 & -67 & 39 & -9 & -85 & 1,724 & 54,196 & 55,418 & 28,7 & 21,2 & 92,724 & 1,059 \\
\hline 265 & -5 & 5,0 & 0,4 & 55 & 39 & 27 & 33 & 36 & 1,727 & 54,193 & 55,416 & 28,8 & 21,2 & 92,723 & 1,059 \\
\hline 265 & -10 & 10,0 & 0,9 & 53 & 44 & 21 & 31 & 36 & 1,730 & 54,190 & 55,415 & 28,8 & 21,2 & 92,723 & 1,059 \\
\hline 265 & -15 & 14,9 & 1,3 & 48 & 49 & 14 & 27 & 35 & 1,732 & 54,186 & 55,413 & 28,8 & 21,2 & 92,722 & 1,059 \\
\hline 265 & -20 & 19,9 & 1,7 & 41 & 52 & 7 & 23 & 32 & 1,735 & 54,183 & 55,412 & 28,8 & 21,2 & 92,722 & 1,059 \\
\hline 265 & -25 & 24,9 & 2,2 & 30 & 55 & 0 & 20 & 28 & 1,738 & 54,180 & 55,411 & 28,8 & 21,2 & 92,722 & 1,059 \\
\hline 265 & -30 & 29,9 & 2,6 & 15 & 56 & -6 & 17 & 24 & 1,740 & 54,177 & 55,409 & 28,8 & 21,2 & 92,721 & 1,059 \\
\hline 265 & -35 & 34,9 & 3,1 & -5 & 56 & -13 & 1 & 20 & 1,743 & 54,174 & 55,408 & 28,8 & 21,2 & 92,721 & 1,059 \\
\hline 265 & -40 & 39,8 & 3,5 & -24 & 55 & -16 & -32 & 16 & 1,745 & 54,171 & 55,407 & 28,8 & 21,2 & 92,721 & 1,059 \\
\hline 265 & -45 & 44,8 & 3,9 & -40 & 53 & -47 & -46 & 11 & 1,748 & 54,167 & 55,405 & 28,8 & 21,2 & 92,720 & 1,059 \\
\hline 265 & -50 & 49,8 & 4,4 & -60 & 49 & -56 & -61 & 0 & 1,751 & 54,164 & 55,404 & 28,8 & 21,2 & 92,720 & 1,059 \\
\hline 265 & -55 & 54,8 & 4,8 & -72 & 44 & -60 & -71 & 3 & 1,753 & 54,161 & 55,402 & 28,8 & 21,2 & 92,719 & 1,059 \\
\hline 265 & -60 & 59,8 & 5,2 & -81 & 38 & -63 & -83 & 0 & 1,756 & 54,158 & 55,401 & 28,8 & 21,2 & 92,719 & 1,059 \\
\hline
\end{tabular}


APÊNDICE III

CALIBRAÇÕES DOS TRANSDUTORES DE PRESSÃO 

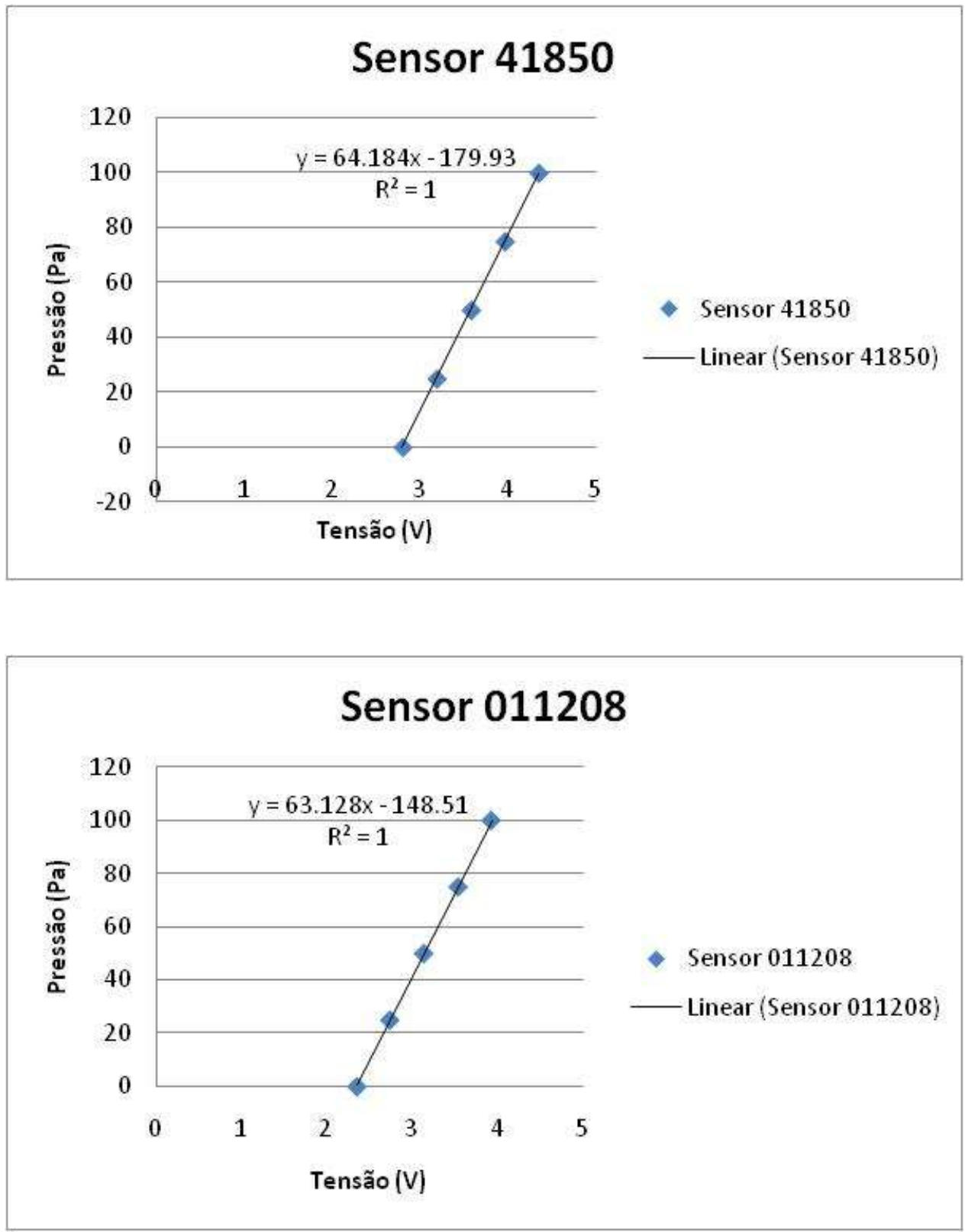

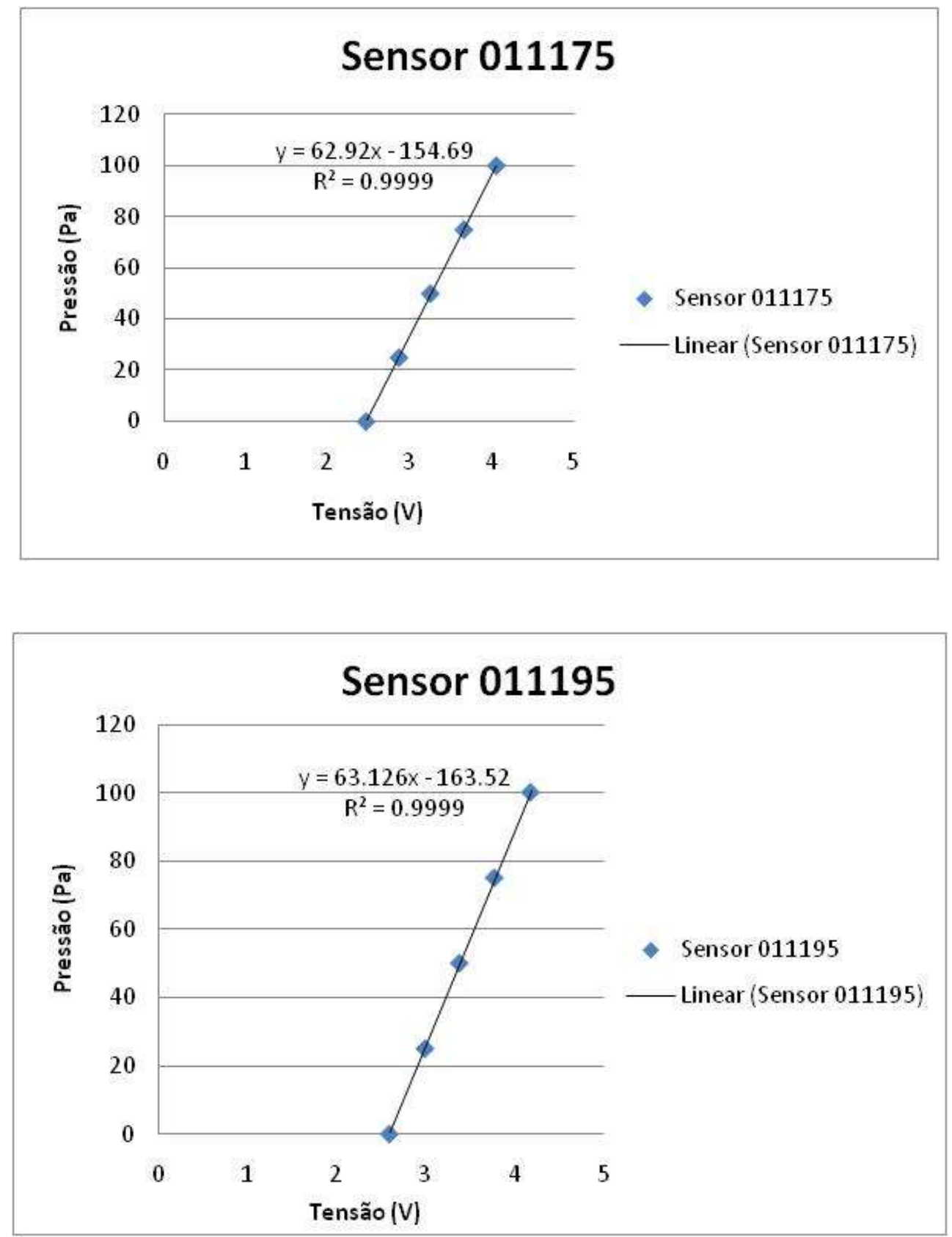

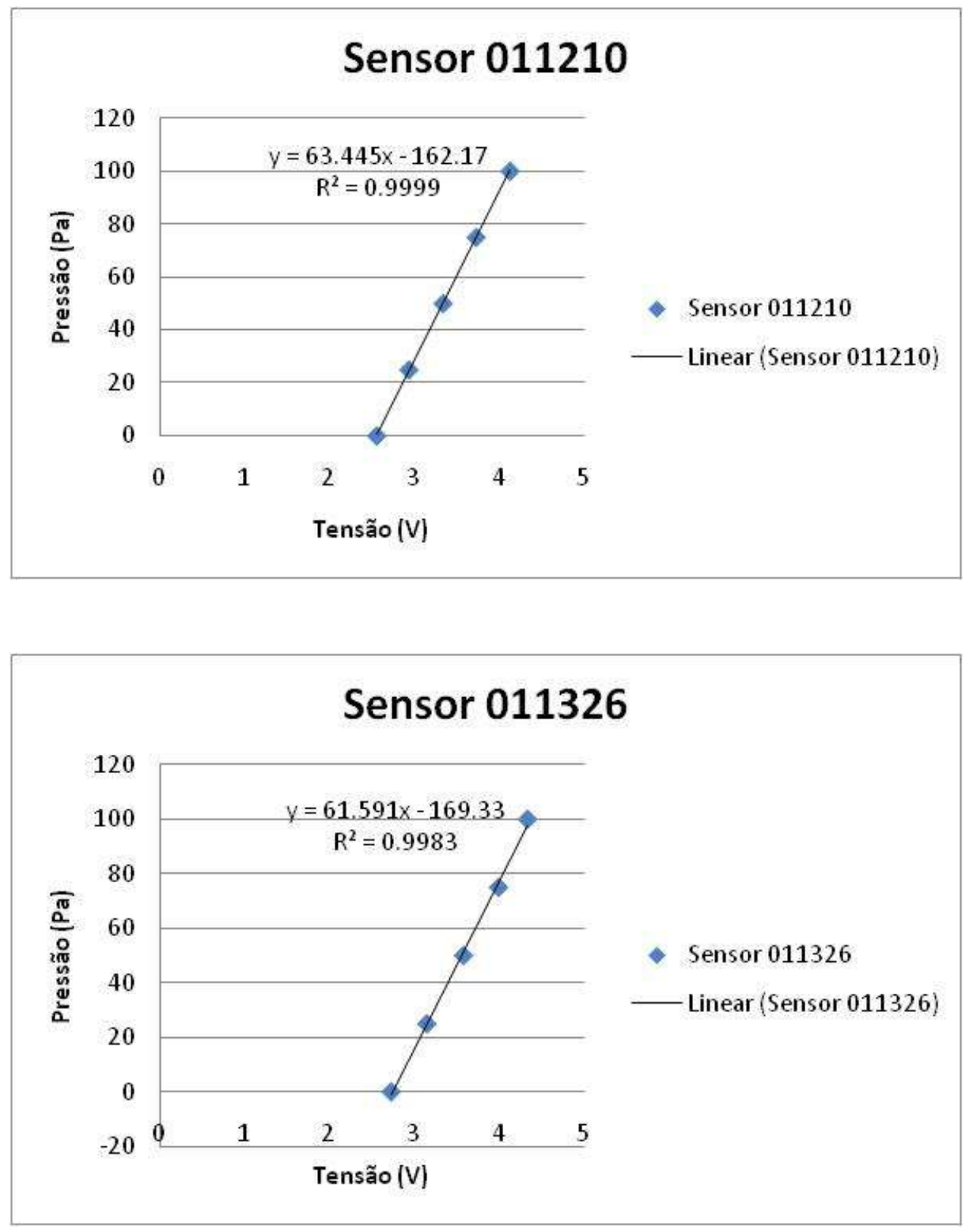